\begin{abstract}
Appoximation torhuiguen are an important andert of digital signal and image

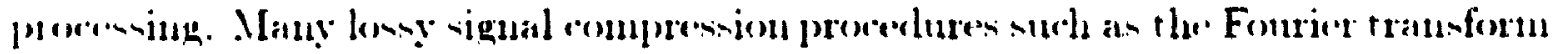

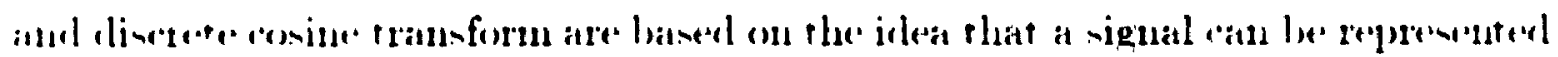

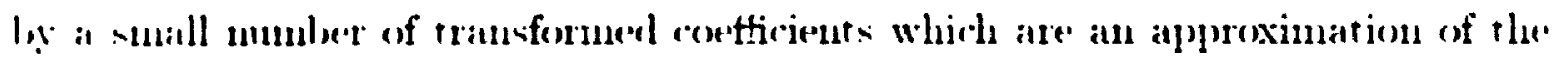
ariginal.

Exinting ipproxination rechuignes approach this problem in either a time/-pancial domain or transform domaiu. lut not hoth. This thesis. tirst of all.

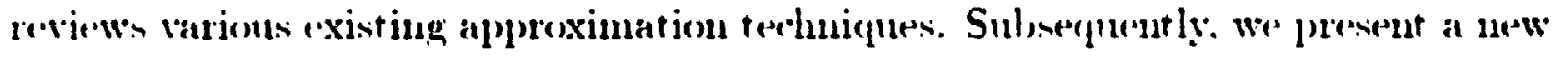

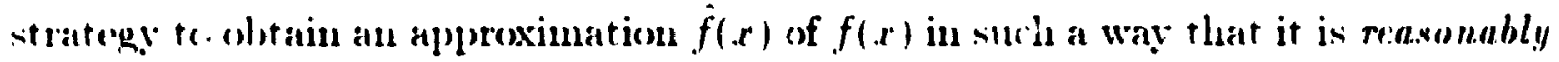
reme to the original function in the clomain of the ratiable $r$. but it also esactly prenerves some properties of the transformed domain. In this particular ase. the properties of the transformed values that are preserved are geometric moments of the original function. The proposed technique has beren applied to one-rlimensional funtions. two-dimensional planar curves. and two-dimensional images.
\end{abstract}

Keywords: signal processing. image proressing. sнupling. approxination. unument-presterving 
National Libray

of Canada

Acouisitions and Biblographic Senvices Branch

305 Whetringen street Orine Orisas Kinow
Bibliotheque nationale

du Canada

Direction der acquisitions el

des senvices bibliographiques

3:5 no winm

Onime (Ontaio)

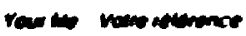

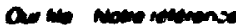

NOTICE

AVIS

The quality of this microform is heavily dependent upon the quality of the original thesis submitted for microfilming. Every effort has been made to ensure the highest quality of reproduction possible.

If pages are missing, contact the university which granted the degree.

Some pages may have indistinct print especially if the original pages were typed with a poor typewriter ribbon or if the university sent us an inferior photocopy.

Reproduction in full or in part of this microform is governed by the Canadian Copyright Act, R.S.C. 1970, c. C-30, and subsequent amendments.
La qualité de cette microforme dépend grandement de la qualité de la these soumise au microfilmage. Nous avons tout fait pour assurer une qualité supérieure de reproduction.

S'il manque des pages, veuillez communiquer avec l'université qui a conféré le grade.

La qualité d'impression de certaines pages peut laisser à désirer, surtout si les pages originales ont été dactylographiées à l'aide d'un ruban usé ou si l'université nous a falt parvenir une photocopie de qualité inférieure.

La reproduction, même partielle, de celte microforme est soumise a la Lol canadienne sur le droit d'auteur, SRC 1970, c. C-30, et ses amendements subséquents. 


\title{
Moment-Preserving Piecewise Linear Approximations of Signals and Images
}

\author{
be \\ Thai B. Ninuren. B.C.S.
}

\author{
A thesis submitted to \\ the Farulty of Graduate Studies and Research \\ in partial fulfillment of \\ the reculuirements for the rlegree of \\ Master of Computer Science
}

Srhool of Computer Science

Carleton Lniversity

Ottawa. Ontario

November 1994

(1)1994. Thai B. Ngityen 


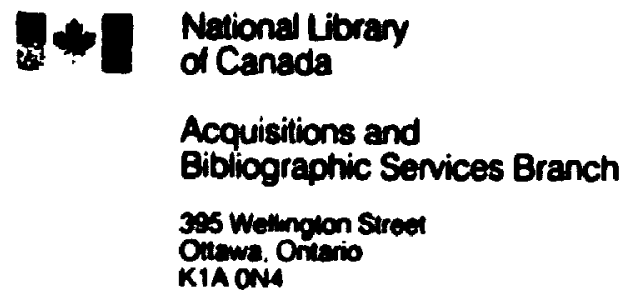

Bibliotheque nationale du Canada

Direction des acquisitions of des senvices bibliographiques

395, no Weingrion

Ontawa (Onterio)

KIA ONA
THE AUTHOR HAS GRANTED AN IRREVOCABLE NON-EXCLUSIVE LICENCE ALLOWING THE NATIONAL LIBRARY OF CANADA TO REPRODUCE, LOAN, DISTRIBUTE OR SELL COPIES OF HIS/HER THESIS BY ANY MEANS AND IN ANY FORM OR FORMAT, MAKING THIS THESIS AVAILABLE TO INTERESTED PERSONS.

THE AUTHOR RETAINS OWNERSHIP OF THE COPYRIGHT IN HIS/HER THESIS. NEITHER THE THESIS NOR SUBSTANTIAL EXTRACTS FROM IT MAY BE PRINTEO OR OTHERWISE REPRODUCED WITHOUT HIS/HER PERMISSION.
L'AUTEUR A ACCORDE UNE LICENCE IRREVOCABLE ET NON EXCLUSIVE PERMETTANT A LA BIBLIOTHEQUE NATIONALE DU CANADA DE REPRODUIRE, PRETER, DISTRIBUER OU VENDRE DES COPIES DE SA THESE DE QUELQUE MANIERE ET SOUS QUELQUE FORME QUE CE SOIT POUR METTRE DES EXEMPLAIRES DE CETTE THESE A LA DISPOSITION DES PERSONNE INTERESSEES.

L'AUTEUR CONSERVE LA PROPRIETE DU DROIT D'AUTEUR QUI PROTEGE SA THESE. NI LA THESE NI DES EXTRAITS SUBSTANTIELS DE CELLECI NE DOIVENT ETRE IMPRIMES OU AUTREMENT REPRODUITS SANS SON AUTORISATION.

ISBN $\quad 0-612-03007-5$ 
Nome

Dissertation Abstracts International is arranged by brood, general subject calegories. Please salect the one subject which most nearly describes the content of your dissentation. Enter the corresponding four-digit code in the spoces provided.

\section{Subinct Cosegories}

\section{Tu nunarmus ans soctal seinners}

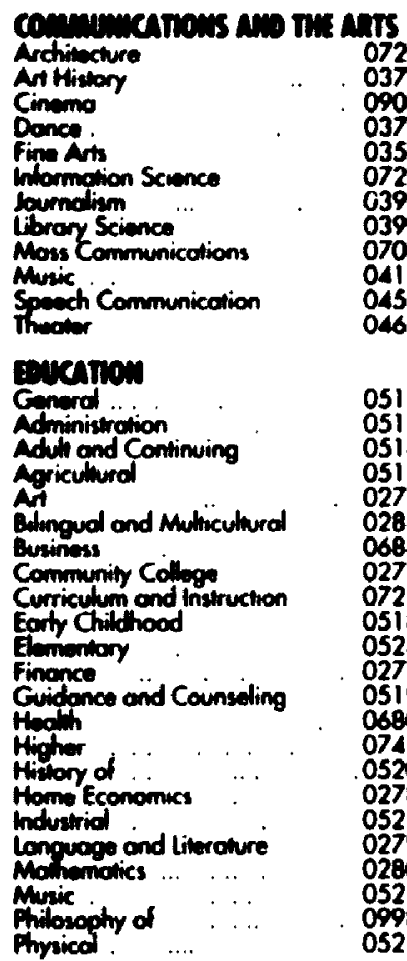

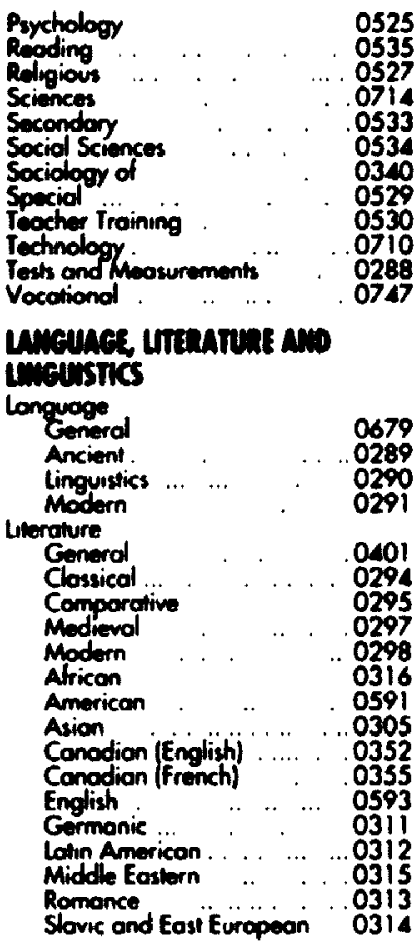

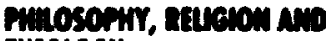
Tinevery

Philosophy

Religion

0422

Eenerol

Clerey ....... ... 0319

Hivery of … . . 032

Theology . . . . . ... 0469

samisating

Americon Sudies

Anthropology

Archasolory ..... . $\quad 032$

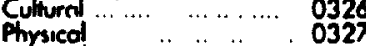

Business Administration

Generol.

Accounting. .... .

Bonking 0770

Monogement ...... , 045

Morteing

Economics

Generol .... ..... 050

Agriculurd . ...... 0503

Commerce-Business $\quad 0505$

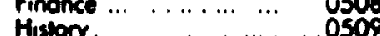

Hislory

Thoor

Folklore

Geogrophy

Histony

General

0510

0511

0366

0351

0578
Biblical Studies ....... . 032

Philosophy of. . ..... 0322

Conodion Shudies

stuect coo
Ancient . . ................0579

Medievol . .. .................0581

Modern ........... ..........0582

Alock .......................... 032

Africon ... ..................033

Asia, Australia and Occonio 0332

Conodion ......................0334

European ..........................0335

Midd Eosiern ... ................0333

Unitud Simine .................. .0337

History of Science ....................0585

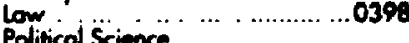

Gel Science

internationd ion and

.0615

Relations ..............

Public Administrotion ...........0817

Recreotion .... .........................0814

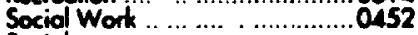

Sociology

Gented.. ......................0626

Criminology ond Pondogy ...0627

Drmogrophy ...................993

individual and Fanily

Shidien ond fomily

industriat and lobor

Relations and

public and Sociol Wijitiore... 0630

Social Structure and

Dewolopment .................. 0700

Theory and Mashods .............0344

Tronsportation .... ............... 0709

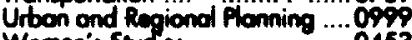

Women's Sudies .....................0453

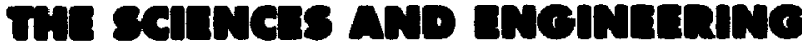

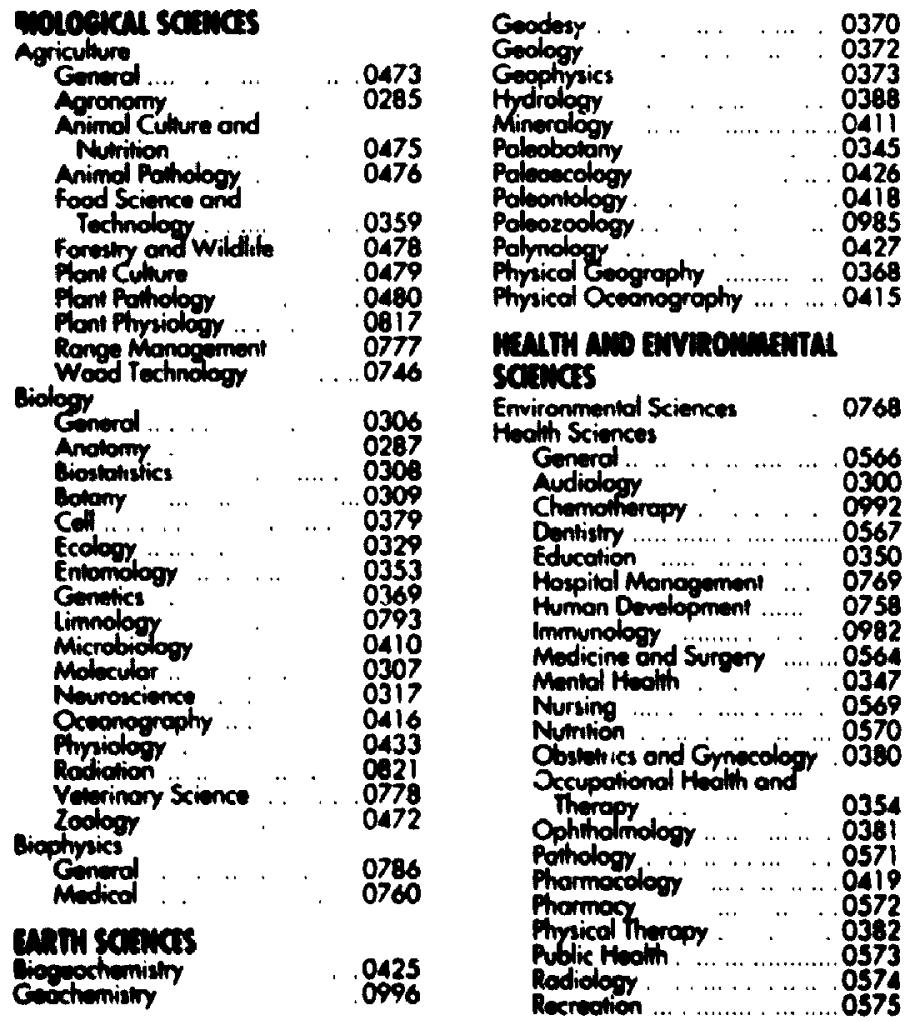

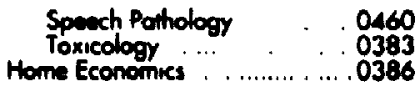

\section{Pirsen satuces}

Pure Sciences

Chemistry

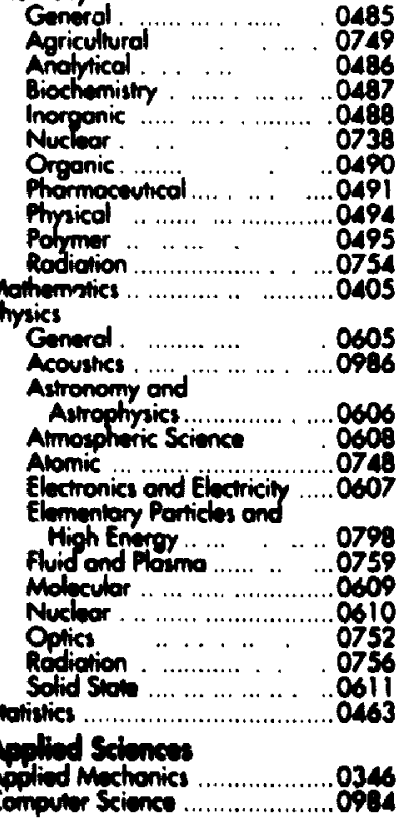

Enginewing

Generot ...........................0537

Aerospoce . ……............... 0538

Aulomotive ............................. 54

Biomedicol ................................55

Chemieal ...........................0542

Civil ...............................0543

Electronics ond El Ectrical .......0544

Hoot and Thermodynanics ...0348

industrial ..............................0546

Morin

Moteriolis Science -............... 079

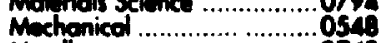

Motollurgy .......................0743

Mining …............................ Oss

Nucloor

Pockoging …………............0549

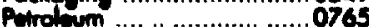

Sonitory ond Municipol '........ Oss

Srytem Science .................... Or9

Goolutundogy ..........................0428

Plastics Tectnolooy ..................... Op

Toxtile Tectnology .......................0994

criciereor

Genorol ...................................621

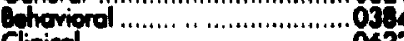

Clinicol ..............................522

Experimentol .............................0623

Experimiol ....................................052

Preondity..............................525

Phyiologised ...........................0989

Pischomeric

Sociol 
The undersigned herebe recomumend to the Fandulty of Gradluater Studien and Reneatreds acreptance of this thesis Moment-Preserving Piecewise Linear Approximations of Signals and Images

submitted by. Thai B. Agnven. B.C.S.

in partial fultillment of

the recpuirements for the degrere of

Master of Computer Science.

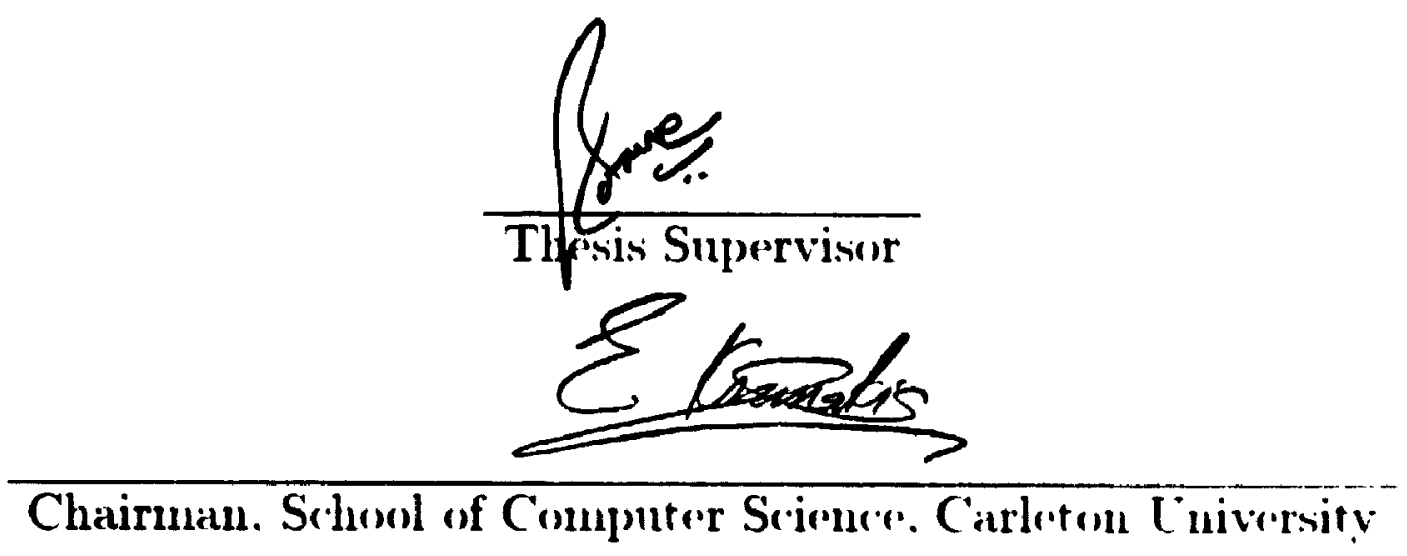

Dee. 19, 1994

Dattr 


\begin{abstract}

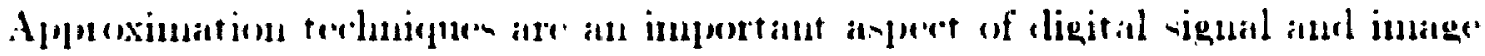

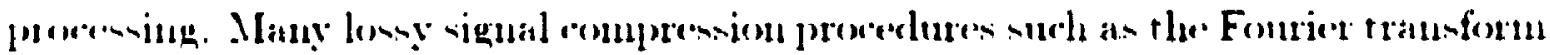

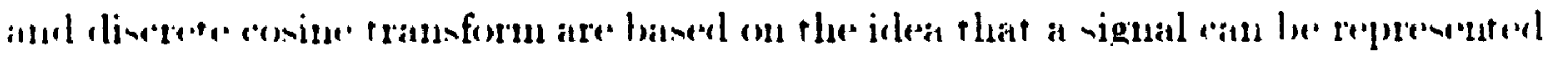
lụ a small mumber of transformed contficients which are an apploximation of the miginal.

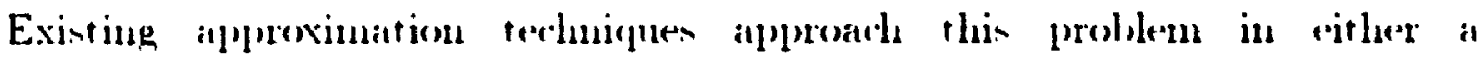

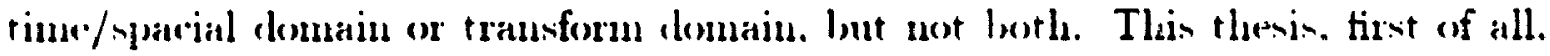
reviews varions existing approximation techniques. Subnecquently. We prestent a ne-w strategy te obtain an approximation $\dot{f}(x)$ of $f(x)$ in stuh a way that it is reasunubly .lone to the original function in the domain of the variable $x$. but it also esactly prenerves some properties of the transformed romain. In this particular caste the propertices of the transformed values that are preserved are geometric moments of the original function. The proposed technioue has been applied to ome-dimensiomal functions. two-dimensional planar curves. and two-dimensional images.
\end{abstract}

Keywords: signal proressing. inage processing. sampling. approximation. unoment-presterving 


\section{Acknowledgements}

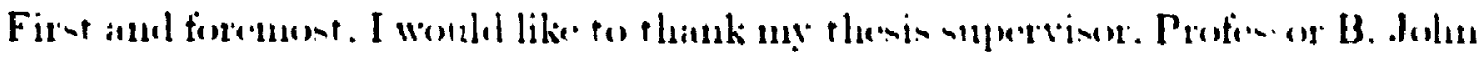

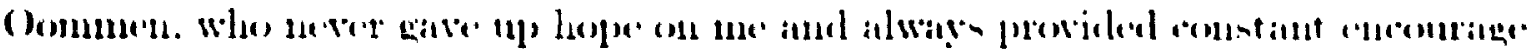

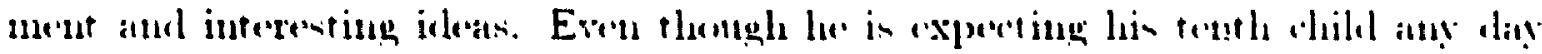
now. he still manages to find the time to leelp me through with this thesin.

I would aloo like to thank Dares and Margaret Thomas for hering extrenely.

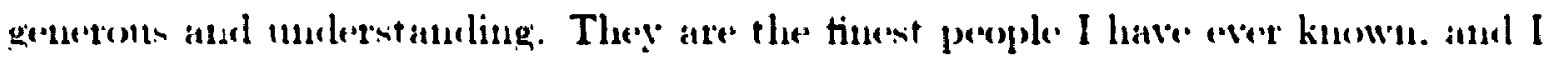
an fortunate enongh to be working for theme.

I an also very fortunate to be working with stuch a great gromp of perople at OTI. If I had more room on this page. I wonld have thanked canch one of them individually: I wonld like to make a sperial mention of the follewwine people at ()TI who have made the task of completing this thesis possible: Gireg Adimn, John

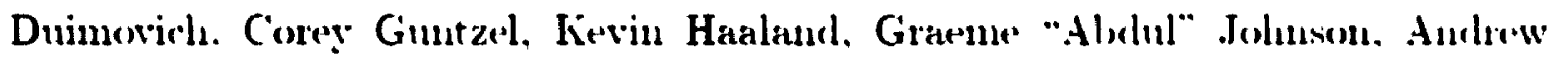
"Roo" Low. Kerin "Wirlget" Mr.Guire. Ted O'Grady: and Date Thommon. Kirvin. Terl. Gireg ( with his "sea of red ink"). Corey. and "Widget" were extremely hedpful in proofreacling this thesis. John, who neter knows what I an working on in (ITI. was very helpful by not bothering me about work for the past conple of monthe. Without "Aludul"'s expertise in .US-Exrel. all these graphionl results would uot have. been part of this thesis. CorelDraw and MS-Excel put up a good tight. Int they were no match for "Rero" who had to stay at work late a couple of nights to help me do battle with these uonderful software packages.

I would also like to take this opportnuity to thank the Dean of Graduate. Stullien and the School of Computer Srience for permitting me two semester "xtensioms in complete the thesis. Working fulltime and rloing my thesis simnltanemsly was quite a juggling art. and I appreciate the consideration that they have given me.

I would like to thank Markene Wilson who helped in providing mo with rurour 


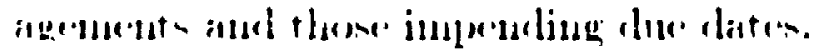

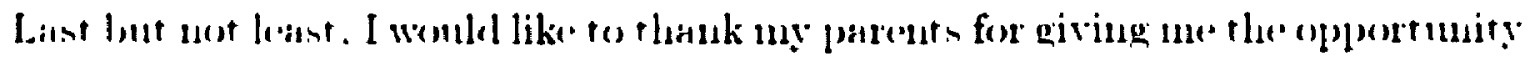

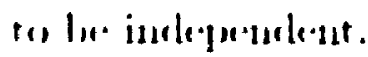

That Nemeru. Novernber 1094 


\section{Contents}

1 Introduction $\mathbf{1}$

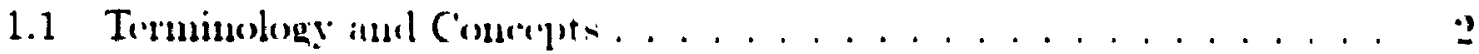

1.2 Morimation ........................ (i

1.3 ()urline of theis ......................... . .

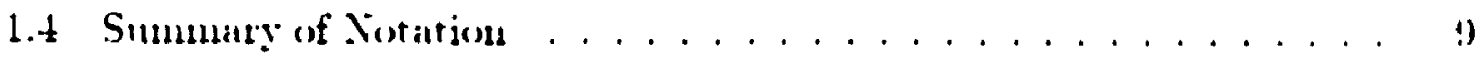

2 Related Work on One-dimensional (1-D) Functions 11

2.1 Spacial or Temporal Domain Funtion Approximation . . . . . . . . 12

2.1.1 Sulnampling . . . . . . . . . . . . . . . . 12

2.1.2 Lonst squares polynomial ................ . 1.

2.1 .3 Piecowise lintear . . . . . . . . . . . . . . . . 201)

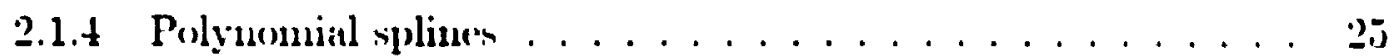

2.2 Transformed Domain Function Approximation . . . . . . . . . . 30

2.2.1 Karhunen-Loeve Transform . . . . . . . . . . . . 34

2.2.2 Fonrier Transform . . . . . . . . . . . . . . . 36

2.2.3 Haclamard and Walsh-Hadamarel Transforms . . . . . . . . . 39

2.2.t Discrete Comine Transform . . . . . . . . . . . . . . . 41

2.3 Resiults of Provious Methords . . . . . . . . . . . . . . . 44

3 Related Work on Two-dimensional (2-D) Functions 66

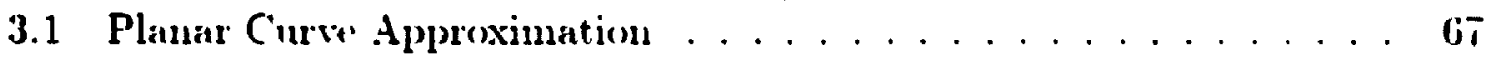

3.1.1 Time/Spacial Domain Approximation . . . . . . . . . liT

3.1.2 Transformerl Domain Approxination . . . . . . . . . . . s.;

3.2 Digitized Image Approximations . . . . . . . . . . . . . . . . 90

3.2.1 Time/Sparial Domain Techniques . . . . . . . . . . . 90)

3.2.2 Transform Domain Terhniques ............... 96

3.3 Results of Previous Planar Curve Approximation Mothocls . . . . . . 99

3.4 Resinlts of Digitized Image Approximation Methork . . . . . . . . . . 111

4 Moment-Preserving Method for 1-D Functions 124

t.1 Introduction to Moments ................... . 12t

4.2 Relationship between Moments aud the Chatacteristir Equations . . 126

4.3 Moment-Preserving Approximation . . . . . . . . . . . . 128

4.3.1 Single Straight Line (2-point) Approximation . . . . . . . . 130)

4.3.2 Two-Piecewise-Linear (3-penint) Approximation . . . . . . . 134

4.3.3 Approximation usiug " Piecewise Linerar Segunents . . . . . 137

4.3.t Coutiuusus versus Discrete Functions $f(x)$. . . . . . . . 141

4.4 Experimental Resints on One-rlimensional Functions . . . . . . . . . 142

5 Moment-Preserving Methors for 2-D Functions 156 


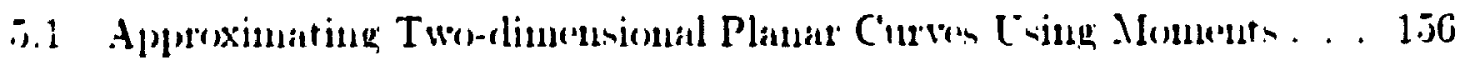

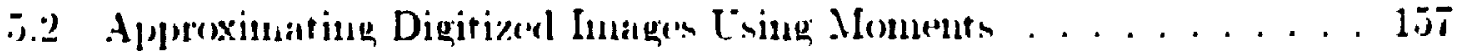

5.3 Expurimental Results un Planat (invers and Digitized Images . . . . 160)

6 Conclusion and Open Problems 180

6.1 Review of Moment-prenerving Terhuighue . . . . . . . . . . 180

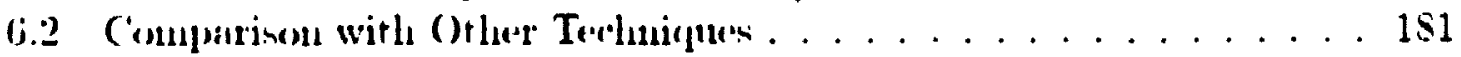

6.3 Disensolon on Inplenuentation . . . . . . . . . . . . . . 182

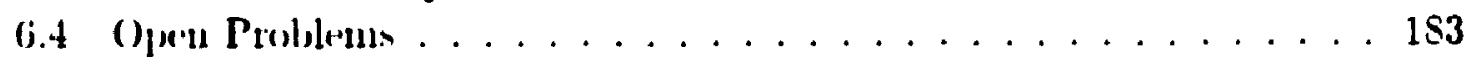

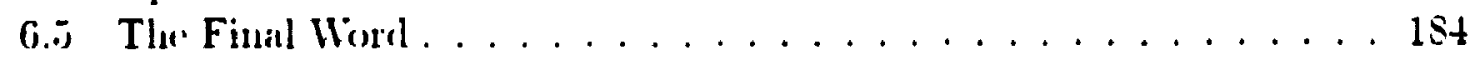

$\begin{array}{ll}\text { References } & 185\end{array}$ 


\section{List of Figures}

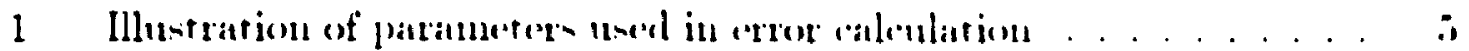

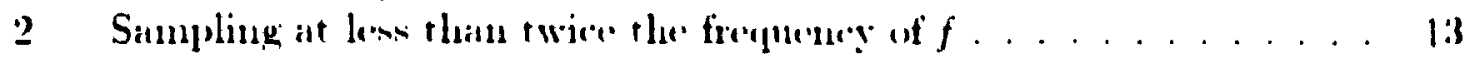

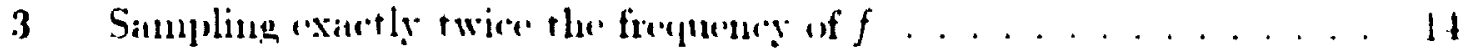

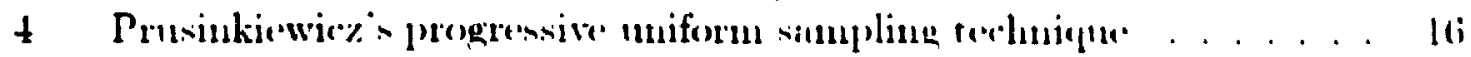

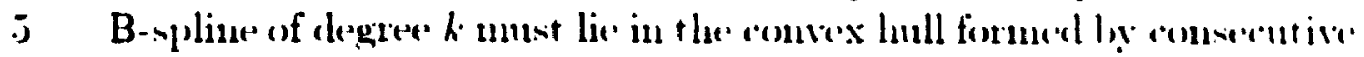
groups of $k+1$ points. (a) $k=1$ (linear). (b) $k=2$ (quadratic). (1.)

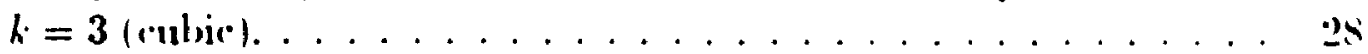

6 Rotation transform example . . . . . . . . . . . . 320

7 Basis functions for the discrete Fontier transform where $" 1=8 . \ldots$ t

8 Basis functions for the discrete cosine transform where $n=8 \ldots \ldots$ t.

9 (a) Original function $f_{1}$. (b) to (o): Approsinations of function $f_{1}$ using techniques (1) to (t) listerl in Sertion 2.3. . . . . . . ts

10 (f) to (i): Approximations of function $f_{1}$ using terhnignes (5) to (S) listed in Section 2.3. . . . . . . . . . . . . . . . . . . 4!

11 Results of the rarions approximation terluichues applied on function

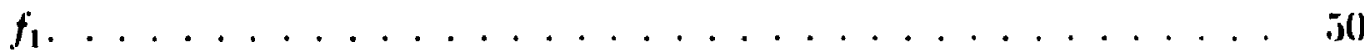

12 (a) Original function $f_{2}$ (normal bell curre). (b) to (a): Apposinat-

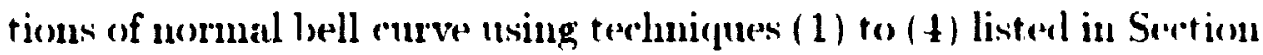
2.3 .

13 (f) to (i): Approximations of normal bell rurve using terhniqu's (5) to (S) listed in Section 2.3.

14 Restults of the varions approximation terduniquess applient on normal

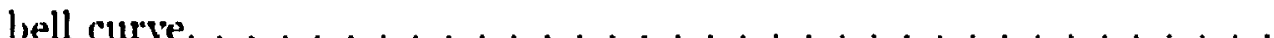

15 (a) Original function $f_{3}$ (sawtooth waves). (b) to (a): Approxinuations of sawteoth waves using techniques (1) to (4) listed in Sertion 2.3 .

16 (f) to (i): Approximations of sawtooth waves using terhuninu's (j) to (8) listed in Section 2.3. . . . . . . . . . . . . . . . .

17 Results of the varions approximation techuiques applied on sawtooth waves. . . . . . . . . . . . . . . . . .

18 (a) Original function $f_{4}(f(x)=\sin x / x)$. (b) to (c): Approximations of function $f_{4}$ using terhniques (1) to (4) listerl in Sertion 2.3. . . .

10 (f) to (i): Approximations of function $f_{4}(f(x)=\sin r / r)$ using terhniques (5) to (8) listed in Sertion 2.3.

20 Results of the varions approximation techniques applion on function $f_{4}(f(x)=\sin x / x)$.

21 (a) Original funetion $f_{5}$ (sum of sewtosoth waves and $7 \sin , r / r$ ). (i, ) to (e): Approximations of function $f_{i}$ asing tereluniques (1) to (4) listerl in Section 2.3 . 


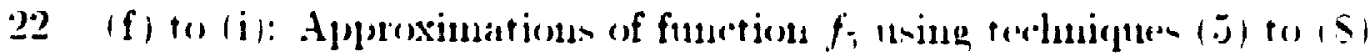
listed in Section 2.3. . . . . . . . . . . . . . . . 01

23 Rondt of the varions approximation terhujegues applied on function $f_{i} \ldots \ldots \ldots \ldots \ldots \ldots \ldots \ldots$

21 (a) ()riginal fumetion fi, (simulated uoisy signal). (b) to (o) : Approx-

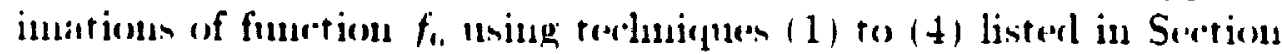
2.3 .

(f) to (i): Approximations of function fir using terbnicpues $(j)$ to (S) listerd in Section 2.3.

Rentulto of the varions approximation torluniques applied on fuuction

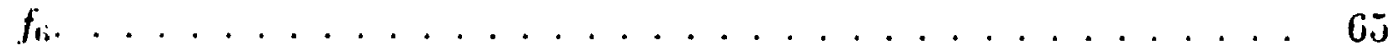

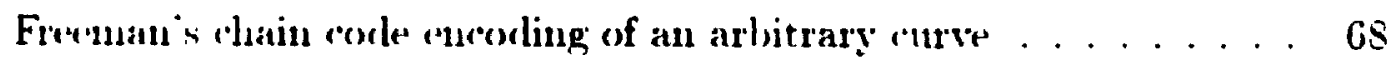

Ramer: ande approximation methorl.

Minimax approximated line for thres points.

Minimax approximated line for a convex polygon.

31 (a) Minimax approximated line for $i$ points. (h) Minimax approximated line for $j+1$ points.

Computing the approximation error using the translated aud rotated

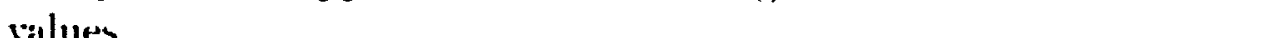

Lintes aud a gles from $p_{0}$ to $p_{k}$.

35 Steps taken loy algorithm for subdividing a curve into its most perreptually signiticant straight line segments. ........... $\$ 4$

36 Example of eoutonu function. ................ sj

37 A polygonal homulary. . . . . . . . . . . . . . . . . . sG

38 Paranetric representation of a planar curve with tangential direction $\theta(l)$ and cumulative angular bend function $o(l) \ldots \ldots \ldots$

39 (a) Planar eloserl curve with starting point from benudary of rharicter "H". (b) Cumulative angular bend function o(l) for rurve in (a). (c) Normalizerl cumulative angular bend function $\phi^{-}(t)$ for the curve in (a).

t0 Pyramicl rlata structure for four levels 0,1,2, and 3. . . . . . . . 01

t1 String of sampling points. (a) to (d) represent the string of sampling points $S(0,0), S(0,1), S(0,2)$. and $S(0.3)$, respertively. (e) represents the substring $S(1,0)$ which is the concatenation of the substrings from (a) to (d).

4.2 String of sampling points. (a) to (d) represent the string of sampling prints $S(1,0), S(1.1), S(1,2)$, and $S(1.3)$, respectively. (e) represents the substring $S(2,0)$ which is the concatenation of the substrings from (a) to (d) . . . . . . . . . . . . . . . . 95

43 Inplicit perionlicity of the discrete Fonrier and cosine transforms. . . 9T 


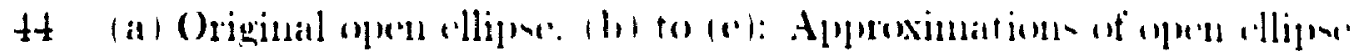

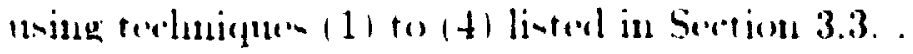

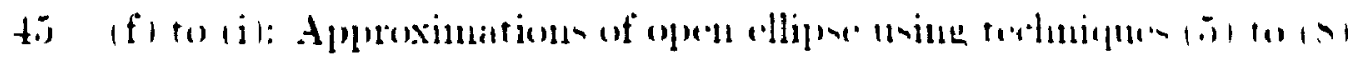
linterl in Sextion 3.3.

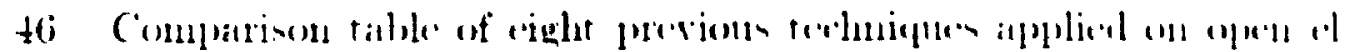
liper.

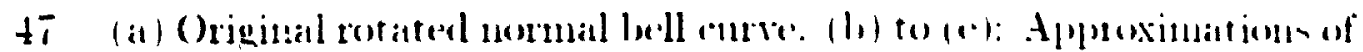

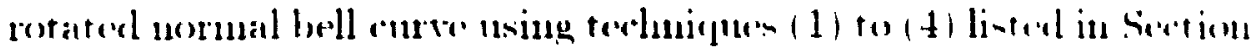
3.3 .

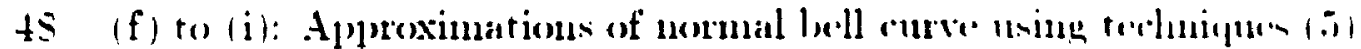
(1) (8) listerl in Sitotion 3.3.

49 Comparion table of eight previons terehoigues alplied on totated nomal bell rurve.

III

50) (a) Original amplex eloned aurve. (b) to (a): Apleximations of

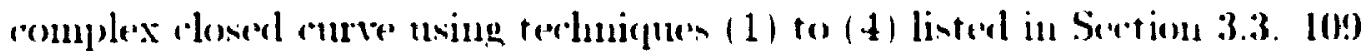

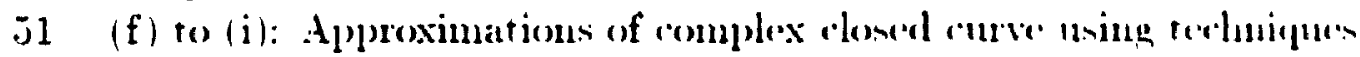
(J) to (8) listed in Section 3.3.

j2 Comparison table of eight previoms techniques applienl on eomplex rloserd ritries.

53 (a) Original complex cloned enrve with simulated moise. (lo) to (e):

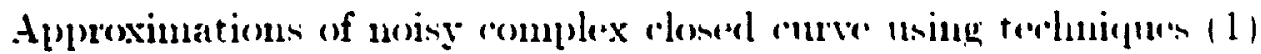
to (1) listed in Sertion 3.3.

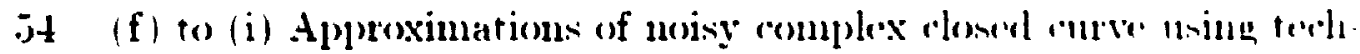
uivpurs (J) to (S) listerl in Sertion 3.3.

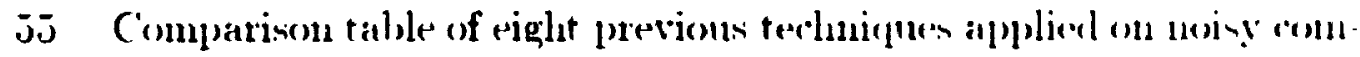

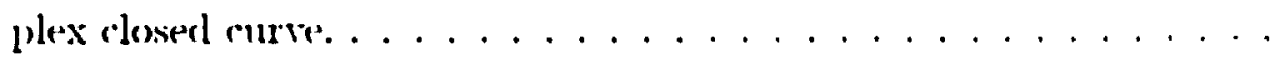

j6 (a) Original self-intersecting enrve. (h) to (o): Approximations of self-intersecting rurve using terhnigues (1) to (4) listed in Sortion 3.3. 11.j

j7 (f) to (i): Approximations of self-intersecting encre nsing ter-huigum (j) to (8) listorl in Section 3.3. . . . . . . . . . . . . . . 116

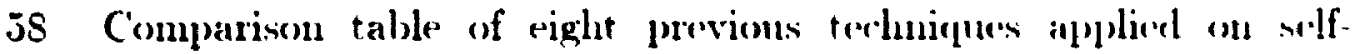
interserting curve.

j9 (a) Original picture of a human fare. (b) Seatest-neighlowur approximation. (c) Hologram-like approximations. (d) Discrete Fomrier trausform approximation. (e) Discrete cosine trausform alpheximation.

60 (a) Original picture of a deats. (b) Vearest-neighbour approximation.

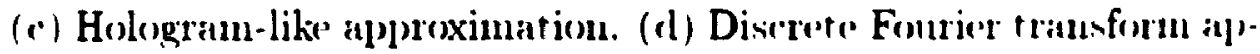
proximation. (e) Discrete cosine transform apleroximation.

61 (a)Restults of approximation terelumigues applied to the limuan farce

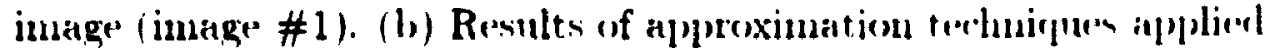
to the deres image (image \#2). 
(j) (a) ()riginal picture of at -quirrel. (b) Xearest-meighlontr apptoxima-

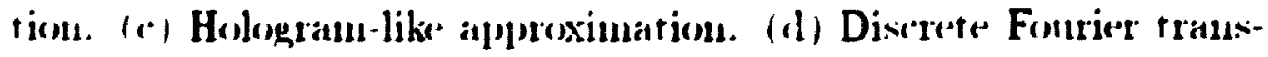

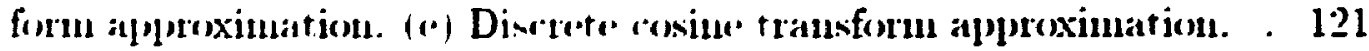

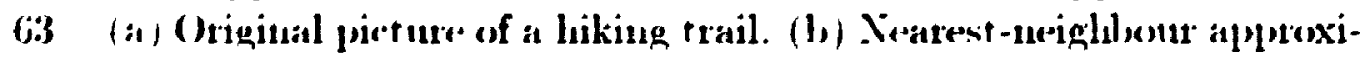

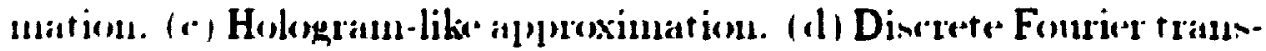
form appoximation. (e) Discrete cosine transform approximation.

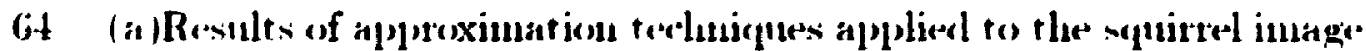
(image \#3). (1,) Restes of approximation techuigues applied to the liking trail inage (image \#4).

(6.) Finetion $f(x)=-(. r-2)^{2}+4$ detined in the interval $[0.2] \ldots$. . . 133

66 Result of single lime approximation pasing through the different kuor values. (a) Kinot values $r_{t_{0}}=0$ and $r_{t_{1}}=2$. (b) Kinot values $r_{t_{0}}=0$ and $r_{t_{1}}=3 / 2$. ( $(r)$ Kinot values $r_{i_{0}}=1$ and $r_{t_{1}}=2$. (d) Kinot values $r_{t_{1}}=1 / 2$ and $s_{t_{1}}=3 / 2 \ldots \ldots \ldots \ldots$

67 Rexult of different mumler of approximating lines different knot values. (a) Thres kuot values $x_{i_{0}}=0, x_{i_{1}}=2$. and $x_{i_{2}}=4$. (b) Four knot valuess $x_{10}=0 . x_{11}=4 / 3 . x_{12}=8 / 3$. and $x_{11}=4$. (c) Five knot values $r_{1 n}=0$ and $r_{11}=1$. $r_{12}=2$. $r_{13}=3$. and $r_{14}=4$. (d) Six kinct values $x_{t_{0}}=0, x_{11}=4 / 5 . r_{1_{2}}=8 / 5, x_{13}=12 / 5, r_{14}=16 / 5$. and $r_{t}=4 \ldots \ldots \ldots \ldots \ldots$

68 (a) to (h) Original function $f_{1}$ and several moment-preserving approximations with the number of approximating points being $\mathrm{J}$. $\mathrm{S}$. 11. 14. 17, 20. and 25, respertively. . . . . . . . . . . . . . . . . 144

69 C'omparison table of various approximation techniques on function $f_{1} .145$

i0 (a) to (h) Original function $f_{2}$ and several moment-preserving al)proximations with the number of approximating points being 3 . $4 . \mathrm{J}$. J. 6. 7 . and \&. respertively. . . . . . . . . . . . . . . 146

i1 Comparison table of various approximation techniques on function $f_{2} .147$

i2 (a) to (h) Original fumotion $f_{3}$ and several moment-preserving al)proximations with the number of approximating points being 2.5 .6 . 10. 14. 17. and 21. respectively. . . . . . . . . . . . . . . . 148

73 Comparison talse of varions approximation techniques on function $f_{3} .149$

it (a) to (a) Original function $f_{f}$ and several moment-preserving ap)proximations with the mumber of approximating points being 2. 3.5. 6. 8. 11, and 17, resipertively. . . . . . . . . . . . . . 150

ij Comparison table of varions approximation teduniques on function $f_{4} .151$

i6 (a) to (h) Original function $f_{5}$ and several moment-preserving ap)proximations with the unuber of approximating points being 5. 6. 8 . 9. 11. 14, and 21. respertively. . . . . . . . . . . . . . . . . 152

if Comparison table of varions approximation terhuiques on function $f_{5} .153$ 


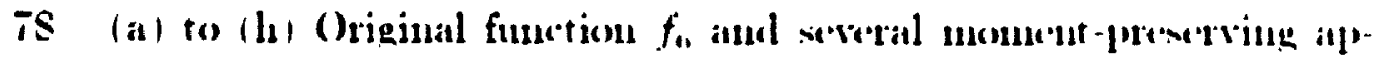

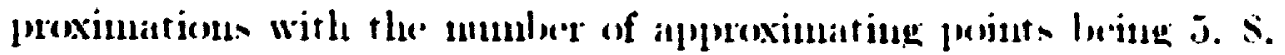
11. 14. 17. 20. and 25. revpectively. . . . . . . . . . . . . . . 1.34

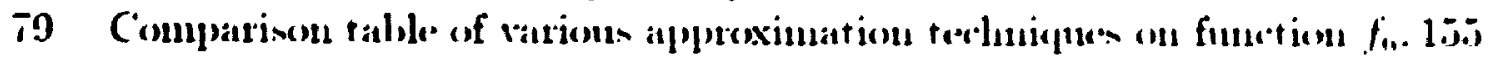

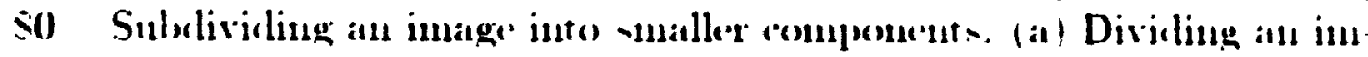

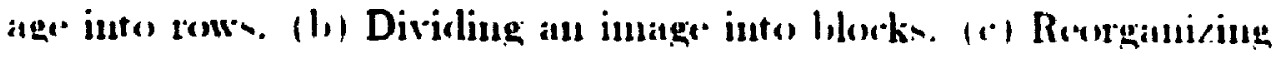
pixel values into liuear form. . . . . . . . . . . . . . . 15s

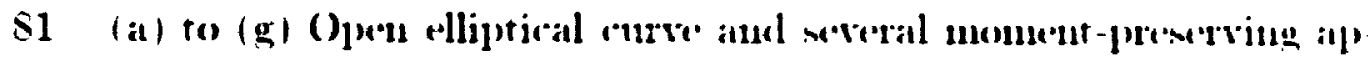
proximations with the unuluer of approximating points being 5.7 .9$. 11. 13. and 15. respectively: . . . . . . . . . . . . 162

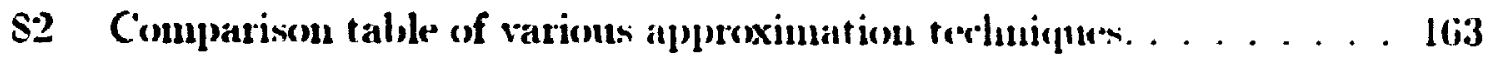

S3 (a) to (h) Rotated bell curve and sereral moment-presterving alphoximations with the number of approximating points lxcing 3.5 .5 .8 . 9. 11. and 14. respertively. . . . . . . . . . . . . . . . 164

S4 Comparion talsle of varions approximation techniques. . . . . . . 165

SJ (a) to (d) Complex closed curve and stereral moment-presserving alpproximations with the munler of approximating points being 9. 12. aud 14. respertively. . . . . . . . . . . . . . 166

S6 (e) to (h) Mloment-preserving approximations of comple $x$ elosed course with the unmber of approximating points being 16. 19. 22.2. and 23 . respertively. . . . . . . . . . . . . . . 167

st Comparison talje of varions approximation technicques. . . . . . . 168

SS (a) Noisy complex closed curve and seteral moment-preserving approximations with the number of approximating points locing 9.12. aud 14. respectively. . . . . . . . . . . . . . .

89 (e) to (h) Moment-preserving approximations of novisy comple $x$ rlosed curve with the number of approximating points being 16. 19. 22. and 23. respectively. . . . . . . . . . . . . . i.0

90 Comparison tal)le of various approximation terhniques. . . . . . 171

91 (a) to (h) Self-interserting curve and seivral moment-preserving alpproximations with the number of approximating points being 4. $\mathrm{j}$. $\overline{\text { i }}$. $\mathbf{7}, \mathbf{0}, 13$, and 29, respertively. . . . . . . . . . . 172

92 Comparison talse of varions approximation techniques. . . . . . . 173

93 (a) Original image of human fare. (b) Monuent-presinging alproximation with the mumber of approximating points lecing 32 x 32. (c) . Nearest-neighbour. (d) Hologram-like. (e) Discrete Fonrier traunform. (f) Discrete cosine transform.

94 (a) Original image of a cleer. (b) Moment-preserving approximation with the mumber of approximating prints being $32 \times 32$. (r) . Ainatestneighlour. (d) Hologram-like. (e) Discrete Fonrier trausform. (f) Discrete cosine transform. . . . . . . . . . . . 17is 
95 (a) Comparimon talse of varions approximation tedhichess on image \#1. (b) Comparion talole of tarious approximation rechniques on innug \#2. . . . . . . . . . . . . . . 170

gf (a) (Griginal inage of a spirrel. (b) Mlome-nt-preserving approximation with the anmuser of alpreximatine ocints being $32 \times 32$. (c) Siarest-ueighloutr. (d) Hologram-like. (e) Discrete Fourier tratusform. (f) Discrete cosinte transform. . . . . . . . . . . . . 17T

97 (a) Original image of a hiking trail. (1) Mfoment-preserving alyproximation with the munher of approximating points being 32 $x 32$. (c) Siarest-neighlour. (d) Hologram-like. (e) Discrete Fourier trans. form. (f) Discrete cosine transform. . . . . . . . . . . 1is

98 (a) Comparison talsle of varions approximation terhuiques on image \#3. (b) Comparison table of various approximation terluniques on imagt \#4. . . . . . . . . . . . . . . . 179 


\section{Chapter 1}

\section{Introduction}

A signal. by definition from the 1990 Concise (Oxford Dirtionary is "an ele etrital impulse or impulses. or radio waves .... or a sequence of these." The term signal processing is used to describe an operation or a seequence of operations courried ont. on a signal in order to simplify its analysis and storage. Approximation terhniques are an important aspect of signal proressing. For example, an analogue signal cau be represented by a digitized signal which is an approximation of the original one. Electronic voice mail messages. photographic images, and X-ray images ate ofto's digitized and encoded to reduce their storage and transmission costs. Apluroximition and encoding is a small segment of the field of signal prowessing which alos includes scaling, filtering. sucoding, structural pattern recognition, feature extrartion. scene analysis, motion detection, and image understanding $[\operatorname{Pr} 78]$. The main forcus of this thesis is on the approximation of digitized signals.

Approximation techniques are crucial in practical digital signal processing. For example, the typical bandwirlth of digitized speech voice, varies from betweren 2.4 Kïlobits per second (Kops) to $64 \mathrm{~K}$ bps, depending on the enscodling algorithun userl. Indeed. for compact dise quality auclio this value may be up to 1.4 Meyallits per serond. Using these bandwidths. a 10-minute digitized speech sample condel repgire from 180 Kilobytes to 100 Megabytes of storage.

The landwidth requirements of digitized images and graphirs are much greater than that of digitized speech. A still colonar image with a ressolution of 1024 by 1024 pirture elements (pixels. or pels) at 24 bits per pixel requiress 24 Megalsits of storkge. 


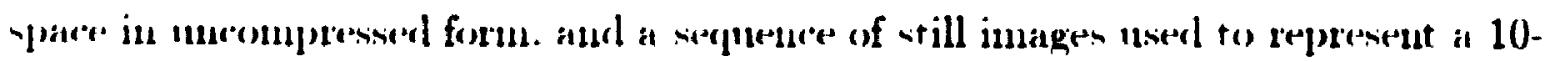

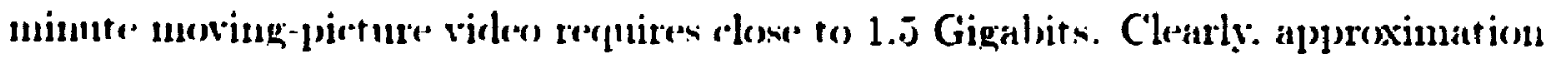

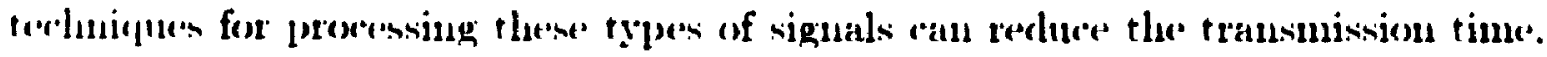

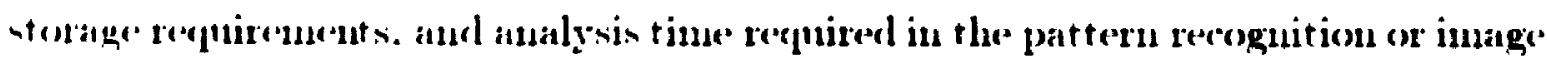
understaudiug phase.

Approximation techniçues are also nsed to remove excess noise or to simplify: highly complex signals. A simple linear approximation technignte is often applied to remore undesiralde noise from the gartbled version of the artual signal [Pa 73 ]. [PH 7t]. [Sk 70]. [Mo T0]. Indeed. unfiltered noisy siguals can learl to gross misinterpretation of data. To clarify this. Ballard and Brown [BB 82] present a case where it benuclary detcrotion algorithm was applied to a radiograph of a chest in which an edge of a ril, was olsstructed by random noise. They show how the acrurate detection of the ril, was impossible due to the unfiltered novise.

\subsection{Terminology and Concepts}

Lot $f(x)$ represent a one-rlimensional function to be approximated. and let it be detined over a domain $D$. For a continuous function. $D$ describes an interval [a.b]. and the fumction is definer for all values of $x$ between $a$ and $b$. For a discrete function. $D$ is a set of $N$ distinct values of $x_{0}, x_{1}, \ldots, x_{N-1}$. In most cases, the function $f$ is uot given explicitly. but often is defined by a set of $N$ distinct values $S=\left\{\left(x_{10}, f\left(x_{0}\right)\right),\left(x_{1}, f\left(x_{1}\right)\right) \ldots \ldots\left(x_{N-1}, f\left(x_{N-1}\right)\right)\right\}$. The values in the domain $D$ are strictly increasing in order and value, that is, for any two values $r_{i}$ and $x$, in $D$. if $i<j$ then $x_{1}<x_{\mu}$. Let the distance between any two arljacent values $x_{1}$ and $r_{1+1}$ lo represiented ly $\Delta x$, then only one of the $x_{2}$ 's is required, and the other $x$ 's "Ha loe cxpressed in terms of the known values $x_{k}$ and $\Delta x$. For example, suppose $x_{11}$ is giren and the values $x_{i}$ 's are equirlistant apart, then $x_{i}=x_{0}+i \Delta x$ for all $i=0.1 \ldots . . .+1$.

A two-rlimensiomal function is often used to describe a planar rurve or a digitizerl 


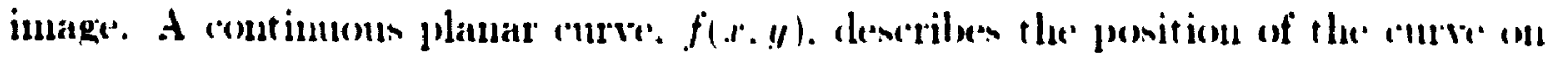

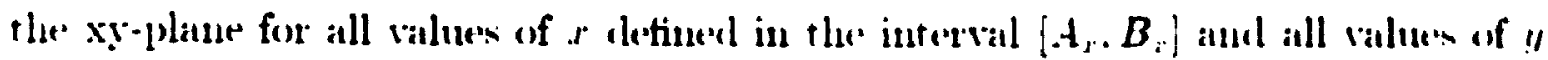

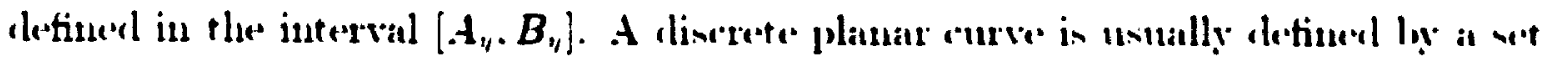

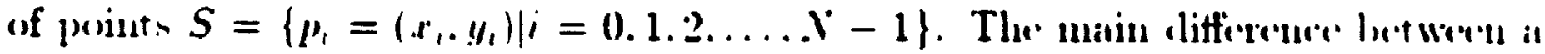

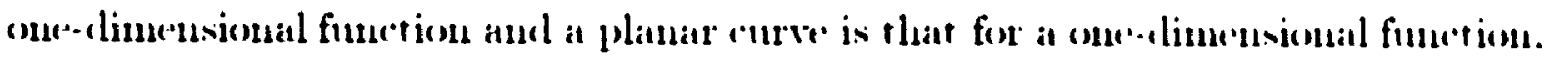
there is a one-fo-one mapping between the domain and range of $f$. Whereas for a planat curve, there may be more than one value in the range for canch value in the domain. If the function $f(x, y)$ is used to descriler a digitized image whose width is $I^{\circ}$ and whose height is $H$. then the value $f(x, y)$ repressents the clututized int "nsity of the image (greyscale value) at position (r.y) where $0 \leq x \leq \mathbb{W}^{\circ}$ and $0 \leq \| \leq H$.

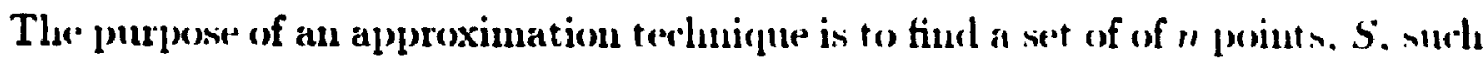
that $\hat{S}=\left\{\left(\hat{x}_{0}, \hat{f}\left(\hat{x}_{0}\right)\right),\left(\hat{x}_{1}, \hat{f}\left(\hat{x}_{1}\right)\right) \ldots .\left(\hat{x}_{n-1}, \hat{f}\left(\hat{x}_{n-1}\right)\right)\right\}$. where $\|<x$. If $r_{1}=\hat{r}$, for some $\left(x_{1}, f\left(x_{\imath}\right)\right) \in S$ and $\left(\hat{r}_{\jmath}, \hat{f}\left(x_{1}\right)\right) \in \hat{S}$. it is not necessary true that $f(x)=,\hat{f}(\hat{r}$,$) .$ The approximated data points in $\hat{S}$ are joined ly a polynomial of order at most "' -1 with an error norm less than a prespecified quantigy 6. By restrieting $m=2$. alproximation polyomials will be limited to linear expations.

When $f$ clescribes a one-dimensional waveform surh as an andio signal. it is the measured value of the signal at a speritied time variable $r$. In the field of computer vision and pattern recognition. the function $f$ often describes an murve on line segment which is dependent on the position varialse. $r$. Thus, $f$ is referreel to as a time or spacial domain function. A function can. therefore, be vir.werl ans a small machine that converts unmbers into other numbers: indeedl. the input to the function is a number aud the coutput of the function is austher uumber. A transform. can be viewed as a "bigger" marhine in an unakgons why: it converts functions into other functions. For example. the Fourier transform takes a continuons function of time (like a sound wave) or spare (like an image), say $f(x)$. and couverts it into a continuous function of frequency. $F(\omega)$. An approximation rechuignu in the transform domain derives an approximation $\dot{F}(\omega)$ by quntizing co trumerating 


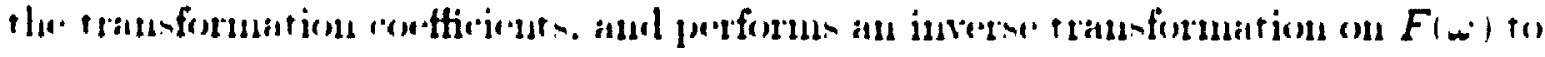
Intive $f$.

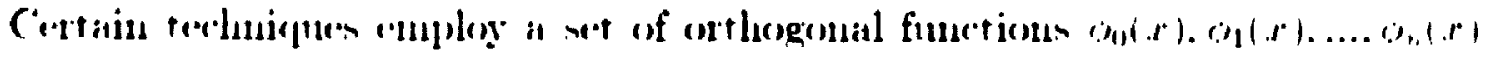
wo ilphoximate fler). The term orthogonal derives from the Cireek word orthos

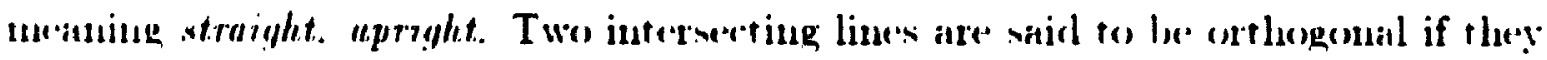
atre at right angles to anch ofluer. and in general. two $n$-dimensional rectors $\mathbf{u}=$

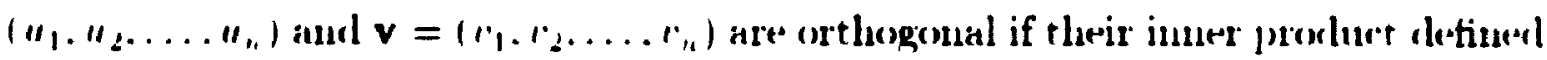

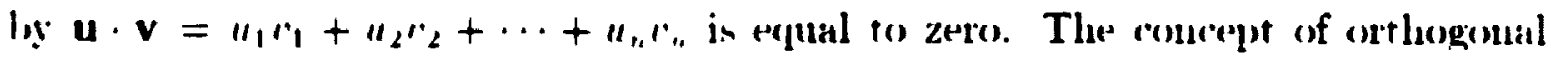
fum tionn follow direstly from that of orthogonal rectors.

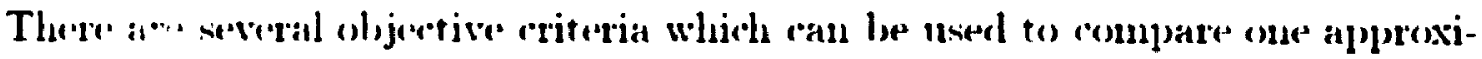
mation rechenicgle with another. Some of these ariteria are:

1. Spered atficienury.

2. Memory atticiency. i.e. how much data is kept in order to retain a good alpproximation of the original function. and.

3. Minimal anomut of error in the approximated function compared to the original fuurtion.

The'se evaluation standards will be applied to all of the terhnigutes reviewed. and a special emplonsis is made on how well each method performs in terms of error minimization. Since there are many different ways of looking at the error values. ind since each methorl may favour oue technique over another. the following three error calculating methods will be nsed:

1. maximum exror (XIE).

2. mean-sigured error (ISSE), and.

3. sigual-to-noise ratio) (S.IR). 


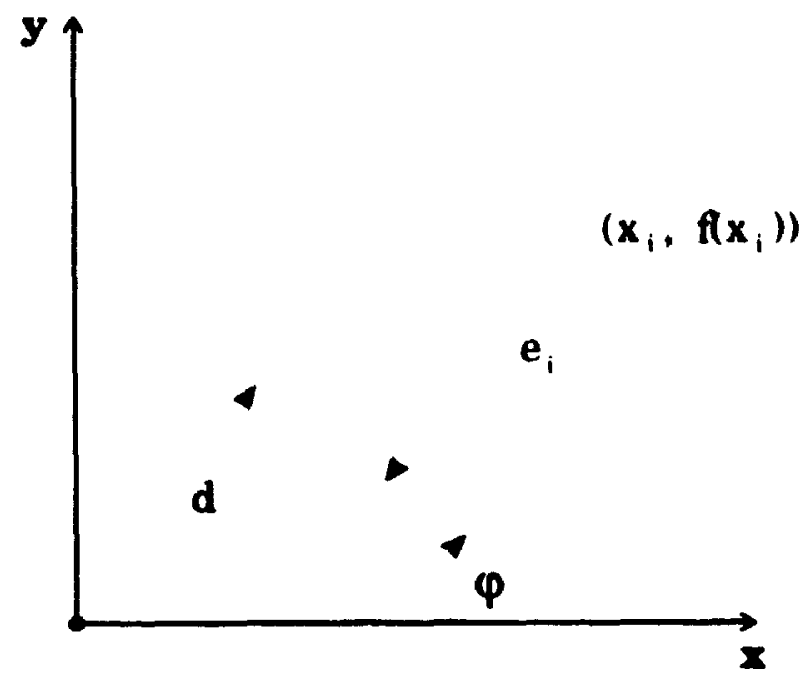

Figure 1: Illustrauson of parameters nsed in error calculation

Let + , be the error value of the $i^{\text {th }}$ point approximation. For one-elimenesional functions. $c_{1}=\left|f\left(x_{1}\right)-\hat{f}\left(x_{1}\right)\right|$. where $\hat{f}(x)$ is the approximating function. For $t$ wo .

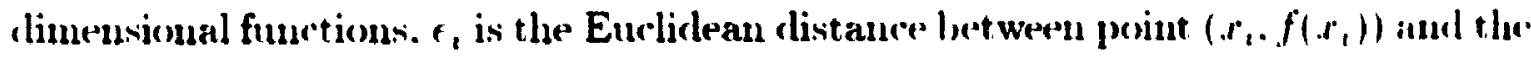
approximating curve evaluated at point $\left(x_{2}, \hat{f}\left(x_{1}\right)\right)$. If the ilpluoximating fuuction is given as a linear fumetion.

$$
\sin +x+r(\sin ; \cdot y=d
$$

then.

$$
\epsilon_{1}=\left|\sin p \cdot r_{1}+\cos r \cdot f\left(r_{1}\right)-d\right|
$$

where $d$ is the distance from the origin to the line and $\vec{r}$ is the angle of line with the x-axis.

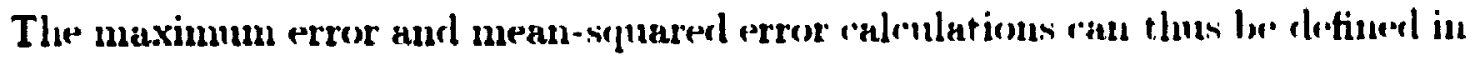
terms of $f$, is as follows:

$$
M E=\max _{1}\{t\}
$$




$$
M S E=\frac{1}{11} \sum_{i=1}^{n}
$$

The related meensure of signal-to-uoise ratio ( $S . R$ ) is often used as a standard

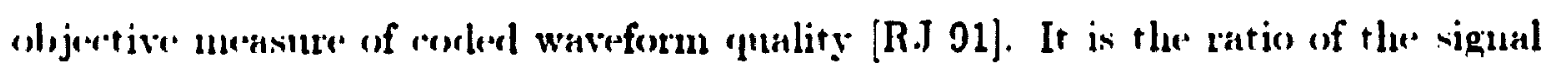
vatiance to the recoustruction error variaure. and for historical reasons is measured in deribels $(d B)$. Its compontation is defined as:

$$
S . I R=10 \log _{10}\left(\frac{\sum_{t=1}^{n} f\left(x_{1}\right)^{2}}{\sum_{t=1}^{n} f_{i}^{2}}\right)
$$

Panlidis and Horowitz [PH 74 ] showed that sensitivity to noise is an important difference between the .IE and MSE error norms. If the curve $y=\cos (x)$ on the interval $[0.2 \pi k]$ is fitted by the line $y=0$ by both methods the .ISE value inrevenes proportionately with increasing integral values of $k$ whereas ME remains constant. Jayant and Noll] [JN S4]. and Wang [Wa S8] indirated that it is rather difficult to correlate leetween objertive error measurements and the subjective quality of a human observer. Jayant and Noll eves. proceeded further by asserting that sulpjective measures of quality are more relevazi than objertive measures such us signal-to-noise ratio in the in the coding of signals such as speech and video. How(ver. reliable valuen of subjective measurements are, in general, more difficult to whtain.

\subsection{Motivation}

Existing approximation techniques for one- and two-dimensional functions such ans the ones presented by Stone[St 61]. Gluss[Gl 61]. Bellman[Be 61]. Montanari[Mo 70]. Ramer[Ram i2]. Pavlidis and Horowitz [PH i4], Kurozmmi and Davis [ID S2]. Prusinkiewicz[PC 85], Dunham[Du 86], and many others derive a solution ly working with constraints in the time/spacial domain. Some of them only work with continuons functions, while others work with both continuons and 


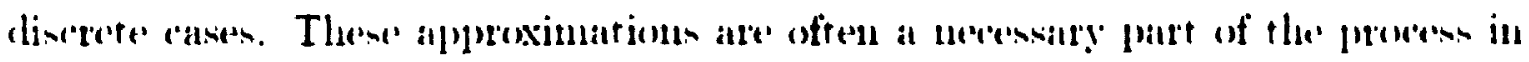

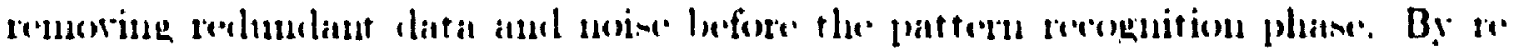

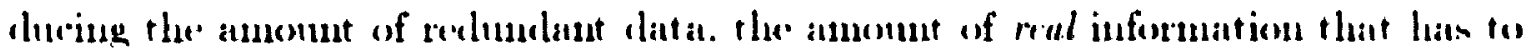

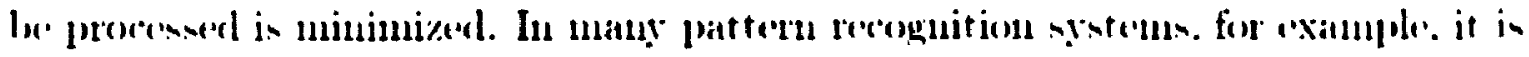

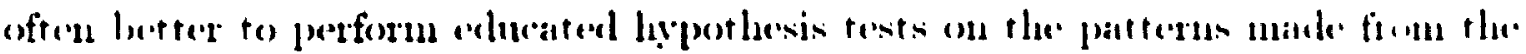

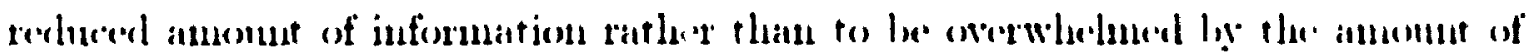
original clata which recpures much mure processing time.

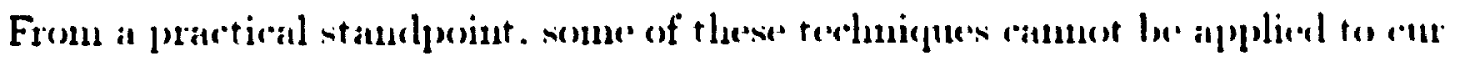

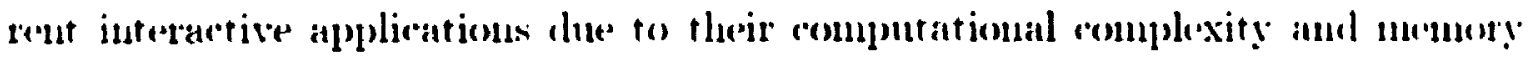
repuirements. Mauy of the trausform domain tedhuigues such as the Fondier transform. discrete rosine transform. nud Wilsh-Hanlamard transform. and ot hers hatr.

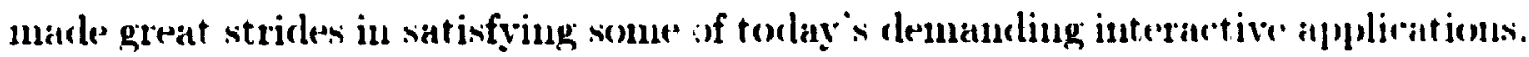
With a few exerptions, most of the approximation terhniques on one-rimensional functions can be extended and appliod to planur curves and digitized innages. ()ue

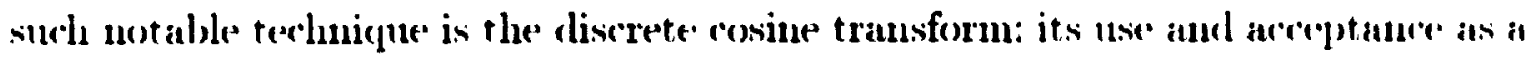
standard bx the Joint Photographie Experts Group (JPEG) and the Motion Pieture Experts Group (.MPEG) contirm that transform methorls are one of the solutions to some of the problems courrenty faced loy interactive applications.

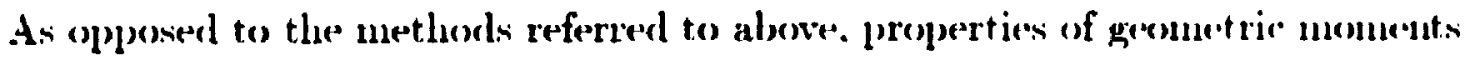

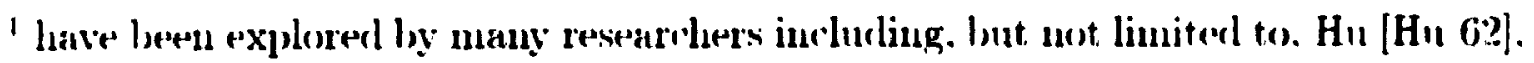
Duclaui et al. [DBM T7], and [Pa TS], [TC S6], to perform patterm recognition mul classitication. Berause of the close relationship between these gerometrie moments and the Fourier transform. they are considered to be in the transform domnin. A $t$. nite number of these moments cau, in fact, be used to recomstact an approximition

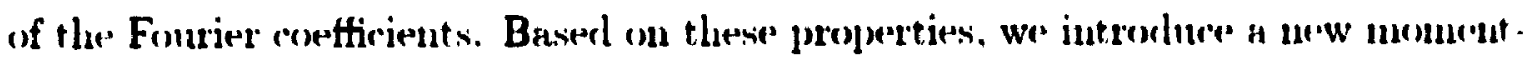

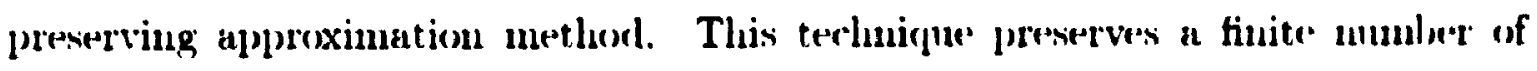
the gerometrie moments which are relateel to the trausform domnin. It is. Luwev-

\footnotetext{
'The geometris moment of a function $f(x)$ in defined as $\int_{-\infty}^{\infty} s^{k} f(s) d s$ for $k=11.1 .2$.
} 


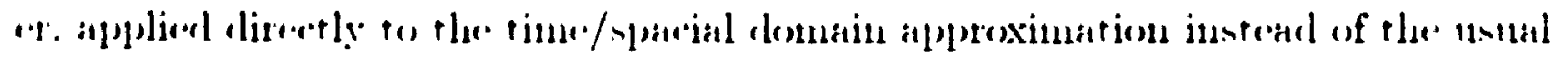

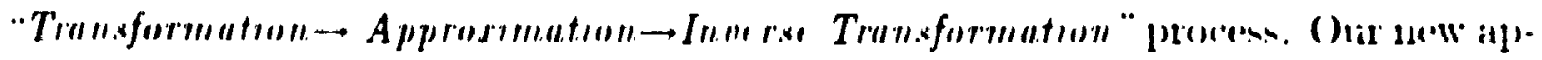

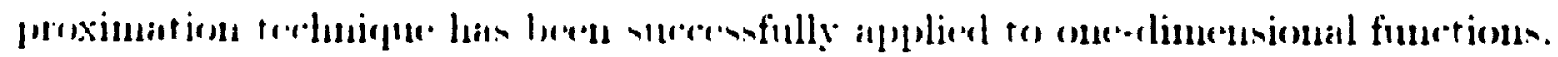
planat entrien. and digitizad images.

\subsection{Outline of thesis}

The renuinder of this introrluetory dhapter consists of a summary of all the uotations uned in this thesis. In rhapter 2. a review of some of the existiug at)-

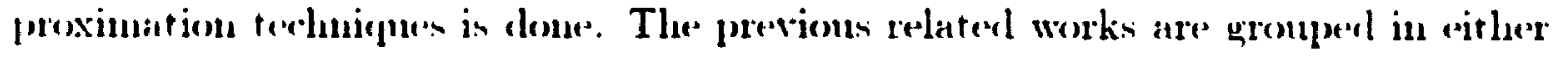
the time/sparial domain or the transform clomain. and in each of these two a ategerie.s. the work is presented in chromological order. Chapter 3 is a conrinuation of review of previoms work from Chapter 2. All the methodis geviewed in this section are divided into two-dimensional planar enrves aud digitized images. and the terhuiguen are grompeel aceoreling to theje spacial or transform domain. (Our new

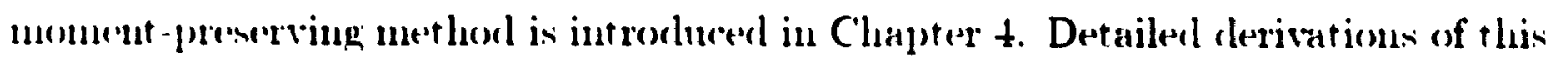
ilproximation terelnique and experimental results for one-rlimensional funetions are presented in this rhapter. Chapter 5 contains an extension of this terhnicpue us it is used to approximate planar curves and digitized images. Results of planar cunve and digitized imnge approximations are included at the end of this chapter. C'hapter 6 romelueles the thesis with a smmmary of the rurrent work and some pessible futhure resiegreh work.

The novel work done in chapters $\&$ to 6 are a result of a joint collaborative work with Professor ()ommen. The work is currenty wailuble as a potential publitation [N() 94]. A preliminary version of this paper will appear in the Procesecling: of I.AS-4. the Foneth International Comference on Intelligent Antonomoms Systems. Liarkrulue. Ciermany, March 1995. 


\subsection{Summary of Notation}

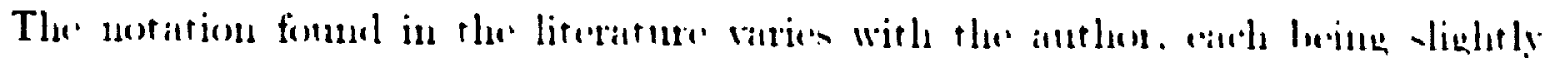

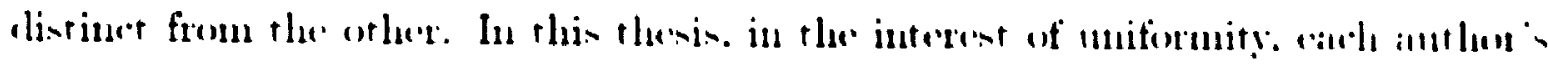

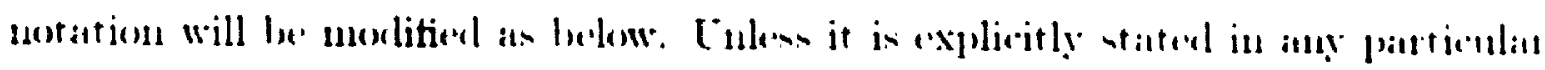
sertion. the notation below applien muiformly to the entire thesis.

$$
\begin{aligned}
& \Delta t \text { or } \Delta r=\text { nampline interval } \\
& \lambda=\text { decimation factor } \\
& D=\text { domain of a function } \\
& f=\text { maximmu allowable ertor limit } \\
& f_{1}=\text { pointwise error at }\left(x_{1}, y_{1}\right) \\
& E[\mathbf{X}]=\text { expectation of random variable } . \mathrm{X} \\
& f(x)=\text { original function to be approximated } \\
& f_{t}=f(x,)=\text { ralue of the function } f \text { at } x_{1} \\
& f_{t}^{\prime}=f^{\prime}(r,)=\text { value of the tirst clerivative of the function } f \text { int } x \text {, } \\
& f_{l}^{\prime \prime}=f^{\prime \prime}\left(x_{1}\right)=\text { malue of the second derivative of the function } f \text { it } r^{\prime} \\
& f_{t}^{(k)}=f^{(k)}\left(x_{1}\right)=\text { value of the } k^{\text {th }} \text { derivative of the function } f \text { at } r_{\text {, }} \\
& \frac{d^{\prime \prime} O(\omega)}{d \omega}=\text { the } n^{\text {th }} \text { derivation of the fuartion o with renperet to } \omega^{\prime \prime} \\
& f(x)=\text { approximation of the original function } f(x) \\
& \langle\mathbf{x} . \mathbf{y}\rangle=\text { deot product of two vectors } \mathbf{x} \text { ind } \mathbf{y} \\
& \phi_{k}(x)=\text { polyuomial approximation of } f(x) \text { in segment } l \text {. } \\
& F(\omega)=\text { trausform of the function } f(x) \\
& F^{\prime \prime}\left(\omega^{\prime}\right)=\text { complex-salued function } \\
& \mathbf{F}=\text { transformation matrix } \\
& \mathbf{F}^{r}=\text { trunspose of matrix } \mathbf{F}
\end{aligned}
$$




$$
\begin{aligned}
& \mathbf{F}^{-1}=\text { imserse of matrix } \mathbf{F} \\
& \mu=E[\mathbf{I}]=\text { utrau value of a function } \\
& m=h^{\prime \prime \prime} \text { theoretical monment of a fincetion } \\
& \text { ing }=h^{\text {th }} \text { moment of approximated function }
\end{aligned}
$$

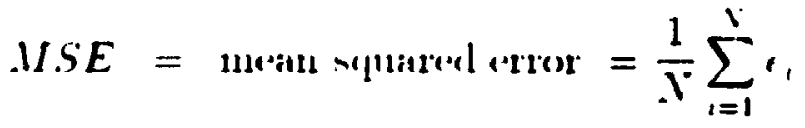

$$
\begin{aligned}
& M E=\operatorname{maximum} \text { error }=\max _{1 \leq \leq \leq, 1}\left\{\ell_{,}\right\} \\
& V^{*}=\text { mumber of original sampled values } \\
& 11=\text { unmulser of sampled values selected }
\end{aligned}
$$




\section{Chapter 2}

\section{Related Work on One-dimensional (1-D) Func- tions}

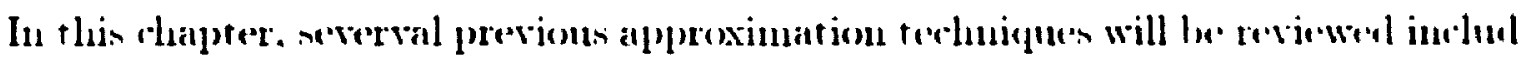

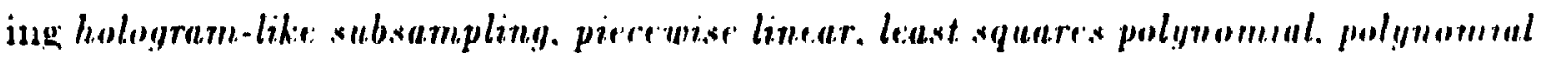
splines. Fourier tran.sform. Walsh-Hadamard tran.sform. Kurh.umen-Luene trun.sform. cosine: tran.sform. and fractals. Each of these terlunicumes falls into cone of the follow ing two categ(uries:

1. spacial or temporal domaun approximations. and.

2. transformed clomain approximations.

The tirst gromp of terhniques ralenlates its appreximation. $f(x)$. by dirently using the given values of $x$ and $f(x)$. They ate cousidered to be alpuroximation methorls in the spacial or temporal domain. The second gronp determines the apporexinntion of $f$ log transforming it into another function. say $F$. approximating $F$. and exploiting

an inverse transform to clerive $\hat{f}(r)$. These approximation tevhuirques (n) transformed function $F$ and in the domain of the transformed function. These two gromps of approximation techniques will be describerl in derail in their renpertion

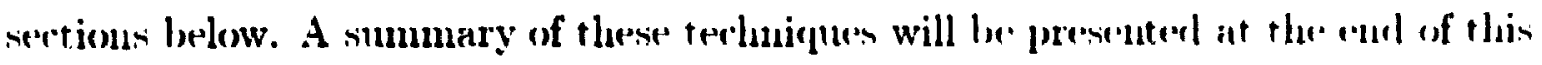

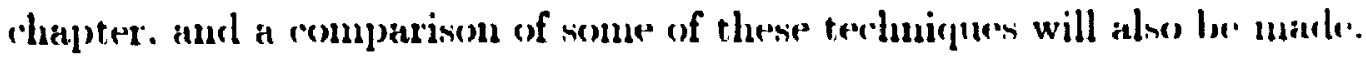




\subsection{Spacial or Temporal Domain Function Approximation}

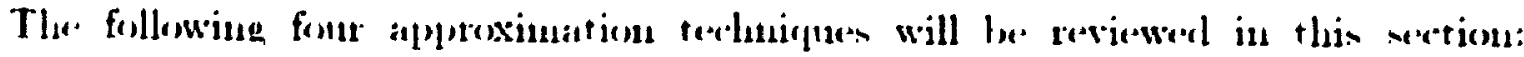

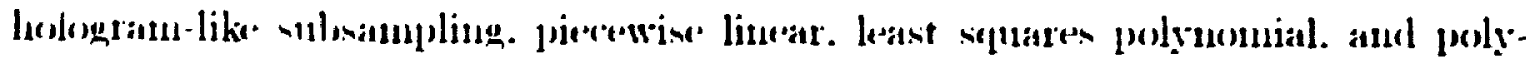

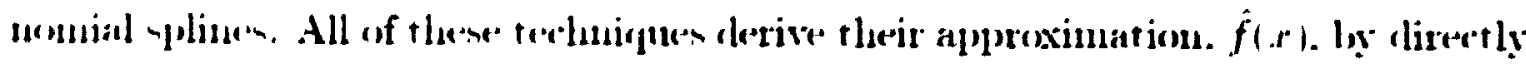

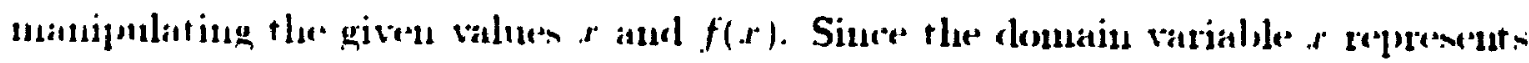

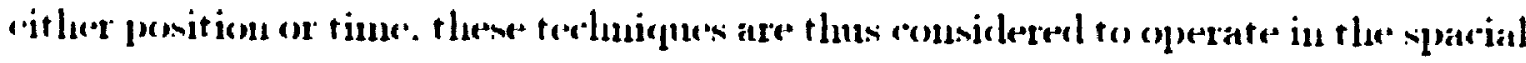
or temporal domain.

\subsubsection{Subsampling}

In many signal promensing applications, esperially in digital andio. it is necessary to convert an analog signal into a discrete sechence of munbers. The conversion process is commonly dome by sampling the continuous analogue signal. $f(r)$ at wegnlar interval $\Delta x$ to produce a secpueuce $S=\left\{f\left(x_{0}\right), f\left(x_{1}\right), f\left(x_{2}\right) \ldots \ldots f\left(x_{n-1}\right)\right\}$. where $r_{2}=r_{1}+i \Delta r$ and $r_{0}$ is some given starting time. There are sperial rases where the sampling interval is irtegular, and in these circumstances. the set must sperify both the time or position and the ralue of the sigual at that particular time or powition. such that $\left.S=\left\{\left(x_{1}\right), f\left(r_{0}\right)\right),\left(r_{1}, f\left(r_{1}\right)\right),\left(r_{2}, f\left(r_{2}\right)\right), \ldots\left(r_{n-1}, f\left(r_{n-1}\right)\right)\right\}$. For simplicity of expressing the dependent values $f\left(x_{1}\right)$ is without introducing any confusion or ambiguity. we shall use the notation $f_{t}=f\left(x_{1}\right)$.

The sampling theorem places a restrirtion on the magniturle of $\Delta x$ as specitied by the frequency content of the sigmal $f(x)$. The theorem. as described by Stearns aud Hush [SH 90]. is stated below:

Theorem 1 To be able to reconer $f(x)$ exactly, it is necessary to sample $f(x)$ at a rate grinter than twice its highest frequency.

For example. if the signal. $f(x)$, in a sine ware as shown in Figure 2. then more tham two samples per cycle are required to reconstruct $f$. If two or less samples are liserd. then the samples ate the same as these of sinusoid $g(x)$. Aliasing is a term 


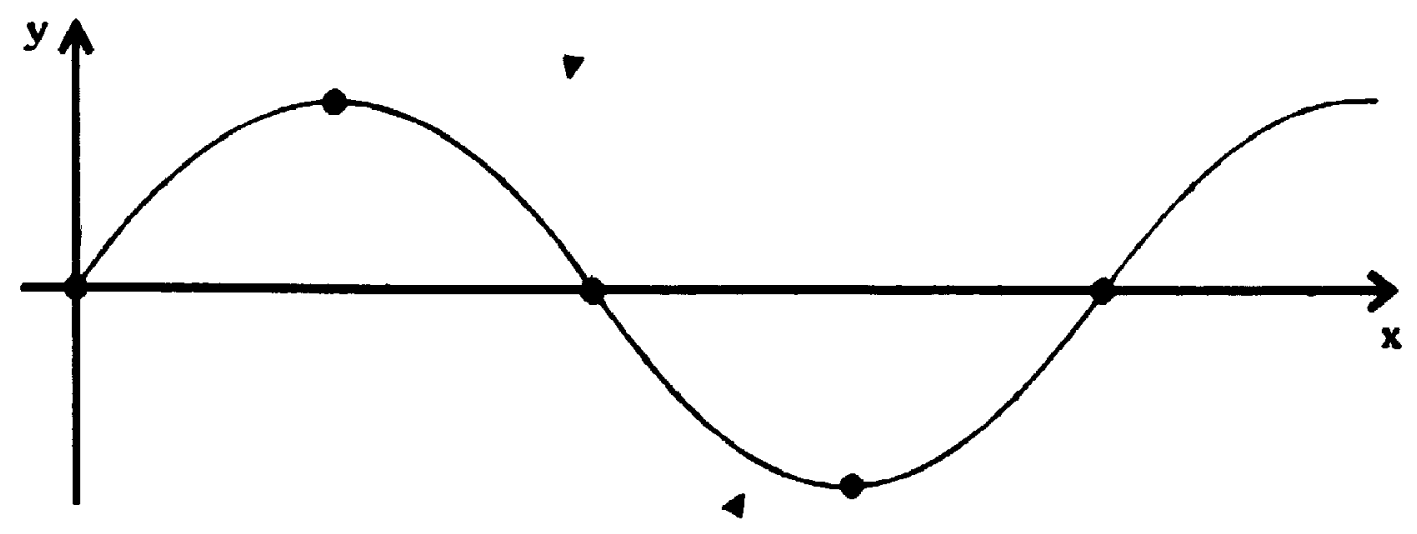

$g(x)$

Figure 2: Sampling at le'ss than twice the freculuery of $f$

which is often used in signal processing to describe such frequency folding. Even with the sampling rate of exarty twice that of the highest frecqueney as shown in Figure 3. the samples still cannot be used to reconstruet function f cortertly:

The sampling theorem. however. is not a good predietor of how ansily objerets ran he recognized by computer programs. Often, ohjerts can be unore cinily rereognized in images that have a low sampling rate [BB 82]. Essentially, there ine two fundamental reasons for this surprising result. First of all, the complutations are fewer because of the reduction in dimensionality. and secondly. the confusing details contained in the high-resolution version of the images may not alpuar it the rerluced resolution.

Subsampling. also known as derimation, consists of determining a seplunere $S$ which contains exactly $"$ uniformly selerted points from $S$, where $"-x$. Fre.

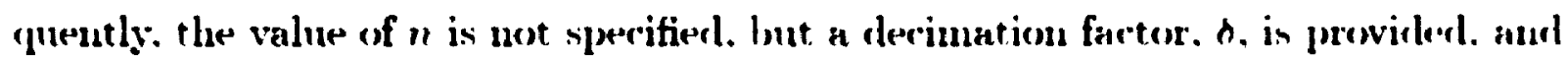

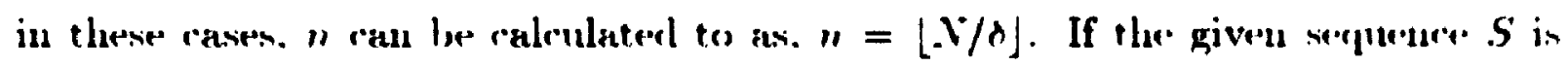




\section{$f(x)$}

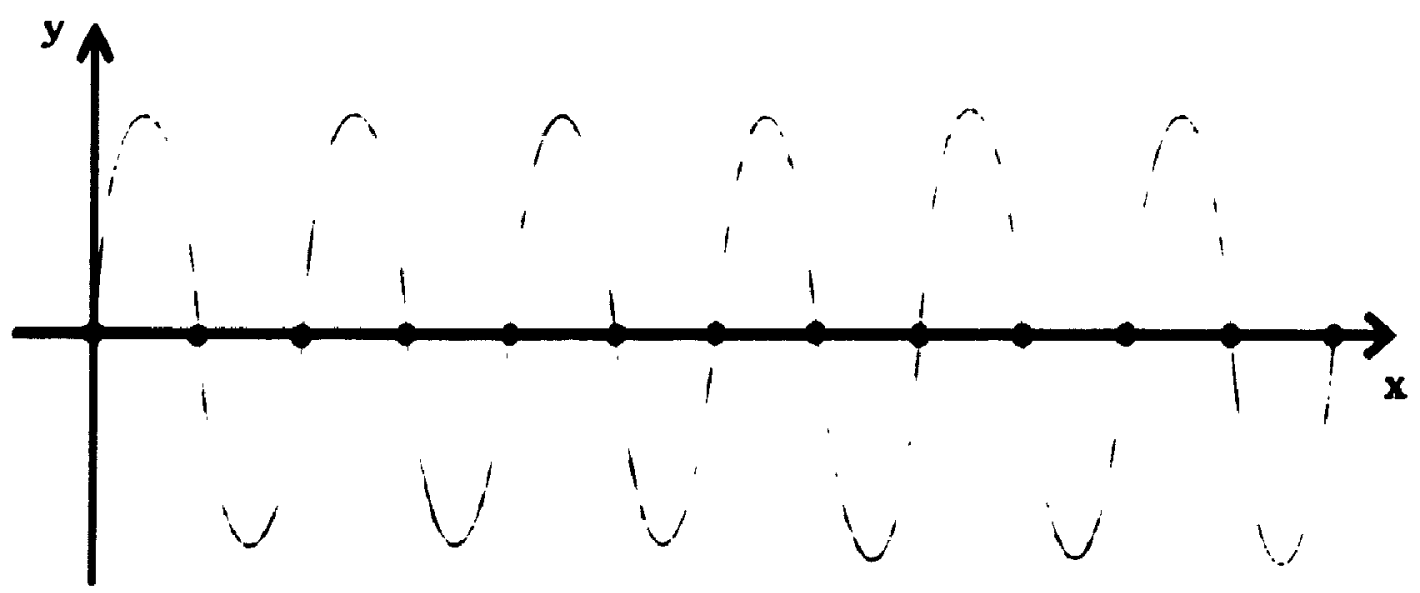

Figure 3: Sampling exartly twice the frequency of $f$

uniform. then the derimation by a fartor of $\delta$ will generate an approximation sequener. $\hat{S}=\{f(x)$,$\} where j=0, \delta, 2 \lambda \ldots, n \delta$. This technique requires practically uor anloulations on $x_{z}$ or $f\left(x_{z}\right)$. For example, suppose that $S$ contains 2000 uniform samples. where earh sample is one millisecond apart. If $S$ is derimated by a fartor of tive (i.e.. $\delta=5$ ), then $\hat{S}$ contains 400 samples where earlh sample is five milliseconds apart. Another way of looking at uniform decimation is that every seçuence of five samples in $S$ is used to form a single sample in $\hat{S}$.

If $S$ contaius a sequence of non-uniform samples, the subsampling process rannot be applied to $S$ directly because subsampling can only be applied to a uniform secquence of values. For example, suppose $S$ contains 2000 non-uniform samples silch that

$$
\begin{aligned}
S= & \{(0.0),(20.50),(21,100),(22,20) \cdot(23,-5),(24,0), \ldots \\
& (20 i .50),(20 i+1.100),(20 i+2,20),(20 i+3,-5) \cdot(20 i+4.0), \\
& \ldots \\
& (7980.50),(7981.100) .(7982.20) .(7983,-5),(7984.0)\}
\end{aligned}
$$

for $1 \leq i<400$. If one ont of every tive samples in $S$ is used. starting at the first 
sample (0.0). to derive $\dot{S}$. then $\hat{S}$ contains 400 samples whose values arte arto. To

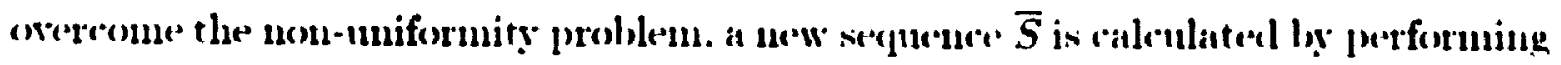
interpolation of $S$ such that all the values in $\bar{S}$ are equidistant apart ly $\bar{S} \cdot \boldsymbol{r}$. Where $\bar{J} r$ is the smallest $\Delta . r$ in $S$. The decimation prosess is then performed on the seduluence $\bar{S}$ to derive $\dot{S}$.

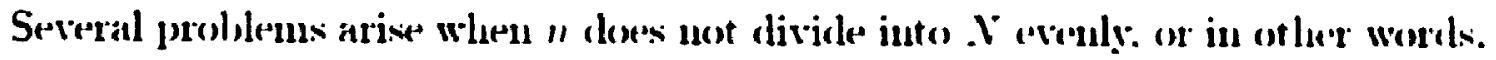
the sonte factor $A$ is non-integral. For example. suppose $X$ is 640 . and $"$ is 100 . A sample camot be taken at every $6 . t$ samples to give exactly 100 values in $\dot{S}$. If

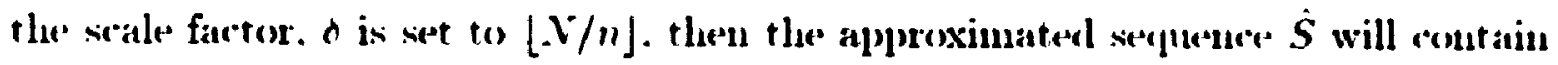
100 samples: and if $\partial=\lceil. V / n\rceil$ then $\hat{S}$ will contain 91 samples. In order to attain $\hat{S}$. an interpolation of $S$ by a factor of $k$ must be dome to derive a new secpluence. $\bar{S}$. and a selection of one ont of every o samples from $\bar{S}$ is then performed. The main drawback with this method is that the "s samples are relatively unform with respect to $\bar{S}$ but not uniform with respect to $S$.

Prusinkiewicz [PC 85] proposed a progressive subsampling scheme which is inthitively based on the following two propositions:

1. A translated set of sampling points uniformly distributed in a line is it set of uniformly distributed points, and.

2. The union of appropriately translated sets of uniformly clistrilunted points is also a set of uniformly distriluted points. with a reduced distance between arljarent points.

If a given string of data $S$ represents a signal of full resolution. it cau lor dividerl into substrings $S_{0}, S_{1}, \ldots, S_{n}$ as shown in Figure $4($ a) to Figure $4($ h) . Earle sill,string $S_{1}$. representing a lower resolution of $S$, resilts from the traversal ilgorithm (sulsampling terhnique) and the overlapping samplerl areas.

Let $S=<f_{0}, f_{1}, f_{2} \ldots>$ be a string of points of the one-elimensional function $f$. and $S(i, j)$ be o suldstring of $S$ described by: 


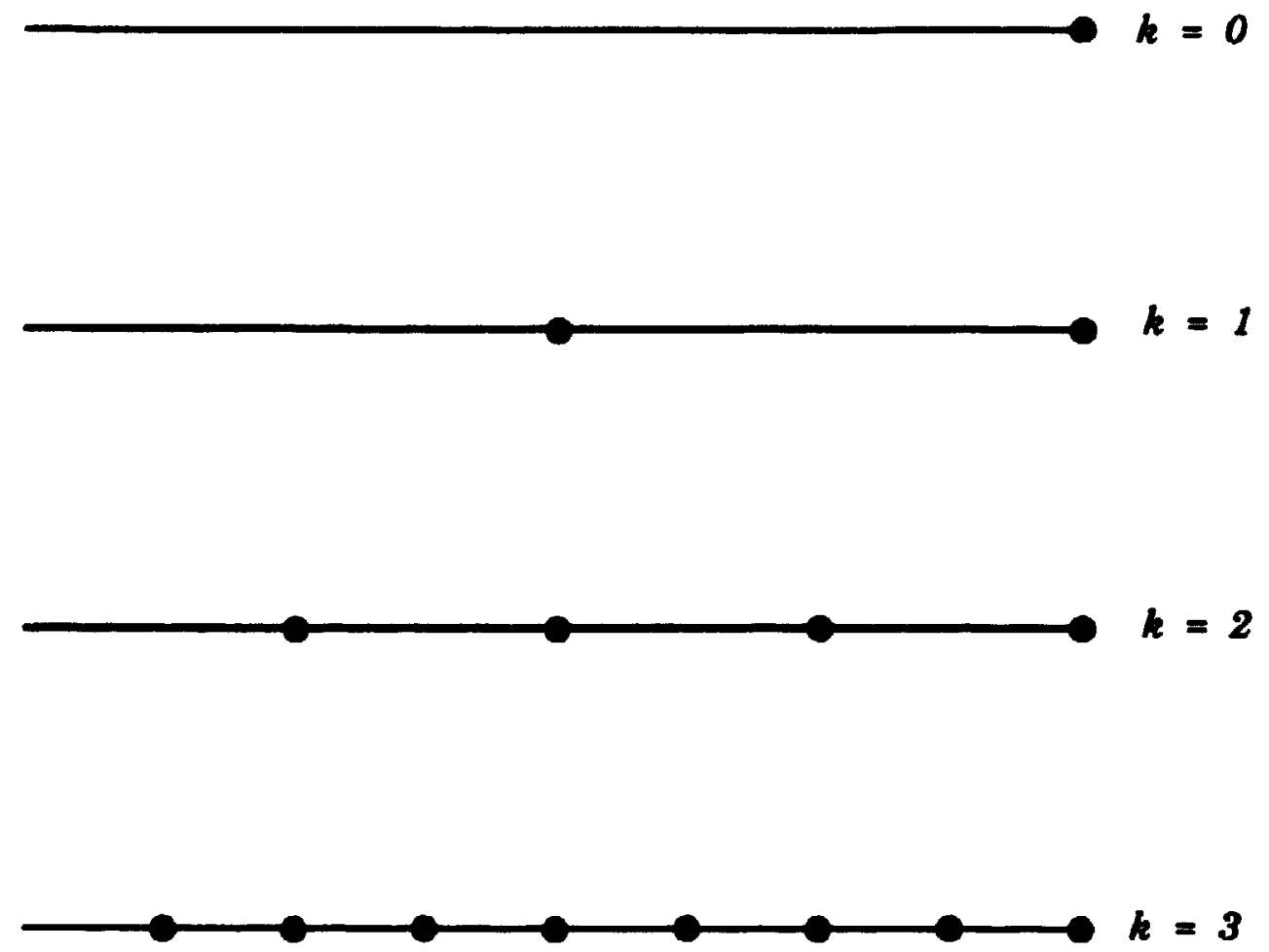

Figure 4: Prusinkiewicz's progressive uniform sampling technique

$$
S(i, j)=\left\langle f_{, \cdot 2^{i}}, f_{j \cdot 2^{i}+1}, \ldots f_{(j+1) \cdot 2^{\prime}-1}>\right.
$$

Furthermore, let $S_{7}(i, j)$ denote the translation of the sulsstring $S(i, j)$ by the vertor $\vec{x}$.

Let $\boldsymbol{N}$ denote the size of the original sequence $S$ which represents the sampler values of the function $f$. The string of sampled points is then defined as follows:

$$
\begin{aligned}
S(0,0) & =\left\langle f_{N}\right\rangle \\
S(k, 1) & =S_{-N \cdot 2^{-k-1}}(k .0) \\
S(k+1,0) & =S(k, 0)+S(k, 1)
\end{aligned}
$$

where + denotess the couratenation of strings, and $k=0.1 \ldots$ Prusinkiewicz has proverd the following result regarding the $x$-coordinate of the $k^{\text {th }}$ point. 
Theorem 1 Let the binary word $r_{21-1} r_{2-1} \ldots r_{1} r_{1}$ represent indes $h$ of a sumple. point $\left(. t_{k} . f_{k}\right)$ in the: pure benar!! number suste:t!:

$$
k=\sum_{i=1}^{i-1} r_{i},
$$

The re-contrdinate: of point $f_{k}$ is:

$$
r_{k}=T\left(1-\sum_{i=1}^{1-1} r_{2 i} 2^{-(1+1)}\right)
$$

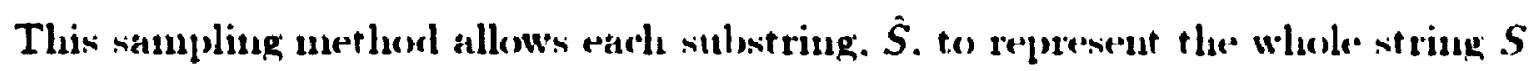
at that particular resolution. These sampling techniques are asy to apply and are" romputationally inexpensive clue to the alsenese of any complioated mathemational equations. This lack of (computation is also the main downfall of sulssimpling teneltniçues hecause it introrluces aliasing into the approximateol signals which, in turu, rauses andio signals to lose their high frequeney components and inuge's to besoume hlurry.

\subsubsection{Least squares polynomial}

One of the most well-known approximation terhnicuess is the least squares polynomial appreximation. It is based on the Legendre s prineiple of lenst squares which states that "when the available data in the domain $D$ are either exart. or of eruual relial,ility, then the 'best approximation' over $D$ is that oue for which the ingreante (sum or integral) of the squared error in $D$ is lenst." [Hi 8T]. More generally. if $u \cdot\left(x_{1}\right)$ is the measure of dependability of the value of $f(x)$ when $r=r_{1}$, then the eriterion also requires that the squared error at $r_{\text {, be }}$ multiplied hy the weight we( $\left.r_{t}\right)$ before the aggregate stum is calculuted. For a uniformly distrilunted set of cliscrete. values. the weights are of equal significance, and for the sake of simplieity in the calculation. they are assumed to be nity.

This terhuigute cun be applied to both rases when the given function $f(r)$ is continuons or discrete: however, it is often applied to cases where $f(x)$ is a rlis-

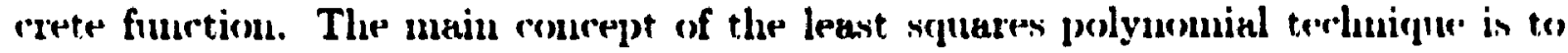




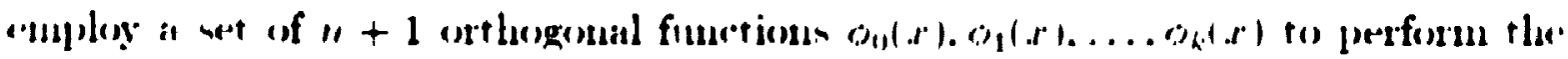
:pproximation surle that.

$$
f(x) \equiv \sum_{i=11}^{\prime \prime}(t, c)(x) \approx f(x)
$$

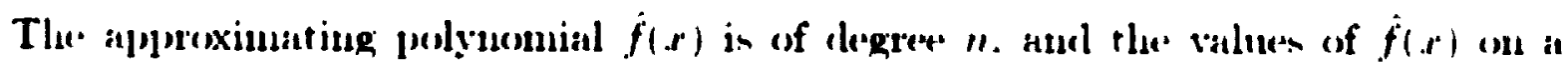
set of $x+1$ periuts agrese "as well as ponsible" with known values of $f(x)$ it theme. prints. If the residual fumetion $r(x)$ is given as

$$
\begin{aligned}
r(x) & =f(x)-\hat{f}(x) \\
& =f(x)-\sum_{i=0}^{n} a_{1} o_{l}(x) .
\end{aligned}
$$

then the hest approximation is refined to be that for which the ralues $a$, is are determinerl so that the aggregate sim or integral of $u(x) r^{2}(x)$ over $D$ is minimal. Thus. ly differentiating the aggregate sum partially with respect to $a$, for $j=$ $0.1 \ldots . .1$ and setting it to zero. a system of $n+1$ normal equations involving the $"+1$ unknowns $\left\|_{11} a_{1} \ldots \ldots\right\|_{n}$ can be formulated as shown below:

$$
\frac{\partial}{\partial u_{k}}\left\{\sum_{i=0}^{n} \mu\left(x_{1}\right)\left[f\left(x_{1}\right)-\sum_{j=0}^{n}\left(1, o_{j}\left(x_{1}\right)\right]^{2}\right\}=0 . \quad(k=0.1 \ldots \ldots n)\right.
$$

which yields:

$$
\begin{aligned}
& u_{11} \sum_{i=11}^{x} w\left(x_{1}\right) O_{k}\left(x_{i}\right) O_{0}\left(x_{1}\right)+a_{1} \sum_{i=0}^{x} \mu\left(x_{1}\right) O_{k}\left(x_{i}\right) O_{1}\left(x_{2}\right)+\cdots+a_{k} \sum_{i=0}^{x} w\left(x_{1}\right) O_{k}\left(x_{i}\right) O_{k}\left(x_{1}\right) \\
& =\sum_{i=1}^{n}\left(x\left(x_{1}\right) o_{k}\left(x_{i}\right) f\left(x_{1}\right) . \quad(k=0.1 \ldots n) .\right.
\end{aligned}
$$

Thesse normal equations can be obtained by first writing dewn the $. \boldsymbol{v}+1$ equations where the $x+1$ points $x_{0}, x_{1} \ldots \ldots, x$ exartly equal $f(x)$

$$
\begin{aligned}
& a_{11} O_{11}\left(r_{11}\right)+a_{1} O_{1}\left(x_{1}\right)+\cdots+a_{n} o_{n}\left(x_{0}\right)=f\left(x_{0}\right) \\
& n_{10} O_{11}\left(x_{1}\right)+n_{1} O_{1}\left(r_{1}\right)+\cdots+a_{n} o_{n}\left(x_{1}\right)=f\left(x_{1}\right)
\end{aligned}
$$

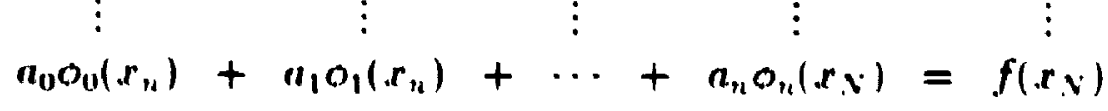




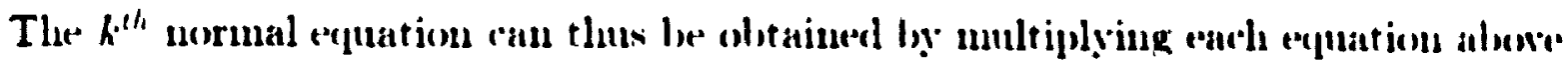

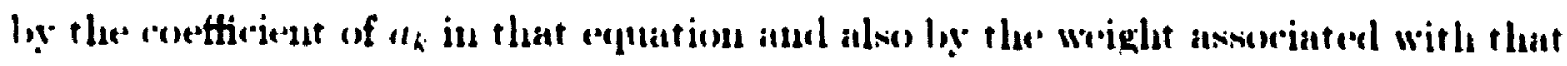
chlations. and sumuning the results.

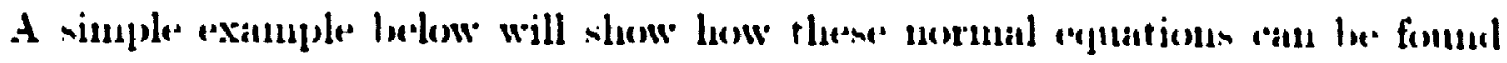

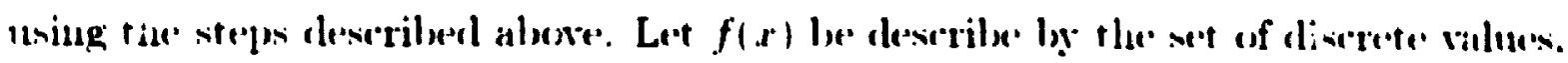

\begin{tabular}{|c|c|}
\hline$x$ & $f(x)$ \\
\hline 0.0 & 1.4 \\
0.2 & 1.8 \\
0.4 & 2.7 \\
0.6 & 3.4 \\
0.8 & 4.4 \\
1.0 & 4.5 \\
1.2 & 6.1 \\
1.4 & 8.0 \\
1.6 & 9.4 \\
1.8 & 12.1 \\
\hline
\end{tabular}

$\hat{f}(x)$ loe a polyuomial approximation of degree two. and for the sake of simplicity. let the set of orthogonal functions be $o_{0}(x)=1 . o_{1}(x)=$. and $o_{2}(x)=x^{2}$. then the following equations are formed.

$$
\begin{aligned}
& a_{0}+0+0=1.4 \\
& a_{0}+0.2 a_{1}+0.04 a_{2}=1.8 \\
& a_{0}+0.4 a_{1}+0.16 a_{2}=2.7 \\
& a_{0}+0.6 a_{1}+0.36 a_{2}=3.4 \\
& a_{0}+0.8 a_{1}+0.64 a_{2}=4.4 \\
& a_{0}+1.0 a_{1}+1.0 a_{2}=4.8 \\
& a_{0}+1.2 a_{1}+1.44 a_{2}=6.1 \\
& a_{0}+1.4 a_{1}+1.06 a_{2}=8.0 \\
& a_{0}+1.6 a_{1}+2.56 a_{2}= \\
& a_{0}+1.8 a_{1}+3.24 a_{2}=12.1
\end{aligned}
$$

Curler the assumption that earh clata value $f_{1}$ is of equal signifiraure. we rerive the threas normal equations.

$$
\begin{aligned}
10 a_{1}+0.0 a_{1}+11.4 a_{2} & =52.7 \\
0 a_{0}+11.4 a_{1}+34.2 a_{2} & =57.14 \\
11.4 a_{1}+34.2 a_{2}+24.5328 a_{2} & =57.076
\end{aligned}
$$


By: whing the sytem of three edpations of three moknowus. the approximated fuuction $f(x)$ is determined to lwe.

$$
f(x)=3.7334+1.4460 x+0.2063 x^{2}
$$

and the artual values of $f(x)$ and their corresponding approximated malues ate tallotiated leelow.

\begin{tabular}{|c|c|c|}
\hline$r$ & $f(. r)$ & $f(x)$ \\
\hline 0.0 & 1.4 & 3.7334 \\
0.2 & 1.8 & 4.0309 \\
0.4 & 2.7 & 4.3448 \\
0.6 & 3.4 & 4.6753 \\
0.8 & 4.4 & 5.0222 \\
1.0 & 4.8 & 5.3857 \\
1.2 & 6.1 & 5.7657 \\
1.4 & 8.0 & 6.1621 \\
1.6 & 9.4 & 6.5751 \\
1.8 & 12.1 & 7.0046 \\
\hline
\end{tabular}

If the unmber of ordinates defining $f(x), n$, is greater than the number of orthogonal functions, $k$, then an exart fit of $n$ points is generally impossible. If $n=k$. however. it is possible to determine a function $\hat{f}(x)$ such that the error is reduced to. or close to, zero. This technique beromes impractical for polynomials of high clegress (ten or higher) due to the computational cost and the many local minima. maxima. and inflection points which inherently exist in polynomials.

\subsubsection{Plecewise linear}

In many cases, the original discrete function $f$ is very complex and cannot be expresserl by a simple closed-form equation. The function is thus divided up into smaller segments, and each segment is then approximated by a simple linear equation. The point where one segment joins the next is often referred to as a knot or a joining point. All of the terhniques presented in this sertion are baserl on the same pieceswise linear principle, but they do vary on their predefined conditions surh as 
using a tixed number of knots or variable mumber of knots. and the cluention of whether the spacing hetween the kuots in of tixed size or of varinhle size.

Stone [St 01] presented the problem of trying to obtain a set of hest-tit line segments to a curve and to give a desed form solution for the procedure. The problem formulated $\mathrm{x}$ Stone consists of the miginal given function $y=f(r)$ detherl berwern the two endpoints $u_{0}$ and $u_{x}$. where $u_{1} \leq x \leq 4 x$. Formatly: the problem reduces to determining an approximation. y. where

$$
y= \begin{cases}u_{1}+b_{1} x & u_{1} \leq x \leq u_{1} \\ a_{2}+b_{2} x & u_{1} \leq x \leq u_{2} \\ \vdots & \\ u_{N}+b_{N} v & u_{,-1} \leq x \leq u_{N}\end{cases}
$$

such that

$$
F\left(a_{1}, a_{2} \ldots \ldots a_{N}, b_{1}, b_{2} \ldots \ldots b_{N}, u_{1}, u_{2}, \ldots, u_{N-1}\right)=\sum_{j=1}^{x} \int_{u_{j-1}}^{u_{1}}\left[f(x)-a_{1}-b_{1}, r\right]^{2} d, r
$$

is minimized. If $u_{1}, u_{2} \ldots, u_{N}$ are sperified in advane, then the problem reelueres to the scenario where the best tit over each interval is obtained separately using the traditional least squares procerlure (as presented in the previous section). If the. specified function $f(x)$ is a quadratic, then the kuots are erquidistant apart and are cletined by $u_{p}=u_{0}+\frac{p \cdot\left(u_{x}-u_{0}\right)}{N}$, where $p=1,2 \ldots . . v-1$. The values of as and $b$ : can be calculated from:

$$
\begin{aligned}
& a_{p}=r \alpha_{p}+t \\
& b_{p}=r{\sigma_{p}}_{p}+\cdot
\end{aligned}
$$

where $r, s$, and $t$ are coeffirients of the original quarlratic equation $f(x)=r r^{2}+$ $s, r+t$. The values of $\alpha$ and $i$ are derived from the following formula.

$$
\begin{gathered}
\alpha_{p}=-\frac{1}{6}\left[\left(u_{p}+u_{p-1}\right)^{2}+2 u_{p} u_{p-1}\right] \\
\gamma_{p}=u_{p}+u_{p-1}
\end{gathered}
$$




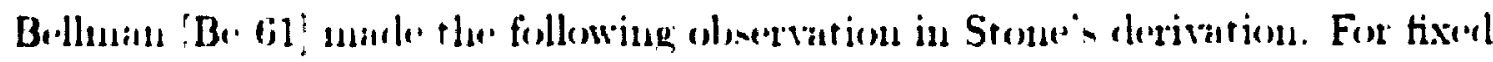

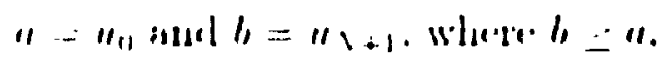

$$
f\left(b_{1}\right)=\left[\min _{n, n, n} F\left(n_{1} \ldots \ldots n_{1}: b_{1} \ldots \ldots b_{x}: u_{1} \ldots \ldots u v\right)\right.
$$

Hlu?

$$
f_{1}(b)=\min \left[\int_{11}^{u_{1}}\left(g(x)-a_{1}-b_{1} \cdot x\right)^{2} d x+\int_{u_{1}}^{h_{1}}\left(a(x)-u_{2}-b_{2} \cdot r\right)^{2} d x\right]
$$

where the minimum is compoted ores:

$$
-x<u_{1} \cdot u_{2} \cdot b_{1} \cdot b_{2}<x . \| \leq u_{1} \leq b .
$$

Thin function is reatily determined since the minima can be computed orer the $\|_{\text {, }}$ and b, and then minimized over $"$, by means of a discrete serarch. For $. l \geq \geq$.

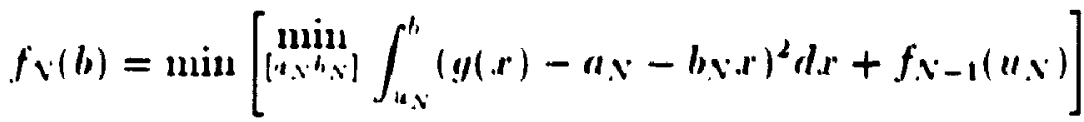

$$
\begin{aligned}
& f_{N}(b)=\min _{1} \leq u_{x \leq n}\left[h(u, x \cdot b)+f_{N-1}(u, v)\right] .
\end{aligned}
$$

Gluss [Cil 61] [Gi 62] reiteruted the problem refined ly. Stone in simpler terms. If the mumber of points sulelividling the given interval $[n ., 8]$ is given. say $n$. then the main task is to tind the " line segments which will give the best least schnares alpproximation to of function $f(x)$ defined in that interval. Although Gluss approach is similar to Bellman's, he alsos offered an equation for $u$, which may be determined ly an erquality sign instead of at minimization. He also showed how clynamir programming produces computationally simple expations for the model in which the ends of the line segments are constrained to lie on the curve $f(x)$.

Phillips [Ph 68] userd a different set of premises than Gluss, Bellman. and Stone. His approanch was to determine an approximation to a given function $f(x)$ by $k$ line segments with any pre-ansigneel arcurary. The approximation is obtained using the minimux norm ${ }^{2}$. If $f^{\prime \prime \prime}(x)>0$ on the interval $[n, y]$. then it is known that the

\footnotetext{
"Minitnizing the maximmun epror norm.
} 


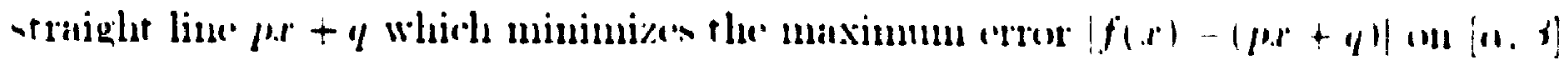
sitintien the following aplutions.

$$
\begin{array}{r}
f(a)-(p)+y)= \\
f(\xi)-(p \xi+y)=-+ \\
f(x)-(p \cdot f+y)=\epsilon \\
f^{\prime}(\xi)-p=0 \Longrightarrow l=f^{\prime}(\xi)
\end{array}
$$

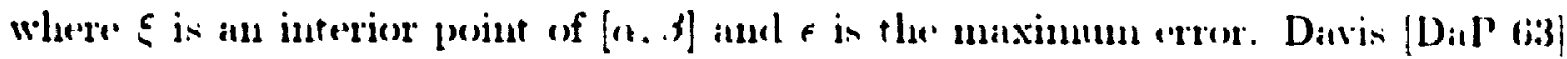

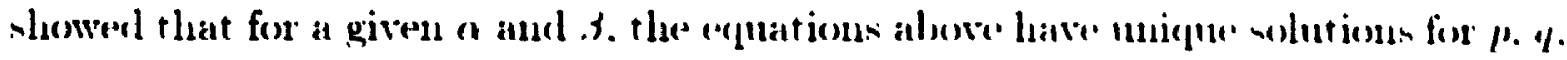

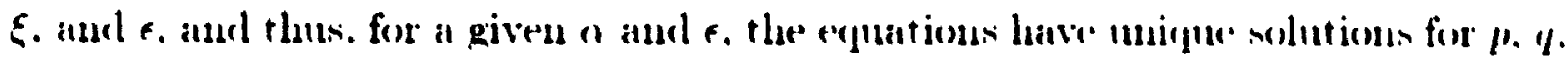

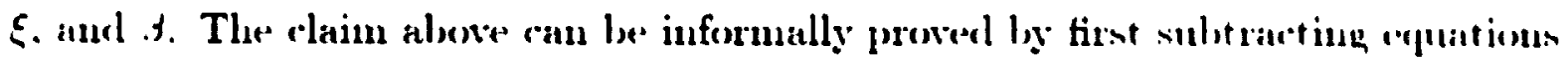
(1) and (2). and then substituting (4) into the result to give.

$$
\begin{aligned}
G(\xi) & =f^{\prime}(\xi)(\xi-n)+f(a)-f(\xi)-\underline{2} \xi=0 \\
G^{\prime}(\xi) & =f^{\prime \prime}(\xi)(\xi-n)+1 \cdot f^{\prime}(\xi)-f^{\prime \prime}(\xi) \\
& =f^{\prime \prime}(\xi)(\xi-a)
\end{aligned}
$$

$\therefore G^{\prime \prime}(\varepsilon)>0$ for $\varepsilon>n$. Therefore. equation (5) has at most one solution $\varepsilon$. . Since from (J). $G(0)<0$. a solution $\xi$ of (5) will exist if und only if $C(1)$ - 11 . If (j) has a solution. then $p$ can be formal from (4). and of from (1). Expration (3) provides a way to determine s. say $H(.3)=0$ sud $H^{\prime}(.5)=f^{\prime}(.5)-f^{\prime}(\xi)$. If for $f>\xi$ implying that there is at most one solution for 6 . Since $H(\xi)$. O, a solution

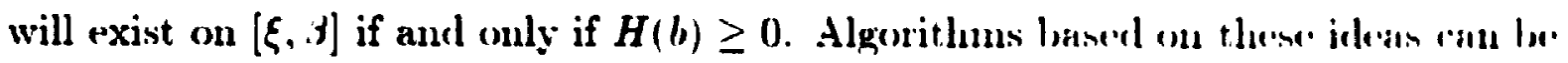
forund in $[\mathrm{Ph}$ 68].

Pavlidis [Pa 73] also presented a waveform segmentation terlunique uning linear npproximution which is based on discrete optimization. Lat $\left(x_{1}, f_{1}\right),\left(x_{1}, f_{1}\right) \ldots\left(x, \ldots, f_{x}\right)$ be the pairs of points deseriling the waveform to lae. analysed in a quantized form. Also. let $\|_{1}^{k} \cdot u_{2}^{k} \ldots \ldots u_{n}^{k}$ be the dividing points at the

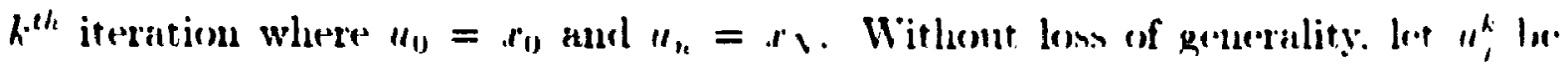




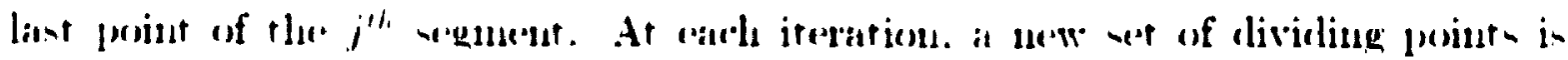

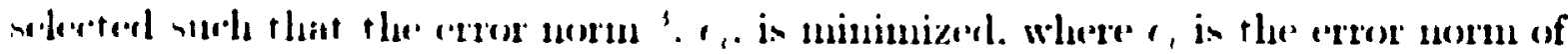

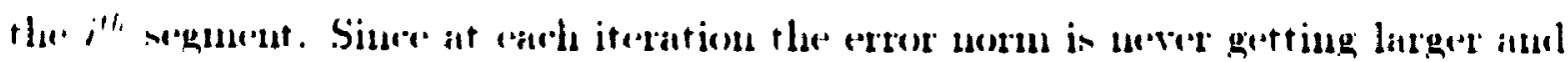
there is at tinite anumber of discrete points cleseribing f $f(x)$. the dividing points will "veruthally conserge on the locerl maxima or minima of the function. The munber of iterations that must be carried ont depends on the initial set of dividing points and the unumber of aridling points.

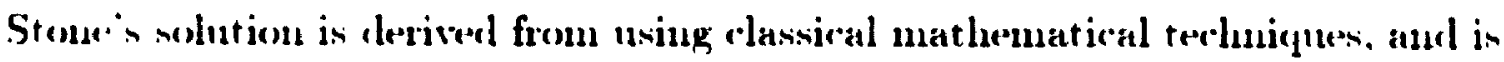
applied only to continuous functions. Bellnan's approand is based on Stone- work. fint it also provided a dyumbe programming technigne to derive an approximated function. Gluss is work is similar to Bellman's, but he also introduced an additional constraint to the problem ly recpuring the endpoints of the approximated functions to be in a predetineed and tixed position. Phillip s approach is based on a pre-assigned crror ancuacy of the approximation, and thus, given a maximum allowalbe error. his scheme yields the line segments that will best approximate a given function. Pavliclis provided an alternative to the dynamir programming technique introduced ly Bellnam ly using a linear incremental search which is dependent on the initial clividing points and the size of the linear increment. All of these techniques. with the exception of Pavlidis:s work. can only be applierl to simple ome-dimensional. contimusus, well-clefined functions where the approximated points do not necessarily lie on $f(x)$. Many other piecewise linear approximation methods inclucling those introduced by Ramer[Ram i2]. Pavlidis and Horowitz [PH i4]. Kurozumi and Daris [ID S2]. and Dumhun[Du S6]. apply to both one-dimensional functions and planar curves. These techniques will be examined in Chapter 3.

\footnotetext{
"For uniform approximation. error norm is tefined as the minimum of the maximum alosolute. vallues of the printwise errors. and for integral square error approxituation. prror norm is ilefined as the sulli of sefuares of the proint wise serrors.
} 


\subsubsection{Polynomial splines}

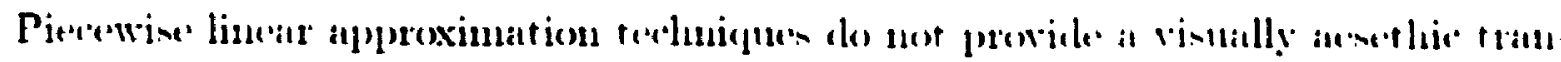
sition from one segment to the next. and thes. they lank the alsility to smonthly

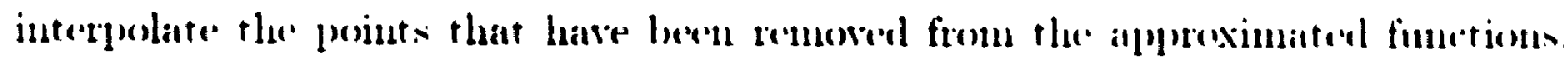

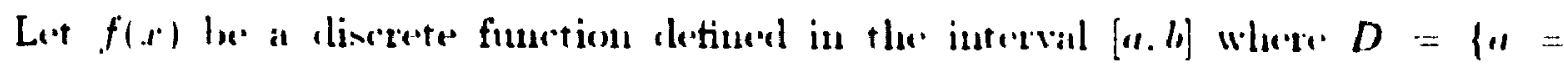

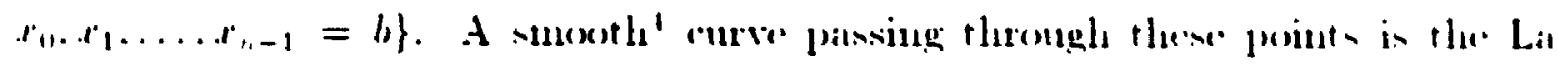
grange interpolating polyonomial:

$$
P(x)=\sum_{i=1}^{n-1} \frac{L(x)}{x-x_{1}} \frac{f_{i}}{L^{\prime}(x, r)}
$$

where

$$
L(x)=\prod_{l=11}^{n-1}\left(. x-x_{1}\right)
$$

The main problem with the Lagrange polsuomial approximation shown above is that as the munber of points increases these polymomials temel to oncillate st rongly: with a clirect dependence on the position of the points $\left(x_{1}, f_{1}\right)$. For cxample, if the set of points are given as $\{(0.6),(6.6),(8.4),(10.6),(14.3),(16.3),(20,2)\}$, then $P$ takes on functional values greater than 30 in the tirst interval [0,6].

As a compromise between a linear approximation and a polyomial of higher degres. a combination of low degree polynomials and a fumction that is often differentiable on the closed interval [a.b] is used. If the set of polynomials of degree $2 m+1$ defined in the intervals $\left[r_{1}, r_{1+1}\right]$, where $m \leq n-1$ ind $;=0.1 \ldots \ldots n-2$ are joined at norles $r_{1} \ldots \ldots r_{n-2}$ in such a way that the resulting function in in ways

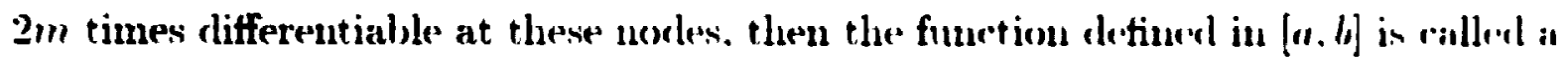
spline function of degree $2 m+1$. If $s(x)$ represents the spline function ind $s(x, f=f$, for $i=0.1 \ldots n-1$. then $s(x)$ is callerl an interpolating spline fumetion. By this detinition. a polygonal path through $\left\{\left(x_{1}, f_{11}\right),\left(x_{1}, f_{1}\right) \ldots \ldots\left(x_{n-1}, f_{n-1}\right)\right\}$ in an first order interpolating spline. A thirel order spline or culdie spline "onsist of " 1 third

\footnotetext{
${ }^{4}$ Simooth in the sense of heing maximally often differentialile.
} 


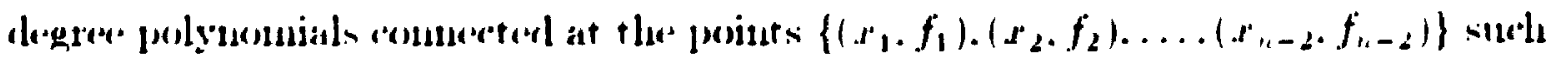
that they and always twiore differentialde at these norles $\left[S_{1}, i t\right]$.

Let $s(x)$ be an interpolating spline function detined in the interval $\left[r_{1}, r_{n-1}\right]$

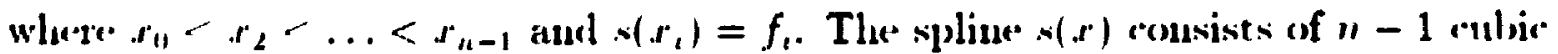
polgumuials on joined at $x_{1}, x_{2} \ldots \ldots x_{n-2}$ such that it is twice differentiable at these joints. Furthermore. let the tirst and sercond derivatives of $x(x)$ evaluated at $x^{2}$, be denoted ly $f_{1}^{\prime}$ and $f_{1}^{\prime \prime}$. and consider a culsic polynomial $o_{k}(x)$ defined in the tixerl iuterval $\left[r_{k}, r_{k+1}\right]$.

$$
\partial_{k}(r)=A_{k}\left(r-r_{k}\right)^{3}+B_{k}\left(r-r_{k}\right)^{2}+C_{k}\left(r-r_{k}\right)+D_{k}
$$

then there are $4(n-1)$ contficients $A_{k} . B_{k} . C_{k}$. and $D_{k}$ to be determined. The function walues and the first and second derivatives of the spline at the endpoints $x_{k}$ ind $r_{h+1}$ are given as

$$
\begin{aligned}
& f_{k}=o_{k}\left(r_{k}\right)=D_{k} \\
& f_{k+1}=o_{k}\left(r_{k+1}\right)=A_{k} \Delta x_{k}^{3}+B_{k} \Delta x_{k}^{2}+C_{k} \Delta x_{k}+D_{k} \\
& f_{k}^{\prime}=o_{k}^{\prime}\left(x_{k}\right)=C_{k} \\
& f_{k+1}^{\prime}=o_{k}^{\prime}\left(x_{k+1}\right)=3 \cdot A_{k} \Delta x_{k}^{2}+2 B_{k} \Delta x_{k}^{2}+C_{k} \\
& f_{k}^{\prime \prime}=o_{k}^{\prime \prime}\left(x_{k}\right)=2 B_{k} \\
& f_{k+1}^{\prime \prime}=\phi_{k}^{\prime \prime}\left(r_{k+1}\right)=6 \cdot A_{k} \Delta x_{k}+2 B_{k} .
\end{aligned}
$$

The roefticients can now be described in terms of the function values and serond derivatives.

$$
\begin{aligned}
& A_{k}=\frac{1}{6 \Delta x_{k}}\left(f_{k+1}^{\prime \prime}-f_{k}^{\prime \prime}\right) \\
& B_{k}=\frac{1}{2} f_{k}^{\prime \prime} \\
& C_{k}=\frac{\Delta f_{k}}{\Delta x_{k}}-\frac{1}{6} \Delta x_{k}\left(f_{k+1}^{\prime \prime}+2 f_{k}^{\prime \prime}\right) \\
& D_{k}=f_{k}
\end{aligned}
$$

The first deriative ralues can thus be rewritten, with the substitution of the coeftirients. ns

$$
\begin{aligned}
& f_{k}^{\prime}=\frac{\Delta f_{k}}{\Delta x_{k}}-\frac{1}{k} \Delta x_{k}\left(f_{k+1}^{\prime \prime}+2 f_{k}^{\prime \prime}\right) \\
& f_{n-1}^{\prime}=\frac{\Delta f_{n-2}}{\Delta x_{n-2}}-\frac{1}{k} \Delta x_{n-2}\left(2 f_{n-1}^{\prime \prime}+f_{n-2}^{\prime \prime}\right)
\end{aligned} \quad(k=0, \ldots, n-2)
$$




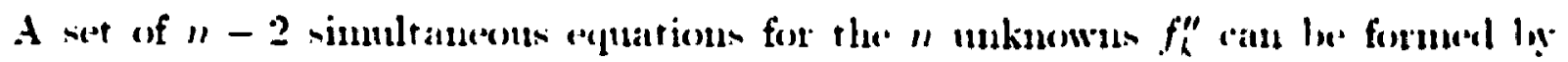
applying the respirement of eontinuty in the tirst derivative.

$$
o_{k-1}^{\prime}\left(r_{k}\right)=o_{k}^{\prime}\left(r_{k}\right) \quad(k=1 \ldots \ldots+2)
$$

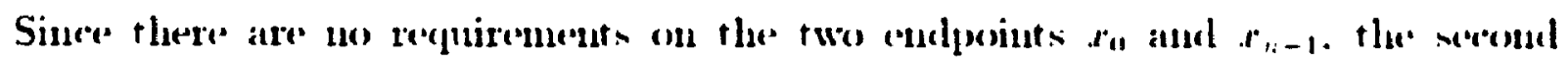

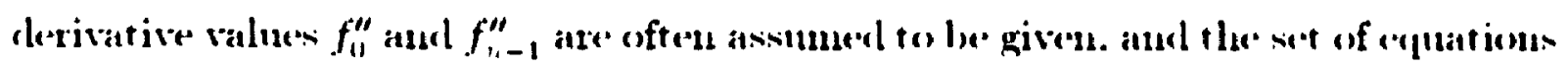
an lee represesuted in a matrix form as follows.

$$
\begin{aligned}
& {\left[\begin{array}{cccc}
2\left(\Delta x_{1}+\Delta x_{1}\right) & \Delta x_{1} & & \\
\Delta x_{1} & 2\left(\Delta x_{1}+\Delta r_{2}\right) & \Delta r_{2} & \\
& \Delta x_{2} & 2\left(\Delta x_{2}+\Delta x_{3}\right) & \Delta x_{1} \\
& \ddots & \ddots & \ddots \\
& & \Delta r_{n-3} & 2\left(\Delta r_{n-3}+\Delta r_{n-2}\right)
\end{array}\right]}
\end{aligned}
$$

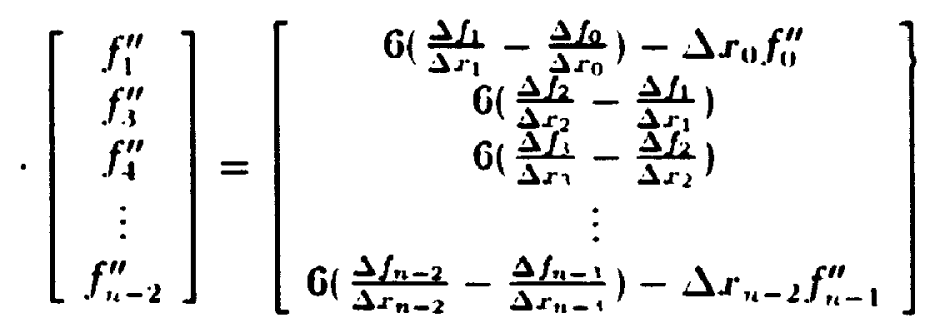

Once the second derivative values are determined. the $"-1$ polynomials can he found log sulstituting into the equations of the coeffirients presented alsove. A more detailed analysis of the derivation of the cubic spline is given ly Belluan [Be 61] and Spätl $\left[S_{p}, 74\right]$.

B-splines are piecewise polynomial curves (usually cubie) which are related to a guiding polygon. B-spline approximations not only have good computational properties but also representational ones over linear and polynomial approximations, [BB 82]. First, they are variation diminishing s: the curve is. therefore. assitured to lie between the convex lunll of groups of $k+1$ consecutive points where $k$ is the degrese of the interpolating polyuomial. Secondly, the interpolation of the rurve is

\footnotetext{
"Variation diminishing means that the curve is guarantered to "vary less" than its guiding polyg ous

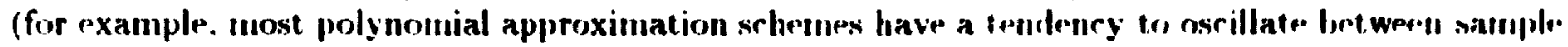
points).
} 


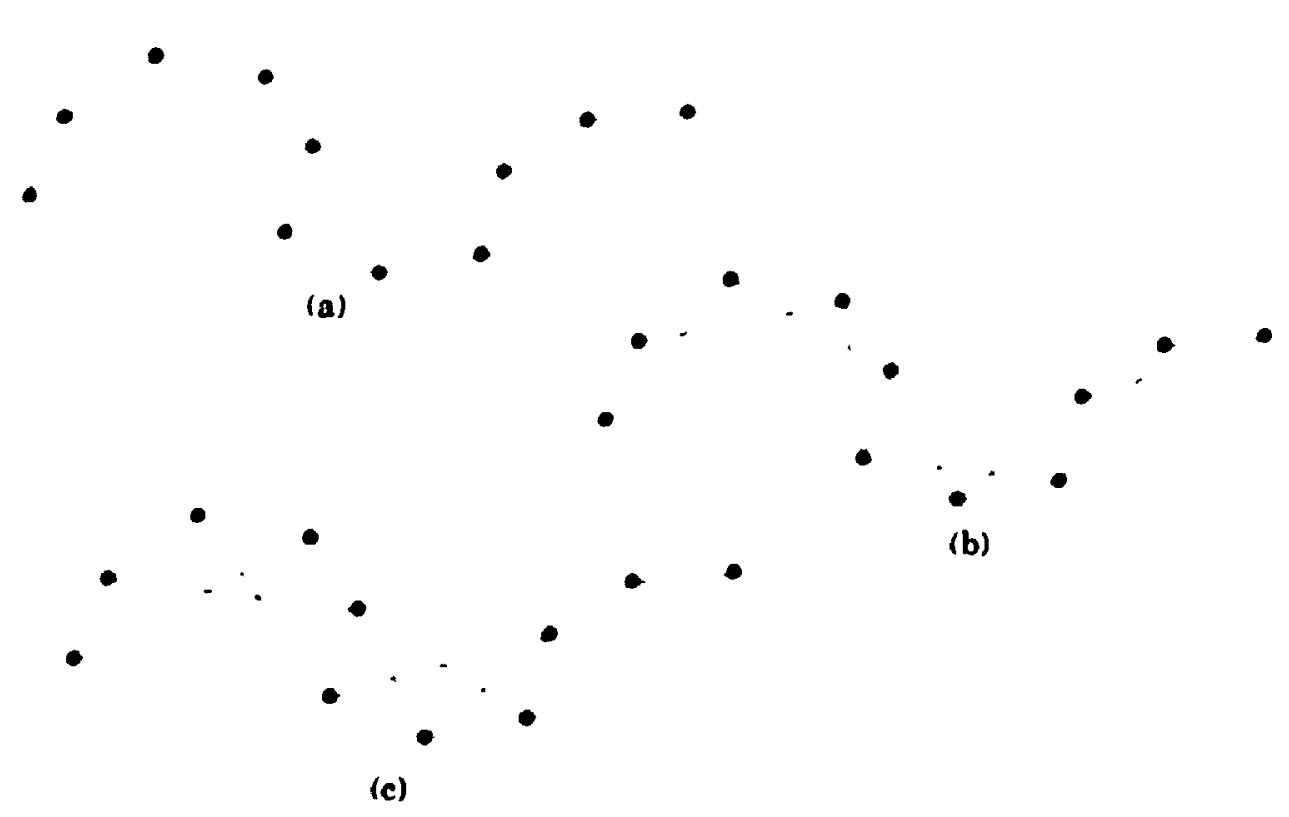

Figure J: B-spline of degres $k$ must lie in the convex hall formed by consecutive gromps of $k+1$ points. (a) $k=1$ (linear). (b) $k=2$ (quadratic). (c) $k=3$ (cubic).

lowal: if a point of the guiding polygon is shifted. then the effects are restricted to nearly points on the spline and not the entire approximation.

Let $\mathbf{x}(. s)$ be a vector valued piecewise polynomial function interpolating through it cliscrete set of points $r_{0}, r_{1} \ldots \ldots x_{n}$. Earh piece of $\mathbf{x}$ is a cubic polynomial which implies that $\mathbf{x}(. *)$ has three orders of contiunity arross the data porints. Formally. $\mathbf{x}($.$) is refined as$

$$
\mathbf{x}(x)=\sum_{i=0}^{n} v_{i} B_{i}(s)
$$

where $v_{i}$ s are uot only the coefticients representing the curve $x(. *)$ but also the rerticess of the guiding polygons, and and $B_{1}$ is are the basis fumctions.

The hasis functions $B_{i}^{\prime}$, are non-negative, and earh $B_{i}$ is uon-zero only for s betwen $i-2$ and $i+2$. Thus. on a given span $(i . j+1)$ there are only four basis functions that are non-zero, uamely: $B_{i-1}, B_{1}, B_{i+1}$, and $B_{t+2}$. For example, to determine $X\left(s_{0}\right)$ for some $s_{0}$, all that is required is to determine which span $s_{0}$ resides in. And a summation of the four terms is performed using the summation 


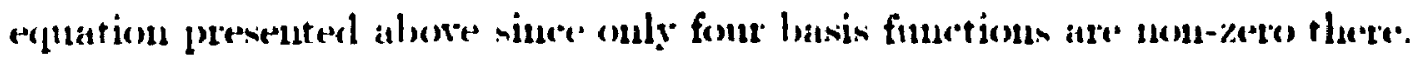

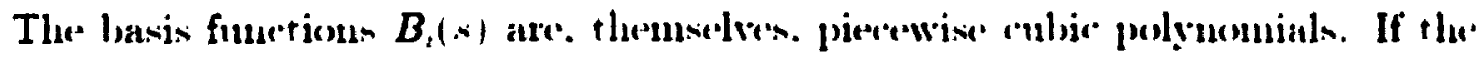
spans uncler their support ate of uniform size. the'n all the hasis functions hatse the same form and atre simply translates of each other. Moreoser. "arth of the hanis

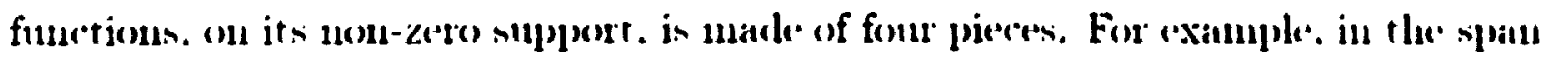
$(1.1+1)$. the fourth piece of $B_{-1}($.$) . the third piere of B_{1}(n)$. the seresud piece of

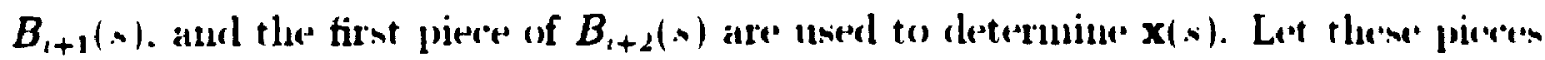
he represented ly $C_{t, 0} \cdot C_{t, 1} \cdot C_{t, 2}$. and $C_{t, 3}$ respertively: Then $x($.$) on the interial$ $(i, i+1)$ can be written as

$$
\mathbf{x}(. x)=C_{1-1.3}(. s) r_{1-1}+C_{1.2}(.) u_{1}+C_{1+1.1}(.) r_{1+1}+C_{1+2.00}(*) u_{1+2}
$$

Csing the fact that the spans are miform, $C_{t, \text { }}$ will have the same shape uo matter what the value of $i$ happens to be. This property permits a simpliation in ralculations, and therefore, the four primitive basis functions can be defined in

$$
C_{i, n}(.)=C_{,}(*-i) \quad i=0 \ldots \ldots n+1: \quad j=0,1.2,3
$$

and interpolation along the curve is done by parameter shifting. For cxample, to find $\mathbf{x}(*)$ where $s$ is in the span $(i . i+1)$ then the following formula is nsed:

$$
\mathbf{x}(*)=v_{1-1} C_{3}(x-i)+v_{1} C_{2}(x-i)+v_{1+1} C_{1}(s-i)+v_{1+2} C_{1}(s-i)
$$

where the $C_{1}(t)$ are given by:

$$
\begin{aligned}
& C_{0}(t)=\frac{t^{3}}{6} \\
& C_{1}(t)=\frac{-3 t^{3}+3 t^{2}+3 t+1}{6} \\
& C_{2}(t)=\frac{3 t^{3}-6 t^{2}+4}{6} \\
& C_{3}(t)=\frac{-t^{3}+3 t^{2}-3 t+1}{6}
\end{aligned}
$$

A more formal rerjution of $B$-spline is given by [BR 74] aud de Boor [de-B 78]. 


\subsection{Transformed Domain Function Approximation}

Transform aroling techuiglus determine the apptoximation of $f$ ly transforming it into another function. say. $F$. approximating $F$. and inverting the transformed "lppresimation to derive $f(x)$. These approximation techniques manipulate os, the frans.uformed function $F$ and then operate in the domain of the transformed finerion. Mlost of the lonny signal compression techniques courrently used hy industry employ:

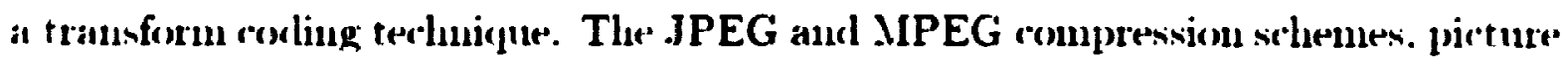
phome transmission. and even some of the new high definition telerision standards (currently heing cousidered ly the Luited States and Canarla ). for example. rmploxa discrete cosine transform technique to reduce the transmission of data.

A transform technique often sub-clivides the original signal into smaller blocks. and cach block is then passed throngh a unitary transform". The main purpose of the transform is to decorrelate the original signal. and the decorrelation generally results in the signal energy being redistributed among only a small set of transform coefficients. [RJ 91]. As indicated by Pạvlidis [Pa i T]. however, transform representations are economical if and only if the input signal can be represented ly a set of orthouormal basis vectors whose coefticients are mostly zero or close to zero.

There are two views of looking int an n-point unitary transform. It can be interpreted as a decomposition of the original block of data into a set of $" 1$ orthogonal loasis functions. Another view is that the transform is a rotation of the n-dimensional coordinate axes defined by the signal values in a block. These views can be further explained by the examples below.

Suppose there is a serpuence of two numbers, $x(0)=2$ and $x(1)=3$. This secpuence can be approximately represented by $\{2.5 .2 .5\}$. which can be written as

$$
\{2.5 .2 .5\}=\frac{j}{\sqrt{2}}\left\{\frac{1}{\sqrt{2}} \cdot \frac{1}{\sqrt{2}}\right\}=\frac{j}{\sqrt{2}}\left\{b_{00} \cdot b_{01}\right\}
$$

The original sequence $x(n)$ ran be exactly represented by adding to it a seculuence

\footnotetext{
"A unitary transform is a reversible linear transform whose kernel describes a set of complete. orthomormal discrete hasis functions.
} 
$\{-0.5 .+0.5\}$. whirh can be expressecl ans

$$
\{-0 . j .+0 . \bar{J}\}=\frac{-1}{\sqrt{2}}\left\{\frac{1}{\sqrt{2}} \cdot \frac{-1}{\sqrt{2}}\right\}=\frac{-1}{\sqrt{2}}\left\{b_{11} \cdot b_{11}\right\}
$$

Thus, the original seconesuce $x(0)$ and er $(1)$ can be represented an a line ar combluation of the hasi- reectors $b_{11}$ and $b_{1}$ as

$$
\left[\begin{array}{l}
r(0) \\
r(1)
\end{array}\right]=\left[\mathbf{b}_{1}, \mathbf{b}_{1}\right]\left[\begin{array}{c}
\frac{5}{\sqrt{2}} \\
\frac{-1}{\sqrt{2}}
\end{array}\right]
$$

where $b_{11}^{T}=\left[\begin{array}{lll}b_{00} & b_{10}\end{array}\right]=\left[\frac{1}{\sqrt{2}} \frac{1}{\sqrt{2}}\right]$ and $b_{1}^{T}=\left[\begin{array}{ll}b_{01} & b_{11}\end{array}\right]=\left[\begin{array}{ll}\frac{1}{\sqrt{2}} & -\frac{1}{\sqrt{2}}\end{array}\right]$

The example alowe shows that the two points are derobrelaterl, that is, they are separated out into high and low components. Thus. transform corling caul be riewed as a decomposition of the original values into different weights of an set of orthogomal basis functions. The basis functions are different for each type of sigual transform. and can be considered as elementary components that can loe used to synthesize a signal given its corresponding transform coefficients.

An "-point transformation can also be viewed as an 1 -dimensional rotation. Suppose there is a set of $n$ highly correlated points as displayed in Figure 6, where most of them lie along the $45^{\circ}$ line defined by $y=x$. The variance in the $x$ direetion is defined as

$$
\sigma_{x}^{2}=\frac{1}{n} \sum_{i=1}^{n}\left(x_{i}-\overline{x_{i}}\right)^{2}
$$

and similarly, the variance in the $y$ direction is defined as

$$
\sigma_{y}^{2}=\frac{1}{n} \sum_{i=1}^{n}\left(y_{2}-\overline{y_{1}}\right)^{2}
$$

A simple method of compression is to represest one of the components (either $r$ (or $y$ ) by its corresponding mean value $\bar{x}$ or $\bar{y}$, respertiven error (MSE) introduced in the reconstructed signal is thus equal to $\sigma_{x}^{2}$ or $\sigma_{y}^{2}$. Since the varianre in both the $x$ and $y$ dirertions is large, an encoding terluicque usiug the mean value will result in large reconstruction errors. If each pesint. however. is 


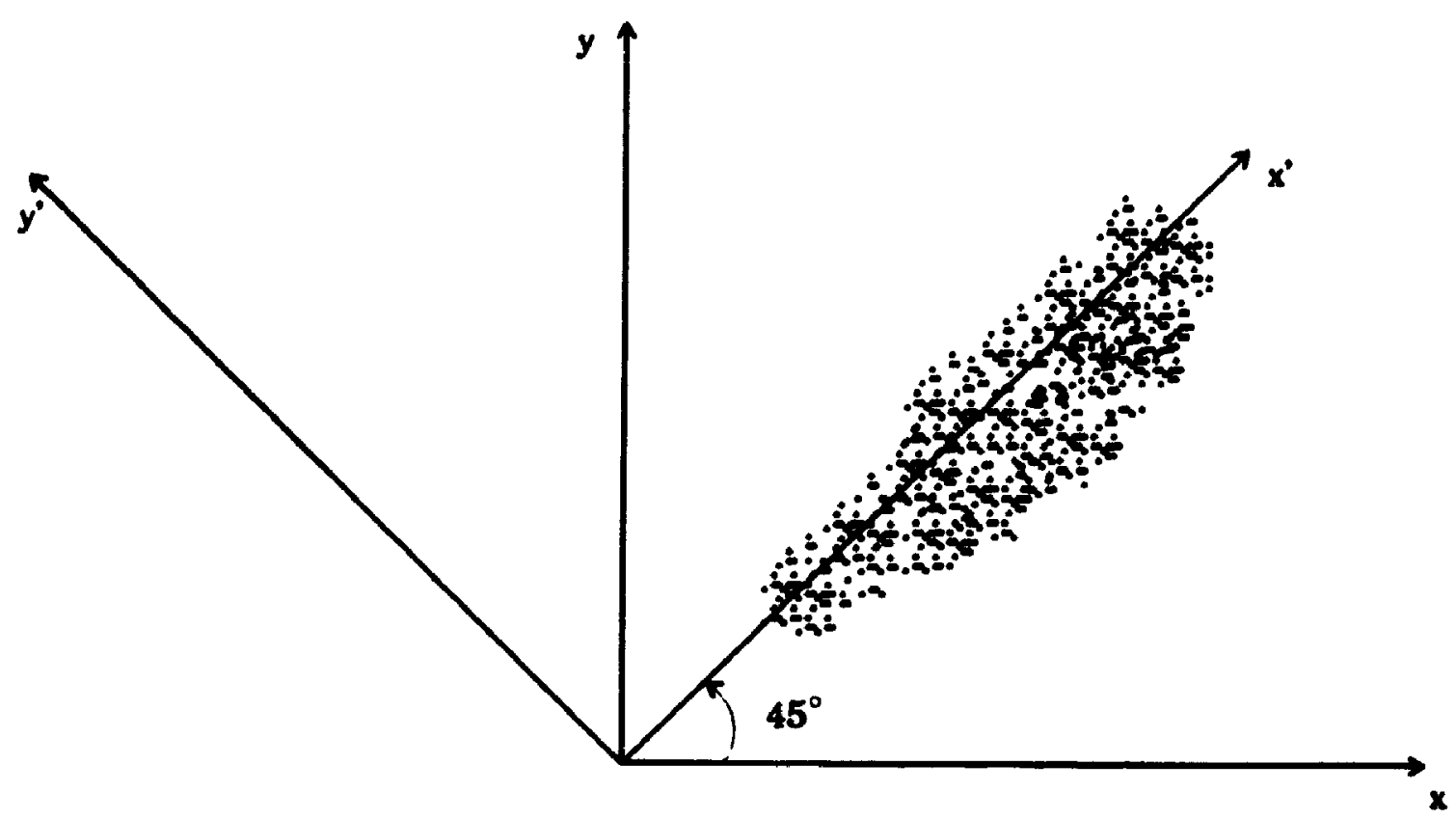

Figure 6: Rotation transform example

int through a unitary transformation which consists of a rounter clockwise rotation alocit the origin ly $45^{\circ}$.

$$
\left[\begin{array}{l}
x^{\prime} \\
y^{\prime}
\end{array}\right]=\frac{1}{\sqrt{2}}\left[\begin{array}{cc}
1 & 1 \\
-1 & 1
\end{array}\right]\left[\begin{array}{l}
x \\
y
\end{array}\right]
$$

then the variance in the $y^{\prime}$ dirertion is much less than that in the $x^{\prime}$ direction $\left(\sigma_{y^{\prime}}<<\sigma_{x^{\prime}}\right)$. An important feature of a unitary transform is that it is clistance preserving: that is, the Euclidian distance between vertors is not changed by the transform. This fact can be used to show that the total variance is preserved by the rotation.

$$
\sigma_{x}^{2}+\sigma_{y}^{2}=\sigma_{x^{\prime}}^{2}+\sigma_{y^{\prime}}^{2}
$$

Therefore. if the $y^{\prime}$ component is replacerl by its mean value (which is zero) during encorling. the resultant MSE is only $\sigma_{y^{\prime}}^{2}$, which is signifirantly less than either $\sigma_{r}^{2}$ or $\sigma_{y}^{2}$. 
In all transform codling schemes. the transform operation doxes mot mehieve any

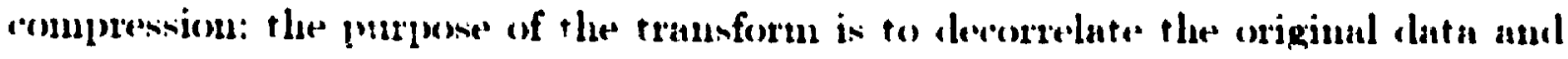
to compart a large portion of the signal energy into a few signitionut unumber of

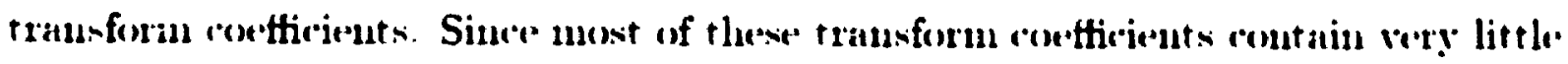
information. compression is mainly achieved by quantizing the conethicients. The level of compression strietly depends on the quatization factor: the conrser the quantization. the higher the compression ratio. but the degradation of the sigmal will also become more notiveshlse.

Another property of a unitary transform is that it is resersible: the original lata can be recowered (assuming that the encoding process does not introduce any errors) ly applying an inverse transform on the cuantized transform coetticients. The inverse transform for the example aloove is a rotation alont the origin by $45^{\circ}$ in the clockwise direction.

$$
\left[\begin{array}{l}
x \\
y
\end{array}\right]=\frac{1}{\sqrt{2}}\left[\begin{array}{cc}
1 & -1 \\
1 & 1
\end{array}\right]\left[\begin{array}{l}
r^{\prime} \\
y^{\prime}
\end{array}\right]
$$

Since the tiansform coefticients are quantized. the inverse transform on these resetficients will result in an approximation to the original data. As indionted ly Rabbani and Jones [R.J 91]. "becalse of the clistance-preserving property of the rotation, the ISE loetween the original image and the reconstructed data is equal to the MSE introduced by the quantization process in the transform domain."

For reasons of convenience and simplicity, all unitary transforms are expressecl in a matrix notation. A sequence of $"$ stumple values $f_{n}, f_{1} \ldots f_{n-1}$ is comsidered as a vector in n-dimensionsl space denoted by f, and similarly, the seepuener " trausformed values $F_{0}, F_{1} \ldots \ldots F_{n-1}$ is clenoted by $F$. Thus, $F$ aud $f$ cau be expresserd Hง

$$
\begin{gathered}
\mathbf{F}=\mathbf{T} \cdot \mathbf{f} \\
\mathbf{f}=\mathbf{T}^{-1} \cdot \mathbf{F}
\end{gathered}
$$

where $\mathbf{T}$ und $\mathbf{T}^{-1}$ are the forward and inverse transformation matrices, respectively. 
The following fonr npproximation terhnigntes will be reviewed in this sertion:

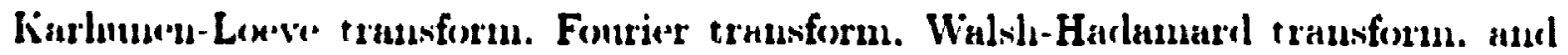
discrete cosine transform. Althongh most of these terduignes an be applied to lesth continumens and discrete domains. only the discrete cases will be presesented in dertrils.

\subsubsection{Karhunen-Loeve Transform}

It is leelpful to tirst consider the Karhunen-Loveve transform from an intuitive point of view. If a simusoiclal signal is transmitted over a medium in a samplecl form. with cach sampled data point being sent in a sequential mamer. then a higher sampling rate will yield a superior reconstruction of the waveform. From at theoretiral point of view. the information content of the sampled values is very low due $t$. the fact that the sampled values are highly correlated. On the other hand, it is ulso well known that the reconstruction of the original signal can be accomplished ly knowing its magnitude, phase, frequency, starting time, and the fact that it is sinusicoicl. Therefore, assuming that there are no errors in the transmission of these five uncorrelated values, the exart same signal can be reconstructed at the seceiver encl. Thus. the set of highly correlated sampled values and the five umcorrelated parameters represent the same sigual. This fact naturally learls to the question of whether or not there is a transformation which can decorrelate the sampled ralues: into un uncorrelaterl set of values that are equivalent to the five pariuneters listed above. The Karhmen-Loeve transform is considered to be in this category of transforms. A summary of the harhmen-Loeve transform (KLT) will be presented below. and more rletailecl analyses of its derivation are done by Jain [Ja 85]. Rao und Yị [RY 00], and Jayant and Noll [JN 84].

Let the $\boldsymbol{V}$ sampled values of a zero mean random vector $\mathrm{f}$ be given us $\mathrm{f}=$ $\left\{f_{0}, f_{1} \ldots \ldots, f_{i-1}\right\}^{r}$. If there exists a set of linearly independent vectors, $\phi_{k}$, spanming 
the . I-rlimensional vertor space, then $f$ an be expressed in terms of $\phi_{k}$ an

$$
\mathbf{f}=\sum_{k=1}^{Y-1} F_{k} \phi_{k}
$$

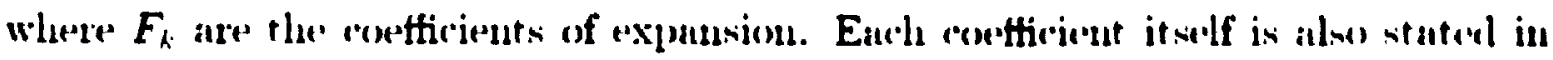
terms of the given inpent $f$ and $\phi_{k}$ as

$$
F_{k}=\frac{\left\langle\mathbf{f} . \phi_{k}\right\rangle}{\left\langle\phi_{k \cdot .} \phi_{k}\right\rangle}
$$

where $k=0.1 \ldots . . N-1$ and $\langle\because\rangle>$ denotes the inuer product of two ventors. Suppesse that only the first $"$ coefticients. where $"<x$. are signitionutly gresuter th an zero, then the vector $f$ can be well represented by only 11 coetticients in the $\phi_{k}$. spares. The approximation of $\mathbf{f}$. $\hat{\mathbf{f}}$. can thas be expressed as

$$
\hat{\mathbf{f}}=\sum_{k=11}^{l-1} F_{k} \phi_{k}
$$

The Firhumen-Loeve transform $s$ main objective is to determine the loest approximation of $f$ in the mean sçuare etror seluse. If $f$ is the mesu spluare crror in the rrumation. then it ran be seen that.

$$
\boldsymbol{f}=E\left[(\mathbf{f}-\hat{\mathbf{f}})^{2}\right]
$$

where $E[\cdot]$ is the expectation operator. By minimizing $\&$ (i.e. clifferentiating with respect to $\phi_{k}$ partially, and setting the equations to zero), the Kindunen-Lon-ver transform of $\mathbf{f}$ is a matrix $\phi$ composed of the eigenvectors of $A$ and is cletiued liy the relation

$$
\boldsymbol{\phi} \mathbf{A} \boldsymbol{\phi}^{T}=\boldsymbol{\lambda}
$$

where $\lambda$ is a diagonal matrix of eigenvalues $\lambda_{k}$ and $\mathbf{A}$ is the anto-covarianer matrix (also referred to as the anto-(orrelation matrix), elefined by $\mathbf{A}=E\left[\mathbf{x x}^{T}\right]$. The wet of basis vectors $\left\{\phi_{0}, \phi_{1} \ldots \ldots \phi_{N-1}\right\}$ form the bases for the Karhumen-Lexeve trausform expansion.

As summarizerl by Rao and Yip [RY 90], the Karhumen-Loeve transform in comsidered to be an optimal transform becanse of the following properties: 
1. It complepely recorrelates the signal in the transform comain.

2. It minimizes the .ISE in bandwidth reduction or dath compression.

3. It couthins the mosst varianse (energy) in the fewest unmoler of transform routthicients.

4. It minimizes the total representation entropy of the serpuence

It is mainly used es a measuring tool against other suboptimal transforms such as the Fonrier trunsform, the Walsh-Hadarmard transform. aud cosine transforms. In praction. the Karlunen-Love transform is not often applied because it is dependent on the input clata: that is, it is difticult to determine the auto-covariance matrix und its diagonalization. Furthermore. the lack of pre-determined basis rectors in the transform clomain has made it an ideal but impractical technique.

\subsubsection{Fourier Transform}

Fonrier's theorem states that for any function $f(x)$ defined in the interval $-\infty<$ $r<\infty$, it is possible to express it as a summation of a series of sine and rosine terms of increasing frequency. The Fourier transform of the function $f(x), F(\omega$. describes the amount of each frequency term that must be added together to make $f(x)$. It is often clescribed as [RY 90] [JN 84].

$$
F(\omega)=\frac{1}{\sqrt{2 \pi}} \int_{-\infty}^{\infty} f(x) e^{-j \omega x} d x
$$

where $j=\sqrt{-1}$. The exponential notation above relies on the mathematical identity (kuown as Euler's formula). $e^{-\jmath w r}=c o s \omega \cdot x-j \sin \omega x$. In certain instances, it may be more convenient to express the Fourier transform in terms of sine and cosine as

$$
F(\omega)=\frac{1}{\sqrt{2 \pi}} \int_{-x}^{x} f(x) \cos \omega x d x+\frac{1}{\sqrt{2 \pi}} \int_{-\infty}^{\infty} j f(x) \sin \omega x d x
$$

The original function $f(x)$ can be expressed in terms of $F(\omega)$ as

$$
f(x)=\int_{-\infty}^{\infty} F(\omega) e^{j \omega x} d \omega
$$


The function $f(x)$ is generally a real-salued fumetion such an time-varving volthge

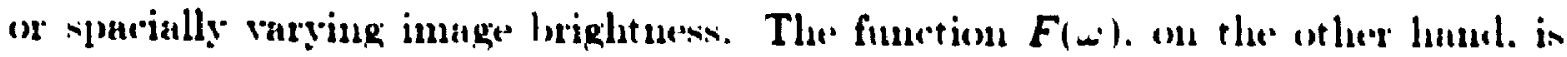
generally complex. consisting of a ronl part and an imnginury part. and it is some-

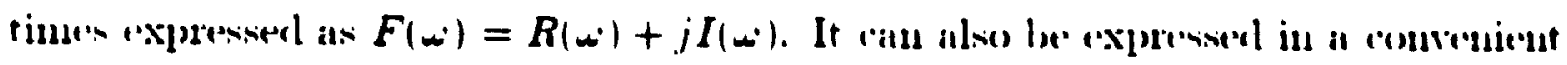

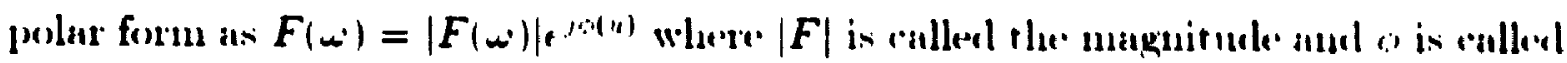
the phase.

An interestimg charateristic of the Fonrier transform is that if the svimuetry of the input signal is known. its corresponding transform will be grently simplitien. A function $f(x)$ is defined to be onen with respect to $x=0$ if $f(-x)=f(x)$, and $f(x)$ is said to be odd if $f(-x)=-f(x)$. If $f(x)$ is event. the'n its corresponding Fontion transform will consist of only the cosine terms.

$$
F(\omega)=\frac{1}{\sqrt{2 \pi}} \int_{-\infty}^{x} f(x) \text { orow werd.r }
$$

On the other haud. if $f(x)$ is odd. then its corresponding Fondier transform will consist of only the sine terms.

$$
F(\omega)=\frac{1}{\sqrt{2 \pi}} \int_{-}^{\infty} j f(x) \sin \omega \cdot x d r
$$

The integrals from $-\infty$ to $+\infty$ will in practice be couverterl to summations of discrete values of $f_{k}$ and $F_{u}$. The discrete Fonujer transform is written as

$$
F_{u}=\frac{1}{\sqrt{n}} \sum_{k=0}^{n-1} f_{k}-f^{2 \pi u k / n}
$$

where $u=0,1, \ldots n-1$, and $n$ is the mumber of uniformly spared sampled points along the function $f(x)$. The inverse Fontrier transform is similar to the forward transform except for the change in sign in the exponential term.

$$
f_{k}=\frac{1}{\sqrt{n}} \sum_{n=0}^{n-1} F_{u^{\prime}}{ }^{2 \pi u k / n}
$$

where $k=0.1 \ldots \ldots n-1$. The value $u$ represents the number of discrete freeguenty components arded together to construet the sampled value $f_{k}$. 


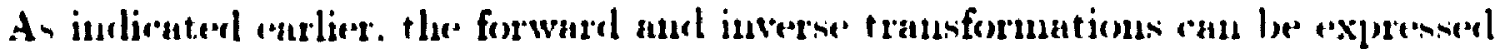
in a matrix notation as

$$
\begin{aligned}
\mathbf{F} & =\mathbf{T} \cdot \mathbf{f} . \text { and } \\
\mathbf{f} & =\mathbf{T}^{-1} \cdot \mathbf{F}
\end{aligned}
$$

where.

$$
\mathbf{T}=\left\{\frac{1}{\sqrt{x}},-12-4 k / n\right\}_{k \cdot 1 t=0.1 \ldots . n-1} .
$$

Figure i show the hasis funetions for the discrete Fonrier transform where $"=\$$ and below are the forward aud incerse Fonrier transformation matrices of sizes $n=$ ? inul $"=4$.

$$
\begin{aligned}
{ }^{2} \mathbf{T}={ }^{2} \mathbf{T}^{-1} & =\frac{1}{\sqrt{2}}\left[\begin{array}{ccc}
f^{\prime \prime} & \mathbf{f}^{\prime \prime} \\
c^{\prime \prime} & f^{-1}
\end{array}\right]=\frac{1}{\sqrt{2}}\left[\begin{array}{cc}
1 & 1 \\
1 & -1
\end{array}\right] \\
{ }^{4} \mathbf{T} & =\frac{1}{2}\left[\begin{array}{cccc}
1 & 1 & 1 & 1 \\
1 & -j & -1 & j \\
1 & -1 & 1 & -1 \\
1 & j & -1 & -j
\end{array}\right] \\
{ }^{4} \mathbf{T}^{-1} & =\frac{1}{2}\left[\begin{array}{cccc}
1 & 1 & 1 & 1 \\
1 & j & -1 & -j \\
1 & -1 & 1 & -1 \\
1 & -j & -1 & j
\end{array}\right]
\end{aligned}
$$

The inverse transformation kernel is the conjugate transpose of the forward kernel. Although, in general, the matrices $\mathbf{T}$ and $\mathbf{T}^{-1}$ have complex elements of the form $"+j b$, a conjugate symmetry property can be applied if the input values ure real (i.e. $f \in R^{\prime \prime}$ ). As a comsequence, the discrete Fourier transform representation involves a total of only $"$ and uot $2 n$ elements. The conjugate symmetry cun be desicriberl by

$$
F_{u}=F_{n-u}^{*} ; u=1.2 \ldots(n / 2)-1
$$

where $F^{*}$ clenotes the complex comjugate of $F$. The complex values of $F_{u}^{*}$ can be expresised in separate real and imaginary values as

$$
\operatorname{Re}\left[F_{u}\right]=\operatorname{Re}\left[F_{n-u}\right]: u=1.2 \ldots(n / 2)-1
$$




$$
\begin{gathered}
\left.\operatorname{Im}\left[F_{n}\right]=-\operatorname{Im}\left[F_{1,-11}\right]: \|=1.2 \ldots \ldots \mid n / 2\right)-1 . \text { mull. } \\
\operatorname{Im}\left[F_{n !}\right]=-\operatorname{Im}\left[F_{n / 2}\right]=0 .
\end{gathered}
$$

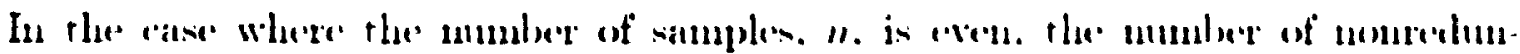

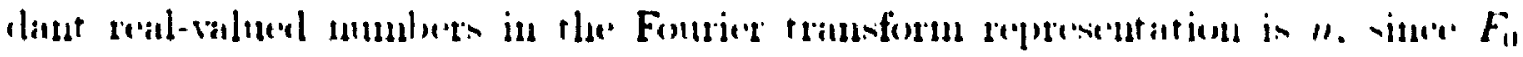

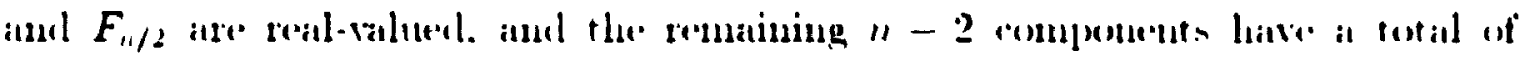

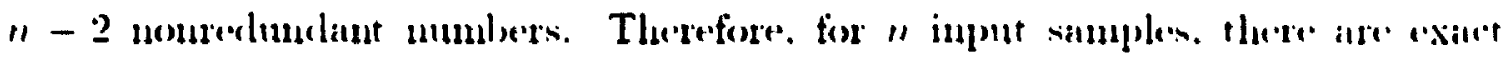

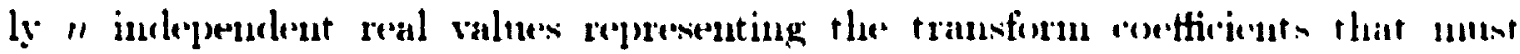
he quantized and processed. For example, if $"=4$ and the input valuen, expressed in at vector format. are $f^{r}=(3 .-1.4 .2)$, then the transformed raluen are $\mathbf{F}^{r}=(4.1 / 2+3 j / 2.3 .-1 / 2-3 j / 2)$. It can be clenty seen that the correcipondieg

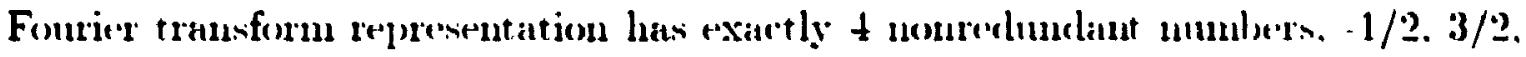
4. and 3.

\subsubsection{Hadamard and Walsh-Hadamard Transforms}

The Hadamard and Walsh-Hadamard transforms aze not an ettichent in in e'uergy parking sense as the other transforms clescribed above. They ate chatacteriand ley " symetrical matrix whose elements are \pm 1 . and their basis veretors atre orthomotmal. The term sequency is detined as one-half the munber of changes in sign in one perioul of $n$ sequence. For example. if the sequence is $\{2,-3,1,-4\}$, then its secpluney is 3/2. The sequeney of a rectangular hasis waveform in the Walsh-Hadlumard transform has the same connotation as the frecluency of a trigonometrie sine and conime waveform as in the Fourier transform. The Hadlamard transformation matricen ane only clefined for input sequence of sizes $\underline{2}^{n}$ or $4 p$ for any pessitive integral value of $p$. The Walsh transformation matrices are similar to the Hadramad matricen except that they can be of any size and thent the ordering of the lasis vertors is slightly different. The term Walsh-Harlamard transform is generally used to denstribe any transform that has basis rectors with elements \pm 1 and that its size. "I. in some 


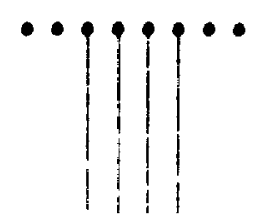

(a)

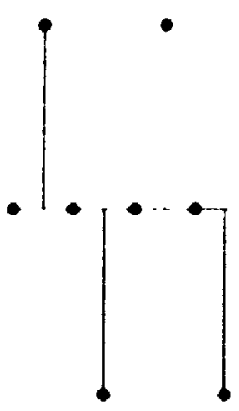

(e)

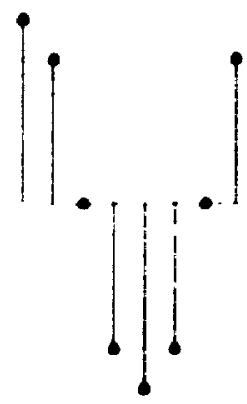

(b)

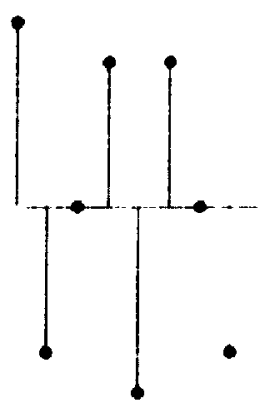

(f)

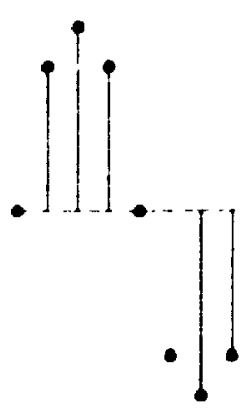

(c)

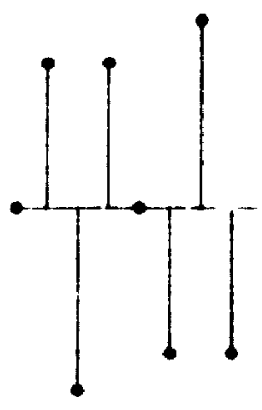

(g)

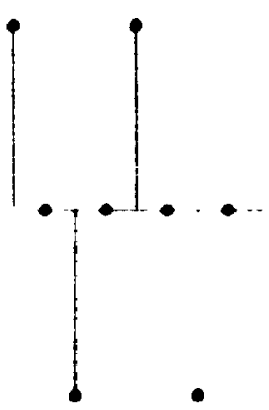

(d)

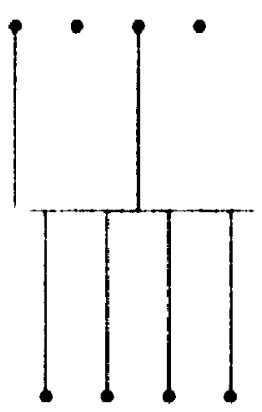

(b)

Figure i: Basis functions for the discrete Fourier transform where $"=\mathrm{S}$.

pewere of 2 .

Let $\mathbf{H}$ and $\mathbf{H}^{-1}$ le the Hadamard transformation matrix and its inverse, resperetively: Then they can be defined as

$$
\begin{aligned}
{ }^{2} \mathbf{H} & ={ }^{2} \mathbf{H}^{-1}=\frac{1}{\sqrt{2}}\left[\begin{array}{cc}
1 & 1 \\
1 & -1
\end{array}\right] \\
{ }^{4} \mathbf{H} & ={ }^{4} \mathbf{H}^{-1}=\frac{1}{2}\left[\begin{array}{cccc}
1 & 1 & 1 & 1 \\
1 & -1 & 1 & -1 \\
1 & 1 & -1 & -1 \\
1 & -1 & -1 & 1
\end{array}\right] \\
{ }^{2 n} \mathbf{H} & ={ }^{2 n} \mathbf{H}^{-1}=\frac{1}{\sqrt{2}}\left[\begin{array}{cc}
{ }^{n} \mathbf{H} & { }^{n} \mathbf{H} \\
{ }^{n} \mathbf{H} & -{ }^{n} \mathbf{H}
\end{array}\right]
\end{aligned}
$$

for $"=2.3 \ldots$. As indicated above, the recursive definition of the Hadamand transform recguires that the number of sampled values are always $2^{p}$ for positive integrill $\mu$. Mi note, in passing. that Hadamard matrices of other sizes such as 
12. 16. ...0 modulo 4. . . may also exist.

Let $\mathbf{W}$ and $\mathbf{W}^{-1}$ he the Walsh transformation matrix and its interese. respere. tively:

$$
\begin{aligned}
\mathbf{w}={ }^{2} \mathbf{W}^{-1} & =\frac{1}{\sqrt{2}}\left[\begin{array}{cc}
1 & 1 \\
1 & -1
\end{array}\right] \\
\mathbf{W}={ }^{\mathbf{}} \mathbf{W}^{-1} & =\frac{1}{\sqrt{3}}\left[\begin{array}{ccc}
1 & 1 & 1 \\
1 & 1 & -1 \\
1 & -1 & 1
\end{array}\right] \\
{ }^{\mathbf{t}} \mathbf{W}={ }^{t} \mathbf{W}^{-1} & =\frac{1}{2}\left[\begin{array}{cccc}
1 & 1 & 1 & 1 \\
1 & 1 & -1 & -1 \\
1 & -1 & -1 & 1 \\
1 & -1 & 1 & -1
\end{array}\right]
\end{aligned}
$$

The Walsh transform. "W. and its inverse. "W-1. are charateterized hạ the lanis vertor sequenries of $\left(0, \frac{1}{2}, 1, \frac{3}{2}, \ldots, \frac{n-1}{2}\right)$.

The Walsh-Hadamard transforms do not diagonalize covariance matrices whith are Toeplitz. and thus. they are suboptimal in an enetgy-parking sense (not ron asymptotically). They do possess some decorrelating characteristies, aud they atre (quite popular due to their simplicity.

\subsubsection{Discrete Cosine Transform}

The discrete cosine transform is derived from the discrete Fonrier ratusform. It is widely used in many lossy signal compression terluniques, inclucling the .JPEG and MPEG standards arlopted hy industry in the image processing field. Althonght it is not as optimal as the Karhumen-Loeve transform, it is more officient in an energy-parking sense than most of the other transform terdunirgues surdh an the Fontier and the Walsh-Hardamard transforms.

The discrete cosine transform provides a way of performing freegueney antityas. lout yet it avoids the complex walued results generated from the Fomrier transform ly exploiting a unique festure of symmetric functions and their Fonrier transforms. If the $n$ input sample is given as $\left\{f_{1}, f_{1} \ldots \ldots f_{n-1}\right\}$. then the discrete coniue trausform 


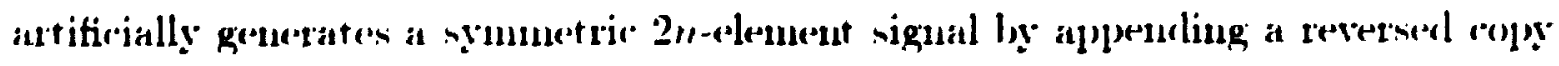

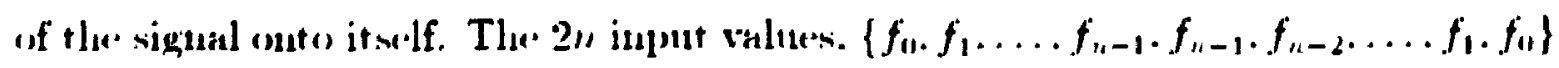
will he pht theongle a variaut of the discrete Fonrier transform. As indionted earlier in Sertion 2.2.2. Nince the ingut values ate known to be an even funetion. all of the aretticients for the sine waveforms will be zero. and thus, the transformed values. $\left\{F_{0} . F_{1} \ldots F_{2 n-1}\right\}$ will be real insteral of complex. Meteorer. only the tirst $"$ of the 2 " transformed coetficients need to be kejer since the remaining " values are the

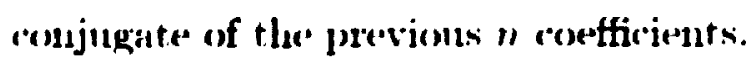

The diserete cosine transform and its inverse can be defined in a more formal setting than the dereription aloove as [A.TR 85].

$$
F_{k}=\sqrt{\frac{2}{n}} a(k) \sum_{i=1}^{n-1} f_{i}(0) \frac{(2 i+1) k \pi}{2 n} ; \quad k=0.1 \ldots \ldots n-1
$$

aund

$$
f_{i}=\sqrt{\frac{2}{n}} a(k) \sum_{k=0}^{n-1} F_{k} \cos \frac{(2 k+1) i \pi}{2 n}: \quad i=0.1 \ldots \ldots n-1
$$

for $a(0)=\frac{1}{\sqrt{2}}$ and $a(k)=1$ for $k \neq 0$. Similar to the Fourier transform, the discrete osine transform and its inverse can expressed in a matrix format as

$$
\mathbf{F}=\mathbf{C f}: \quad \mathbf{f}=\mathbf{C}^{-1} \mathbf{F}
$$

where $\mathbf{C}$ is the forward transformation matrix whose basis vectors are

$$
c_{k}=\left\{\sqrt{\frac{2}{n}} n(k) \cos \frac{(2 i+1) k \pi}{2 n}\right\}_{i=0.1 \ldots n-1}
$$

for $k=0.1 \ldots, n-1$. The inverse transformation matrix is simply the transpose of the forward transformation matrix, that is.

$$
\mathbf{C}^{-1}=\mathbf{C}^{T}
$$

For $n=2$. the forward and inverse discrete cosine transforms are identical to the Karhumen-Loxere and Fonrier transforms,

$$
{ }^{2} \mathbf{C}={ }^{2} \mathbf{C}^{-1}=\left[\begin{array}{cc}
\frac{1}{\sqrt{2}} & \frac{1}{\sqrt{2}} \\
\cos \frac{\pi}{4} & \cos \frac{3 \pi}{4}
\end{array}\right]=\frac{1}{\sqrt{2}}\left[\begin{array}{cc}
1 & 1 \\
1 & -1
\end{array}\right]
$$


For $n=4$. the discrete cosine transformation matrix and its incerse are.

$$
\begin{aligned}
{ }^{4} \mathbf{C} & =\frac{1}{2}\left[\begin{array}{cccc}
1 & 1 & 1 & 1 \\
a & b & -b & -a \\
1 & -1 & -1 & 1 \\
b & -a & a & -b
\end{array}\right] \\
{ }^{4} \mathbf{C}^{-1} & =\frac{1}{2}\left[\begin{array}{cccc}
1 & a & 1 & b \\
1 & b & -1 & -a \\
1 & -b & -1 & a \\
1 & -a & 1 & -b
\end{array}\right]
\end{aligned}
$$

where $a=\sqrt{2} \cos \frac{\pi}{\alpha}$ and $b=\sqrt{2} \cos \frac{3 \pi}{\alpha}$. The basis functions for the discrete coniue tranform for $n=S$ is shown in Figure 8.

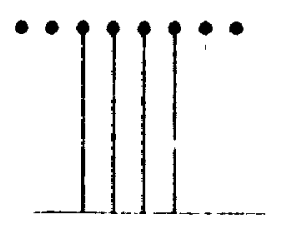

(a)

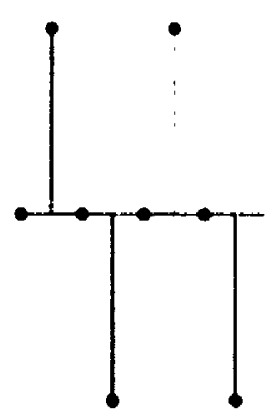

(e)

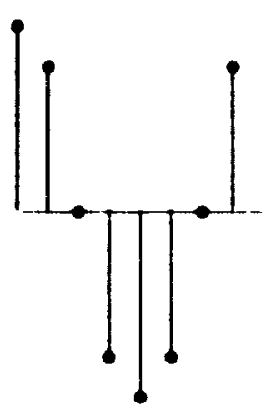

(b)

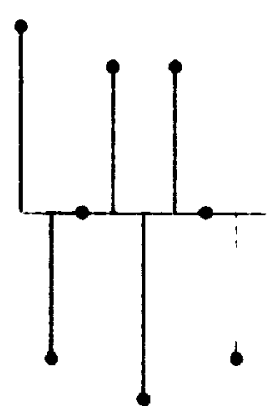

(f)

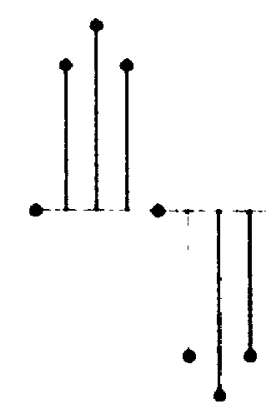

(c)

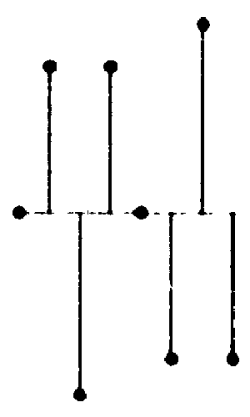

(g)

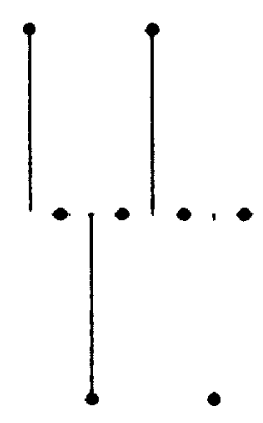

(d)

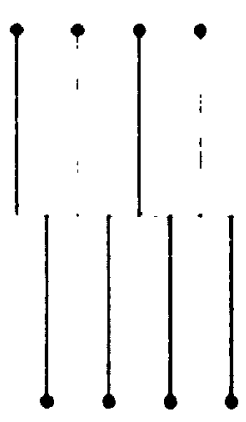

(h)

Figure 8: Basis functions for the discrete cosine transform where " $=8$.

Let $\dot{f}$, represent the 2 -element samples with even symmetry defiued loy

$$
\tilde{f}_{j}=\left\{\begin{array}{ll}
f_{j} & j=0.1 \ldots \ldots n-1 \\
f_{2 n-1-1} & j=n .11+1 \ldots 2 n-1
\end{array} .\right.
$$


Then the ?n discrete Fontrier transform of $\tilde{f}$ is.

$$
\begin{aligned}
\hat{F}_{k} & =\frac{1}{\sqrt{2 n}} \sum_{i=11}^{2 n-1} \tilde{f}_{i},-\lambda(2-k n / 2 n) \\
& =\frac{1}{\sqrt{2 n}},{ }^{\prime k-12 n} \sum_{i=0}^{n-1} f_{i} \cos \left(\frac{2 i+1) k \cdot \pi}{2 n}\right) .
\end{aligned}
$$

Comparing the discrete Fontier transform. $\dot{F}_{k}$. and the discrete cosine transform. $F_{h}$. it can loe clearly seren that

$$
F_{k}=2 n(k \cdot) \epsilon^{-.1 k \pi / 2 n} \check{F}_{k}
$$

There are seteral reasons why the discrete cosine transform is used in many signal processing applications. It is almost as optimal as the Karhunen-Loeve transform yet its basis vertors are independent of the input signals. Compared to the Fourier transform. it does not have to handle complex numbers. and it ran be computech using a fast discrete Fourier transtorm terhnique.

\subsection{Results of Previous Methods}

In this chapter many different approximation terhniques on one-dimensional functisms have been reviewerl. Of the methods that have been examined. the following algorithms are selerted and used as a basis to compare the schemes against each other:

1. Linear search and split (Ramer)

2. Split-and-merge algorithm (Pavlidis and Horowitz)

3. Nearest-neighbour averaging algorithm (extension of Tanimoto)

4. Hologram-like approximation algorithm (Prusinkiewirz)

j. Minimax Polygon (Kiurozumi and Davis)

6. Recursiov biuary search and split (Duda and Hart. Lowe) 
i. Discrete Fontier transform (Racr. Yip. ot al.)

S. Discreter coniue tratusform (Rao. Yip. ot at.)

Thene methods provide a cross section of time/spancial domain and transform domain approximation techniques. The first six methork arre antegorized as the. time/spacial domain terduniques. and the last two (as their names imply) are tramsform comain techniques. Within the time/spacial domain categors: whereas the hologram-like and nearest-neighbour terhniques use uniform knot points, the oth. er time/spacial comain techniques use non-tunform knots. In order to impartially compate the different terhniques. they have been applied to the following six onedimensional functions:

1. $f_{1}(r)=5 \sin 4 x+4 \cos 3 x$. defined in interval [0. 10].

2. $f_{2}(x)=\frac{20}{\sqrt{2 \pi}},-2 x^{2}$ defined in interval [-6.6].

3. $f_{3}(x)=$ Sawtooth waves defined in interval [-12, 12].

4. $f_{4}(x)=\frac{i \sin x}{x}$ definted in interval $[-10.2 .12 .1]$.

J. $f_{5}(x)=\frac{i \sin x}{x}+$ Sawtooth waves defined in interval $[-10.2 .12 .1]$.

6. $f_{i,}(x)=5 \sin 4 x+4 \cos 3 x+2 \cos 200 x$ defined in interval [0.10].

One of the main reasons why these methods were chosen is becantse they can he applied to both one-dimensional functions and planar curves. The cror estimation for the minimax and hologram-like techniques is aimed at planar curvess nud areas. and as such, the errors do not neressarily reflect the vistubl correctuess of these approximations. The techniques provided by Ramer. Pavlidis and Horewits, Liurozimi and Davis, and Lowe are uot contained in this chapter: a review of thesse techuigues is pressented in Chapter 3 in which planar curve hud digitizerl inage" approximation methorls are discusseed. 
The resialts of these npproximation technicques are displayed and talmbated at the end of this section. The columu with the herading "\# of Approx. Points"

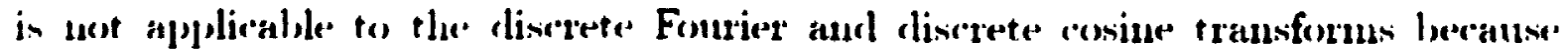
their estination is clone in the transform domain. Both of these terhnignes divide. the original sampled data into groups of 10 data values. The transformation is rarried ont using these terhuiques. and only three of the 16 ghantized coetficients ate reetained. The incerse transformation is then performed on the cluantized coesticients to derive the appreximated values in the time/sparial domain.

From the results of the different approximation terhiques. it is chear that the best time/sparial domain approximation techniques are the linear split algorithm proposed l,y Ramer [Ram i2] aud the rerursive split algorithun suggested by Durla and Hart [DH 73] and Lowe [Lo S7]. These techniques derive a piecewise linear approximation with the smallest error while simultaneously requiring a minimal amonut of tinie. (Mue major problem with this terhnique is that if the original signal is noiss: it will incorporate the uosise as part of the signal as shown in the approximation of function $f_{i i}$ (which is but a noisy version of function $f_{1}$ ). The nearest-neighbour ulgorithm, however. is computationally efficient, yet in terms of error minimization. it is the worst time/spacial domain technique. The hologram-like approximation proposerl by Prusinkiewirz $[\operatorname{Pr} 84]$ only works if the original function is oversamplecl. and since all six sampled functions provided are oversampled, this algorithm performs quite well for these cases. The split and merge algorithm proposied by Pavlidis and Horowitz [PH 74 ] does not arhieve its goal of minimizing the number of approximation points; in fart, it introdures more umeressary computations and approximating line segments. The minimax methorl proposied by hurozumi and Daris [KD 82], in most cases, arhieves its goal of minimizing the number of line segments. However, in sloing sos, it is computationally inefficient compared to the linear and recursive split algorithms. An interesting point must be noterl with regard to the minimax terhuique as applied to the sawtosoth waves: even thongh the 
Enclidean distame berwen the anthal corse and the approximatiug line segments

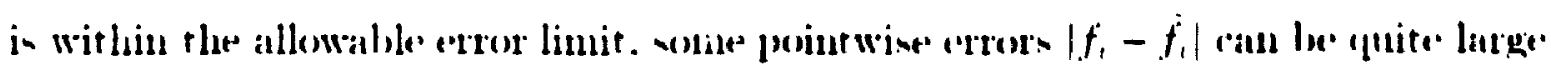
cansing it to be unateptable in terme of error calues. (Dtherwise. the minimax

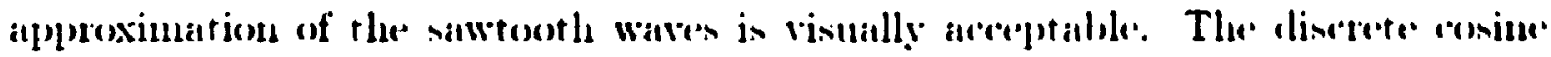
ransorm provides a good approximation if the original function is a smesth churo

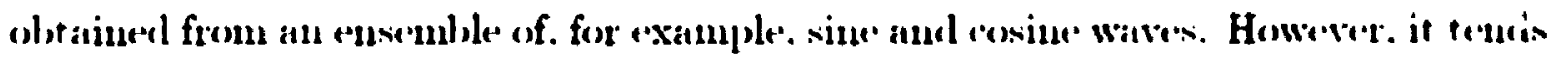
to ronud ont the sharp edgers containerl in functions such as the sawtooth waves. 


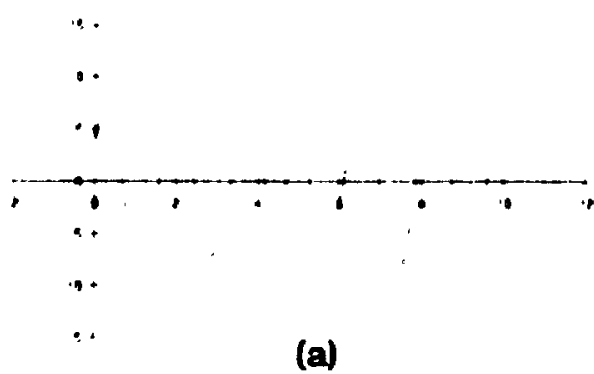

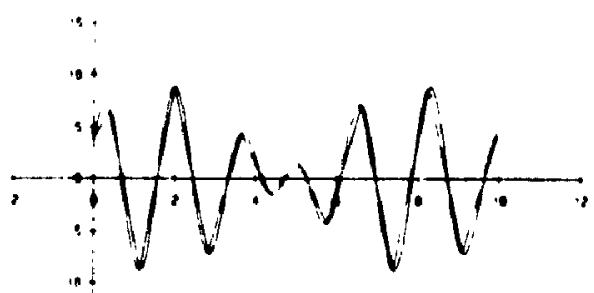

(b)

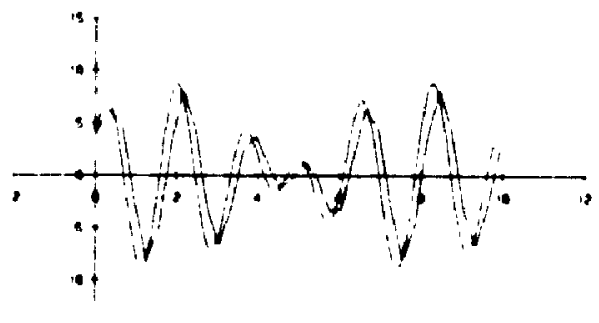

(d)

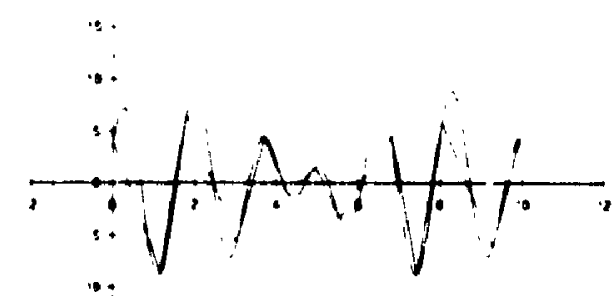

(c)

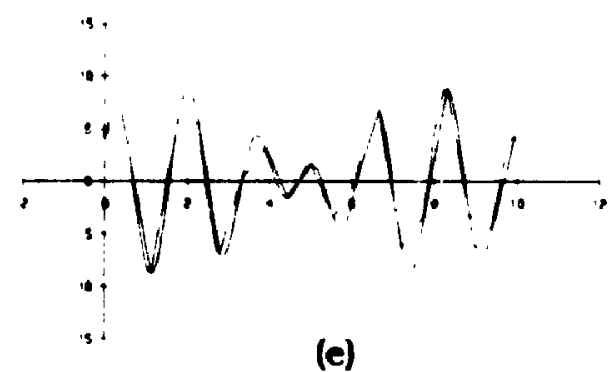

Figure 9: (a) Original function $f_{1}$. (b) to (e): Approximations of function $f_{1}$ using terchuiques (1) to (4) listed in Section 2.3. 


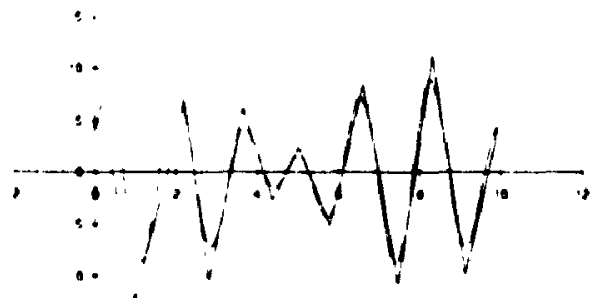

(f)

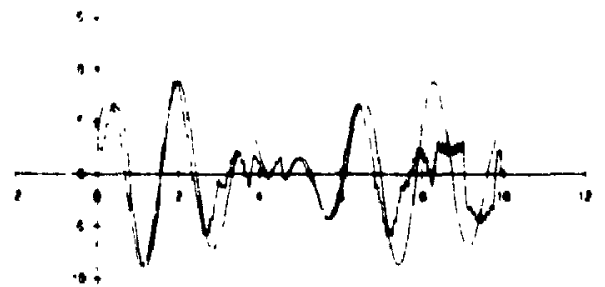

(h)
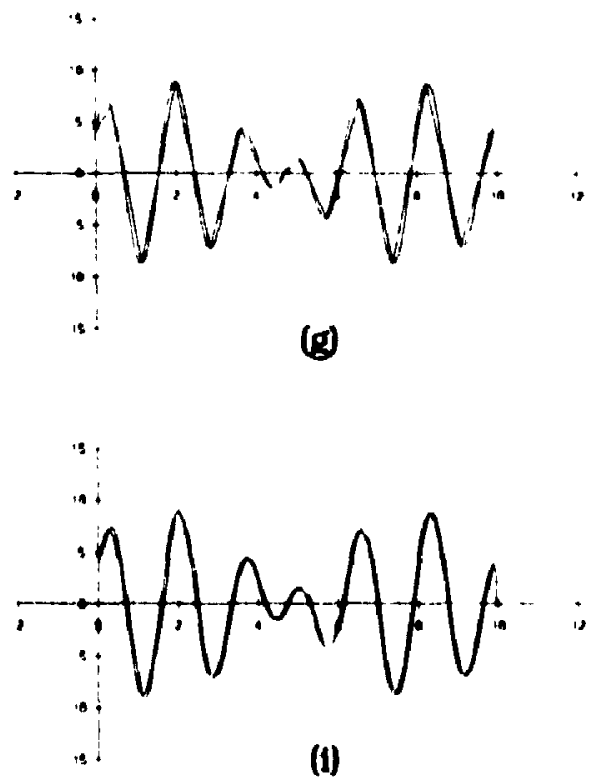

Figure 10: (f) to (i): Approximations of function $f_{1}$ using techniques (5) to (8: listed in Section 2.3. 


\begin{tabular}{|c|c|c|c|c|c|}
\hline $\begin{array}{l}\text { Approximation } \\
\text { Mothod }\end{array}$ & $\begin{array}{l}\text { of Approx. } \\
\text { Points }\end{array}$ & $\begin{array}{c}\text { Timo } \\
\text { Required }\end{array}$ & $\begin{array}{l}M E \\
\left(E_{m}\right)\end{array}$ & $\begin{array}{l}\text { MSE } \\
(E: N)\end{array}$ & $\begin{array}{l}\text { SNR } \\
\text { (DB) }\end{array}$ \\
\hline $\begin{array}{l}\text { Linoar Split } \\
\text { (Ramer) }\end{array}$ & 14 & 216 & 2.350 & 1.1337 & -11.7755 \\
\hline soiminape & 30 & 1004 & 4.0756 & 3.0008 & -17.1851 \\
\hline $\begin{array}{l}\text { Avg. naighbours } \\
\text { (Tanimoto) }\end{array}$ & 18 & 52 & 6.9249 & 19.2216 & -24.0685 \\
\hline $\begin{array}{l}\text { Habegram-ike } \\
\text { Pruainkionioc) }\end{array}$ & 18 & 48 & 3.0010 & 2.4007 & -15.2042 \\
\hline $\begin{array}{c}\text { Minmax } \\
\text { (Kurozumi) }\end{array}$ & 14 & 1664 & 8.3923 & 6.7534 & -19.5258 \\
\hline $\begin{array}{l}\text { Amentive epill } \\
\text { (Lom) }\end{array}$ & 14 & 200 & 2.300 & 1.1337 & -11.7765 \\
\hline DFT & NA & 236 & 9.5971 & 9.8354 & -21.1585 \\
\hline DCT & $\mathrm{NA}$ & 193 & 2.1801 & 0.0002 & 0.5873 \\
\hline
\end{tabular}

Figure 11: Results of the various approximation techniques applied on function $f_{1}$. 

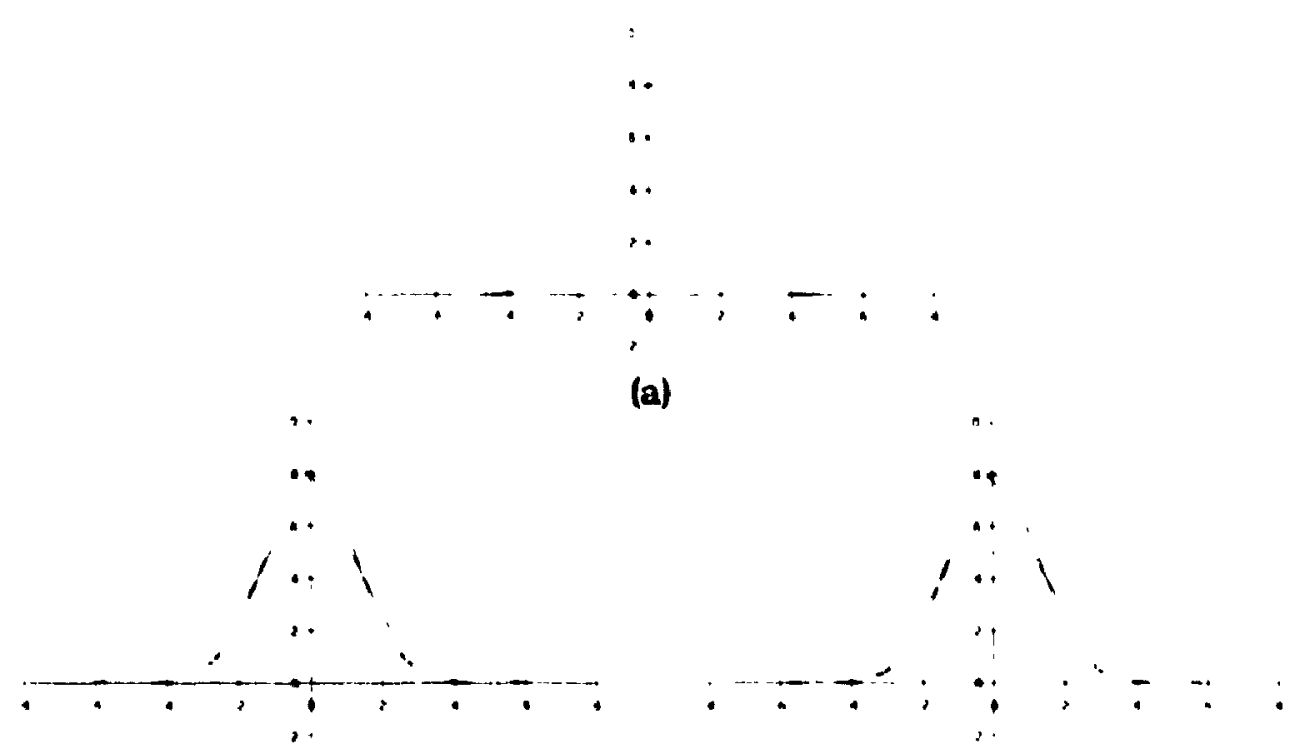

(b)

(c)

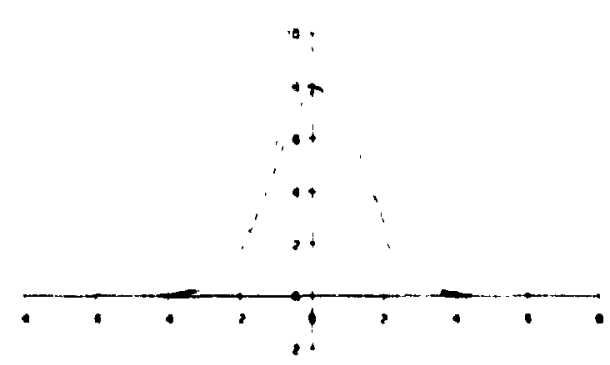

(d)

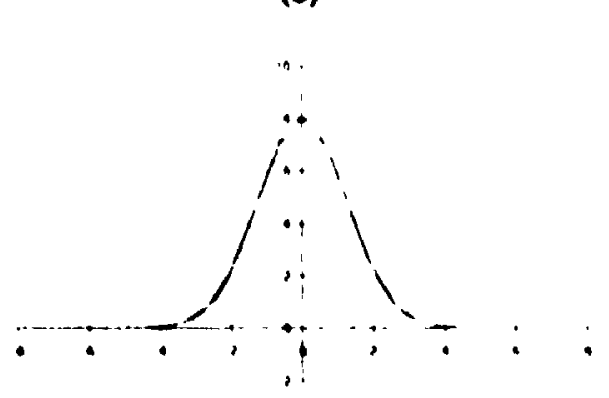

(e)

Figure 12: (a) Original fumetion $f_{2}$ (uormal bell (eurve). (b) to (o): Approximitious of normal bell curve using techniques (1) to (4) listed in Section 2.3. 


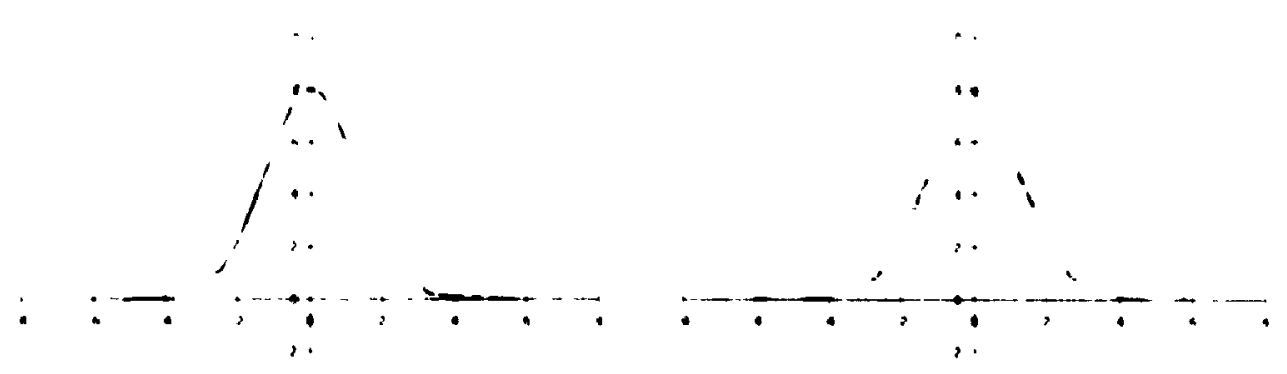

(f)

(a)

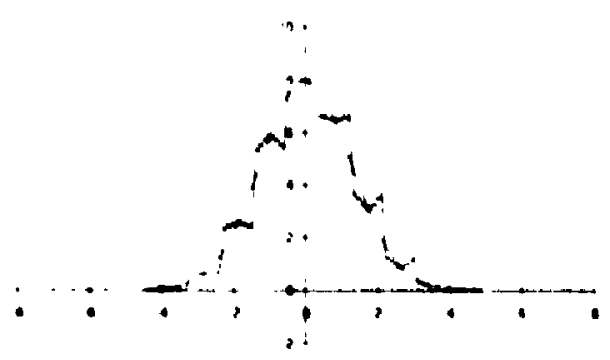

(h)

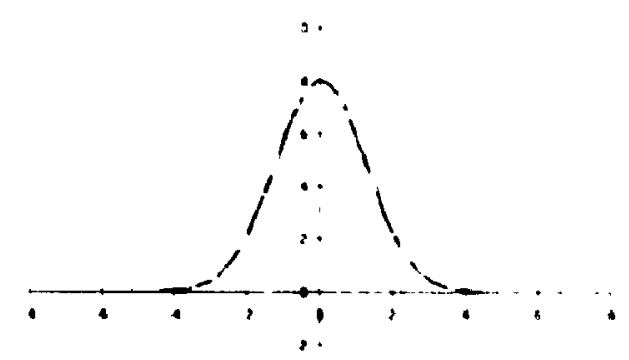

(i)

Figure 13: (f) to (i): Approximations of normal bell rurve using tedhniques (j) to (8) listed in Sertion 2.3. 


\begin{tabular}{|c|c|c|c|c|c|}
\hline $\begin{array}{c}\text { Approximation } \\
\text { Mothod }\end{array}$ & $\begin{array}{l}\text { of Approx. } \\
\text { Pounts }\end{array}$ & $\begin{array}{c}\text { Time } \\
\text { Requireo }\end{array}$ & $\begin{array}{l}M E \\
\left(E_{-}\right)\end{array}$ & $\begin{array}{l}M S E \\
\left(E_{:} / N\right)\end{array}$ & $\begin{array}{l}\text { SNA } \\
\text { (dB) }\end{array}$ \\
\hline $\begin{array}{l}\text { Linear Split } \\
\text { (Ramer) }\end{array}$ & 5 & 129 & 0.73505 & 0.1346 & 11.9091 \\
\hline $\begin{array}{l}\text { Solitnuages } \\
\text { (Pavidia) }\end{array}$ & 12 & 692 & 0.8403 & 0.133 & 11.9590 \\
\hline $\begin{array}{l}\text { Avg. neighbours } \\
\text { (Tanimoto) }\end{array}$ & 34 & 62 & 0.8028 & 0.1633 & 11.0704 \\
\hline $\begin{array}{l}\text { Hologram-lko } \\
\text { (Prusinisemicz) }\end{array}$ & 18 & 55 & 0.2442 & 0.0055 & 25.7088 \\
\hline $\begin{array}{c}\text { Minimax } \\
\text { (K.urozumi) }\end{array}$ & 7 & 5901 & 1.4142 & 0.2721 & 8.8518 \\
\hline $\begin{array}{l}\text { Procurative split } \\
\text { (Lowy) }\end{array}$ & 5 & 122 & 0.735 & 0.1346 & 11.9091 \\
\hline DFT & NA & 243 & 1.6673 & 0.2059 & 10.0619 \\
\hline oct & NA & 198 & 0.1275 & 0.002 & 30.2411 \\
\hline
\end{tabular}

Figure 14: Results of the varions approximation techuipues appliecl on morual bell iurve. 


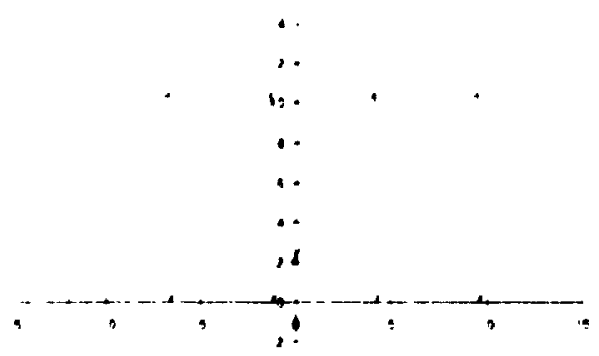

(a)

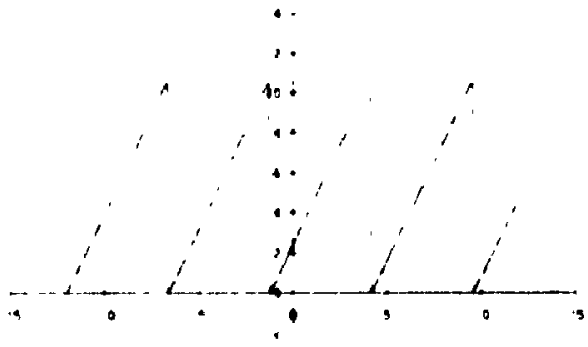

(b)

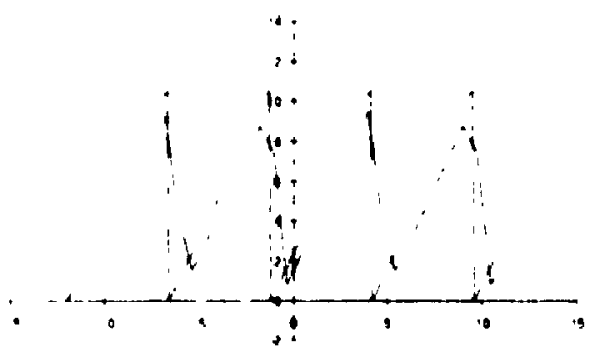

(d)

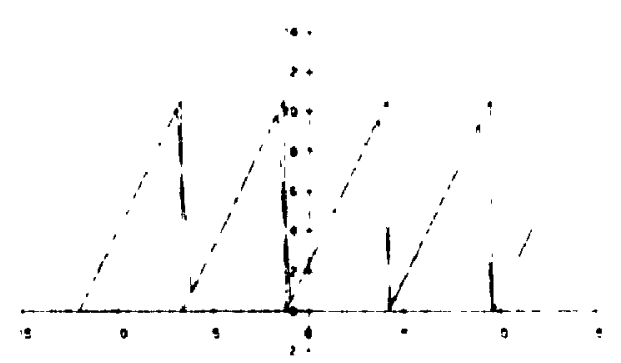

(c)

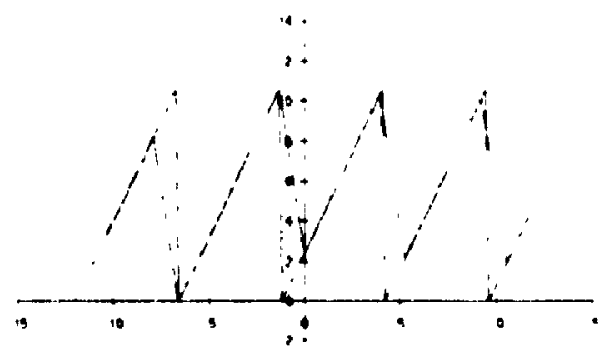

(e)

Figure 15: (a) Original function $f_{;}$( sawtooth waves). (b) to (e): Approximations of sawtooth waves using techniques (1) to (4) listed in Sertion 2.3. 


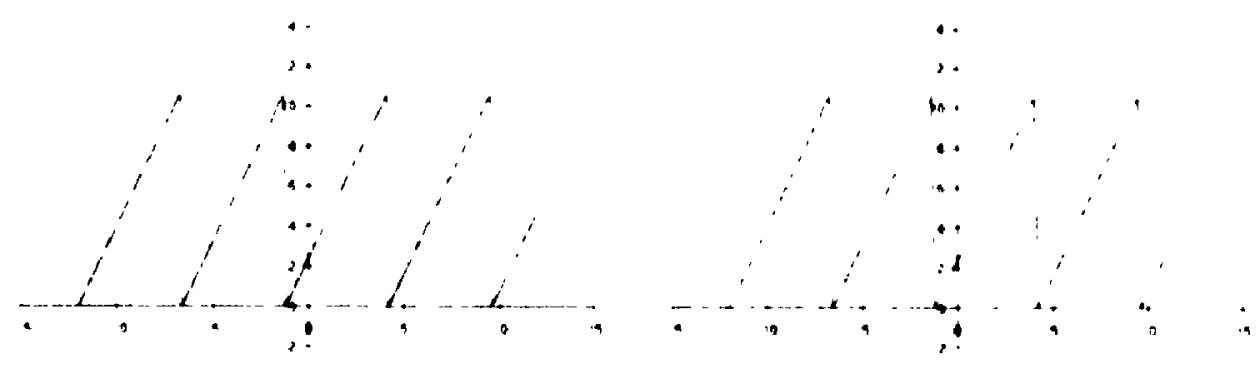

(f)

(g)

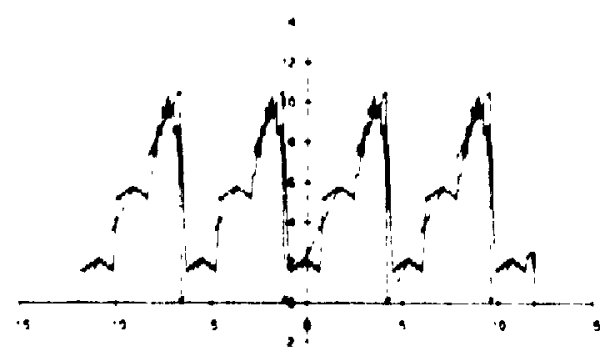

(h)

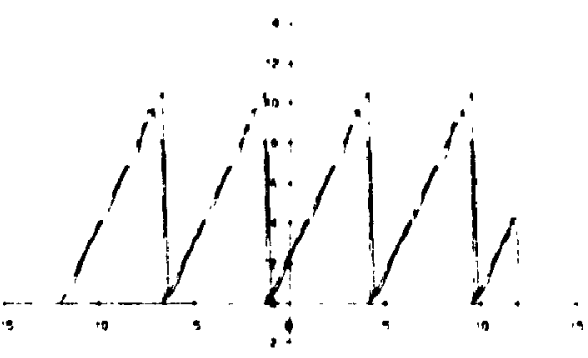

(i)

Figure 16: (f) to (i): Approximations of sawtooth waves using terchniques (j) to (8) listed in Section 2.3. 


\begin{tabular}{|c|c|c|c|c|c|}
\hline $\begin{array}{l}\text { Approximation } \\
\text { Momod }\end{array}$ & $\begin{array}{l}\text { of Approx. } \\
\text { Points }\end{array}$ & $\begin{array}{c}\text { Tromo } \\
\text { Required }\end{array}$ & $\begin{array}{l}M E \\
\left(E_{-\mu}\right)\end{array}$ & $\begin{array}{l}\text { MSE } \\
\left(E_{2} N\right)\end{array}$ & $\begin{array}{l}\text { SNR } \\
\text { (dB) }\end{array}$ \\
\hline $\begin{array}{l}\text { Linear Split } \\
\text { (Ramer) }\end{array}$ & 10 & 200 & $7.11 E-15$ & $3.86 E-30$ & 301.1069 \\
\hline 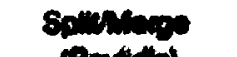 & 18 & 1122 & 9 & 2.1176 & 3.7130 \\
\hline $\begin{array}{l}\text { Avg. neighbours } \\
\text { (Tanimoto) }\end{array}$ & 34 & 64 & 7.71 & 4.2873 & 0.6505 \\
\hline Halogrentwe & 18 & 45 & osfer & 20071 & .0 .8789 \\
\hline$\underset{\text { (Kurozumi) }}{\text { Minimax }}$ & 10 & 754 & $3.24 E+01$ & $3.27 E+01$ & -8.1678 \\
\hline 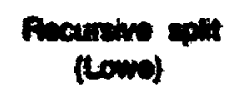 & 10 & 192 & $7.11 E-15$ & $380 E-80$ & 301.1068 \\
\hline DFT & NA & 240 & 3.918 & 1.5705 & 5.0118 \\
\hline DCT & $m$ & ins & 3.7447 & aram & avese \\
\hline
\end{tabular}

Figure 17: Results of the various approximation techniques applied on sawtooth whves. 


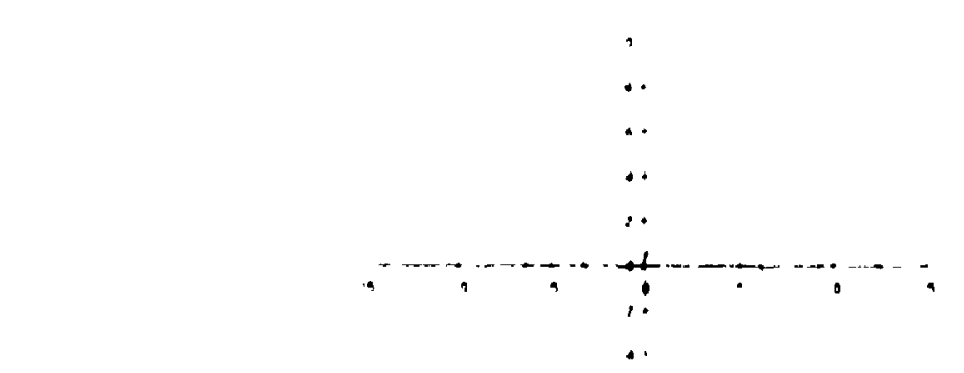

(a)

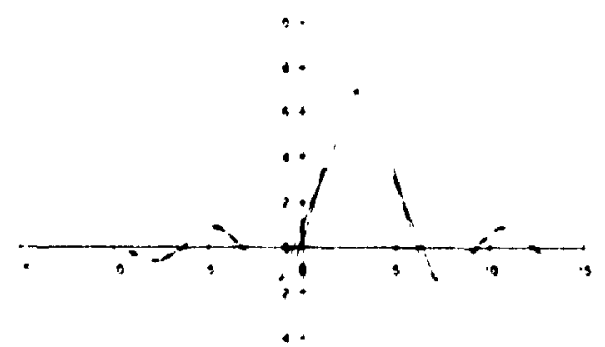

(b)

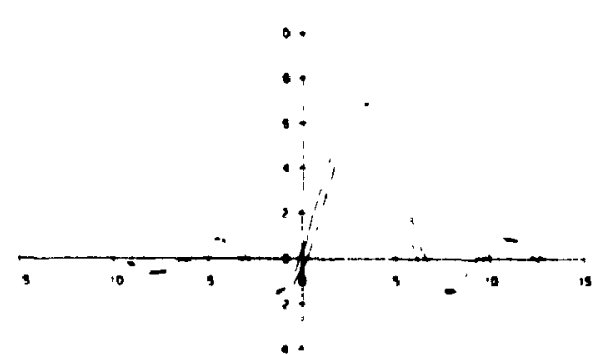

(d)

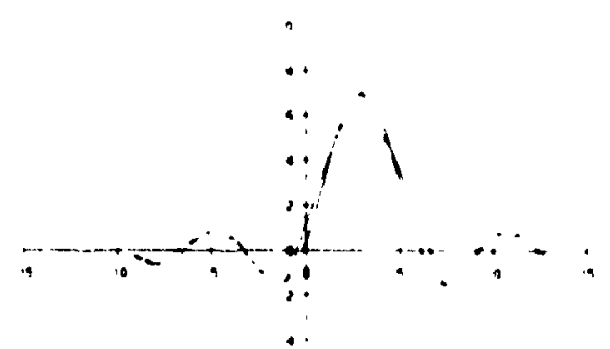

(c)

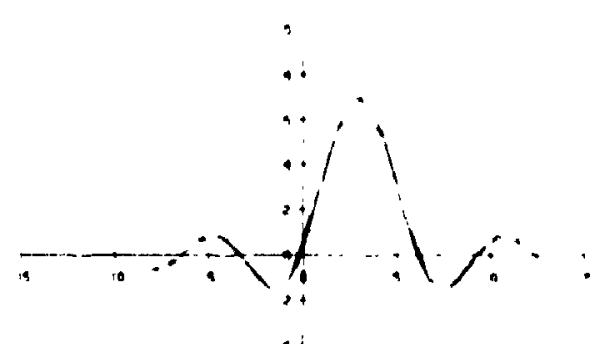

(e)

Figure 18: (a) Original function $f_{4}(f(x)=\sin x / x)$. (b) to (c): Approximations of function $f_{4}$ using techniques (1) to (4) listed in Section 2.3. 


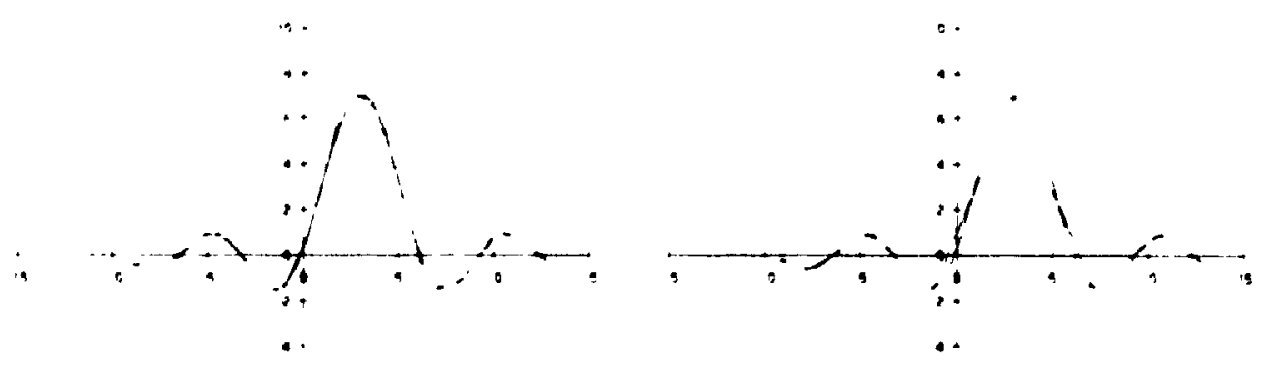

(f)

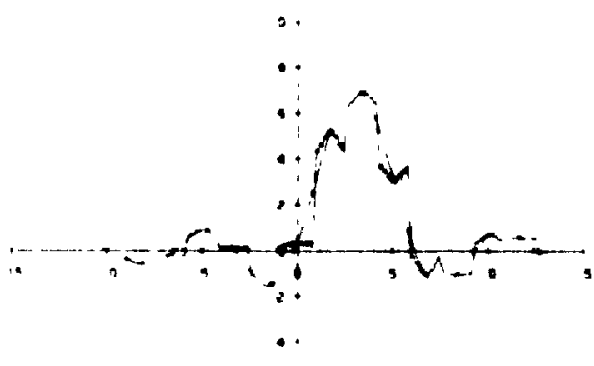

(h) (g)

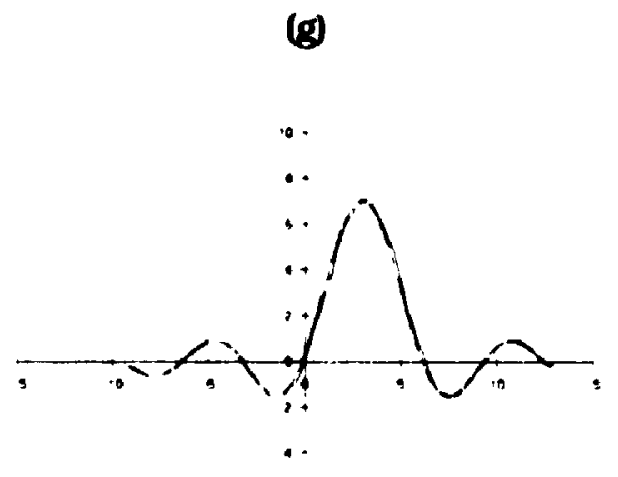

(i)

Figure 19: (f) to (i): Approximations of function $f_{4}(f(x)=\sin r / x)$ using terdhniques (j) to (8) listed in Section 2.3. 


\begin{tabular}{|c|c|c|c|c|c|}
\hline $\begin{array}{l}\text { Approximation } \\
\text { Method }\end{array}$ & $\begin{array}{l}\text { of Approx. } \\
\text { Points }\end{array}$ & $\begin{array}{c}\text { Trme } \\
\text { Roquired }\end{array}$ & $\underset{\left(E_{\alpha}\right)}{M E}$ & $\begin{array}{c}\text { MSE } \\
(E, N)\end{array}$ & $\begin{array}{l}\text { SNR } \\
\text { (dE) }\end{array}$ \\
\hline $\begin{array}{l}\text { Linear Split } \\
\text { (Ramer) }\end{array}$ & 8 & 155 & 0.998 & 0.1579 & 7.974 \\
\hline $\begin{array}{l}\text { Spinnures } \\
\text { (Pantiotis) }\end{array}$ & 24 & 897 & 1.00003 & 0.1377 & 8.5694 \\
\hline $\begin{array}{l}\text { Avg. neighbours } \\
\text { (Tanimoto) }\end{array}$ & 34 & 62 & 1.1705 & 0.3105 & 5.0371 \\
\hline $\begin{array}{l}\text { Halograntite } \\
\text { (Prusintionica) }\end{array}$ & 18 & 46 & 0.3003 & 0.021 & 16.7380 \\
\hline $\begin{array}{l}\text { Minimax } \\
\text { (Kurozumi) }\end{array}$ & 12 & 2121 & 1.3175 & 0.0993 & 9.9887 \\
\hline $\begin{array}{l}\text { Procurive sain } \\
\text { (Lowe) }\end{array}$ & 6 & 148 & 0.996 & 0.1579 & 7.974 \\
\hline DFT & NA & 235 & 2.4872 & 0.3941 & 4.0023 \\
\hline DCT & NA & 197 & 0.2168 & 0.00037 & 24.2448 \\
\hline
\end{tabular}

Figure 20: Results of the various approximation terhniques applied on function $f_{4}$ $(f(x)=\sin x / x)$. 


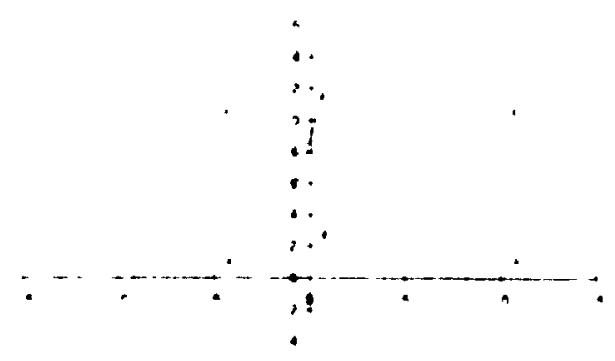

(a)

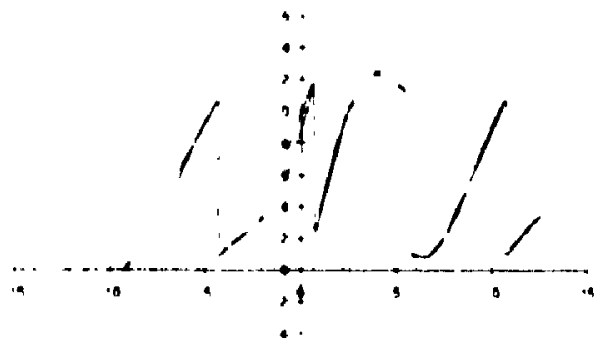

(b)

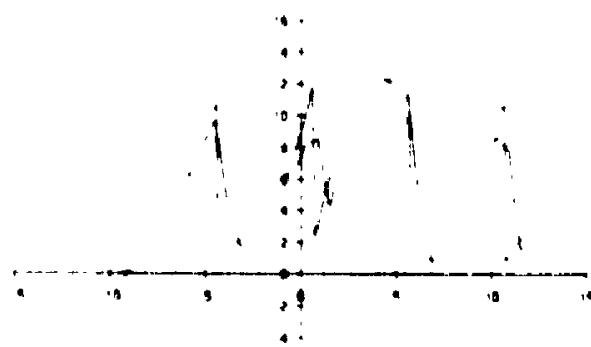

(d)

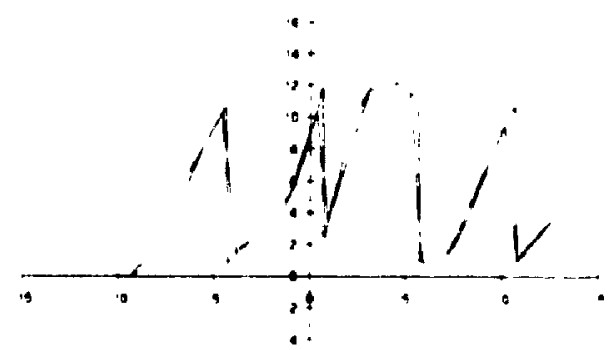

(c)

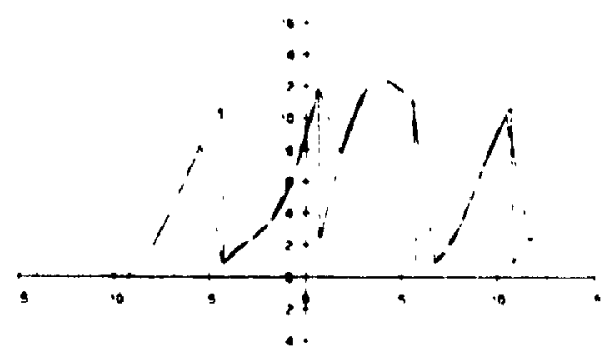

(e)

Figure 21: (a) Original function $f_{5}$ (sum of sawtosth waves and $i \sin x / x$ ). (b) to (e): Approximations of function $f_{5}$ using terhniques (1) to (4) listerl in Section 2.3 . 


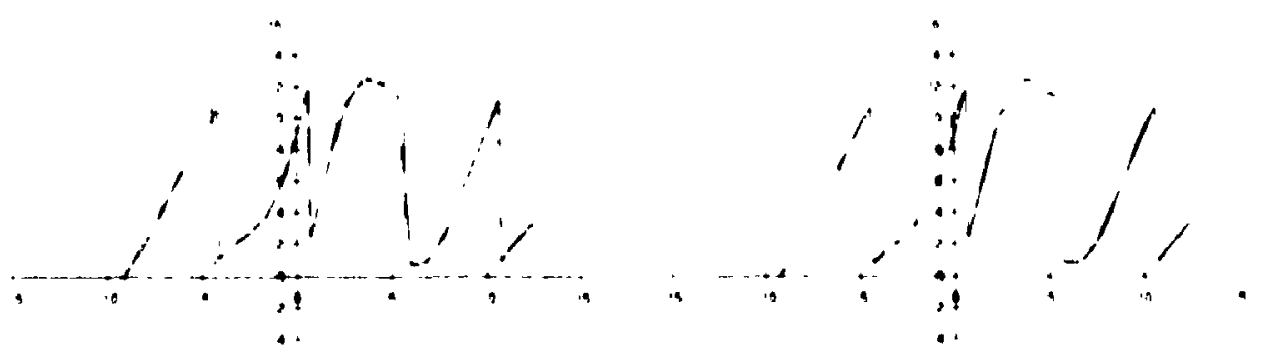

(f)

(a)

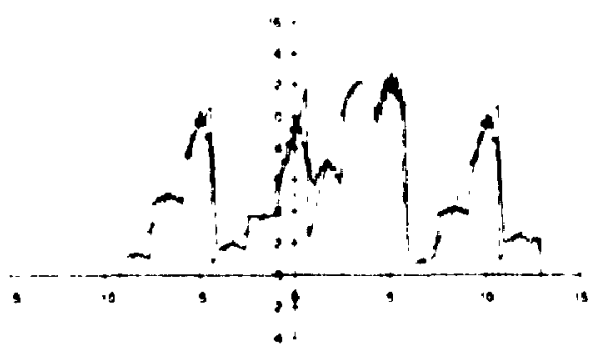

(h)

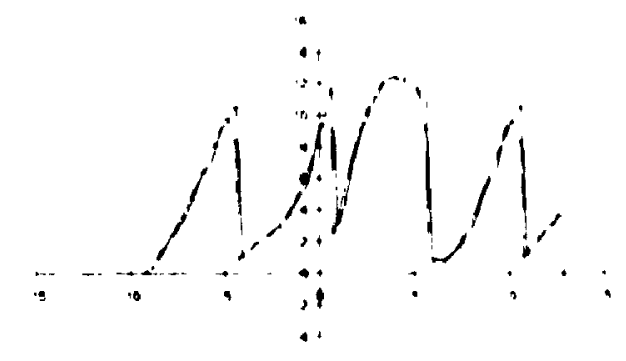

(i)

Figure 22: (f) to (i): Approximations of function $f_{5}$ using terhuirques (5) to (S) listed in Section 2.3 . 


\begin{tabular}{|c|c|c|c|c|c|}
\hline $\begin{array}{l}\text { Approximation } \\
\text { Mothod }\end{array}$ & $\begin{array}{l}\text { - of Approx. } \\
\text { Points }\end{array}$ & $\begin{array}{c}\text { Time } \\
\text { Required }\end{array}$ & $\begin{array}{l}M E \\
\left(E_{-\infty}\right)\end{array}$ & $\begin{array}{l}\text { MSE } \\
\left(E_{2}, N\right)\end{array}$ & $\begin{array}{l}\text { SNR } \\
\text { (OB) }\end{array}$ \\
\hline $\begin{array}{l}\text { Linad Split } \\
\text { (Ramer) }\end{array}$ & 15 & 210 & 1.5017 & 0.2252 & 13.9691 \\
\hline $\begin{array}{l}\text { Epimaniange } \\
\text { Paxtidis) }\end{array}$ & 28 & 1011 & 8.3011 & 1.9746 & 4.5400 \\
\hline $\begin{array}{l}\text { Avg. noighbours } \\
\text { (Tanimoto) }\end{array}$ & 34 & 62 & 8.3229 & 4.1081 & 1.3591 \\
\hline 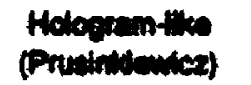 & 18 & 47 & 0.1760 & 53602 & 0.207 \\
\hline$\underset{\text { (Kurozumi) }}{\text { Minimax }}$ & 16 & 1458 & 30.1181 & 26.2339 & 6.6931 \\
\hline 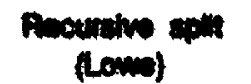 & 15 & 201 & 1.5017 & 0.2262 & 13.0091 \\
\hline DFT & $N / A$ & 238 & 4.4599 & 1.7246 & 5.1287 \\
\hline DCT & $\mathbf{N A}$ & 108 & 3.5019 & 0.6746 & 2205 \\
\hline
\end{tabular}

Figure 23: Results of the various approximation techniques applied on fumction $f_{5}$. 


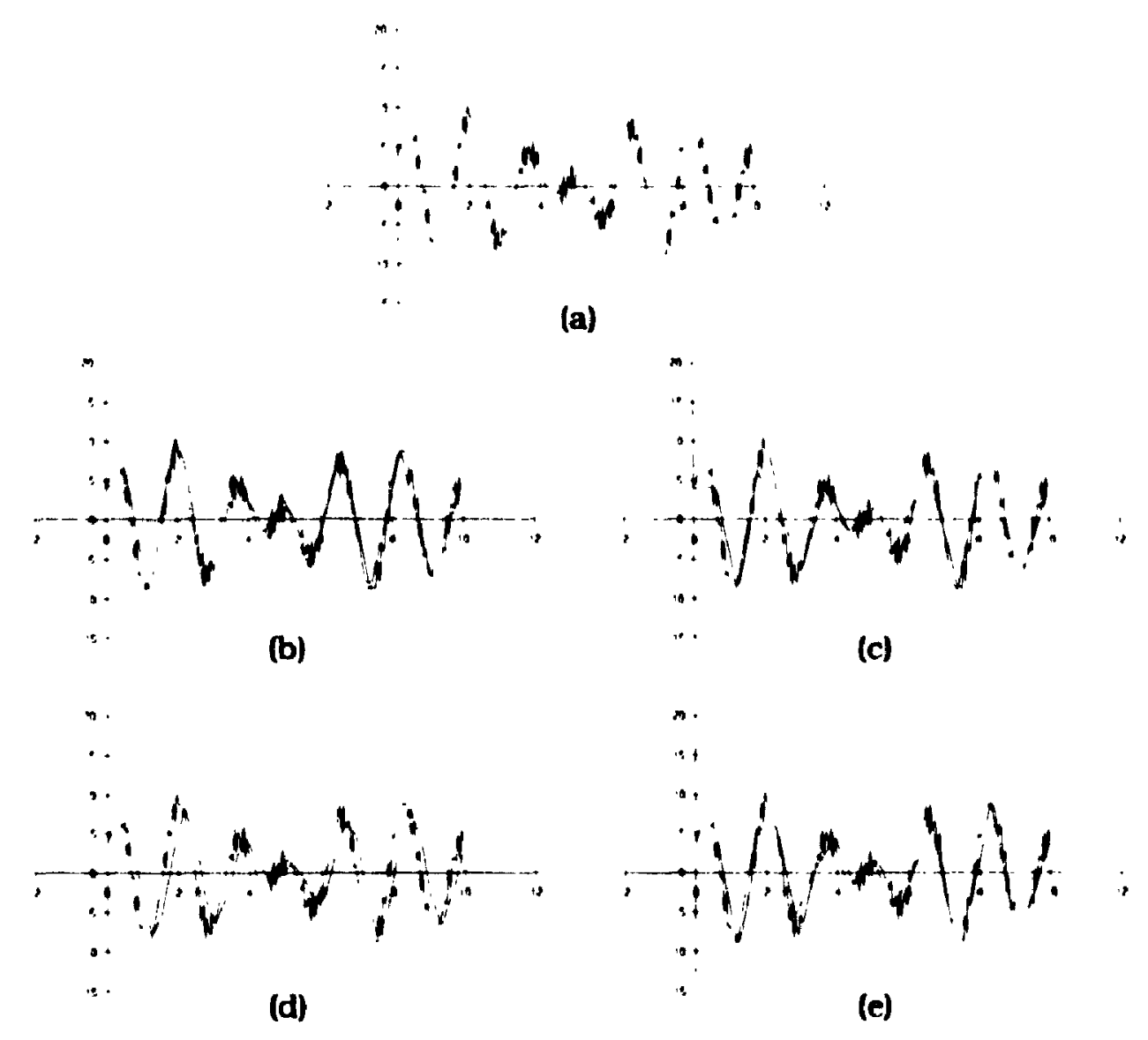

Figure 24: (a) Original fumrtion $f_{6}$ (simulated urisy signal). (b) to (a): Approximations of function $f_{6}$ using terhniqgues (1) to (4) listerl in Sertion 2.3. 


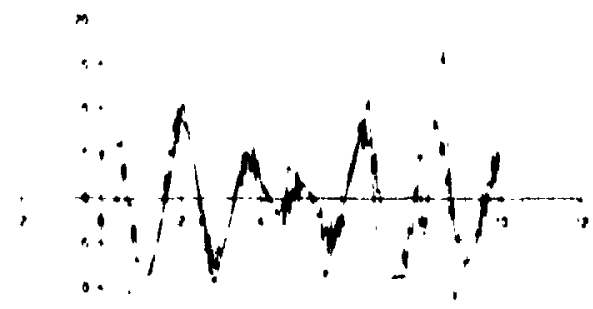

(f)

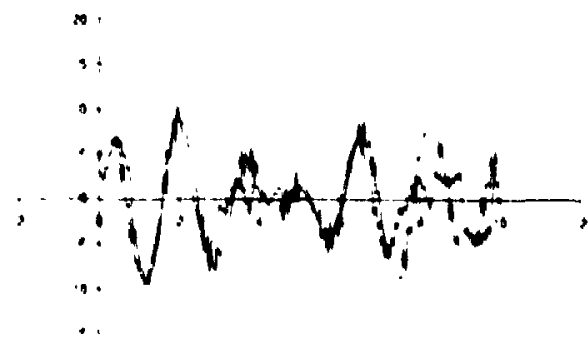

(f)
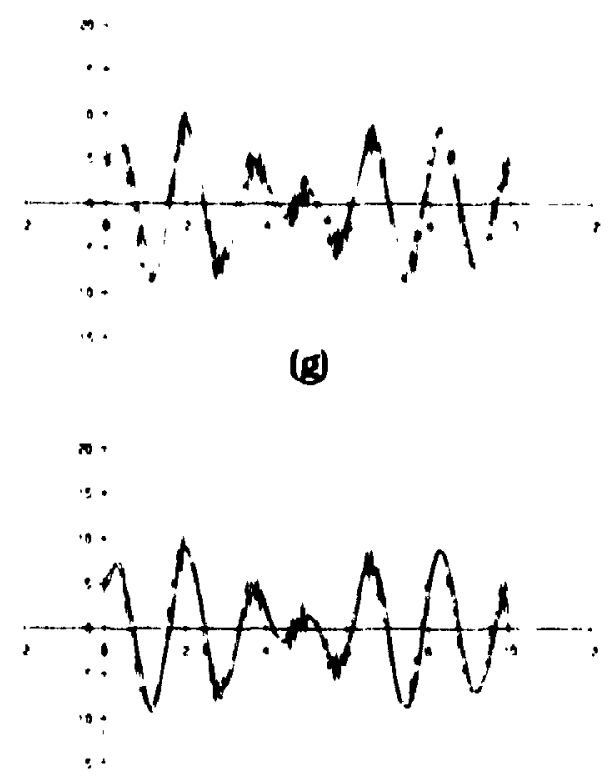

(g)

Figure 25: (f) to (i): Approximations of function $f_{6}$ using techniques (j) to (8) listerl in Section 2.3 . 


\begin{tabular}{|c|c|c|c|c|c|}
\hline $\begin{array}{l}\text { Approximation } \\
\text { Mathod }\end{array}$ & $\begin{array}{l}\text { of Approx. } \\
\text { Points }\end{array}$ & $\begin{array}{c}\text { Time } \\
\text { Required }\end{array}$ & $\begin{array}{l}M E \\
\left(E_{*}\right)\end{array}$ & $\begin{array}{c}M S E \\
\left(E_{:} / N\right)\end{array}$ & $\begin{array}{l}\text { SNR } \\
\text { (OB) }\end{array}$ \\
\hline $\begin{array}{l}\text { Linear Split } \\
\text { (Ramer) }\end{array}$ & 14 & 252 & 4.6696 & 2.7531 & .15525 \\
\hline $\begin{array}{l}\text { Splunsorge } \\
\text { (Pentidia) }\end{array}$ & 28 & 673 & 6.3583 & 6.218 & $\cdot 18.0632$ \\
\hline $\begin{array}{l}\text { Avg. neighbours } \\
\text { (Tanimoto) }\end{array}$ & 34 & 62 & 6.9121 & 9.306 & -20.8143 \\
\hline $\begin{array}{l}\text { Hologren-tike } \\
\text { (Pruminkionver) }\end{array}$ & 18 & 45 & 4.8693 & 3.9021 & -17.1278 \\
\hline $\begin{array}{c}\text { Minimax } \\
\text { (Kurozumı) }\end{array}$ & 16 & 1491 & 42.5632 & 115.6809 & -31.7593 \\
\hline $\begin{array}{l}\text { Aecursive split } \\
\text { (Lomo) }\end{array}$ & 14 & 232 & 4.6000 & 2.7531 & -15.525 \\
\hline DFT & NA & 237 & 9.5968 & 10.5518 & .21 .36 \\
\hline DCt & $N$ & 195 & 2.8431 & 1.0720 & -11.4325 \\
\hline
\end{tabular}

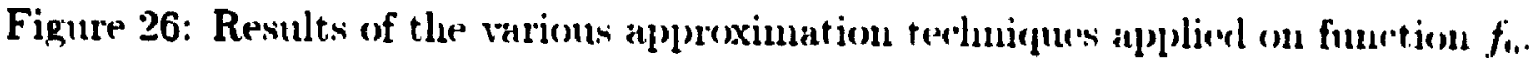




\section{Chapter 3}

\section{Related Work on Two-dimensional (2-D) Func- tions}

Approximation of planar corves and digitized intages is an important part of patteru eneognition. image processing, and graphies applications. Sot only does it provide a simple methorl of describing boumdaries in a compart way. it also allows data features to lu cinsily extracted by filtering out the undesirable noise that may be part of the original data. The problem of approximation for two-rlimensional funetions Las reveived a lot. of attention by many authors (see [Sk 70]. [Mo 70]. [Ram 72]. [Gr 72]. [ZR 72]. [DH 73]. [PH 74]. [RW 72], [PF 77]. [DBM 77]. [DaL 79]. [SG s0]. [Vi 78]. [Ti 79]. [Pa 82]. [FB 86]. [KD 82]. [Du 86]. [Al, 89]. [FWL 89]. [DLTII 90]. [AK 91]. [IN 91]. and [PD 94]). All of the results mentioned above are "philosophirally" hased on the one-rlimensional terhniques presented in the previons chapter. ind they ran be divirled into two rlistinet categories:

1. Planar curve approximations, and

2. Digitized image approximation

Within each one of these categories, the approximation techniques will be grouperl as either sparial or transformed domain approximation. These methorls are not in any way a complete list of all approximation techniques. Nevertheless. they do provide a comprehensive sample of the different approaches to the approximation problem. A derailed analysis of most of these techniques will be reviewerl in this chaptert. 


\subsection{Planar Curve Approximation}

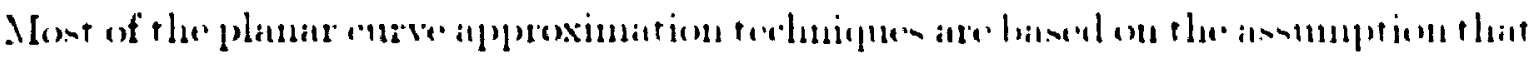

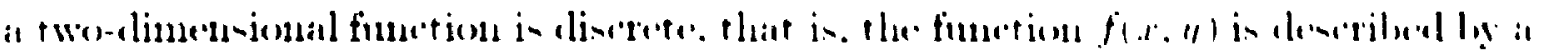

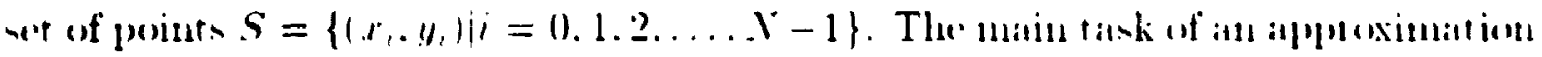

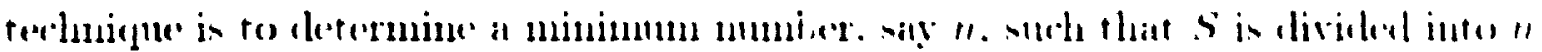

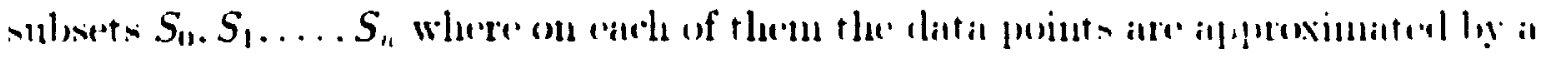

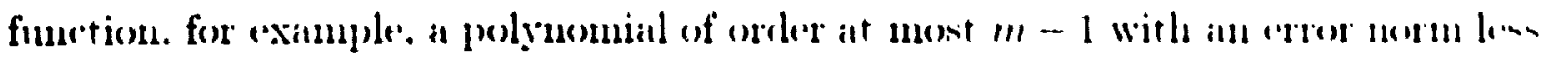

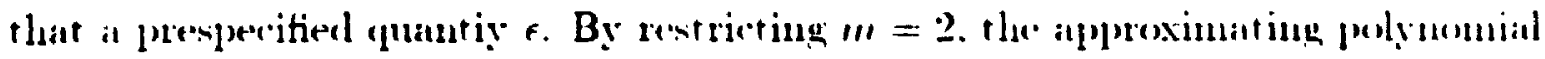
will be lindent to a line:ar form.

\subsubsection{Time/Spacial Domain Approximation}

\section{Freeman's Chain Code Encoding}

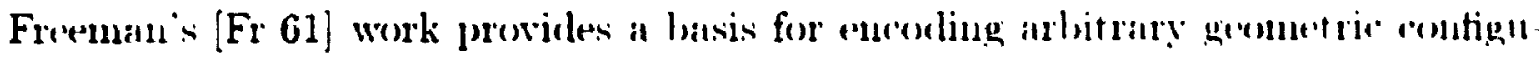
rations in order to facilitate their analysin and manipulations. An arbitrary curve.

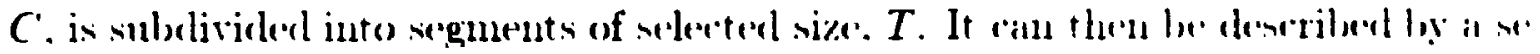
quence of angles and a standard distance as shown in Fignue 27. The antmal anoul jug ran be simplitied by limiting the mumber of permissible angles. For rxample. if the encoding is restrieted to 16 standard angles in $22.5^{\circ}$ increments. and these angles

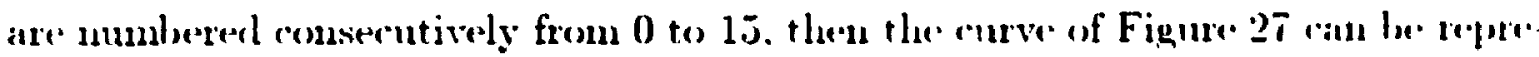
sented hy the following series of numbers: 1.1.0.0.2.6.7.7.6.2.1.0.0.15.14.11. It

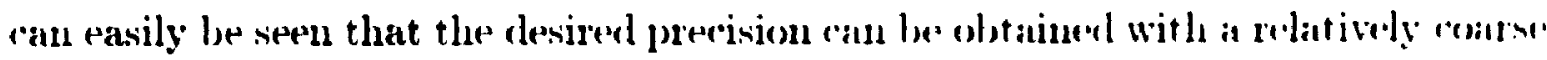
angle quantization by making the standard distance arbitrarily small. This methenl

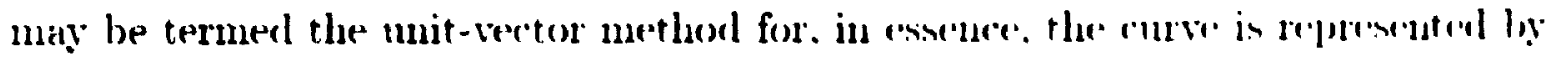

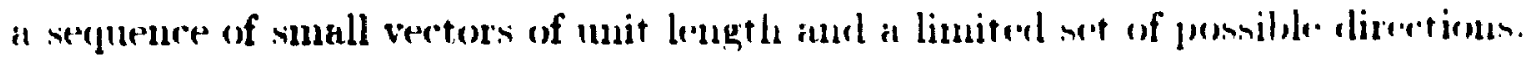

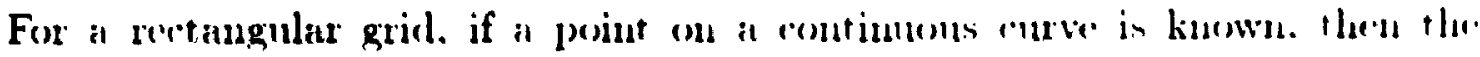

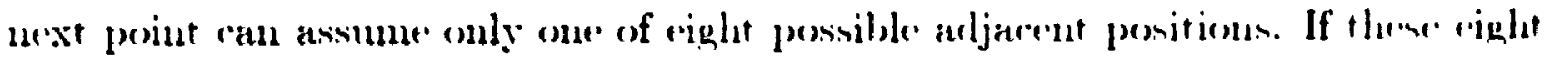
possible positions are pach assigned a munber from 0 te $T$ tartiug with the on" 


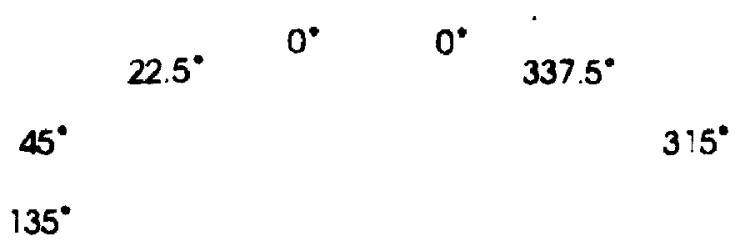

$247.5^{\circ}$

$157.5^{\circ}$

$157.5^{\circ}$

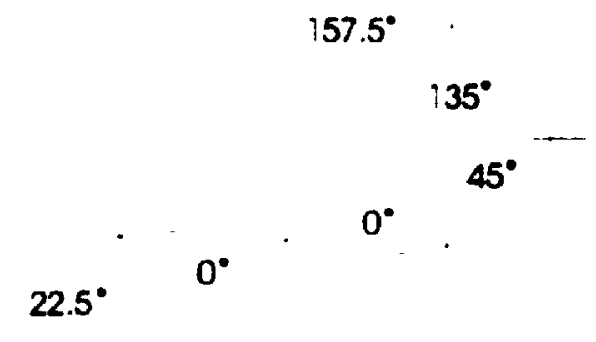

$22.5^{\circ}$

Fignure 27: Fresman - chain code encoding of an arbitrary curve

Lorizontally to the right and continue enumerating in a counter-elockwise direction. any atbitanry digitized curve on a rectangular grid can be described. Each point is describerl relative to the previons one, and so only the first point needs to be located in in alsolute sense. There main arlvantage associated with this method is that the decosding process allows a given figure to be expanderl. contracted. elongated. or cotaterl by an arbitrary amount without any significant addlitional cost.

Although Freman s chain corle is a natural way of representing curves generated on a uniform rectangular grid. it possessies two major drawbacks. First of all. its representation is not compact, and thus, an excess munber of vertices and erlges hitwe to be stored. Consequently: the approximating polygon may not necessarily lee of minimum length. Secondly: since the length of the edges is comparable to the noise introduced ly anantization, concavities for polygons that represent locally coldex curves mon orome. 


\section{Work done by Montanari}

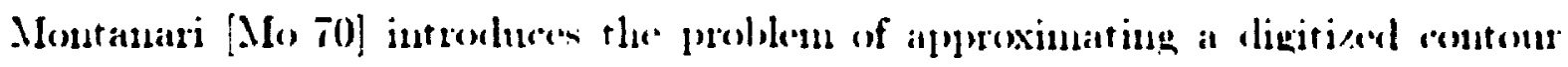
surh that the polygonal approximation has at minimal length. This terdunique takes

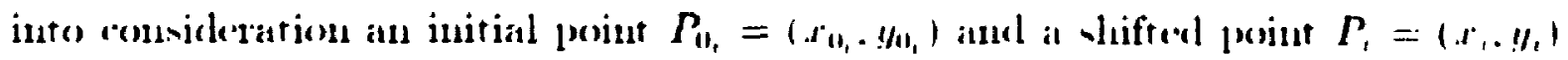

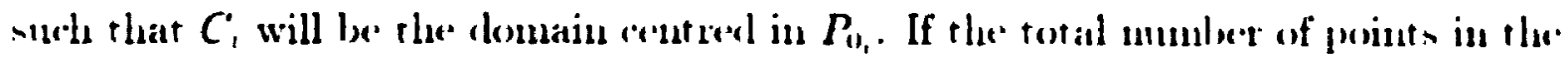

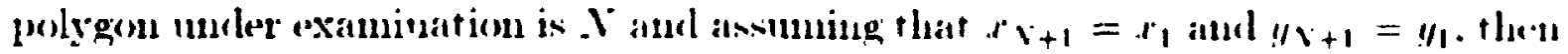
the function

$$
g(\mathbf{z})=\sum_{k=1}^{x}\left[\left(n_{k+1}-r_{k}\right)^{2}+\left(! / k+1-y_{k}\right)^{2}\right]^{\frac{1}{2}}
$$

must be minimized with the constraints

$$
P_{t} \in C_{i} . \quad 1=1.2 \ldots . . .
$$

The function $g(z)$ is a "cost" function of $z$. where $z$ is assimed to loc at vector in ant Encliclean space with $2 . V^{*}$,

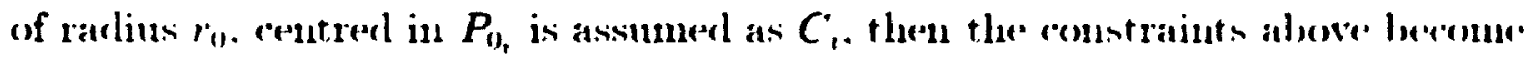

$$
\left(r_{1}-x_{11_{1}}\right)^{2}+\left(y_{1}-y_{w_{1}}\right)^{2}-r_{11}^{2} \leq 0 . \quad i=1.2 \ldots . . v^{\circ}
$$

Thus. Montanari s method of computing the smootlued polygon of minimum length "an be summarized as a nonlinear programming problem. The main drawloack of thin implementation is the excessive time required to determine a solution which satistien the.$V$ ronstraints.

\section{Work done by Jarvis}

Jarvis [Jar i1] presents a methorl for fitting polygons with a small umulure of orlges to boundary lines while still preserving the overall feituren of the bomudaries. His terchuigue uses the least-square fit criterion under the constraint that the vertion of the polygons "ist lie on at set of rays originating at the centire of mass. The initial set of rays is fonud from peaks and tronghs of the polat coordinaten of the bomolary relative to the centre of mass. Adelitional rays ate fonud iteratively in the 
diretions of maximum arror mutil the fit ariterion is satistied. This method is not

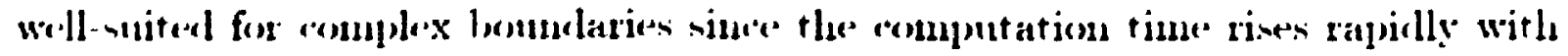
increaning complexity of the lomulary.

\section{Work done by Ramer}

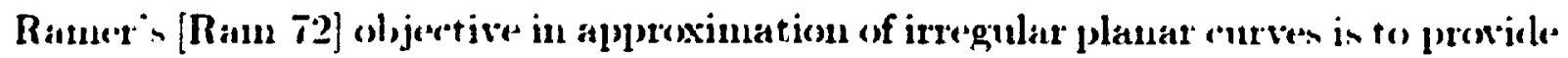

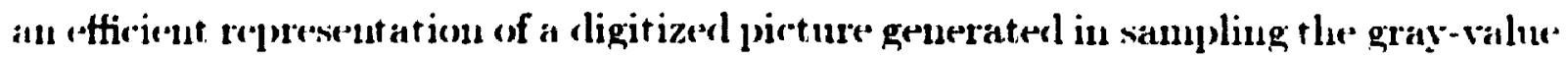
fuuction orer the domatiu of an image on a regular squate grid. The resulting corres ran be interpreted as polgegons whose sertices lie on the sampling points or whose

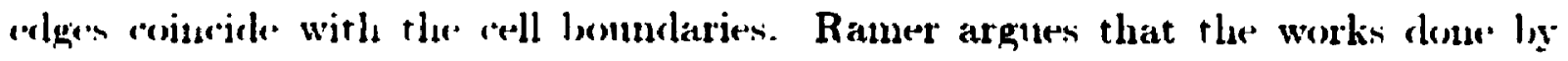
Stonn.[St 61]. Bellman [Be 61]. and Gluss[G1 62] are only concerned with a]proximation of real. single-talned. continuous functions of one parameter polygons, and that they cannot be applied to image processing since they deal strictly with singlevariable functions. He also arguess that the methods presented by Freman [Fr 70$]$. Sklinsky [Sk 70]. Mlontanari [Mo T0]. and Zahn [Za 66] generally result in polygons with too many alges. whereas in most cases. it is desiralule to have approximating polygons which still retain the significant features with the least number of edges.

The parameter to the problem considered by Ramer ronsists of a given curve

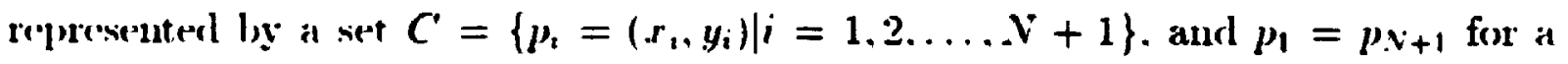
closed curve. The points $p_{2}$ can also bre interpreted as vertices of an open or closed polygon $P$ with $x$ edges. Let the approximated polygon be denoted by $\hat{P}$ with "1 reduced mumlser of $n$ edges. whose rertices $\hat{p}_{k}$ for $k=1,2 \ldots \ldots$ roincirle with vertices of $P$. The approximated polygon $\hat{P}$ then corresponds to an ordered set $\hat{C}$ of points such that $\dot{C} \subseteq C$. The set $\dot{C}$ of vertices $\hat{p}_{k}$ divides $C$ ' into ordered suldsets $S_{k}$ of the following form:

$$
S_{k}=\left\{p_{1} \cdot p_{i+1} \ldots p_{\jmath}\right\}
$$

where $p_{1}=\hat{p}_{k-1}$ and $p_{1}=\hat{p}_{k}$ and that $p_{1}, p_{t+1}$ are conserntive vertices in polygon $P$. $i=0,1 \ldots . . v^{*}$ and $\hat{p}_{k-1}, \hat{p}_{k}$ are consecutive vertices in $\mathfrak{i}$ olygon $\hat{P} . k=1.2 \ldots \ldots n$ 


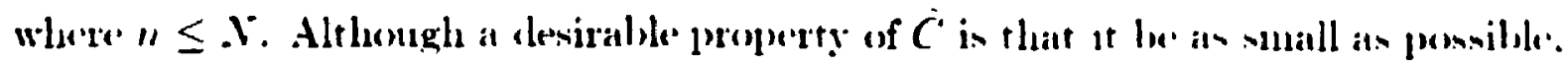

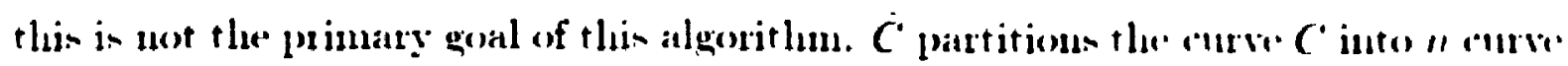

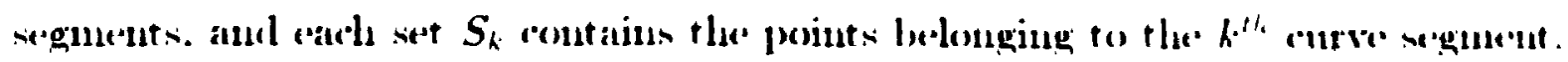
The following propertiess alwayn hold true for the snlosets $S_{k}$ :

$$
\begin{aligned}
& \bigcup_{h=1}^{\prime \prime} S_{k}=C^{\prime} \\
& \left(\cup_{k=1}^{\prime \prime-1}\left(S_{k} \cap S_{k+1}\right)\right) \cup\left\{p_{1}\right\} \cup\left\{p_{k}\right\}=\dot{C} \quad \text { (opreu polygon } \\
& \left.\left(\cup_{k=1}^{n-1}\left(S_{k} \cap S_{k+1}\right)\right) \cup\left(S_{n} \cap S_{1}\right)=\dot{C} \quad \text { (clowerl polygon }\right) .
\end{aligned}
$$

C.

D.

B' "F

$A^{\cdot}$

Figure 28: Ramer's curve approximation methorl.

The algorithm jresented by Ramer is very similar to the recursive binary split algorithm. However, unlike the binary split algorithm, the opu'n or closed state of a polygon must be explicitly sperifier. The algorthm starts with two empty setts: one of them is used as a temporary result, aud the other is the final result. $C$, (ant the termination of the algorithm). If the polygon is open. then the first perint is added to $\dot{C}$. and the last point is adeded to the temporary set. On the other haud.

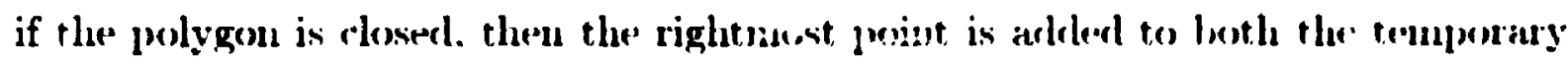
set and $\hat{C}$. and the leftmost point is arded ondy to the temporary set. The line segment joining the last vertices entererl in $C^{\prime}$ and the temporary set is the lineat 


\begin{tabular}{|cccc|}
\hline$C^{\prime}$ & Temporary set & Considered negment & Generated rertex \\
\hline \hline$A$ & B & (AB) & C \\
A & B.C & (AC) & D \\
A & B.C.D & (AD) & \\
A.D & B.C & (DC) & \\
A.D.C & B & (CB) & E \\
A.D.C & B.E & (CE) & \\
A.D.C.E & B & (EB) & F \\
A.D.C.E & B.F & (EF) & \\
A.D.C.E.F & B & (FB) & \\
A.D.C.E.F.B & & & - \\
\hline
\end{tabular}

Talble 1: Vertex generation secquence for the curve $A B$.

anproximation. If the maximum distance between the points of the curve is greater than the allowalde limit. then the proint with the largest distance is plared in the temporary set. If. however, the maximum distance is within the allowable limit. then the last point from the temporary set is moverl to $\hat{C}$. This iterative process is continued until the temporary set becomes empty. Table _ shows the steps taken by the approximation technique presenterl above for the arbitrary curve $A B$ shown in Figure 28.

Ramer's terluique is simple, yet it provides a good linear approximation of the given curre. There are a few problems with this algorithm. If the original curve contaius undesirable noise or spikes, this technique has a tendency + inclurle them as part of the approximation. Moreover, the number of approximating lines is not guaranteed to be minimal.

\section{Work done by Pavlidis \& Horowitz}

Parliclis and Horowitz [PH i4] present an algorithm which approximates a planrr curve ly straight line segments. The main goal of their algorithm is to describe boundaries of objects in a compart and meaningful way by filtering unwanted uorise. 
ret still retaining the major features of the objects. They consider the cane of where the planar curve is clescribed ly a set of discrete proint... $S=\left\{p_{t}=\left(x_{1}, y_{t}\right) \| i=\right.$

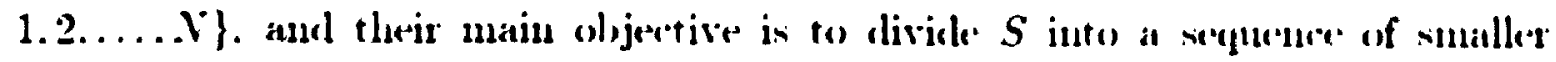

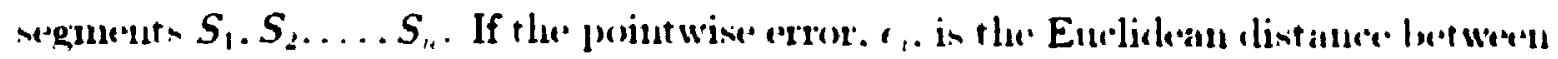

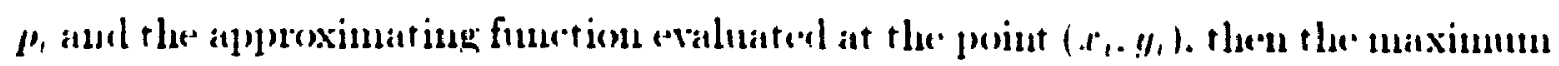
error norm for the segunent $S_{k}$ in cletineed an

$$
E_{V}=\underset{i a}{\max }\left\{f_{1}\right\}
$$

and the integral square error for that same segment is given as

$$
E_{2}=\frac{1}{2}\left\{I_{r x}+I_{y y}-\left[\left(I_{r x}-I_{y y}\right)^{2}+4 I_{s y}^{-2}\right]^{1 / 2}\right\}
$$

where $V_{k}$ is the number of points in $S_{k}$

$$
\begin{aligned}
& l_{r}=\frac{1}{V_{k}} \sum_{s_{a}} r_{t} \quad V_{y}=\frac{1}{V_{k}} \sum_{s_{h}} !_{t} \\
& V_{r s}=\sum_{s_{k}}\left(x_{1}-V_{x}\right)^{2} \quad V_{i y}=\sum_{s_{h}}\left(y_{1}-V_{i j}\right)^{2} \\
& V_{x u}=\sum_{\dot{r}_{i}}\left(r_{1}-V_{i}\right)\left(y_{1}-r_{y}\right) .
\end{aligned}
$$

Their technique is based on the following two propositions: '"

Proposition 1 Let $S_{1}$ and $S_{2}$ be two adjacent segmentss such that the masimum crror of approximation on each one of them does not exceed f. Furthermote. let the: approximation of each segment be represented by the polynomial of order m-1.

$$
\sum_{i=1}^{m} a_{i}^{1} \phi_{i}^{1}(x) \quad \text { and } \quad \sum_{i=1}^{m} a_{2}^{2} \sigma_{1}^{2}(x)
$$

Then the maximum error approximation on $S_{1} \cup S_{2}$,.s bounded from about by

$$
\epsilon+\phi L
$$

\footnotetext{
'Formal proofs for these propositions rall be found in [P'a 72] and [P/l i1]
} 
where

$$
n=\left[\sum_{i=1}^{m}\left(a_{1}^{1}-a_{1}^{2}\right)^{2}\right]^{\frac{1}{2}}
$$

u.n.

$$
L=\max \left[\sum_{i=1}^{m} a_{1}(t,)^{2}\right]^{\frac{1}{2}} \quad \text { for } t_{1} \in S_{1} \cup S_{2}
$$

For pieceruise: linear approximation. $L$ is bounded from above by the are: le:ugth of $S_{1} \cup S_{i}$

Proposition 2 Let $E_{2}^{\prime \prime}$ be the integral square error norm ouer $S_{1}$ and $S_{2}$. and let $\rightarrow$ and $L$ br: defined as in the propositon above. Then if $E_{2}^{u}$ denotes the error uorm. win: $S_{1} \cup S_{2}$ the following holds.

$$
E_{2}^{\prime \prime} \leq 2 E_{2}^{\prime)}+\lambda^{2} L^{2} \cdot M
$$

where $M$ is the number of points in $S_{1} \cup S_{2}$. For piece unise linear approsimations.

$$
E_{2}^{u} \leq 2 E_{2}^{0}+2 \delta^{2} L^{3}
$$

Let $S_{1}, S_{2}, \ldots S_{n_{1}}$ lee the segments at the $k^{\text {th }}$ iteration and $E^{1}, E^{2} \ldots \ldots E^{n d}$ bes the error uorms. " of the respective segments. The technique ronsiders two cases. In the first. it attempts to maintain the error norm in each segment to be less than or e(fual to maximum allowalble error. and so

$$
E^{\prime} \leq E^{m n x} \quad i=1.2 \ldots \|_{k} .
$$

In the second case. it is necessary to have the overall error norm of the segments less than or equal to $E^{\text {max }}$. If the selected error norm is the maximum error, then these two cases coincide since the maximum error, $E^{2}$, of each segment is also the crerall maximum error of the entire curve. If the selected error norm is the integral seluired error, then the crerall error norm is the stum of the error norms of all the seginents. that is

$$
\left(\sum_{1=1}^{u_{k}} E_{2}^{\prime}\right) \leq E^{m n x}
$$

\footnotetext{
"An error norm can be pither the mean squared error or the maximum error
} 
The split-and-merge algorithen for the tirst anse proceceds as follows. For wath

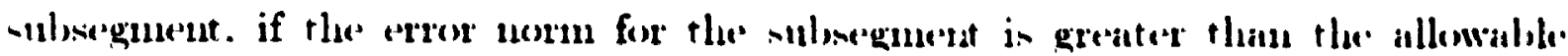
limit. then the subsegment in split into two pieces using the following anle: if iwo or more points are known where the point wise error is maximum. use the midperint loetween a pair of them ats a dividing point: otherwist. divide it into two aptal

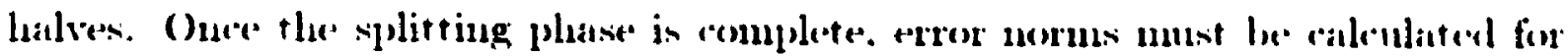

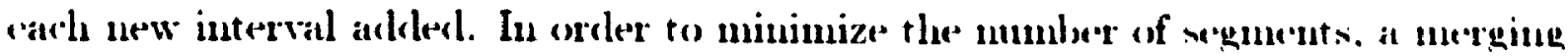
phase is introduced. which performs the opposite operation of the splitriug phatse. It reecombines two adjacent subsegments into one if the error norm of the new

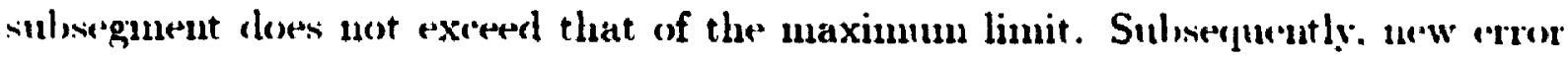
norms must be calculated for all newly formed segments. The entire process in repeated until no more splits or merges can orcur.

The algorithm for the second casse is based on the first algorithm. If the overall error uorm is greater than the allowable limit, the segment with the largest error norm must be split using the same rule as in the first algorithm. Otherwine. a search is performed to find a pair of adjacent segments whose merge will "anse the. smallest increase in the overall error norm and still keep the error norm below the allowable limit. The algorithm is repeated until no further changes oecur.

\section{Work done by Kurozumi \& Davis}

Fure. mi and Davis [KD 82] approach the approximation of the planar "urve problem using a different method of estimating the error between the given curve ind the approximated line segments. They indicate that most of the torhuiques using the least sqquares estimation may miss some of the details of the diut in stuch as in "spikı". or a stedden change of short cluration. Their polygonal apporoximation algorithm uses, the minimax method which olstains a set of line segments which minimize the meximum of the Euclidean distances between the liness and the given points.

A minimax approximaterl line for thee points can be obtained as follows c ane 


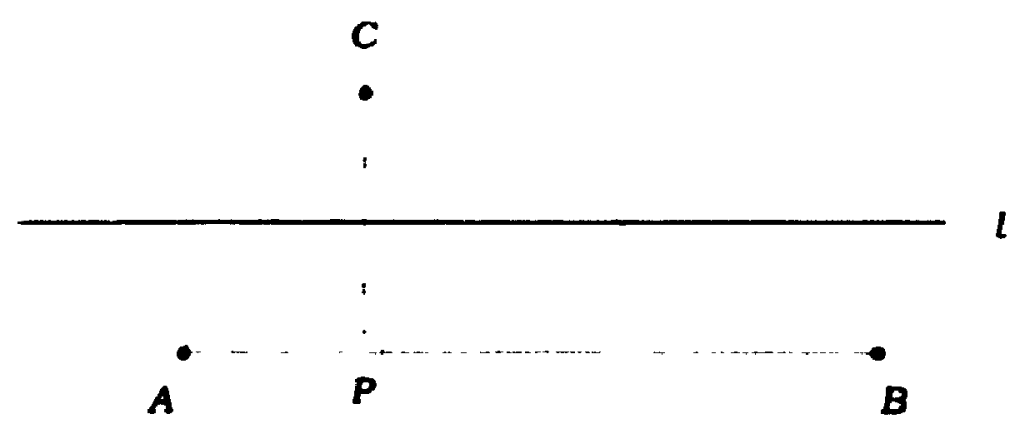

Figure 29: Minimax approximated line for three points.

Figure 29). The line perpendicular to the longest sicle of the triangle passing through the oppesite vertex is calculated. In this particular case. the lomgest side is $\overline{A B}$. auri the perpendienlar line segment is $\overline{C P}$. As shown in the diagram. it is not necessary that the point of intersection $P$ lies on the line segment $\overline{A B}$. The line which bisects the line $\overline{C P}$ and is parallel to the lougest sick $\overline{A B}$ of the triangle is the minimax line of the triangle $\triangle A B C$.

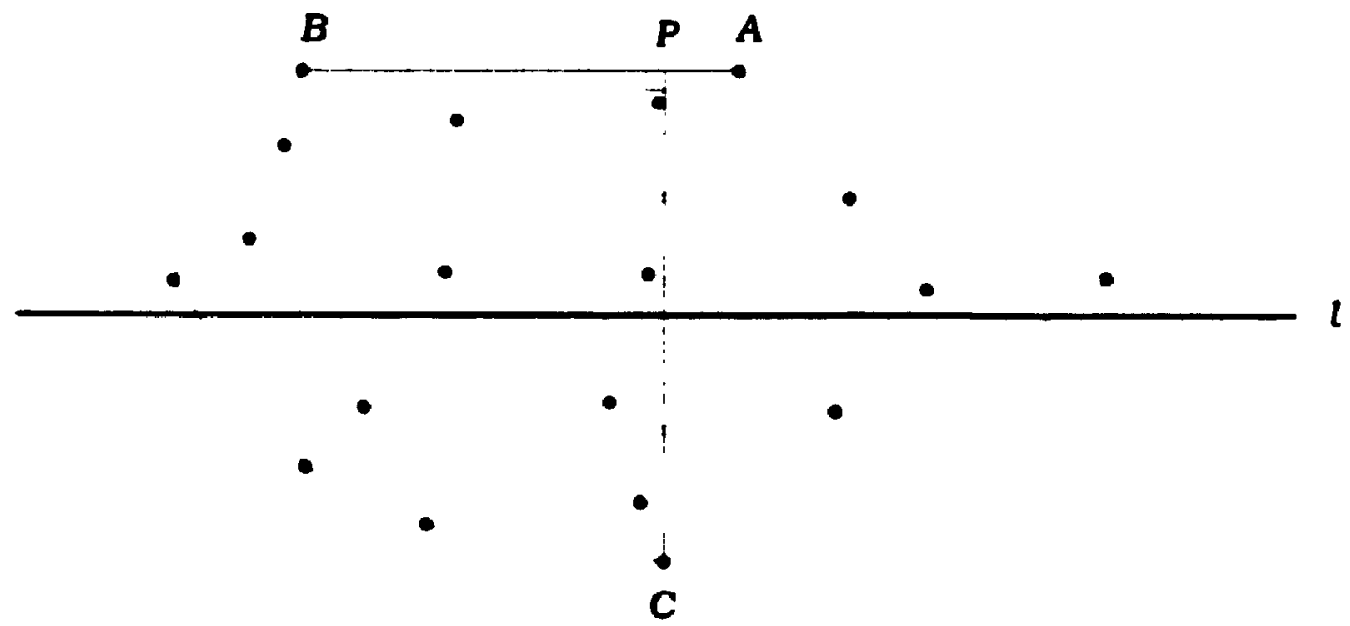

Figure 30: Minimax approximated line for a convex polvgon.

To tiur? a minimax approximated line through a set of $k$ points remands more work than the case of a simple triangle. From the set of $k$ points, an m-sicled convex 
polygon cont aining the $k$ points is ascertained. where $m \leq k$. For an 11 -sidecl cousex

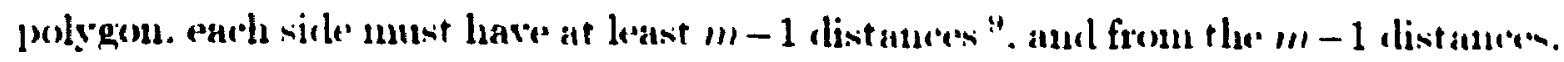
a maximum distance is selected. Therefore, an m-sided rourex polygom contains

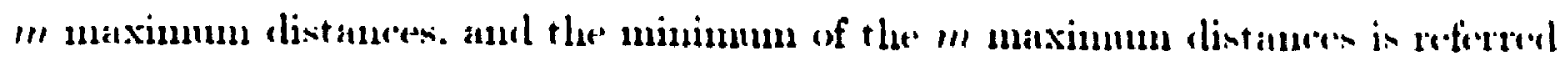
to as the minimax clistance. The minimax approximated line thengh the al-sided rouvex polygon biserts the minimax distance and is perpendienlan to the minimix distance as hlown in Figure 30.

The approximation algorithm presented lye Kinrozumi and Davis is batiod on the minimax line princi, le described above. The given curve is secquentially scaumed. and the parameters of the line $(k$ passing through the tirst two points of sulwegment $S_{k}$ are calculated. As each new point. $p_{\jmath}$, is added to the sulssegment $S_{k}$. it is determined if the point $p$, is within the allowable error limit, $f$, from the line $/ \mathrm{k}$. If it is, then the process is continued with the point $p_{d+1}$ on the curve; otherwise, at minimax approximated line is calculated for the points in $S_{k} \cup \mu$, If the maximum clistance from all the points in $S_{k} \cup p$, to the minimax line is within $f$. then the minimax line becomes the line $l_{k}$ of subsegument $S_{k}$. and the point $p$, is aclded to the sulsegment $S_{k}$. On the other hand. if the distance from one or more points in $S_{k} \cup p$, to the minimax line is greater than $\epsilon$, then a ne'w subsegment $S_{k+1}$ in formerl with points $p_{j}$ and $p_{j+1}$, and a new line $f_{k+1}$ is calculated. It can be safely assumed that if $S_{k}$ contains $i$ points where $i \geq 2$. all $i$ points in $S_{k}$ are within of the minimax approximated line segment.

Kurozumi and Davis also include several optimizations in their algorithm to speed up the minimax distance calculations. Lising the assimption that the poimts are sequentially ordered, the sorting step required to determine a convex peolygons can be entirely omitted. Furthermore, in order to minimize the number of line segments. an ailowable gap is userl. Althongh, two minis: ax lines are allowerl to

\footnotetext{
"In this particular case. distance is defined to be the length of the perpendicular line segunent frotn a vertex 10 an edge.
} 


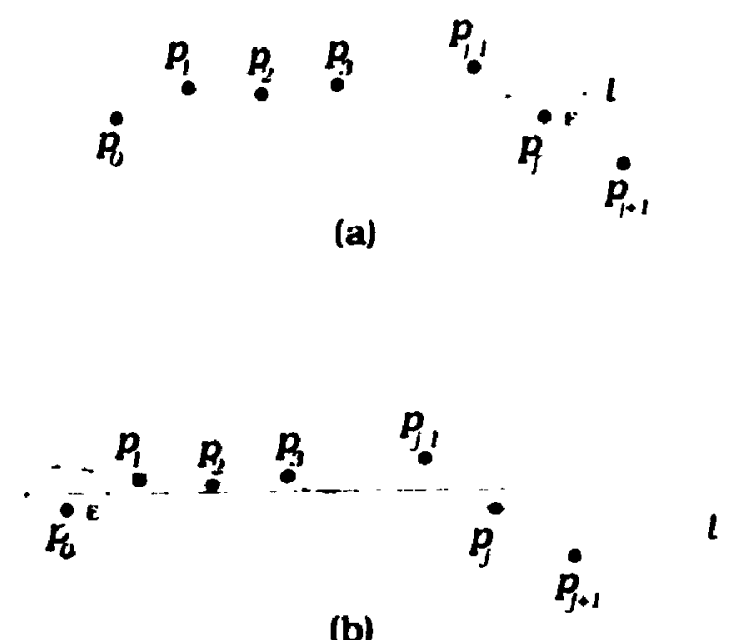

Figure 31: (a) Minimax approximated line for ij points. (b) Minimax approximated liur for $j+1$ prints.

intersect at some point not on the curre. the point of intersection must be within a gat) that is contained in a circle cented by one of the points on the curve with radlus $f$ (see Figure 31 ).

\section{Work done by Dunham}

Dunham ': [D11 86] approach to the approximation of two-rlimensional rigital rurves is based on Bellman's work. However, there several major differences between his work and that of Bellman's. First of all. Bellman uses the mean square error norm whereas Dunham uses the uniform error norm. Secondly. wheress Bellman considers a discontinuons solution. Dunham s approximations are continuous. Finally. Bellman fixes the mumber of line segments and minimizes the error while Dumham fixes the error and minimizes the number of segments. The knots of the piecewise linese approximation are constrained to lie on the original cligital eurve. Dunham antegorizes his method as an optimal solution based on the criterion that his polygonal approximation contains the least number of edges and yet still satisfies the muiform error restrietion.

A discrefte planar course. $C_{A}$, is defined as a set of points parameterized by $0 \leq$ 
$y$-axis

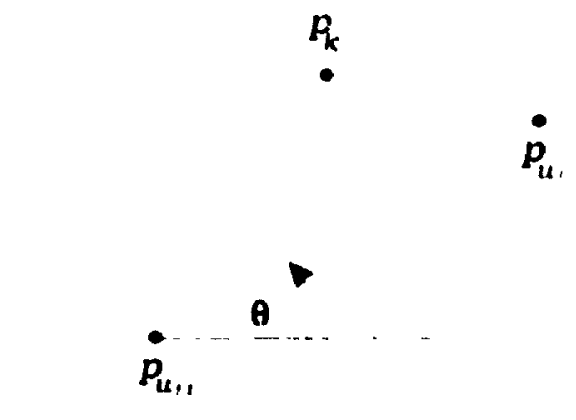

0 $y$-axis

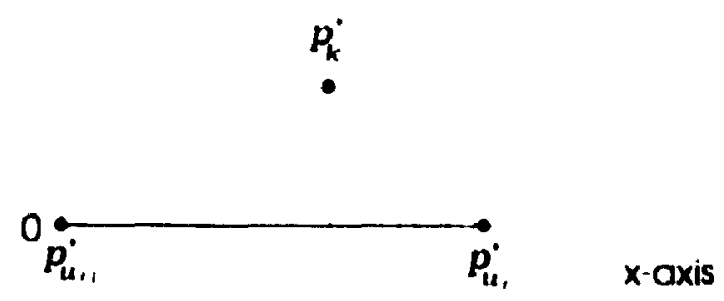

Figure 32: Computing the approximation error uning tle translated and got at vitues.

$i \leq i$

$$
C_{d}=\left\{p_{t}=\left(x_{1}, y_{1}\right) \mid 0 \leq i \leq N\right\}
$$

Its piecewise linese approximation. $C_{n}$, is a subset of the original points. ind is defined as

$$
C_{1}^{\prime}=\left\{p_{u_{0}} \cdot p_{u_{1}} \ldots \ldots p_{u_{n}} \mid 0=u_{11}<u_{1}<u_{2}<\cdots<u_{n}=. V\right\}
$$

Thus, the $j^{\text {th }}$ interval of $C_{n}$ cousists of the straight line segenent which remuerts the pesints $p_{u,-1}$ and $p_{u}$. and is denoted us $\overline{p_{u,-1} \cdot p_{u,}}$. The pointwise error luetwent! " point $p_{k}$ on the curve $C_{l}^{\prime}$ and the line segment $\overline{p_{u_{1}-1} \cdot p_{u}}$ where $n_{1-1}=k \cdot n$, is

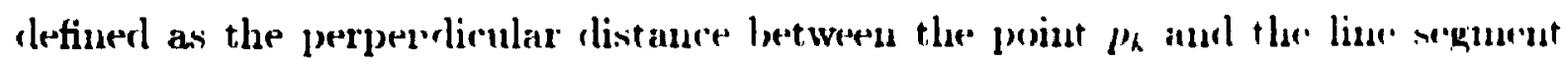

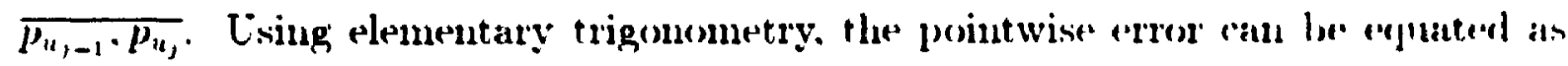
follows.

$$
\left(\left(u_{j}, 1, u_{,}, k\right)= \begin{cases}\sqrt{\left(x_{k}-x_{u,-1}\right)^{2}+\left(y_{k}-y_{u,-1}\right)^{2}} & \text { if } x_{k}^{\prime}-0 \\ \sqrt{\left(x_{k}-r_{u,}\right)^{2}+\left(y_{k}-y_{u,}\right)^{2}} & \text { if } x_{k}^{\prime}-x_{u,}^{\prime} \\ \left|y_{k}^{\prime}\right| & \text { oflurerwise }\end{cases}\right.
$$


where.

$$
\begin{aligned}
& r_{k}^{\prime}=\left(r_{k}-r_{u_{1-1}}\right) \cos \theta+\left(y_{k}-y_{u_{1-1}}\right) \sin \theta \\
& y_{h}^{\prime}=-\left(r_{k}-r_{u_{1}-1}\right) \sin \theta+\left(1 / h-y_{u_{-}-1}\right) \cos \theta
\end{aligned}
$$

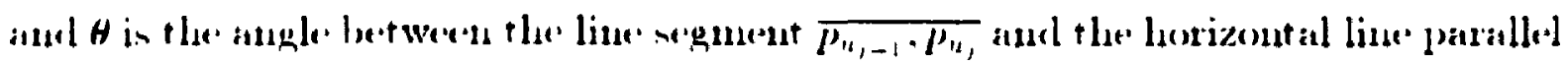

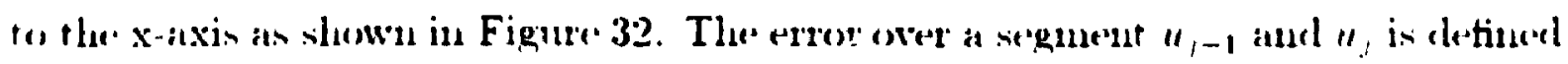
as

$$
\left(\left(u_{j},-1 \cdot u_{\jmath}\right)=\max _{u_{,-1} \leq k \leq u,}\left(u_{,-1} \cdot u_{1}, k\right)\right.
$$

and similarly: the error between $C_{,}$and $C_{n}$ is

$$
\left(\left(C_{1}, C_{11}\right)=\max _{1 \leq 1 \leq n} \cdot\left(11,-1 \cdot u_{1}\right)\right.
$$

For a given index $"$. if $V(u)$ is defined as the set of all the points with $" \leq$ " where $((1, u) \leq f$. and $F(u)$ is detined as the minimal number of segments neerled to approximate the curve $C_{1}$ from points $p_{0}$ to $p_{u}$ within 6 . then $F(u)$ satistics

$$
F(u)=\min _{n \in l(u)} 1+F(v)
$$

with the initial conditions

$$
F(0)=0 \quad \text { and } \quad F(1)=1 .
$$

Since $" \geq 2$. there is one line segment $\overline{p_{r} \cdot p_{u}}$ plus a minimal number of possible segments from 0 to $c . F(u)$ can, therefore, be recursively computed using dynamic programming with the given initial conditions and $F(. N)$ will be the ninimal number of segments needed for $C_{n}$ to approximate $C_{f}$ within $f$. As the value of $F(u)$ is calculaterl. one of the $" \in V^{\prime}(u)$ which satisties the minimum in $(10)$ is storecl. From $F(. N)=F\left(u_{n}\right)$ the value of $u_{n-1}$ can be derived. from $F\left(u_{n-1}\right)$. $u_{n-2}$ wan be derived and so forth. Thus, an optimal continuons piecewise linear planar curve that anproximates $C_{d}$ with tixed endpoints $u_{0}$ and ${ }_{n}$ within $\epsilon$ is generaterl. 


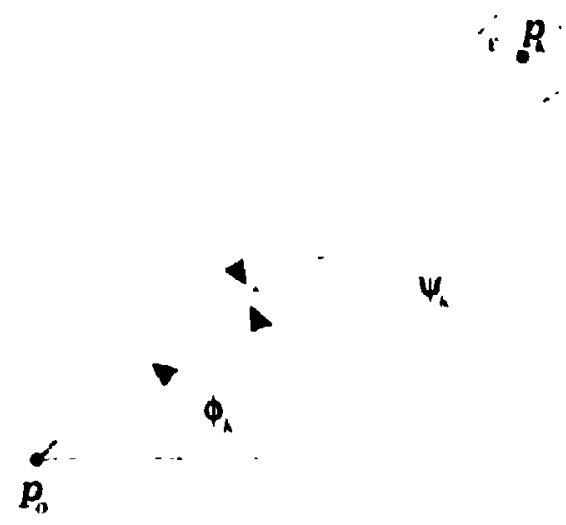

Figure 33: Liness and angles from $p_{41}$ to $p$ h.

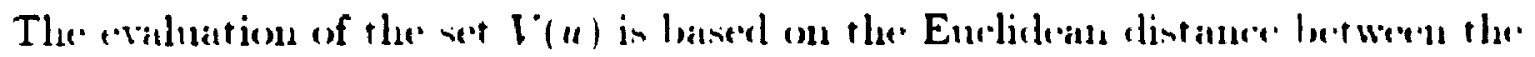

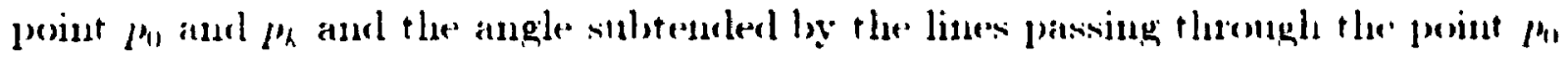
tangent to the circle centred at point $p_{k}$. with the radins 6 as shown in Figure 33. If

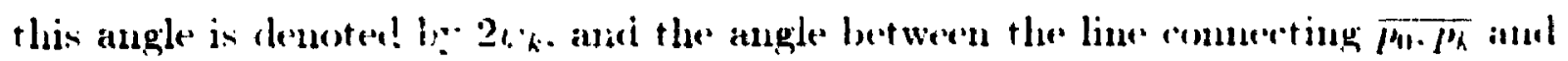

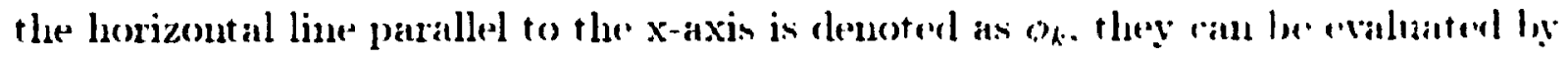

$$
\begin{gathered}
a_{k}=\arctan \left(\frac{y_{k}-y_{0}}{x_{k}-x_{10}}\right) \cdot \text { andl. } \\
\therefore k=\arcsin \left(\frac{\epsilon}{\sqrt{\left(x_{k}-x_{0}\right)^{2}+\left(y_{k}-y_{0}\right)^{2}}}\right) .
\end{gathered}
$$

The set $S_{1}$. for example. represents all the lines through po which passes within distance $f$ of $p_{1}$. Similarly. $S_{2} . S_{3} \ldots \ldots S_{k}$ represente all the lines thromeh an which

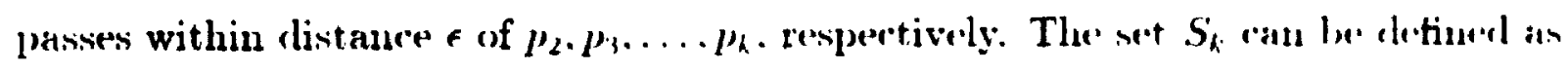

$$
S_{k}=\left\{\theta \mid O_{k}-1 \% \leq \theta \leq 0 k+1 \%\right\}
$$

The intersection of these sets. $T_{h}=S_{1} \cap S_{2} \cap \ldots . \cap S_{k}$ repressents all the lines throngh $p_{0}$ which pass within clistance of all the points from $p_{1} \ldots$... p p . If $T_{h}$ is canpty. then

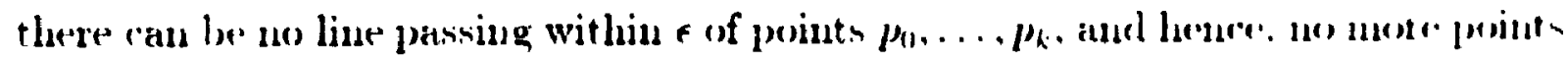

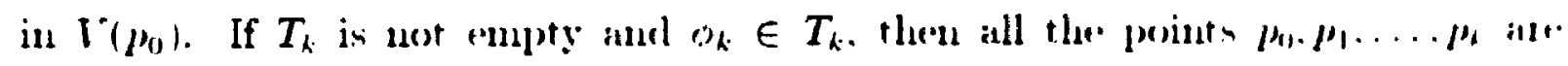



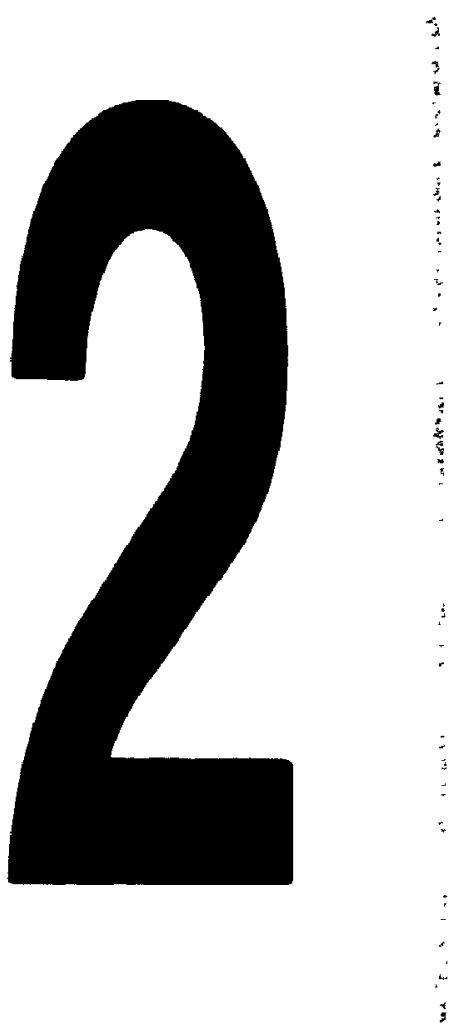

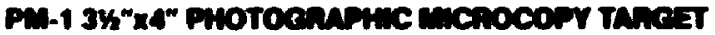

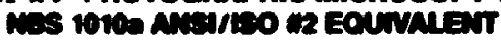

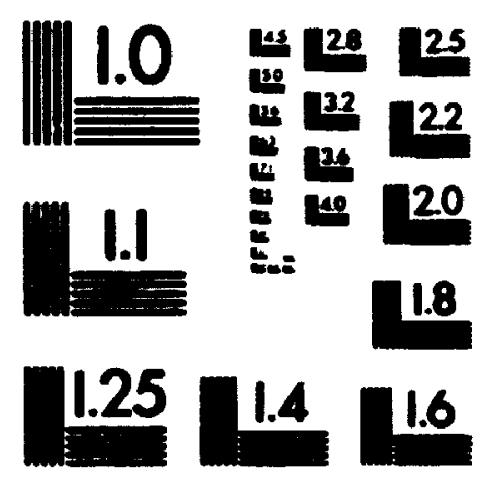

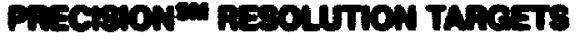




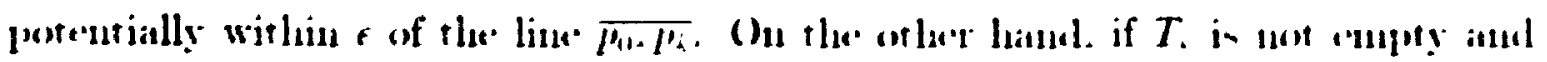

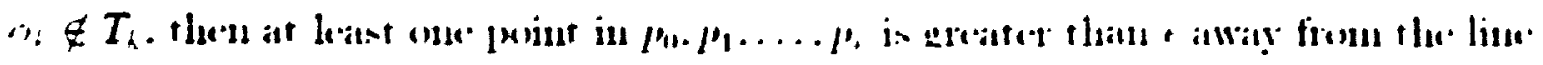

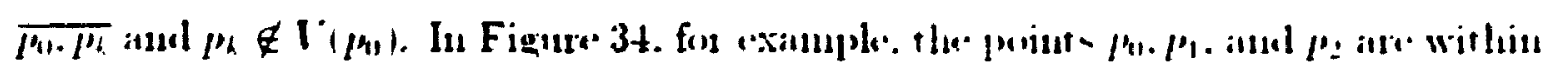

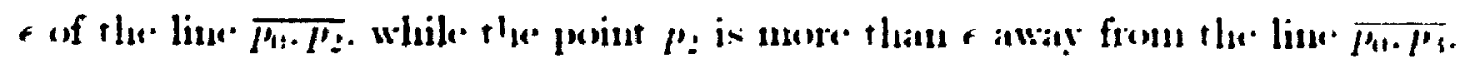

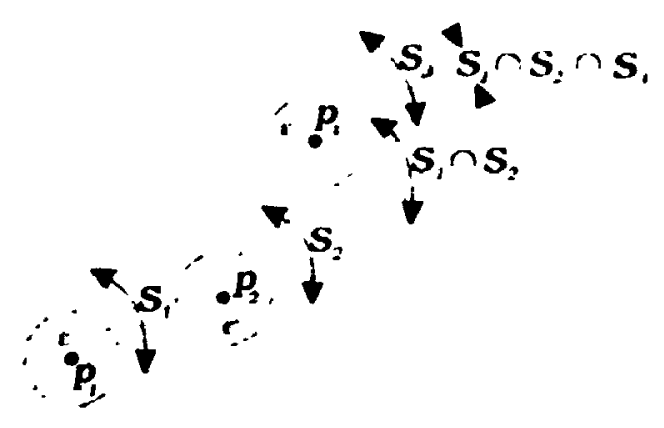

Figure 34: Sran-along procedure from $p_{11}$ to $p_{1}$.

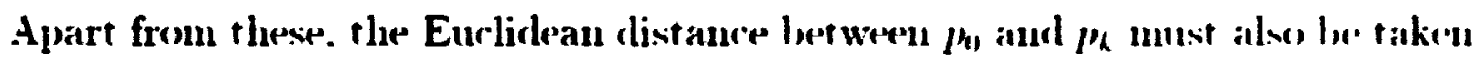
into consideration. It is clefined as

$$
d_{k}=\sqrt{\left(x_{k}-x_{11}\right)^{2}+\left(y_{k}-y_{10}\right)^{2}}
$$

and the maximum distance is

$$
d_{\max . k}=\max _{1 \leq j \leq k} d_{,} .
$$

If $d_{k+1} \geq d_{\text {max.k. }}$. then the $r^{\prime}$, coordinate of the translated and rotated point given ly (8) and (9) will lie between 0 and $r_{k+1}^{\prime}$ for $0 \leq j \leq k$. Therrefore. all the points $p_{n} \cdot p_{1} \ldots \ldots p_{k}$ are within $f$ of the line $\overline{p_{n} \cdot p_{k+1}}$ and $s o p_{k+1} \in V_{m 1}$. Howevere if

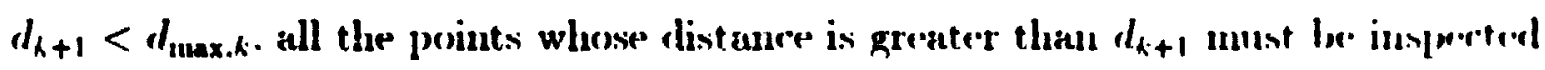
to see if they are within $f$ of the line $\overline{k_{k} \cdot p_{k+1}}$. If they are. then $p_{k+1} \in \mid\left(p_{n}\right)$. otherwise. $p_{k+1} \notin P^{\circ}\left(p_{0}\right)$. 
Althongh Dinuhan offers a method of approximating a planar arve with the

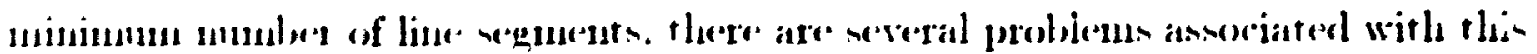

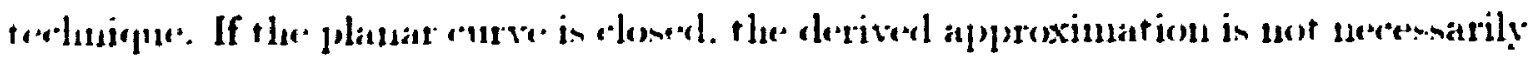

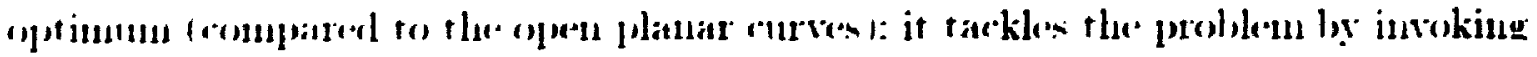
is contly axhatustive nearch uning the open planat curte algorithun. Furthermone. in

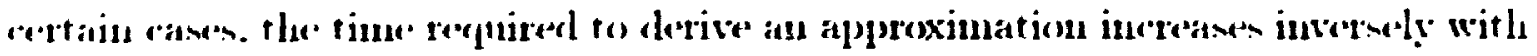
tlı" maximun "rtor limit.

\section{Work done by Lowe}

Lowe $\left[L_{0}, 85\right]$ introduces a piecewise linear approximation terhnique which uses the tatio of the length of the line segment and the maximum deviation of any point from the line. The algorithm in bared on the assimption that a digitized curve is derived from a bitmap. and as such. the maximum deviation is alway's at least two pixels in size to acrount for limitations on measurement arcurary. This error estination. thus. provides a scale-independent measure of significance which places Io prior cxpertations on the allowal le cleviations.

A curre segment is recursively subdivided at the point of maximum deviation from a line connectiug its eudpoints as shown in Figure 35. The process i. repeated mutil each segment is no more than 4 pixels in length. producing a binary trese of pessible divisions. (On unwinding the recursion bark up the tree, a decision is marle it arch junction to determine if the lower-level descriptions can be replaced ly the single higher-level segmeni. The significance of every subsegment is calculated by its length-to-deviation ratio as mentioned above. If the maximum signitivance of iny of the subsegments is greater than the significance of the complete segment. then the subsegments are returned: otherwise, the single segment is returned. By conratenating the ret urned sulsegments together, a pierewise linear approximation is folliadl.

This algorithm is similar to the hinary split algorithm and to thet of Romer's. 
(a)
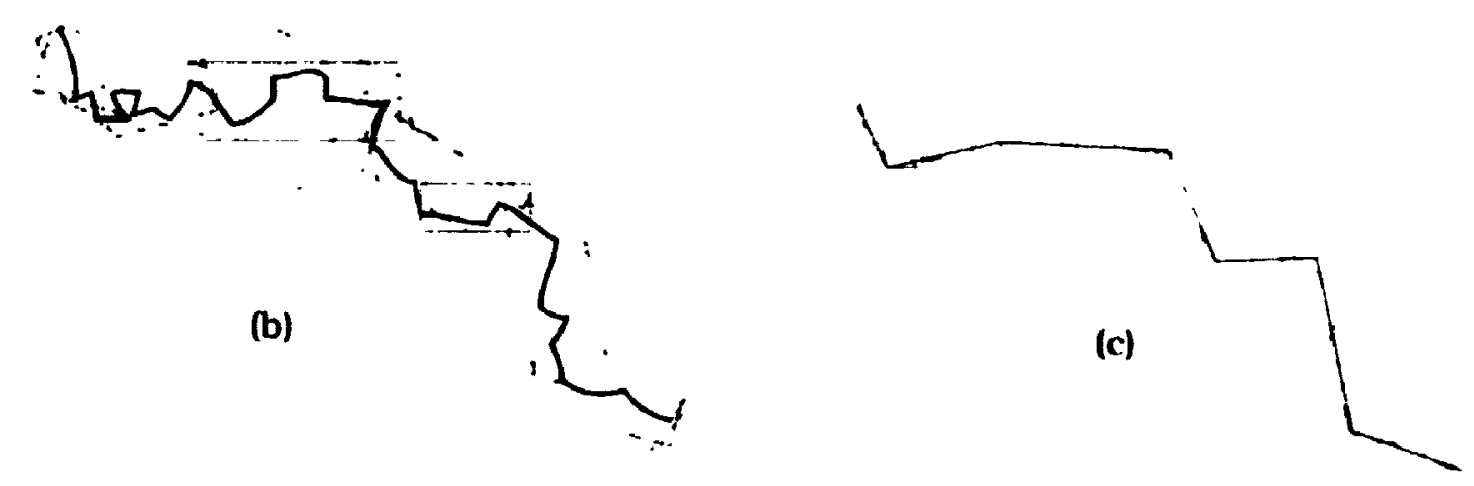

Figure 35: Steps taken be algor:thm for subdividing a curve into its mont perrerpthally signifioant straight line segments.

and it does a teasonable job of deterting the perceptually most signitionut st raight line groupings of the original data points. Whereas other traditional metloods require sefting of a prior thereshold for the amoust of "urise" to be removerl from it curve. this estimation terhnique does not require such a threshold value. It tourls to find the same structures regardless of the size at which an olject apprears in an image, and it avoids breakiug up long lines if shorter coustituents do not pomsens stronger perceptual elements. The major shortcoming of Lowe's ratio of length-todeviation is that if the deviation is zero, it cansess of division-ly-nero crror. Reonin and West [RW 89] [RW 91] have generalized Lowe s terhuigne lyy iuverting the matio to avoirl this problem. 


\subsubsection{Transformed Domain Approximation}

\section{Work done by Granlund}

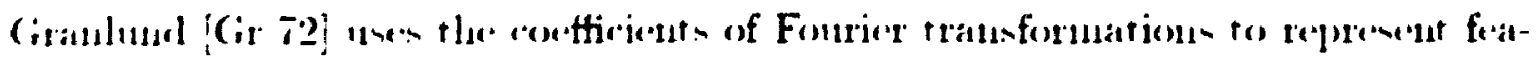

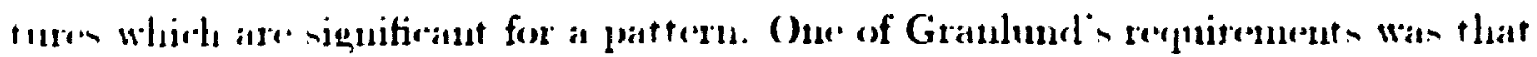

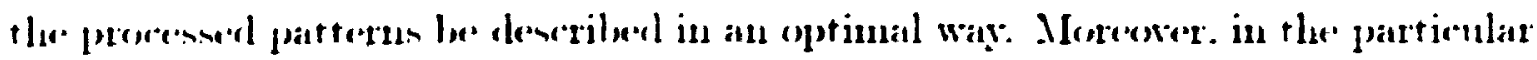
ane of chatacter rerognition. his aim was to determine featnues whirh are invariant for different types of style. size. and slant of tharacter.

$\mathrm{im}$.

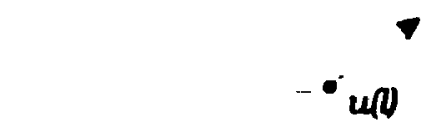

Figure 36: Example of contour function.

A given curve ;. assimed to be closed. is rlefined by a sequence of points $Z(l)=$ $(f(l), y(l))$ where $l$ is the are length along $\gamma$. A point moving along this curve generates the complex function $u(l)=x(l)+j y(l)$ which is periodic with a period $L$ an shown in Figure 36. The Fourier descriptors of q using the complex function "Il) is detiund in

$$
u_{k}=\frac{1}{L} \int_{0}^{L} u(l) f^{-.(2 \pi / L): 1} d l .
$$

In the case where the curve is polygonal as outlined in Figure 37 , the eraluation of 
the dencriptors $a_{h}$ 'an be simplified [PF $i_{1}^{-1}$ to bu:

$$
u_{c}=\frac{1}{L\left(\frac{i-1}{T}\right)^{2}} \sum_{i=1}^{m}\left(b_{i}-1-b_{i} n^{\prime}-12-111 \mathrm{n},\right.
$$

"Where.

$$
\left.l_{1}=\sum_{r=1}^{1}\left|I_{i}-I_{-1}\right| \quad \text { for } k \cdot 0\right) \text { ind } l_{11}-0
$$

and1

$$
\begin{aligned}
& b_{t}=\frac{I_{i+1}-I_{i}}{\left|I_{i+1}-I_{i}\right|} . \quad \text {-nch thait }\left|b_{i}\right|=1 . \\
& V_{n 1}=V_{0} \\
& V_{m 1} \text { - } V_{1}=V_{n+1} \\
& V_{0} \\
& \text { - } v_{n+2} \\
& \text { - } V_{3}
\end{aligned}
$$

Figure 37: A polygonal bormelary:

The original function. " $(l)$. can be reconstructed from the sort of descriptors al. using the following equation

$$
u(l)=\sum_{-r}^{\infty} a_{k \cdot c^{\prime}}(2+/ L) k l .
$$

Some of the advantages of using this representation are that all serpuencen $\left\{u_{k}\right\}$ for which the series in (11) converges describe closed curves, and the inverse transform

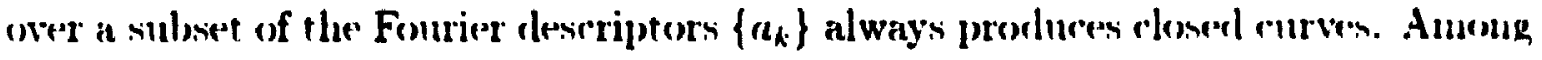

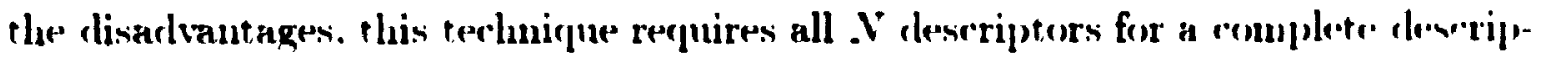
tion beranse a(l) is a function of complex values. Since the leugth in anel an the 


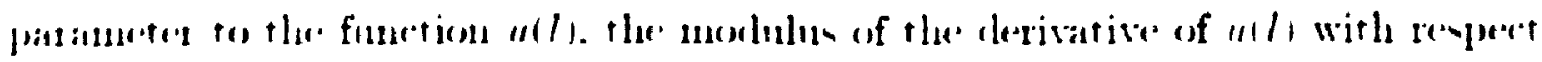

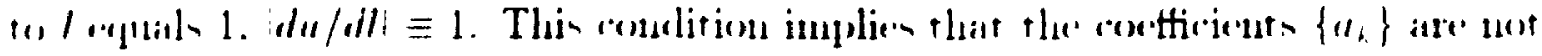

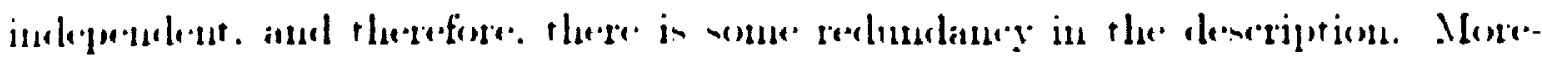

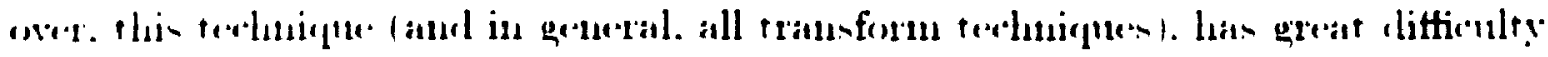
dencribing lomal information [Pa $T s]$.

\section{Work done by Zahn \& Roskies}

The problem of extracting a tinite net of numerioal features from at aseci platuat

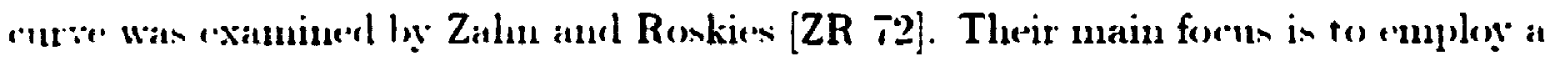

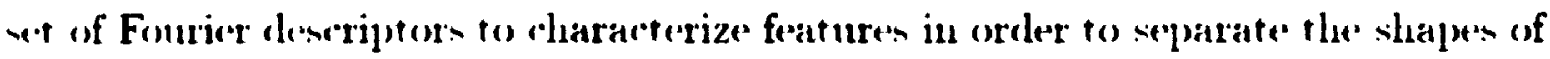
ditferent rlasses relative to the intraclass dispersion. The idea of using the Fonriet clescriptors was tirst suggested by Cosgriff [C'o 60]. and his work was som followed lỵ others iuchuling Borel [Bo 6J]. and Brill [Br 68]. A starting position on the rurve is rhosen. and a funetion $\theta(l)$ is clefined. $\theta(l)$ measures the angular direction of the curve as a function of the are length. After appropriate normalization. this perionlie function is expanded in a Fourier series and the coefficient of a trumegted expansion are used as shajee fatures called Fourier descriptors. The idea presented hy Zahu and Roskies is hased on previous work done by Cosgriff and others, which differ in that they use a different normalizing function than the ones used previously:

Let ; represent a clockwise-oriented simple closed curve with parametric reprerentation $Z(l)=(r(l) . y(l))$ where $l$ is the arr length and $0 \leq l \leq L$. Furthermore. lot the function $\theta(l)$ denote the angular direstion of $;$ at point $l$. and $\phi_{0}=\theta(0)$ be the absolute angular direction at the starting point $Z(0)$. The cumulative angular function $o(l)$ is defined as the net anome of angular bend between the starting point and the point $l$ as slown in Figure 38. By this definition. $o(0)=0$ and $o(l)+\phi_{1}$ is ielentioal to the $\theta(l)$ except for a possible multiple of $2 \pi$. It rau be seru that for all suooth elosed curves with chockwise orientation that $o(L)=-2 \pi$

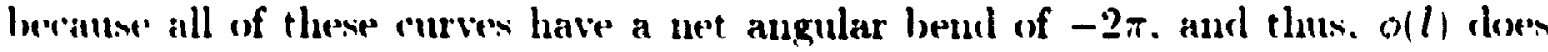


$y$-axis

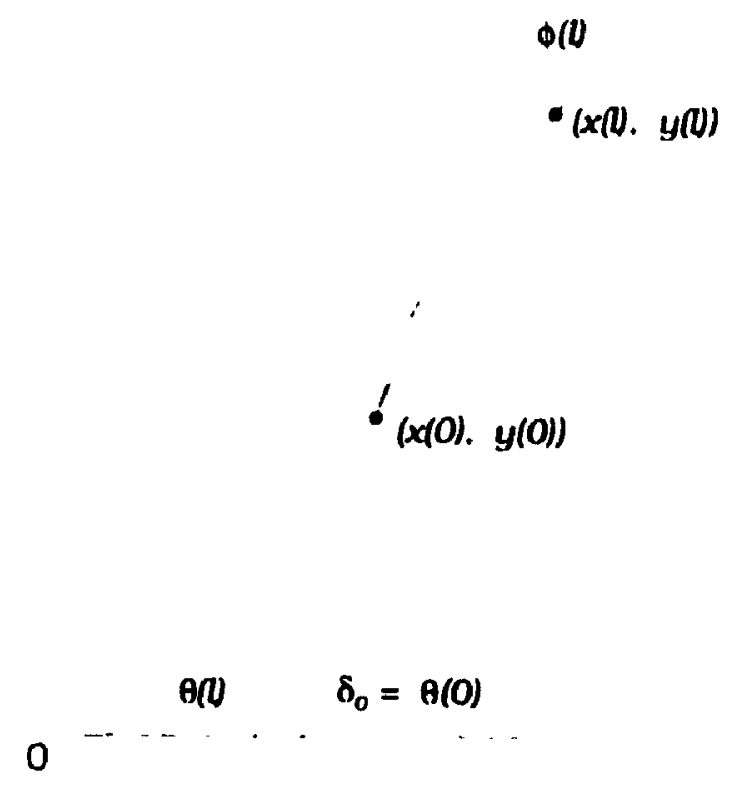

- $(x(N) . y(0)$

$x$-axis

Figure 38: Parametrie representation of a planar rourve with tangential direction $\theta(l)$ and rumulative angular band function oll).

not convey any shape information. The domain of $o(l),[0, L]$. routaius almolute size information. and it is normalized ton an interval of a typoral puriodie function of $[0.2 \pi]$. Hence. a normalized variant $0^{*}(t)$ whose clomain is $[0.2 \pi]$ is rlofinere as

$$
\because(t)=\theta\left(\frac{L t}{2 \pi}\right)+t
$$

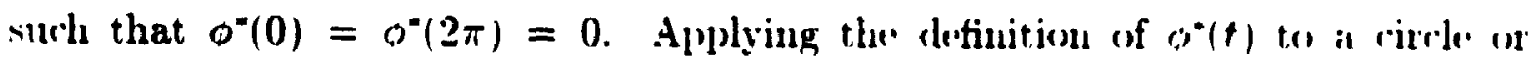

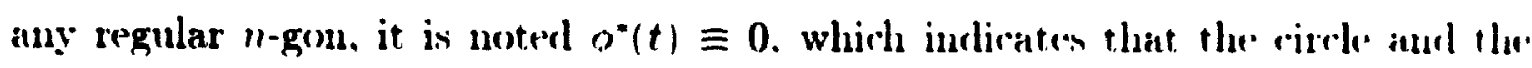
regular $11-\mathrm{gons}$ are the most shapeless closed rurve. Another interesting forture of the function os $\sigma^{*}(t)$ is that it is invariant under translation. ootation. aud changen in parameter $L$. Therefore. two planar enures have ielentichl shape if they ditfer omly bỵ н combination of translation. rotution. and a change in size. 


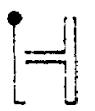

(a)

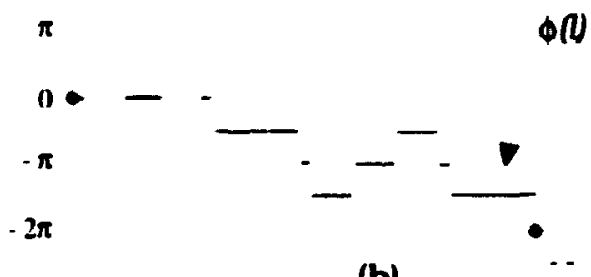

(b)

$\phi^{*}(4$

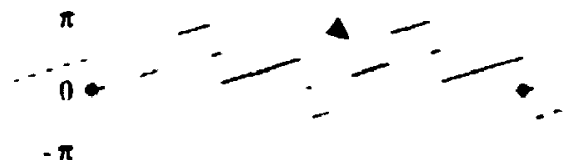

(c)

Figure 39: (a) Planar chosed curve with starting point from boumelary of character "H". (b) Cumulative angular bend function o(l) for curve in (a). (a) Normalized rumulative angular bend function $o^{*}(t)$ for the curve in (a).

The function $o^{*}(t)$ can be expanded into a Fourier series as

$$
\begin{gathered}
\phi^{*}(t)=\mu_{0}+\sum_{k=0}^{x}\left(a_{k} \cos k t+b_{k} \sin k t\right) \\
\phi^{*}(t)=\mu_{0}+\sum_{k=0}^{\infty} A_{k} \cos \left(k t-\alpha_{k}\right)
\end{gathered}
$$

where $\left(A_{k}, \alpha_{k}\right)$ are the polar coordinates of $\left(a_{k}, b_{k}\right)$. The numbers $A_{k}$ and $a_{k}$ are considered as the Fourier descriptors for the rurve $q$ and are known as the $k^{\text {th }}$ harmonic amplitude and phase angle, respectively.

(ne of the major advantages of using this representation is that there is uo redumdant information present in the set of Fourier descriptors $\left\{A_{k}, \alpha_{k}\right\}$ rompared to the representation provided by Granlund [Gr i2]. Therefore, every sequence $\left\{. f_{k}, n_{k}, k=1,2 \ldots\right\}$ describes one curve, and each curve has only one serpuence 


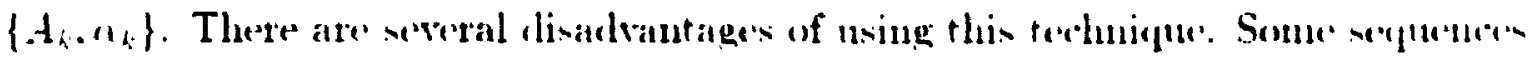

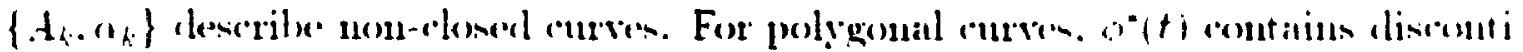

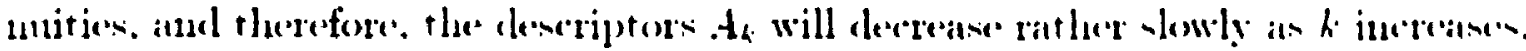

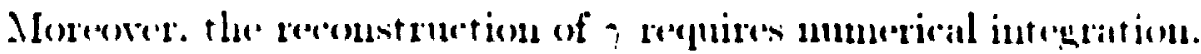

\subsection{Digitized Image Approximations}

An image is often detined as a two-dimensional light intensity fun: ion $/(. r, !)$ where of and $y$ represent the spacial coordinates. A corresponding ligitized inage $f(1, f)$

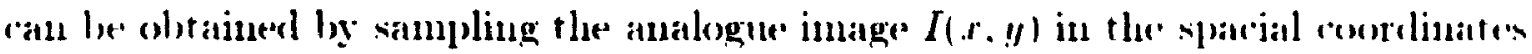
and quantizing the brightuess. Thus. a digitized image $f(x, y)$ an be detined an

$$
f(i . k)=\hat{I}\left(x_{0}+i \Delta x_{0} y_{0}+k \cdot y_{y}\right) \quad \text { for } i . k=0.1 .2 \ldots \ldots
$$

where $I$ is the quantized brightness of the analogue image $I$. and $\Delta_{\text {r }}$ and $د_{y}$ arre the sampling intervals along the $x$ - and $y$-axes, respectively: A digitized intege is considered an an $N$ by.$V$ matrix whose elements are the cluantized lorightuens values at that point. Each element of an image is referred to as an image clement. picture: element. pirel. or pel.

\subsubsection{Time/Spacial Domain Techniques}

An image of sict $512 \times 512$ with 8 bits per pixel (256 possible greyscale values) requires 256 hilobytes of memory storage. If an image of such size is transmitterl one scanline at a time. the amount of time reguired for the entire transmission makes it too slow for most interartive applications. The one-dimensional approx. imation technique presented in Chapter 2. which can be extended and applied to two-dimensional images, is the subsampling terhnique. Two variations of the sulp. sampling schemes known as progressive transmission technieques will be presented in this sections. 


\section{Work done by Tanimoto}

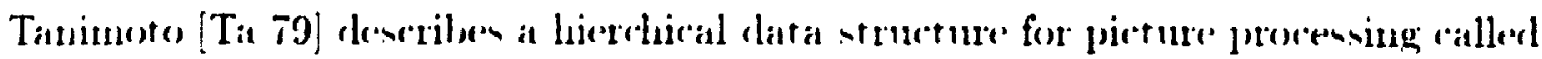

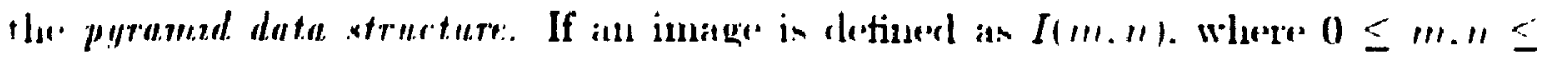

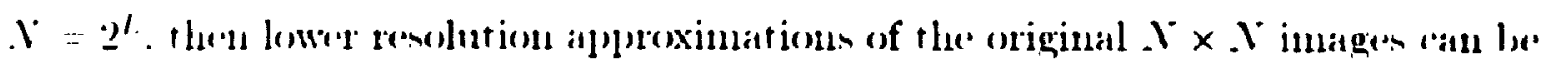
letimed in

$$
I_{k-1}(i . j)=\frac{1}{4}\left[I_{k}(2 i .2 j)+I_{k}(2 i+1.2 j)+I_{k}(2 i+1.2 j+1)+I_{k}(2 i \cdot 2 j+1)\right]
$$

whre $0 \leq k \leq L$ and $0 \leq i, j \leq 2^{k-1}$ as shown in Figure 40.

\section{Level 0}

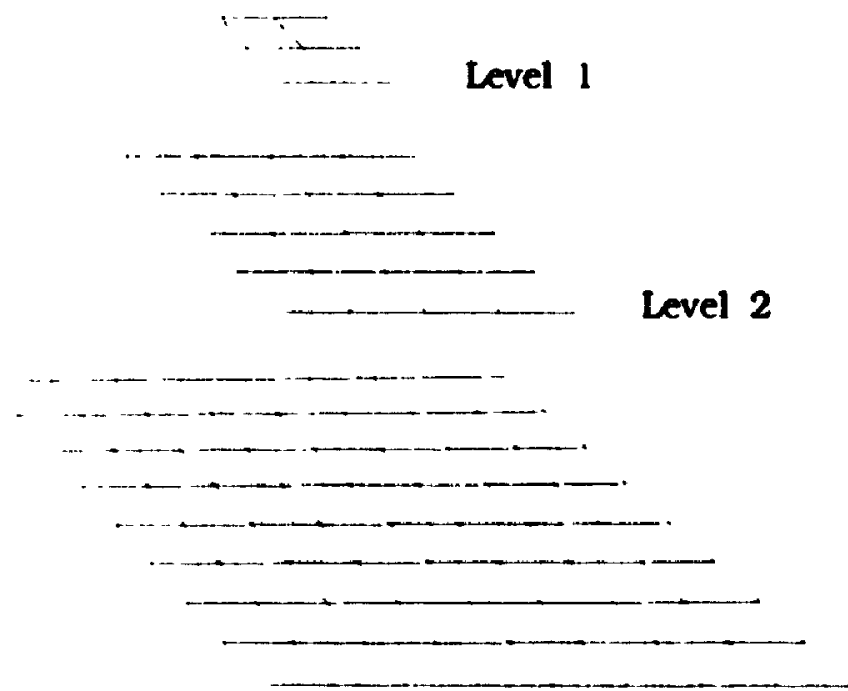

Level 3

Figure 40: Pyramid rlata strurture for four levels 0.1,2. and 3.

A sequence of reduced resolution images from the original is formed by averaging $2 \times 2$ blocks of pixels. There are $L+1$ "levels" of the pyramirl. the most rerluerel of which is a $1 \times 1$ image (a single pixel) whose value is the overall average of the original image. The levels of the pyramid are transmitted topp-rlown: thess. the irerage of the whole image is sent first. followed by the $2 \times 2$ image. $4 \times 4$ image. "tr.. until the $2^{L} \times \underline{2}^{L}$ original is sent. The reduced resolution images are mergerl 
into one another to form an approximation of the original tatting with the 1 , 1

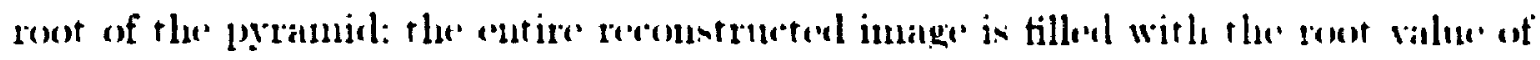

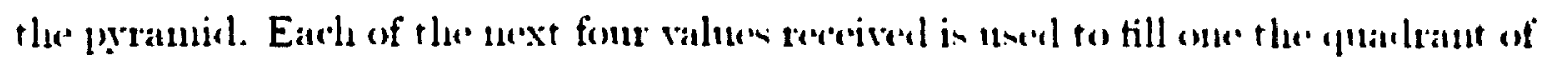

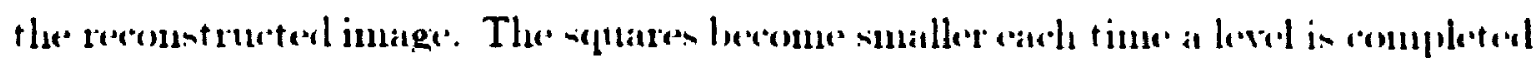
until in the last level the spuares are the individual pixels. A dereision an to what

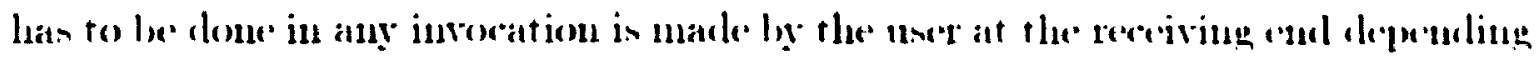
on how much detail he recpuires.

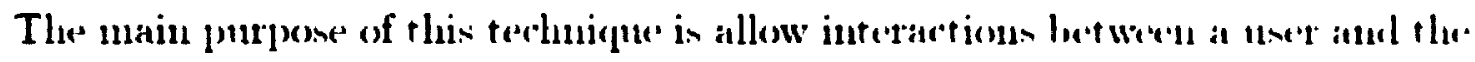
application handling a large anoment of visual information. If inages ance stored in

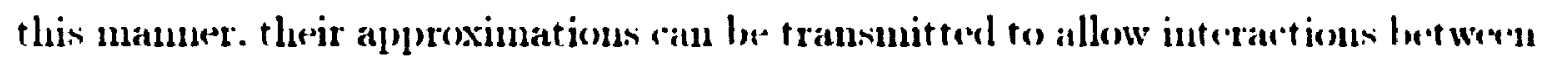
the application and the users and to reduce communiontion eost. In most ais as. only a small mumber of approximations is required to be transmitted luefore the liser an see if the original image has to be sent or if the courrent transmission can lon rancellerl. There are several problems with this pyramid method. The eomstrutetion of the lovamid approximations require a large amome of menory: and in the worst case sepuario. the communication cost is cloubled becanse the original image and all of its approximations need to be sent.

\section{Work done by Prusinkiewicz}

Prusinkiewicz: [Pr 84] one-dimensional subsampling technique can le maly extended to two-dimensional images. If $S$ is the original signal at fitl resolution. then

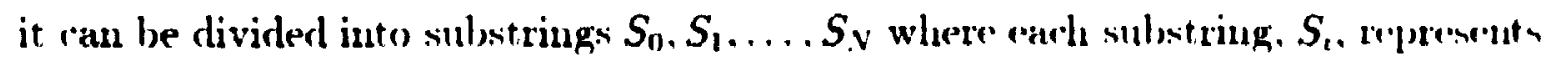
a recluced resolution of $S$. The main difference hetween this methonl and the binary tree. quadtree, or the pyramid structure $\left[T a\right.$ 79] is that any substring. $S_{A}$. rau be userl to reconstrut the original sigual $S$ at the particular resolution at level $\mathrm{k}$. As opposed to this, with the hierarchical structure representution only varions initinl substrings can be used to reconstruet the approximation of the cutire string $S$. their non-initial sulsetrings are meaningless. Moreover. the cost of the overlenenl of 


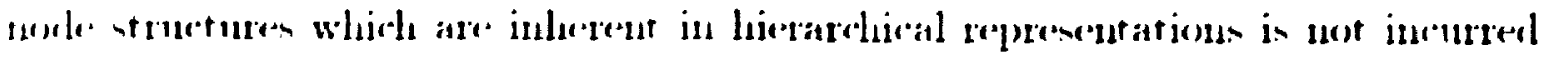
la. Prosinkiewia

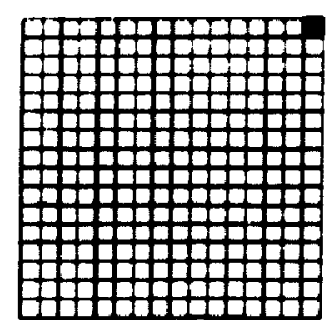

(a)

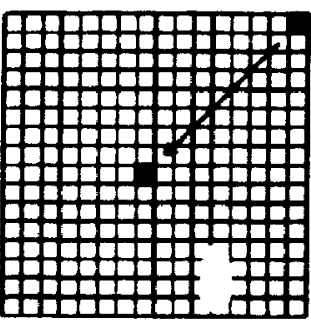

(d)

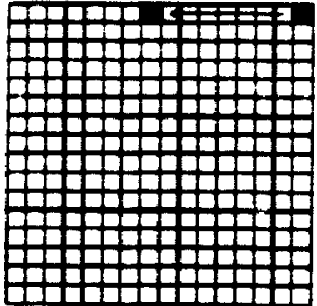

(b)

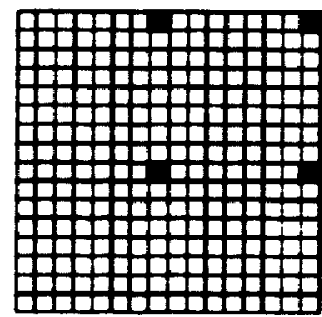

(e)

Figure 41: String of sampling points. (a) to (d) represent the string of sampling points $S(0.0), S(0.1), S(0.2)$, and $S(0.3)$. respectively. (e) represents the sulstring $S(1.0)$ which is the concatenation of the sulsstrings from (a) to (d).

Let $N>0$ be the erlge size of the square sampling region $A(N)$ whose vertices

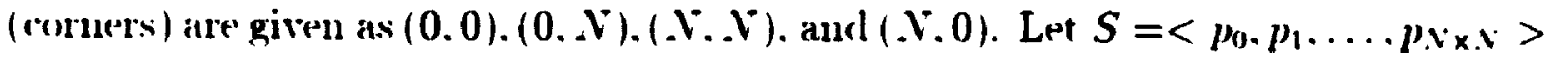
loc a string of points in a plane, and $S(i, h)$ denote a substring of $S$ containing exactly $t^{\prime}$ points

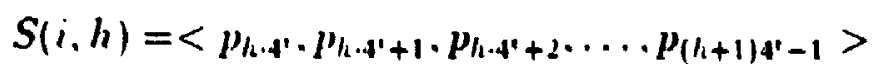

Also. Let $S_{\text {fiti.0 }}$ represent the translation of a sulsstring $S(i .0)=<$

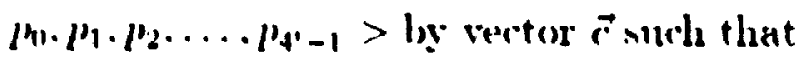

$$
S \cdot(i, 0)=\left\langle p_{0}+\vec{r} \cdot p_{1}+\vec{r} \cdot p_{2}+\vec{r} \ldots . . p_{4^{\prime}-1}+\vec{r}\right\rangle
$$




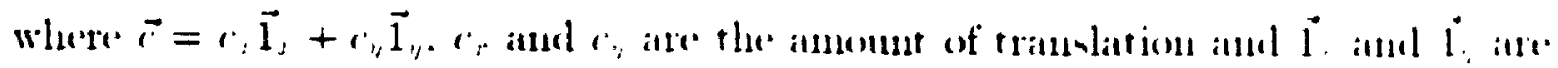

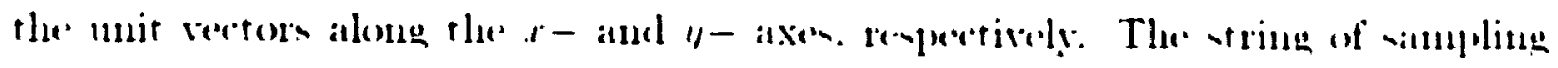
points is then cletined an follow:

$$
\begin{aligned}
& S(0.0)=<p_{11} \times=0 \text { point at }(X, X) \\
& S(1.1)=S_{-1:-1-i \overrightarrow{1}_{1}}(1.0) \\
& S(1,2)=S_{-1,-t-1} i_{1},(1,0) \\
& S(1.3)=S_{-1,2-1-1}\left(i_{1}+i_{1}, 1 i .0\right) \\
& S(i+1.0)=S(i .0) \cdots S(i .1) \therefore S(1.2) \ldots S(1.3)
\end{aligned}
$$

where $\therefore$ denotes the concatenation of strings. and $1=0.1 \ldots \ldots \log _{1}, x$. Prusinkiewicz s traversal subsampling algorithm and the uniformity of the ianpling terdhicute are supported by the following two theorems:"

Theorem 2 Let the inder $k$ of a sample: point $p_{k}=\left(x_{k}, ! k_{k}\right)$ her represented as a binary word $r_{2 q-1} r_{2 \eta-2} \ldots r_{1} r_{0}$ where $r_{1}=0$ or 1 .

$$
k=\sum_{i=0}^{2 y-1} r_{1} 2^{2}
$$

Then the coordinates of point $p_{k}$ are equal to

$$
\begin{aligned}
& r_{k}=T\left(1-\sum_{i=11}^{1-1} r_{2 t} 2^{-(t+1)}\right) \\
& y_{k}=T\left(1-\sum_{i=1}^{T-1} r_{2 i} 2^{-(t+1)}\right)
\end{aligned}
$$

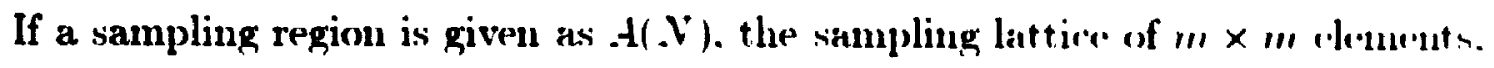
with the origin in porint $\left(c_{x}, c_{y}\right)$. is defined as the set

$$
. M_{m \times m}\left(r_{x} . r_{y}\right)=\left\{\left(r_{x}+(i-1) \frac{N}{m !} \cdot r_{y}+(j-1) \frac{N}{m}\right) \mid i .1=1.2 \ldots \ldots m\right\}
$$

The theorem below in based on the definition of uniform distriloution of $" \prime \prime \prime \prime \prime \prime$ points in a square area $f(N)$ formally iutroduced by Romenfeld and Kak [RK $i G]$.

\footnotetext{
l'Their proofs can bre found in [P( $\mathrm{Ki}$ ]].
} 


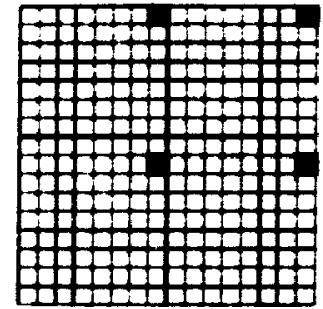

(a)

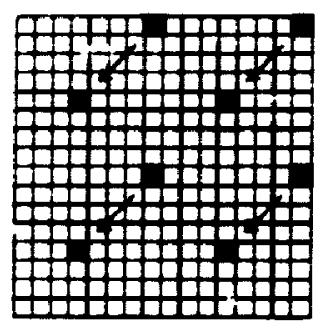

(d)

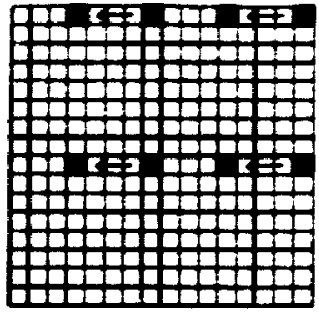

(b)

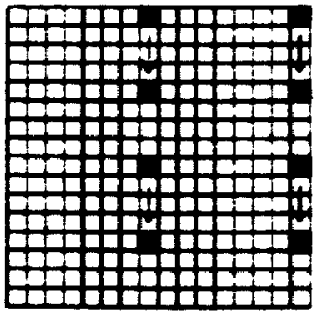

(c)

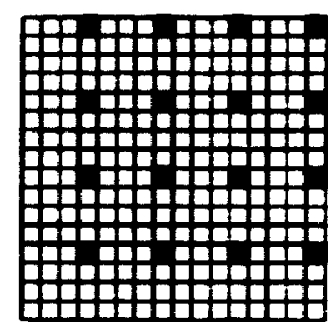

(e)

Finure 42: String of sampling points. (a) to (d) represent the string of simpling points $S(1.0) . S(1.1), S(1,2)$, and $S(1.3)$, respectively. (e) represents the sillistring $S(2.0)$ which is the concatenation of the substrings from (a) to (d).

Theorem 3 Let $\bar{S}$ denote the (unordered) set of elements of the substring $S(i . h)$.

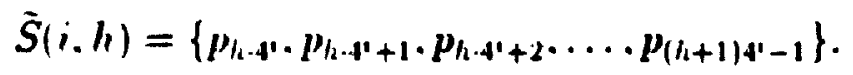

Thr'n for any $i . h=0.1 .2 \ldots .$. the set $\tilde{S}$ is a sampling lattice in the region $A($.$) :$

$$
\begin{gathered}
(\forall i . l=0.1 .2 \ldots)\left(\exists r_{x} \cdot r_{y} \in\left[0 . \frac{i}{2^{2}}\right)\right) \\
\tilde{S}(i, h)=. M_{2^{\prime} \times 2^{\prime}}\left(r_{x} \cdot r_{y}\right) .
\end{gathered}
$$

The sampling methorl proposed ly Prusinkiewicz starts at the top right haurl romer of in inuge and traverses to the bottom-left cornet from one level to the next. (One of the problenus with this traversal algorithm is that if important information is contained in the lower left-liand corner of an image. then the first several sulnerings will le devoid of this information. Severtheless. berantse the wideh and 


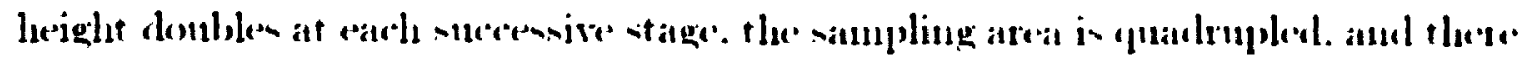

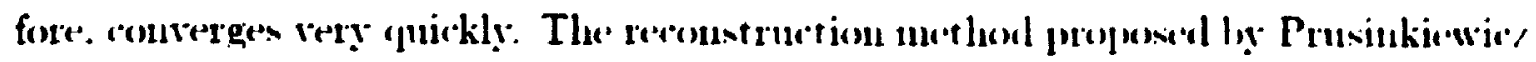
ronsists of linearly interpolating the nuknown cells using the simpled vallues. atul

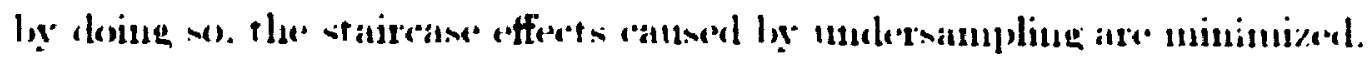

\subsubsection{Transform Domain Techniques}

Most. if not all. of the two-dimensional transform terehniques ane haned on the one dimensional transformed techniques presented in Chatpere 2. and these tenthicpuen ate extended to apply to two-dimensional images. Extensive anum of work has leen done by many researchers in this field including (lout not limited tol the following [ANR S5]. [Ja 85]. [RK i6]. [Pr is]. [BB 82]. [ER S2]. [.J S4]. [Ra 85]. [Wat SS]. [RI 90]. [Ja 91]. [RJ 91]. [Ru 92]. Only two trausform techuiques will he presented in this section. namely the Fonrier transform. and discrete conime transform.

\section{Fourier Transform of Two-dimensional Functions}

The discrete Fourier transform of a two-dimensional function $f(1, k)$ in in extensicre of the one-dimensional transform. and is given as:

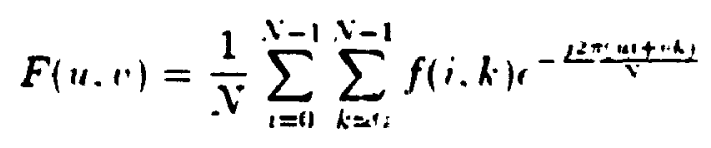

where $0 \leq u . "<x$. Its inverse is refined as

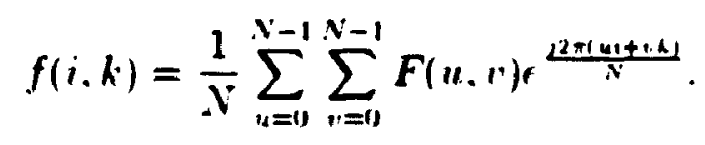

In both equations (12) and (13) alowe, the value of $j$ is rlefined an $j=\sqrt{-1}$.

The main purpose of the rliscrete Fonrier transform is to recompense in image block into its spectral components, and the indicess "aud o are referreel to as the sparial frequencies of the transform. The two-dimensiomal transform keruel in separable. since

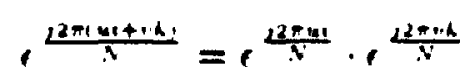




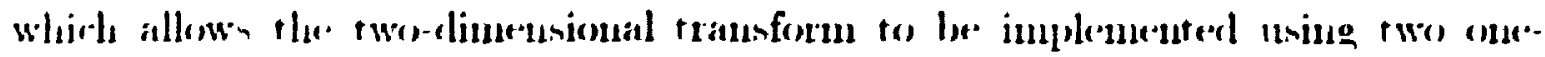
dimensional transforms.

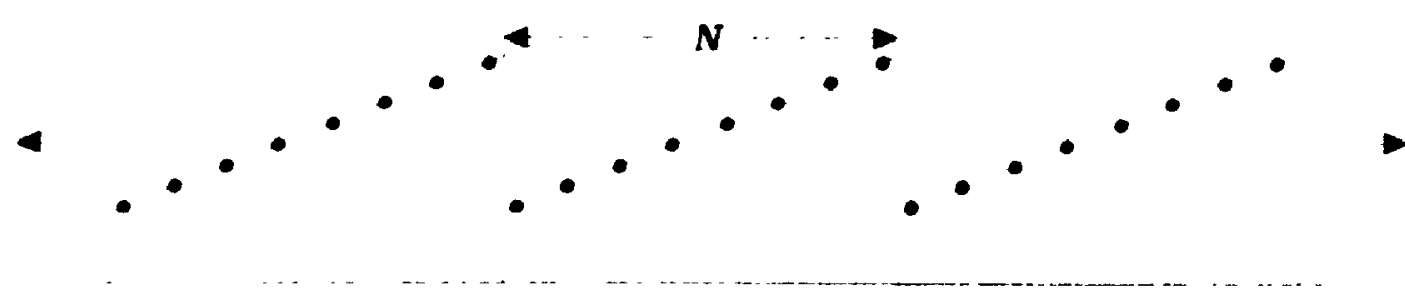

Discrete Fourter transform periodicity

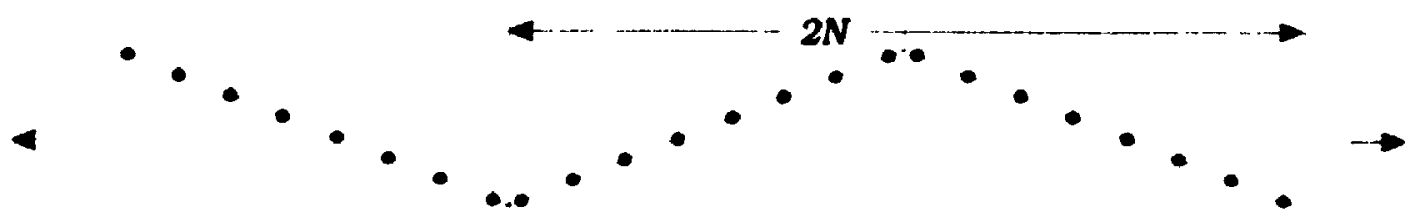

Discrete cosine transform periodicity

Figure 43: Implicit periodicity of the discrete Fourier and cosine transforms.

The discrete Fourier transform is a Fourier series representation of a finiteduration secquesure, and as such. there is an implicit periodicity of the sequence as shown in Figure 43. This periodirity is the result of sampling in the frequency domain. By replicating the original sequence in this manner the process often creates severe discontinuities between segments. Spurious high frequency components can resilt from these discontinuities, and therefore. the efficiency of the transform is greatly reduced. Although these nurions components are not really part of the origiual sequence, they are requized to reconstruct the sharp boundaries in a periodic serguencer. If some of these components are discarded in order to increase the transform efticiency, then the reconstructed signal would result in objectionable errors at the boundaries. In image corling, where an image is broken up into blocks: of pixels to form two-dimensional sequences, these reconstruction errors result in 


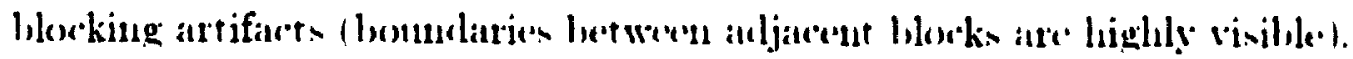

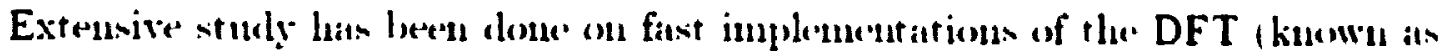

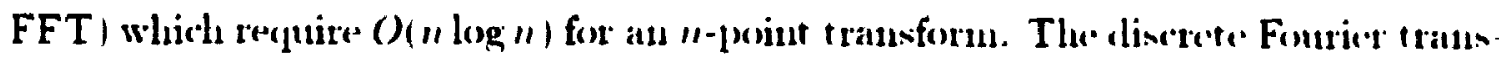

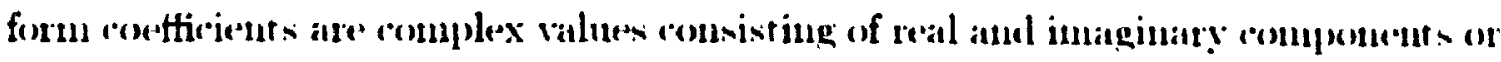

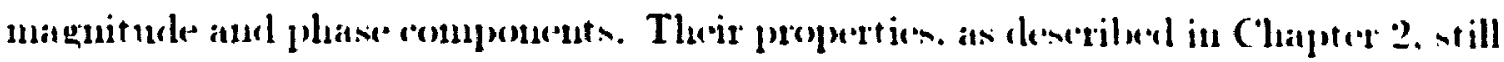
lobld true for two-dimensional funetions. Storage and mamipulation of these complex values ran be dounbersome. Another disadrantage of the diserete Fonrier ransform

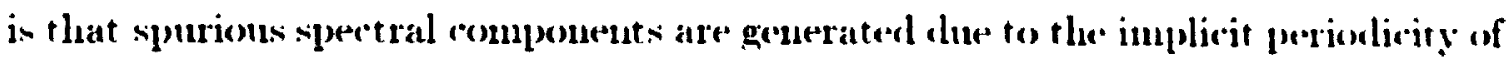
the image blocks. When encoded at low hit rates. the se spurions components maty give rise to severe blork artifacts learling to the so-realled "stairrase effere" [R.I 91].

\section{Discrete Cosine Transform of Two-dimensional Functions}

The discrete cosine transform for a two-dimensional function $f(i, k)$ caun le dencrilued is

$$
F(u . v)=\frac{4 C(u) C(1 \cdot)}{I^{2}} \sum_{i=1}^{N-1} \sum_{i=1}^{N-1} f(i . k) \cos \left[\frac{(2 i+1) u \pi}{2 . V}\right] \cdots\left[\frac{(2 k+1) r \pi}{2 I^{*}}\right]
$$

and the inverse two-dimensional discrete cosine transform is detinerl as

$$
f(i, k)=\sum \sum C(u) C(v) F(u . v) \cos \left[\frac{(2 i+1) u \pi}{2 . v}\right] \cdots\left[\left[\frac{(2 k+1) \mu \pi}{2 . V}\right]\right.
$$

wheres

$$
C(w)= \begin{cases}\frac{1}{\sqrt{2}} & \text { for } w=0 \\ 1 & \text { for } w=1,2 \ldots, v-1 .\end{cases}
$$

Similar to the discrete Fourier trausform. the discrete cosine trausform lans is fast implementation with a computational complexity of $(O(n \log n)$ for an $\|$-point transform. However. it does not generate spurions spertral components, and therofore. it is very efficient in corling by comparting a large anomut of information into a fow roefticients. The discrete cosine transform has become the most widely userl transform for andio and image compression. and has beren arlapted by the Intorthational Strudards Organization (ISO) JPEG still-image corling sche'me'. 


\subsection{Results of Previous Planar Curve Approximation Me- thods}

In this chapter many different approximation terhuiquess on two-rlimensional planate

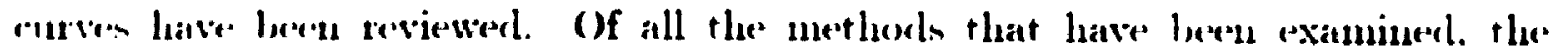
follewing algorithms are selected and used as a basis for comparions:

1. Linuar s'arch and split (Ramer)

2. Split-and-merge algorithm (Pavlidis and Horowitz)

3. Xinarest-neighlourr averaging algorithm (extension of Tanimoto)

4. Hologram-like approximation algorithm (Prtusinkiewirz)

j. Minimax Polygon (Kurozumi and Davis)

G. Recursive hinary search and split (Duda and Hart. Lowe)

7. Discrete Fourier transform (Rao. Yip. et al.)

S. Discrete cosine transform (Rao. Yip, et al.)

These methods provide a cross section of time/spacial domain and transform domain approximation terhuiques. As indicated in the previous chapter. these methork were chosen because they can be applied to both one-dimensional functions and two-dimensiomal planar curves. The first six methods are rategorized as the time/spacial domain terhniqures. and the last two are transform domain terhniques. Within the time/sparial domain category, the hologram-like and nearest-neighbour terehuiques use uniform knot points, wheregs, the other time/sparial domain tedhniques lese uon-1uiform knots. In orcler to acrurately compare the different terhniques, they were applied to the following five discrete planar curves:

1. Opeen ellipse::

$$
\left\{\left(x_{1}, y_{1}\right) i_{1}=3 \cos (0.05 i)+3 . y_{1}=7 \sin (0.05 i)+4 . i=0.1 \ldots .200\right\}
$$


2. Rotaterl uormal hell arre:

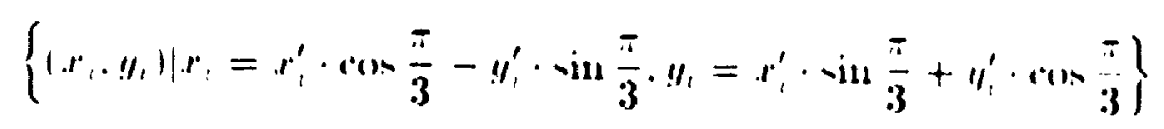

where

$$
r_{1}^{\prime}=0.05 \mathrm{j} i-6 . !_{1}^{\prime}=\frac{20}{\sqrt{2 \pi}},-1 \% .1=0.1 \ldots .2001
$$

3. Complex rlosed courve:

$$
\left\{\left(r_{1}, y_{1}\right) \mid r_{1}=3 \cos (0.025 i)-4 \sin (0.025 i)+4 . y_{1}=5 \cos (0.01251)+\operatorname{in} 2 x+1 i\right\}
$$

for $i=0.1 \ldots .251$.

4. Simulated noisy complex relosed curve:

$$
\left.\left\{\left(x_{1}, y_{2}\right) \mid x_{1}=3 \cos (0.025 i)-4 \sin (0.0251)+4 . y_{2}=5 \cos (0.025 i)+\sin 2 . x+6\right\}\right\}
$$

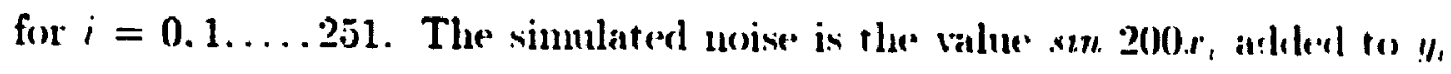
when $10 \leq i$ morlulos $40 \leq 18$.

j. Self-intersecting curve:

$$
\begin{aligned}
& \left\{\left(x_{1}, y_{1}\right) \mid x_{1}=3 \cos (0.02 i)-4 \sin (0.02 i)+4, y_{1}=j \cos (0.02,1 \text {-iis } 2 . r)\right\} \\
& \text { for } i=0,1 \ldots .300 .
\end{aligned}
$$

The results of some of these approximation terhuiquess are displayod and talmlaterl at the end of this section. Similar to the ontput of one-rlimensional funcrions. the column with the hearling " \# of Approx. Points" is not applicalde to the disrete Fonrier and discrete cosine transforms bechuse their estimation is clene in the transform domain. Both of these terhniques divicle the original sampled dat intes groups of 16 data values. The transformation is carried out using thene tereluniplues. 


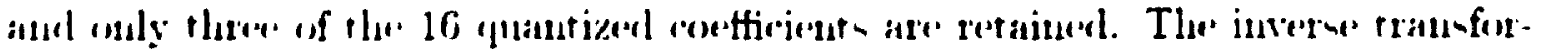

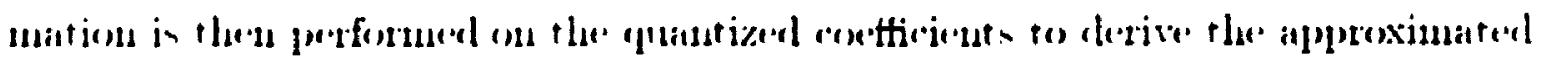
values ia the time/-parial domain.

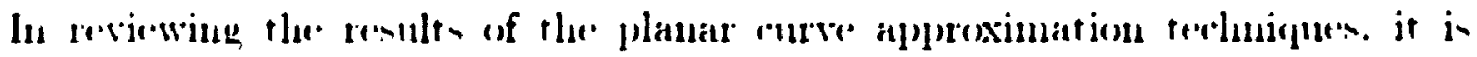

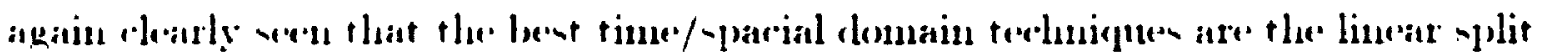

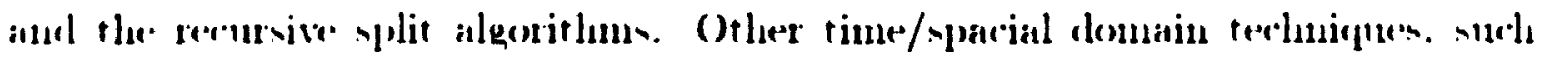
in the hologram-like and uearest-meighlontr approximations. do provide a better ilpproximation in terms of errors for the cases of an open elliptial corre or rorated lnell curve. However. the mumber of approximating points are almost two or theres times bat of the linear and recensive split approximations. The minimax method is the most computationally expensive algorithm: it requires 10 to 20 times an munch time to deriwe as solution with the same error value as the hologram-like approximation.

\subsection{Results of Digitized Image Approximation Methods}

Sereral digitized image approximation methods have been been reviewed including the sulswimpling ter'miques presented by Tanimoto [Ta 79] and Prusinkinwicz [PC' S5] and the discrete Fourier and discrete cosine transforms. These methods provide a cross section of time/spacial domain and transform domain approximation tedhigues. The two subsampling methods presented by Tanimoto and Prusinkiewicz are categorized as the time/spacial domain technigues, and the last two are transform domain techniques. In order to equitably compare the different rehiniques, they are applied to the following four clifferent digitized images:

1. A human fare

2. A derer in a grey backgromul

3. A sepuirrel in a dark background

4. A mountain hiking trail containing light background 


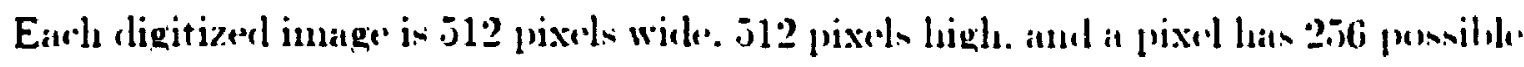

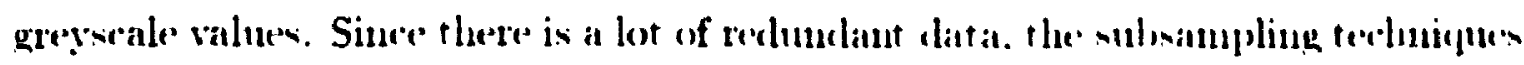

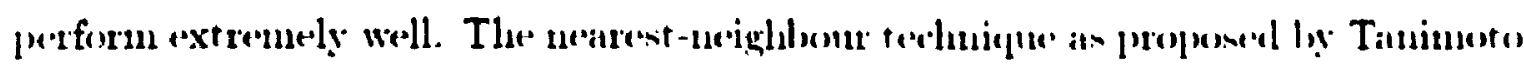

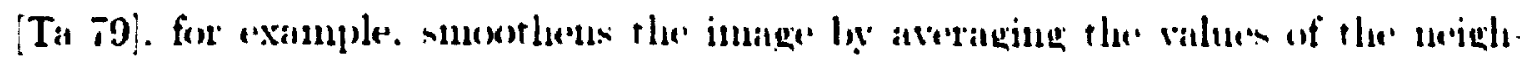

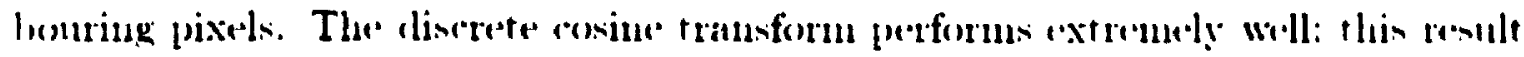
demonstrate why it in noed in the JPEG comprension algonithm. 


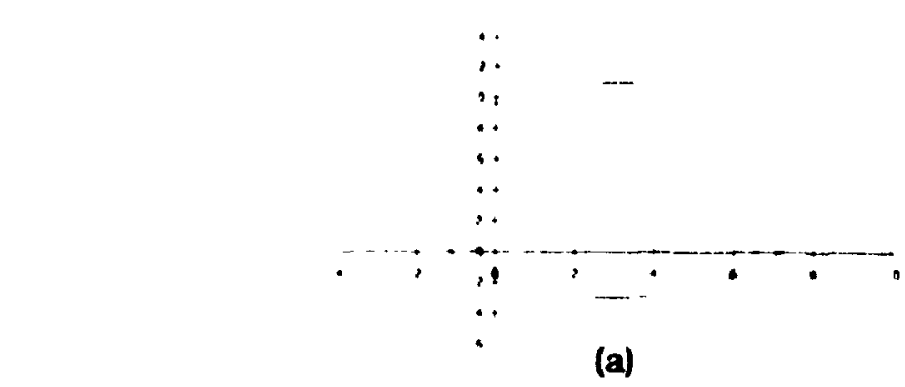

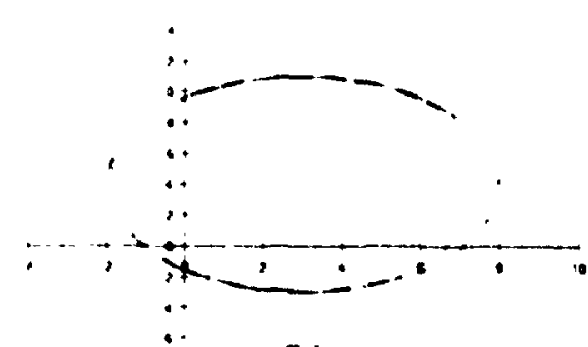

(b)

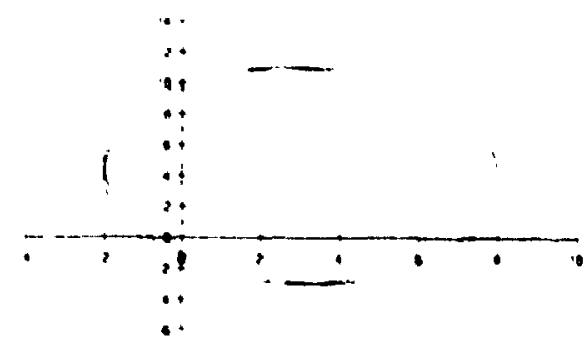

(d)

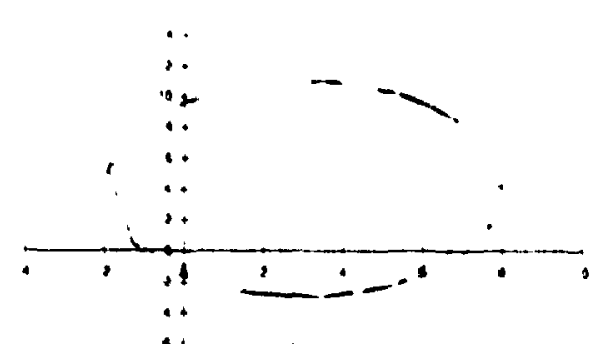

(c)

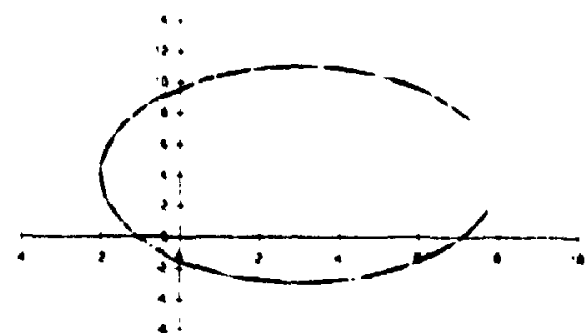

(e)

Figure 44: (a) Original open ellipse. (b) to (e): Approximations of open ellipse using terhniques (1) to (4) listerl in Sertion 3.3. 

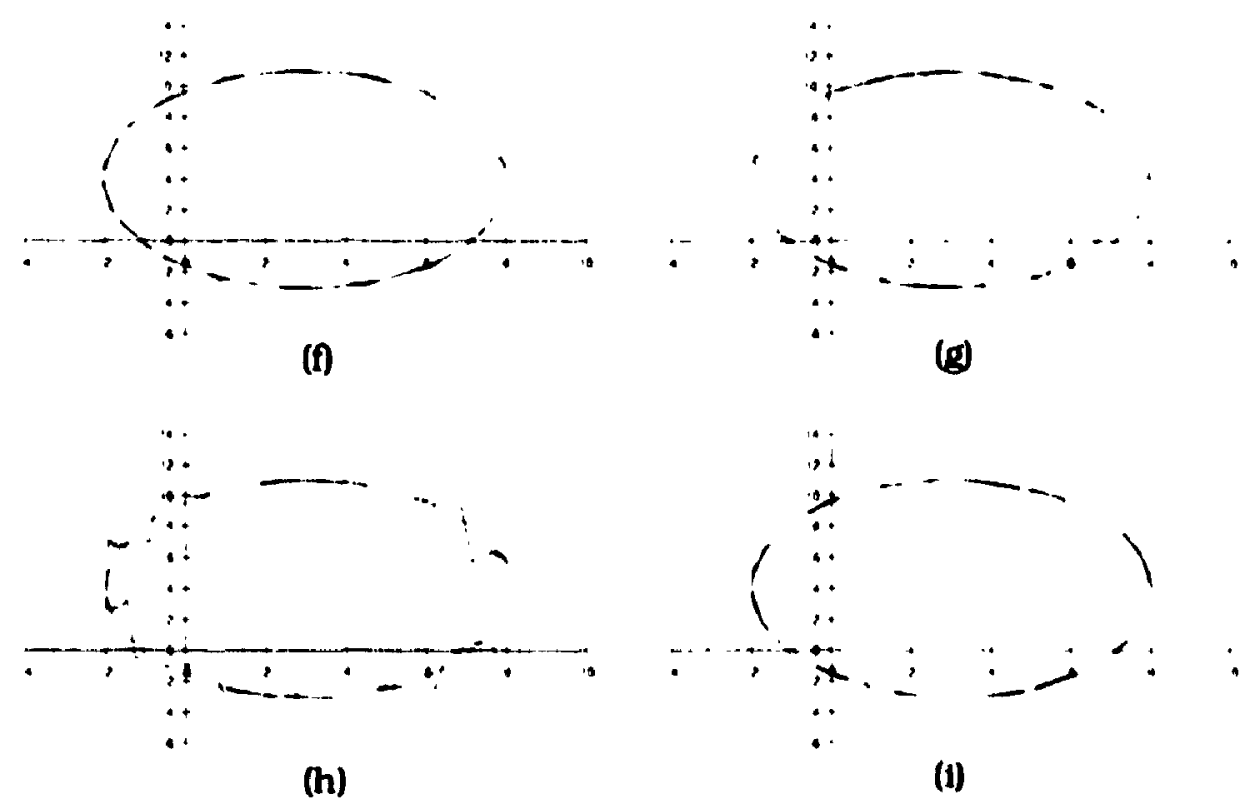

(h)

Figure 45: (f) to (i): Approximations of open ellipse using techuiques (j) to (8) listed in Section 3.3. 


\begin{tabular}{|c|c|c|c|c|c|}
\hline $\begin{array}{l}\text { Approximation } \\
\text { Mothod }\end{array}$ & $\begin{array}{l}\text { - of Approx. } \\
\text { Ponsts }\end{array}$ & $\begin{array}{c}\text { Time } \\
\text { Roquined }\end{array}$ & $\begin{array}{l}M E \\
\left(E_{-}\right)\end{array}$ & $\begin{array}{r}\text { MSE } \\
(E, N)\end{array}$ & $\begin{array}{l}\text { SNR } \\
\text { (ळ) }\end{array}$ \\
\hline $\begin{array}{l}\text { Linear Split } \\
\text { (Aamer) }\end{array}$ & $\$ 1$ & 784 & 0.4035 & 0.0197 & 23.1234 \\
\hline 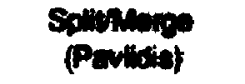 & 30 & 1004 & 4,9750 & 3.9890 & .17 .1851 \\
\hline $\begin{array}{l}\text { Avg. naighbours } \\
\text { (Tanimoto) }\end{array}$ & 34 & 102 & 0.3231 & 0.0415 & 19.8924 \\
\hline $\begin{array}{l}\text { Hologrentilo } \\
\text { Pnumintivinica) }\end{array}$ & 18 & $\pi$ & o.coses & $1.47 E-\infty$ & 34.4063 \\
\hline $\begin{array}{c}\text { Minimax } \\
\text { (Kurozumi) }\end{array}$ & 16 & 2079 & 0.6281 & 0.1146 & 15.4658 \\
\hline 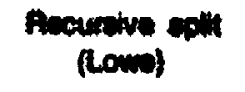 & 13 & 100 & 0.1691 & $53 \times 500$ & $208 \pm 35$ \\
\hline DFT & NA & 210 & 2.1044 & 0.5862 & 6.397 \\
\hline Dor & wa & $\$ 73$ & acensen & 0.0400 & 250478 \\
\hline
\end{tabular}

Figure 46: Comparison table of eight previous techniques applied on open ellipse. 


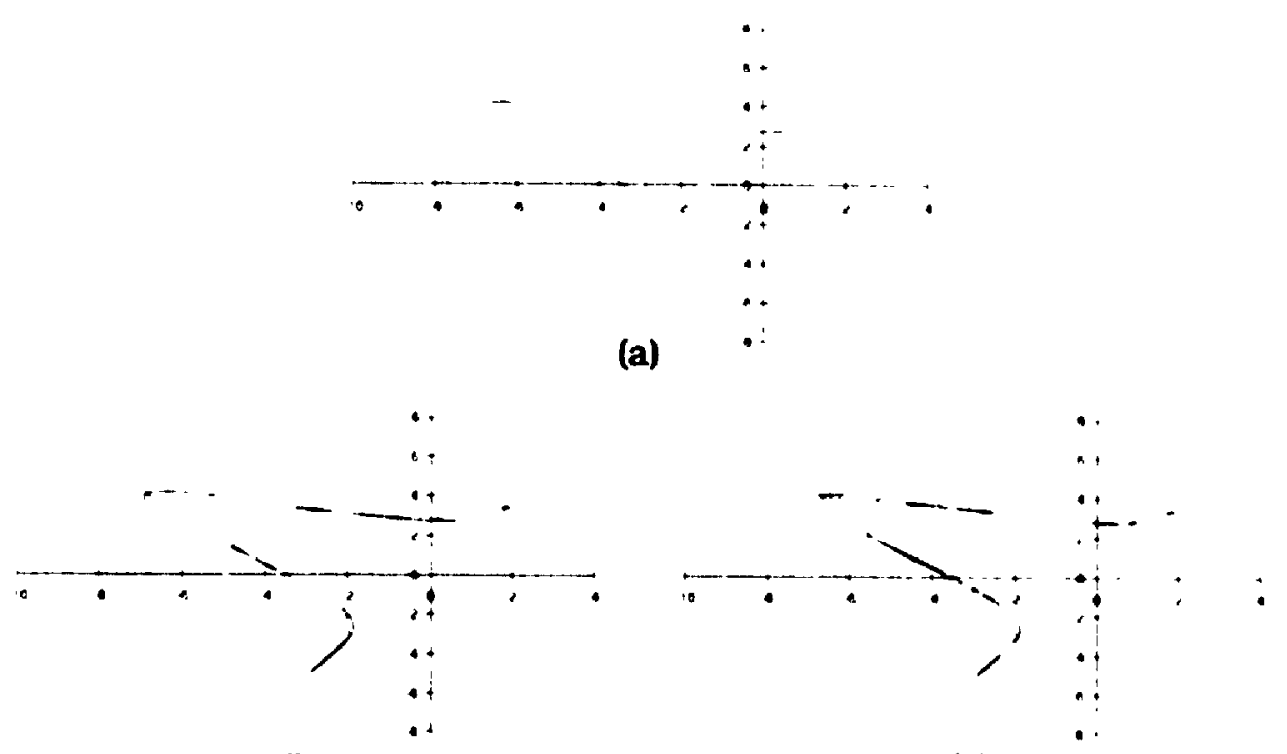

(b)

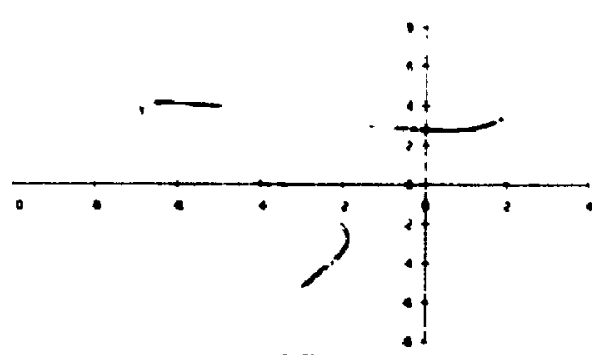

(d) (c)

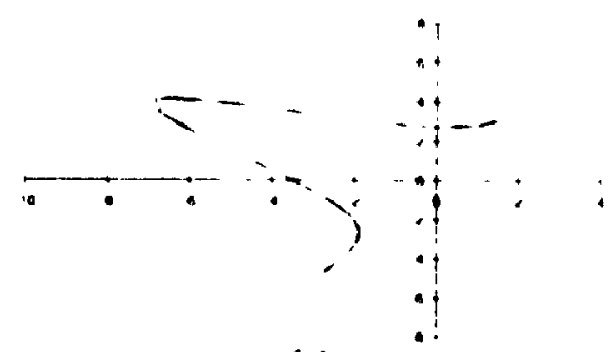

(e)

Figure 47: (a) Original rotated normal bell curve. (b) to (e): Approximations of rotated normal bell curve using terhniques (1) to (4) listed in Sertion 3.3. 


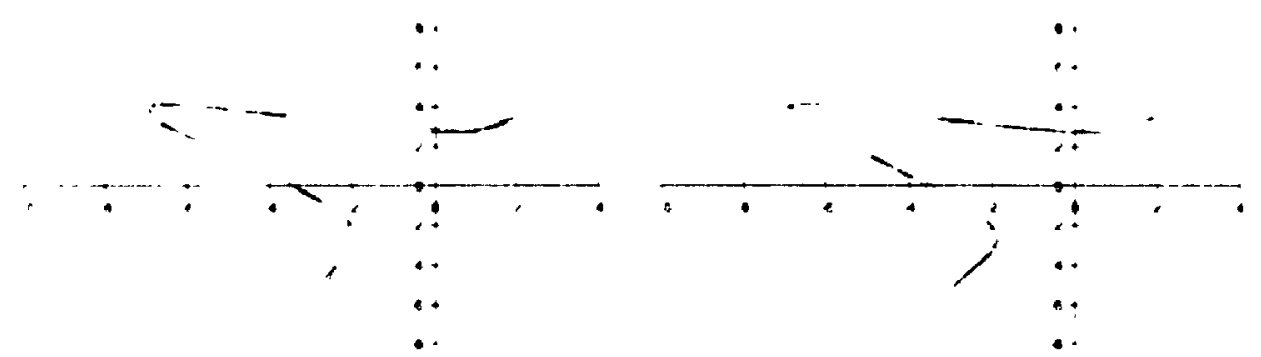

(f)

(g)

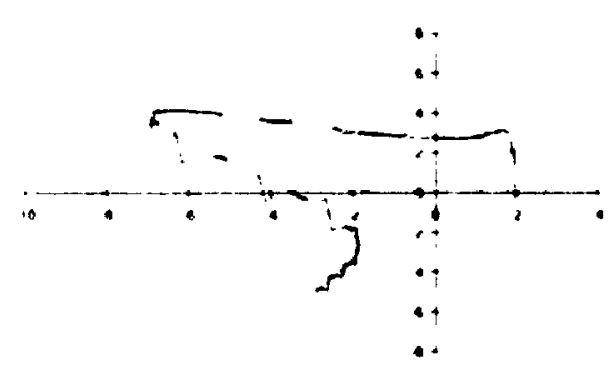

(h)

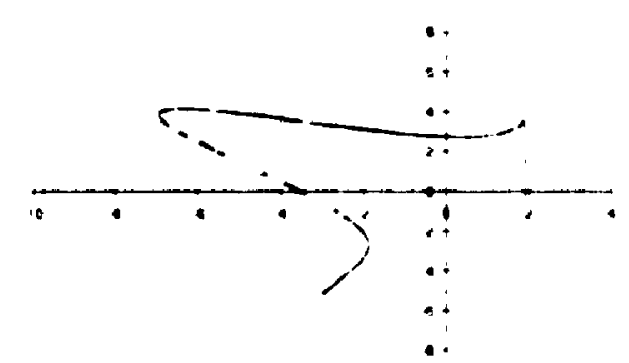

(1)

Figure 48: (f) to (i): Approximations of normal bell rurve using techniques (5) to (8) listed in Sertion 3.3. 


\begin{tabular}{|c|c|c|c|c|c|}
\hline $\begin{array}{l}\text { Approxumation } \\
\text { Mothod }\end{array}$ & $\begin{array}{l}\text { of Approx. } \\
\text { Ponts }\end{array}$ & $\begin{array}{c}\text { Time } \\
\text { Requined }\end{array}$ & $\begin{array}{l}M E \\
\left(E_{-}\right)\end{array}$ & $\begin{array}{c}M S E \\
(E, N)\end{array}$ & $\begin{array}{l}\text { SNR } \\
(\alpha B)\end{array}$ \\
\hline $\begin{array}{l}\text { Linear Split } \\
\text { (Ramer) }\end{array}$ & 6 & 194 & 0.4044 & 0.0209 & 12.4223 \\
\hline $\begin{array}{l}\text { Squnnorge } \\
\text { (Panidis) }\end{array}$ & 7 & 790 & 0.2637 & 0.011 & 15.2147 \\
\hline $\begin{array}{l}\text { Avg. neighbours } \\
\text { (Tanimoto) }\end{array}$ & 34 & 133 & 0.3488 & 0.0234 & 11.9199 \\
\hline $\begin{array}{l}\text { Holograntiva } \\
\text { Pruaintiowica) }\end{array}$ & 18 & 87 & 0.0825 & $4.24=04$ & 20.3477 \\
\hline $\begin{array}{c}\text { Minimax } \\
\text { (Kurozumi) }\end{array}$ & 7 & 9227 & 1.03 & 0.1454 & 3.9925 \\
\hline $\begin{array}{l}\text { Alocursive eplit } \\
\text { (lown) }\end{array}$ & 6 & 188 & 0.4044 & 0.0209 & 12.4203 \\
\hline DFT & NA & 297 & 2.1847 & 0.1348 & 4.3221 \\
\hline DCT & NA & 220 & 1.4584 & 0.0152 & 13.8014 \\
\hline
\end{tabular}

Figure 49: Comparison table of eight previons techuigques applied on rotated uormal bell curve. 


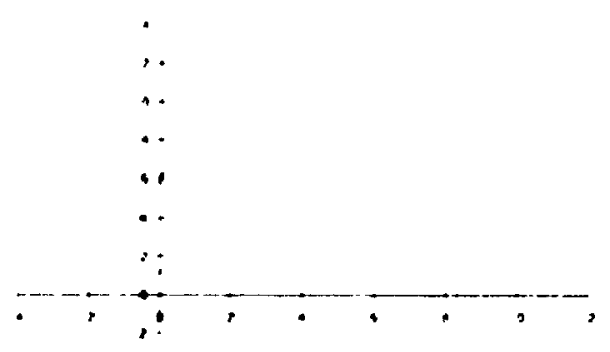

(a)

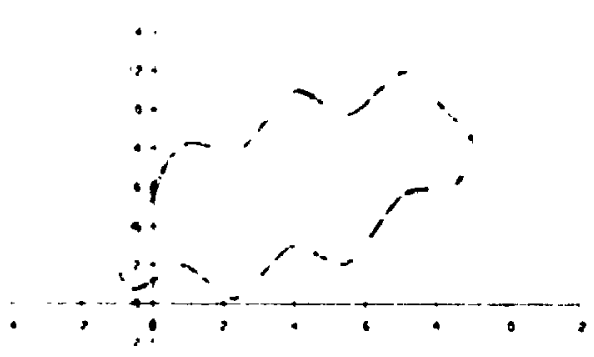

(b)

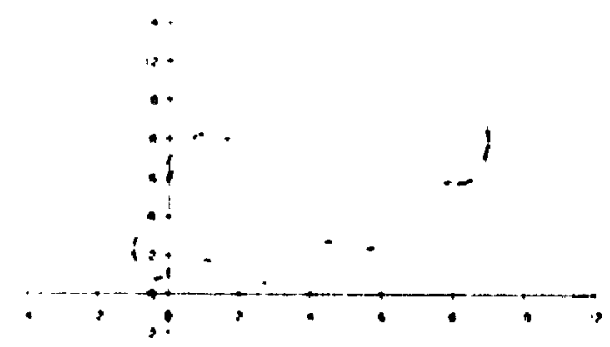

(d)

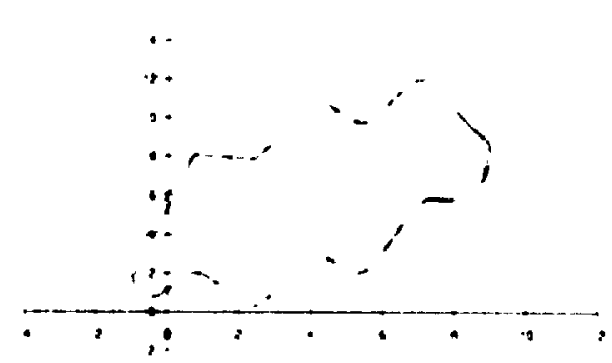

(c)

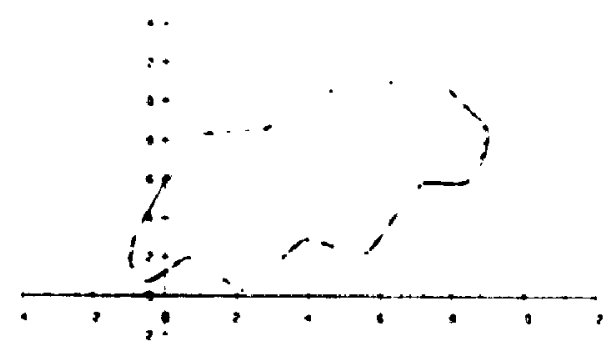

(e)

Figure 50: (a) Original complex clessed curve. (b) to (e): Approximations of complex closed curve using techniques (1) to (4) listed in Section 3.3 . 


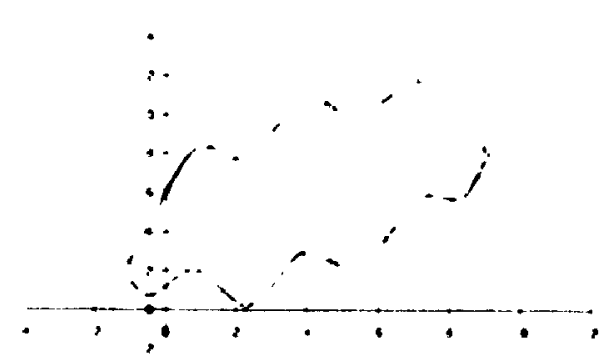

(f)

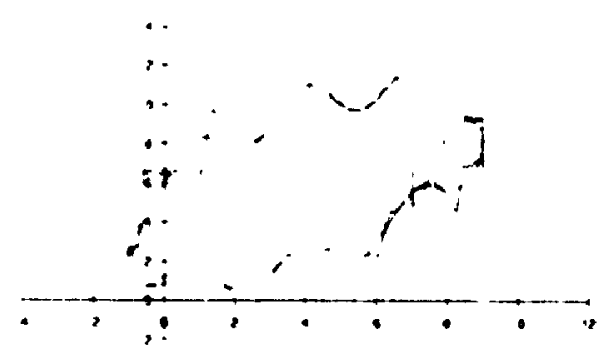

(h)

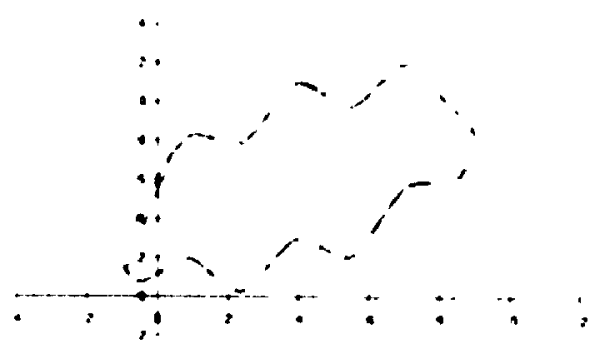

(d)

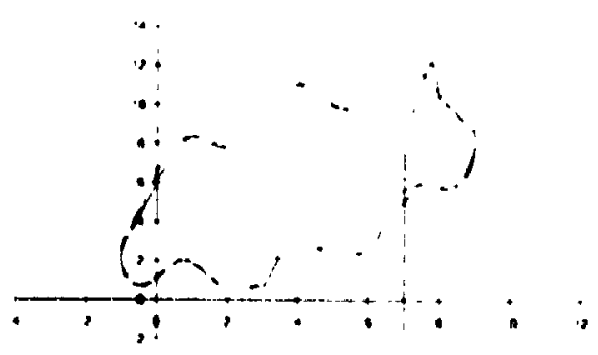

(a)

Figure jl: (f) to (i): Approximations of complex closed rurve using tereluni(pues (J) to (8) listed in Section 3.3. 


\begin{tabular}{|c|c|c|c|c|c|}
\hline $\begin{array}{l}\text { Approxmation } \\
\text { mathod }\end{array}$ & $\begin{array}{l}\text { of Apporox. } \\
\text { Pants }\end{array}$ & $\begin{array}{c}\text { Trmo } \\
\text { Required }\end{array}$ & $\begin{array}{l}M E \\
\left(E_{-}\right)\end{array}$ & $\begin{array}{c}M S E \\
\left(E_{2} N\right)\end{array}$ & $\begin{array}{l}\text { SNA } \\
\text { (dB) }\end{array}$ \\
\hline $\begin{array}{l}\text { Linoar Split } \\
\text { (Ramer) }\end{array}$ & 16 & 229 & 0.3013 & 0.0167 & 25.4022 \\
\hline $\begin{array}{l}\text { Splinnoryos } \\
\text { Pavistis) }\end{array}$ & 16 & 1017 & 0.5692 & 0.0355 & 22.1208 \\
\hline $\begin{array}{l}\text { Avg. neighbours } \\
\text { (Tanimoto) }\end{array}$ & 34 & 107 & 0.6062 & 0.0567 & 20.0959 \\
\hline $\begin{array}{l}\text { Holooramtive } \\
\text { (Prusintionica) }\end{array}$ & 18 & 76 & 1.0022 & 0.0747 & 18.6042 \\
\hline $\begin{array}{c}\text { Minimax } \\
\text { (Kurozumi) }\end{array}$ & 18 & 1511 & 1.1935 & 0.1519 & 15.8125 \\
\hline $\begin{array}{l}\text { Pacurtive } \\
\text { (Lowe) }\end{array}$ & 16 & 205 & 0.5013 & 0.0167 & 25.4022 \\
\hline DFT & NA & 231 & 7.2335 & 2.091 & 4.4256 \\
\hline DCT & WA & 187 & 522086 & 0.3678 & 11.8740 \\
\hline
\end{tabular}

Figure 52: Comparison table of eight previous terhniques applied on complex rloserl rurve. 


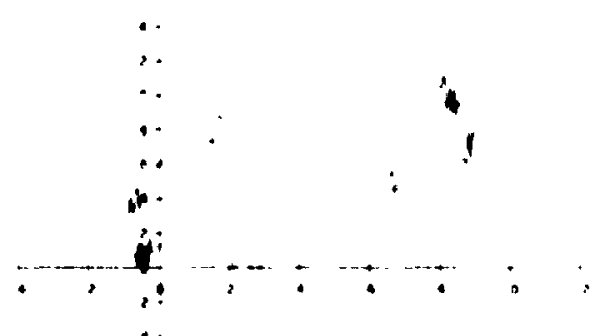

(a)

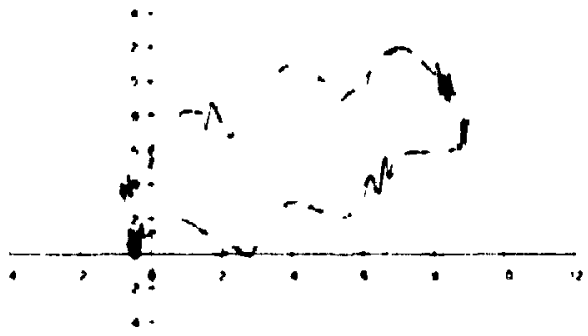

(b)

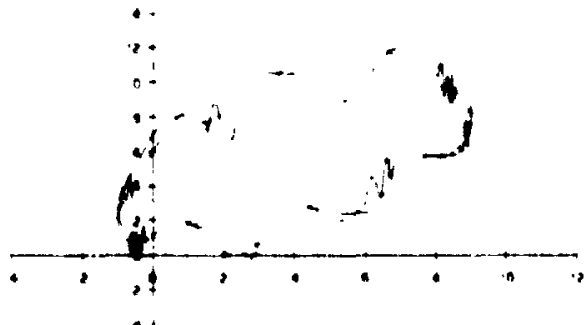

(d)

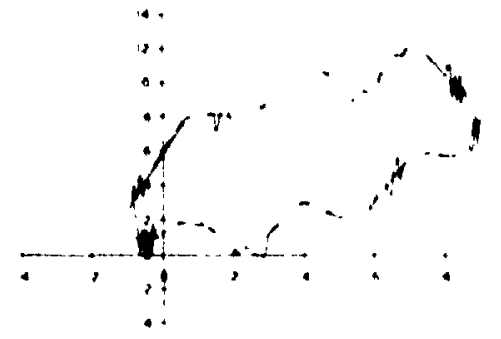

(c)

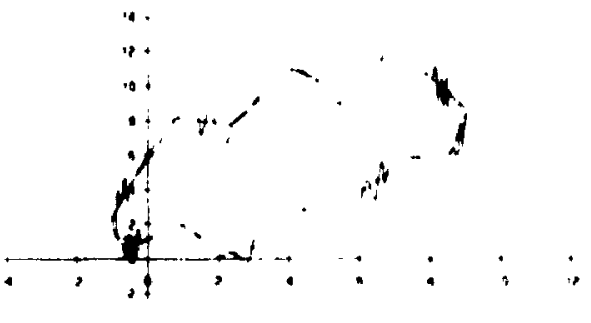

(e)

Figure 53: (a) Original romplex elosed rurve with simulated noise. (1,) to (c): Approximations of noisy romplex rlosed enrve using terduigues (1) to (4) listerl in Sertion 3.3. 


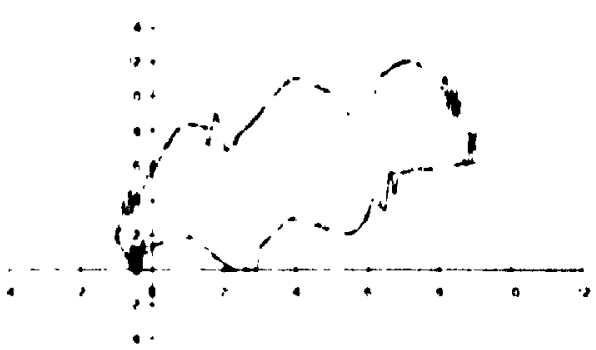

(f)

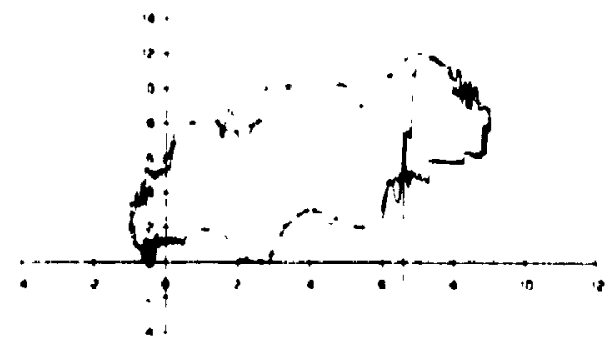

(h)

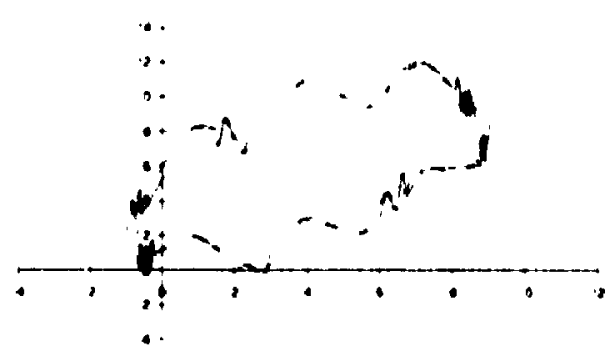

(d)

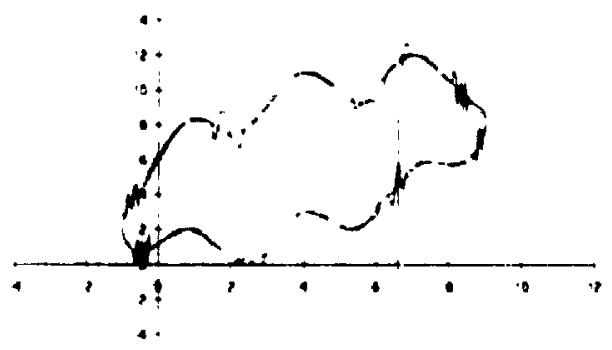

(i)

Figure j4: (f) to (i) Approximations of noisy complex closed curve using techniquess (j) to (8) listed in Sertion 3.3. 


\begin{tabular}{|c|c|c|c|c|c|}
\hline $\begin{array}{l}\text { Approximation } \\
\text { Mothod }\end{array}$ & $\begin{array}{l}\text { of Approx. } \\
\text { Points }\end{array}$ & $\begin{array}{c}\text { Tine } \\
\text { Required }\end{array}$ & $\begin{array}{l}M E \\
\left(E_{-\infty}\right)\end{array}$ & $\begin{array}{c}\text { MSE } \\
\left(E_{2}, N\right)\end{array}$ & $\begin{array}{l}\text { SNA } \\
\text { (de) }\end{array}$ \\
\hline $\begin{array}{l}\text { Linear Split } \\
\text { (Ramer) }\end{array}$ & 32 & 558 & 0.3718 & 0.0151 & 25.8644 \\
\hline 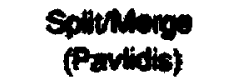 & 24 & 2252 & 1.0721 & 0.0578 & 20.0493 \\
\hline $\begin{array}{l}\text { Avg. neighbours } \\
\text { (Tanimoto) }\end{array}$ & 34 & 160 & 1.1191 & 0.1124 & 17.1616 \\
\hline $\begin{array}{l}\text { Holoprantiba } \\
\text { (Pruairibouica) }\end{array}$ & 18 & 100 & 12506 & 0.1103 & 16.9301 \\
\hline $\begin{array}{c}\text { Minimax } \\
\text { (Kurozumi) }\end{array}$ & 24 & 3479 & 0.9114 & 0.0676 & 19.3705 \\
\hline 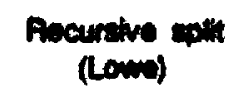 & 32 & 405 & 0.3718 & 0.0151 & 25.8644 \\
\hline DFT & NA & 471 & 7.1492 & 0.7526 & 8.9026 \\
\hline Dot & $\mathrm{NA}$ & 300 & 4898 & 0.1720 & 15.2007 \\
\hline
\end{tabular}

Figure 55: Comparison table of eight previous terhniques applied on moisy complex rloserl curve. 


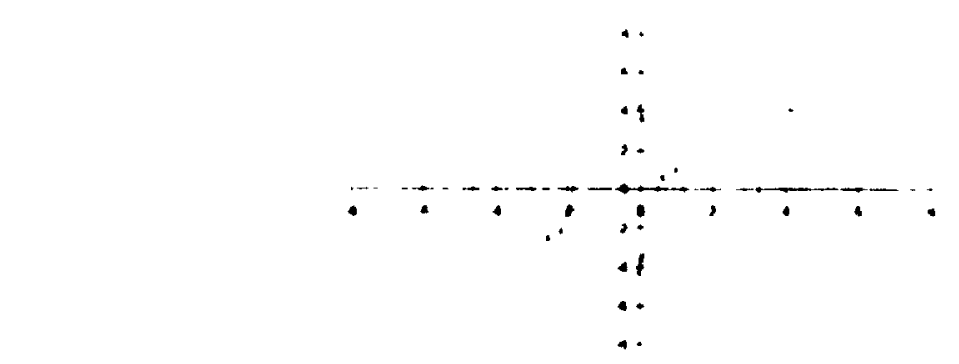

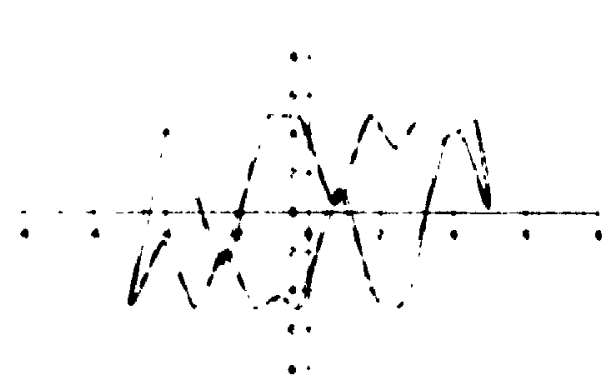

(b)

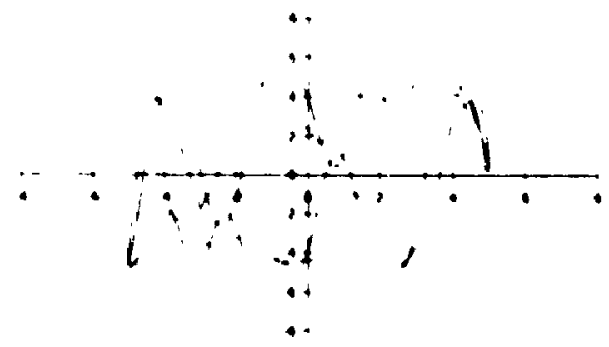

(d)

(a)

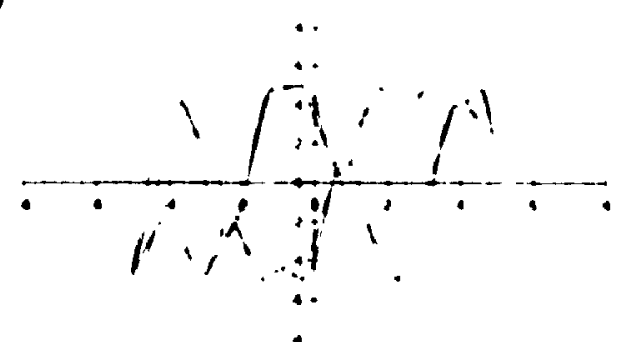

(c)

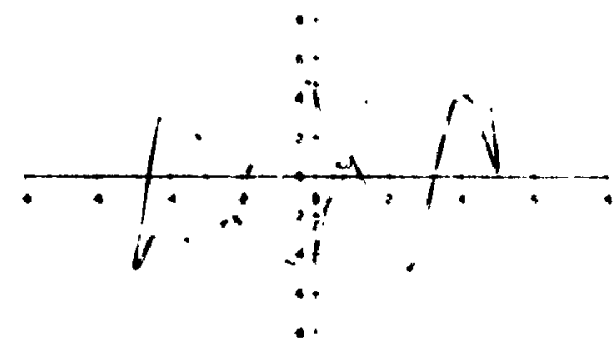

(e)

Figure 56: (a) Original self-intersecting curve. (b) to (e): Approxinnations of self-interserting curve using techniques (1) to (4) listerl in Sertion 3.3. 


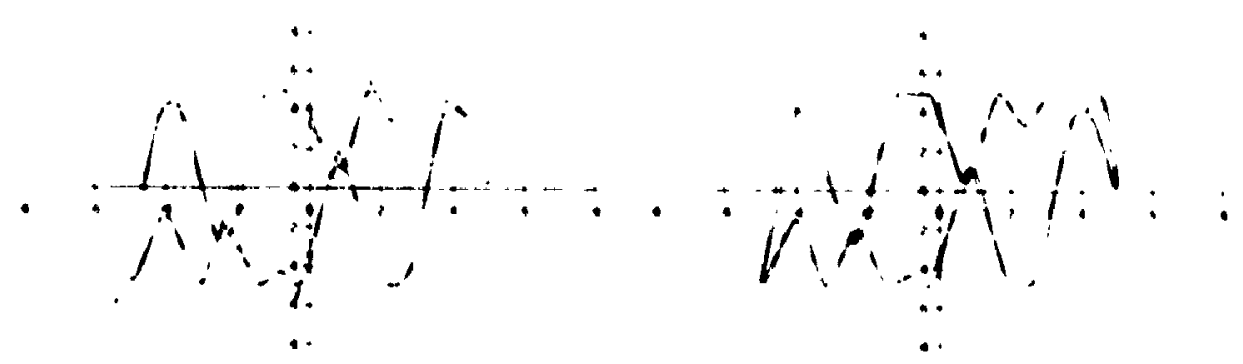

(f)

(a)

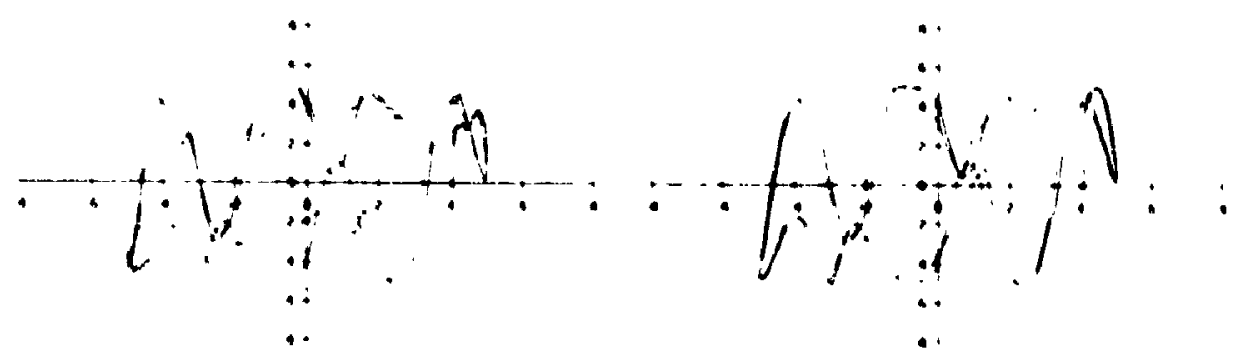

(h)

(1)

Figure ji: (f) to (i): Approximations of self-intersecting corve using terchnipues (J) to (8) listed in Section 3.3. 


\begin{tabular}{|c|c|c|c|c|c|}
\hline $\begin{array}{l}\text { Approximation } \\
\text { Mathod }\end{array}$ & $\begin{array}{l}\text { - of Approx. } \\
\text { Points }\end{array}$ & $\begin{array}{c}\text { Timo } \\
\text { Roquired }\end{array}$ & $\begin{array}{c}M E \\
\left(E_{-\infty}\right)\end{array}$ & $\begin{array}{c}M S E \\
\left(E_{z}, N\right)\end{array}$ & $\begin{array}{l}\text { SNR } \\
(\infty \theta)\end{array}$ \\
\hline $\begin{array}{l}\text { Linaar Split } \\
\text { (Ramer) }\end{array}$ & 23 & 342 & 0.3838 & 0.0182 & 5.1008 \\
\hline $\lim _{2}$ & 22 & 1407 & 1.3401 & 0.100 & 4.134 \\
\hline $\begin{array}{l}\text { Avg. naighboure } \\
\text { (Tenimoto) }\end{array}$ & 34 & 128 & 1.898 & 0.2253 & -5.8149 \\
\hline Holograntitus & 18 & $\boldsymbol{\theta}$ & 3.202 & 0.0024 & -10.4004 \\
\hline$\underset{\text { (Kurozumi) }}{\text { Minimax }}$ & 24 & 1942 & 2.7917 & 0.6481 & -10.4039 \\
\hline Rectsing splith & 23 & 290 & $0.30 \times 8$ & 0.0182 & 5.1000 \\
\hline DFT & N/A & 296 & 3.4027 & 1.3516 & -13.5966 \\
\hline Bot & $\mathrm{kn}$ & 204 & lsine & a.tms & -1.7058 \\
\hline
\end{tabular}

Figure 58: Comparison table of eight previous terhniques applied on self-intersecting curve. 


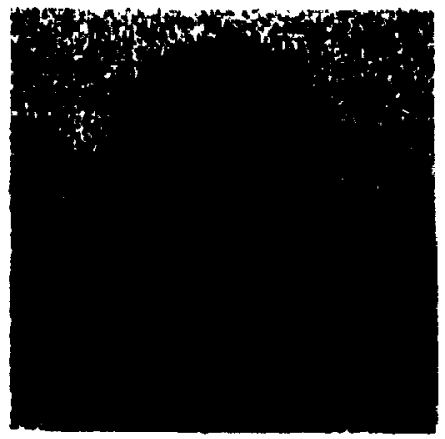

(a)

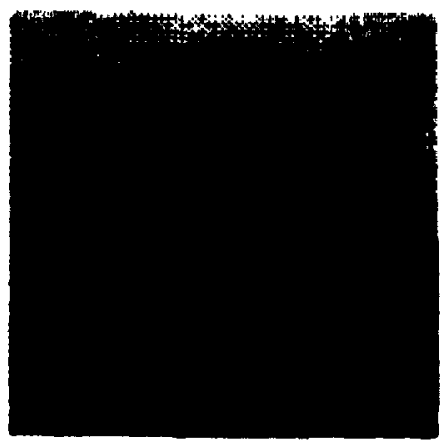

(b)

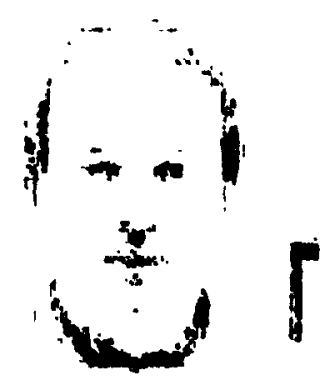

(d)

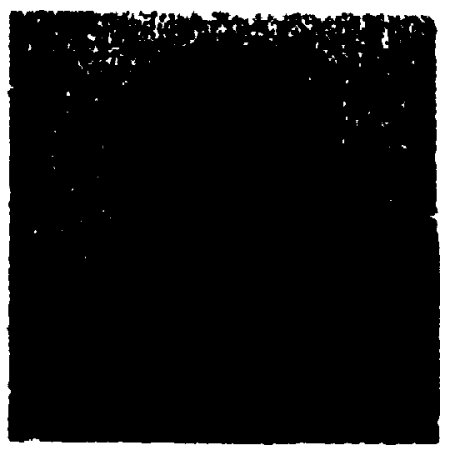

(c)

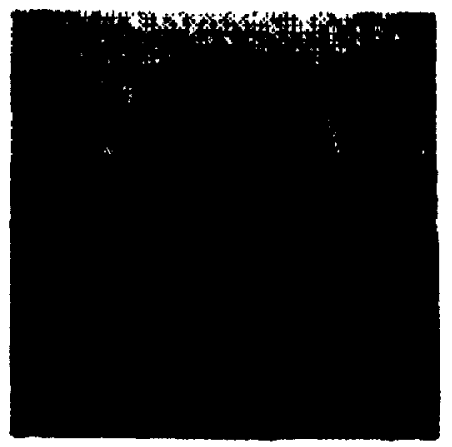

(e)

Figure 59: (a) Original picture of a human face. (b) Nenrest au ighlocour nppreximutions. (c) Holugram-like approximation. (d) Discrete Fontrier transform "lppreximntion. (c) Discrete cosine transform approximation. 


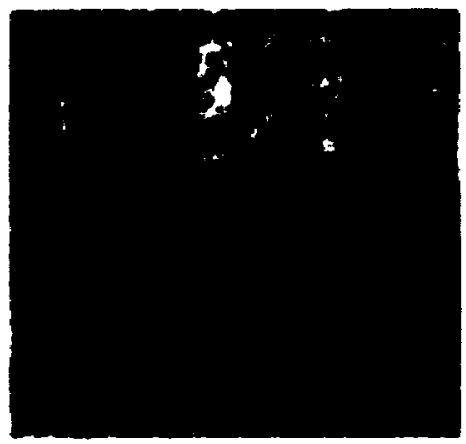

(a)

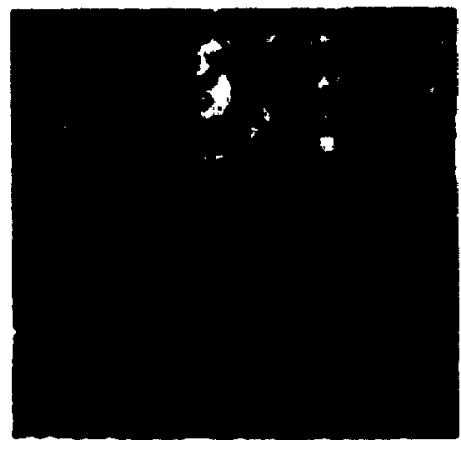

(b)

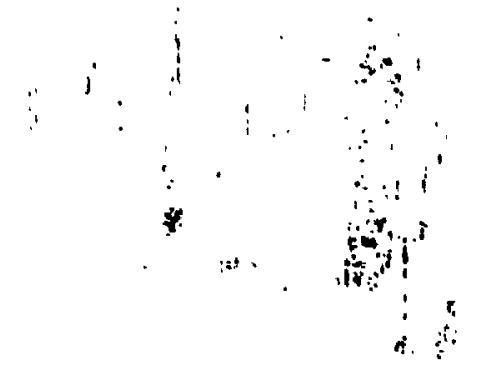

(d)

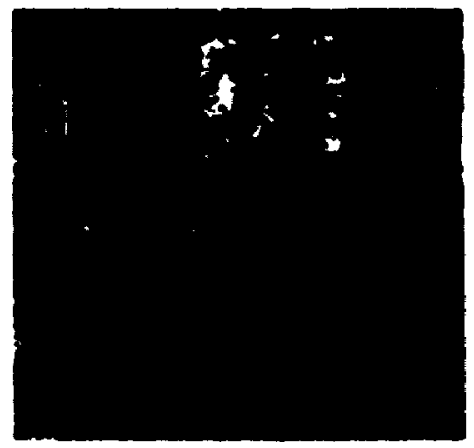

(c)

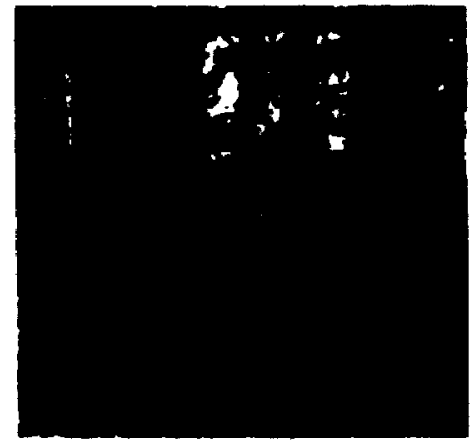

(e)

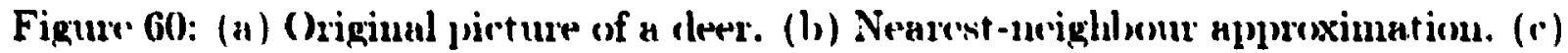
Hologram-like npproximation. (d) Discrete Fonurier transform approximation. (o) Discresce cosine transform npureximution. 


\begin{tabular}{|c|c|c|c|c|c|}
\hline $\begin{array}{l}\text { Approxmation } \\
\text { Mothod }\end{array}$ & $\begin{array}{c}\text { Compression } \\
\text { Alatio }\end{array}$ & Timi & $\begin{array}{c}M E \\
\left(E_{-}\right)\end{array}$ & $\begin{array}{c}\text { MSE } \\
\left(E_{:}, N\right)\end{array}$ & $\begin{array}{l}\text { SNA } \\
(0 \theta)\end{array}$ \\
\hline Hologrem-tike & $16: 1$ & 118 sec. & 198 & 545.0332 & 6.5354 \\
\hline 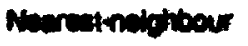 & $18: 1$ & 242 sxo. & 120 & 202.3095 & 3.3603 \\
\hline DFT & $8: 1$ & 710 sec. & 255 & 21665.0011 & -22.5288 \\
\hline Dot & $16: 1$ & 000 sec. & $\infty$ & 200.1510 & $2 \sin 4$ \\
\hline
\end{tabular}

(a)

\begin{tabular}{|c|c|c|c|c|c|}
\hline $\begin{array}{l}\text { Aporaximation } \\
\text { Method }\end{array}$ & $\begin{array}{c}\text { Comprossion } \\
\text { Ratio }\end{array}$ & $\underset{\text { Requined }}{\pi m s}$ & $\begin{array}{l}M E \\
\left(E_{m}\right)\end{array}$ & $\begin{array}{c}\text { MSE } \\
\left(E_{2}, N\right)\end{array}$ & $\begin{array}{l}\text { SNR } \\
(\infty)\end{array}$ \\
\hline Hologram tike & $16: 1$ & $118 \mathrm{sec}$. & 252 & 1839.1405 & -13.8891 \\
\hline 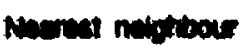 & $16: 1$ & 2440. & 211 & 816.3903 & -10.3706 \\
\hline DFT & $8: 1$ & 726 sec. & 255 & 34371.1837 & .26 .6139 \\
\hline Dot & $10: 1$ & roe & 137 & 406.641 & -8.1146 \\
\hline
\end{tabular}

(b)

Figure 61: (a)Results of approximation terhniques applied to the human facre image (image \#1). (b) Results of approximation techniques applierl to the deere image (image \#2). 


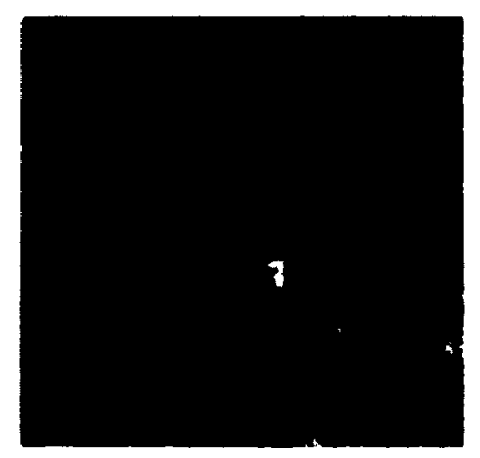

(a)

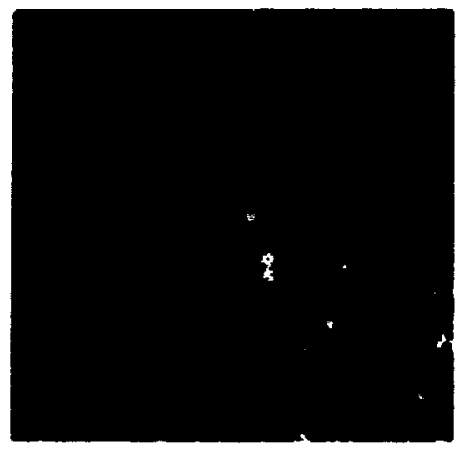

(b)

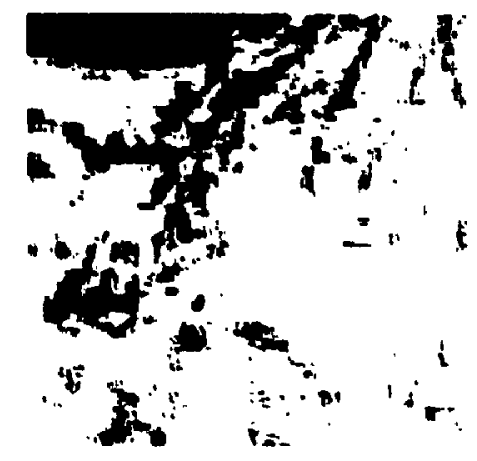

(d)

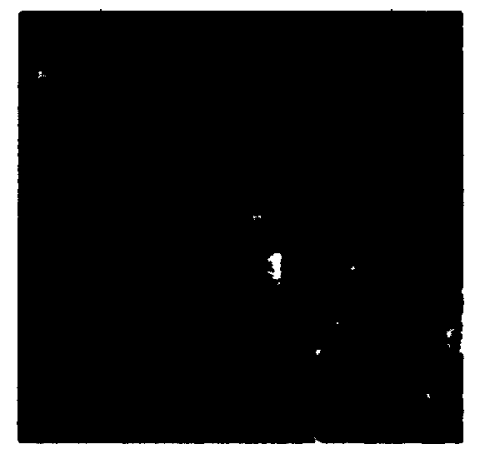

(c)

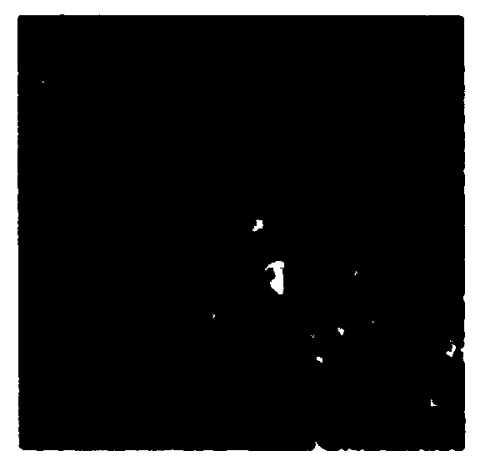

(e)

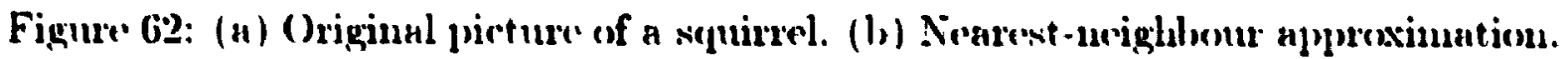
(c) Holegram-like nploximation. (d) Discrete Fonurier transform sppresimention. (c) Discrete cosine transform approximntion. 


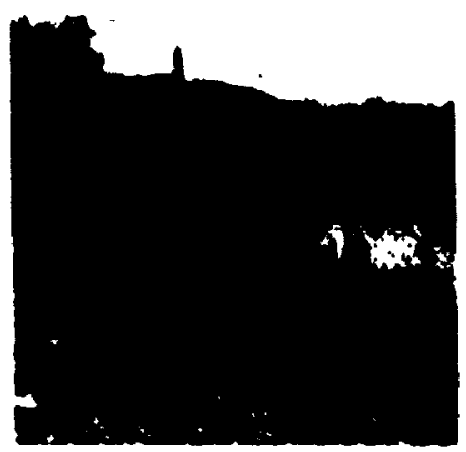

(a)

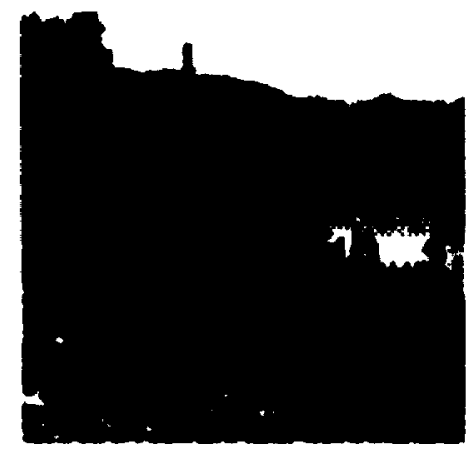

(b)

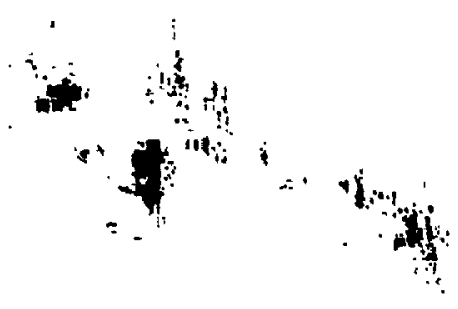

(d)

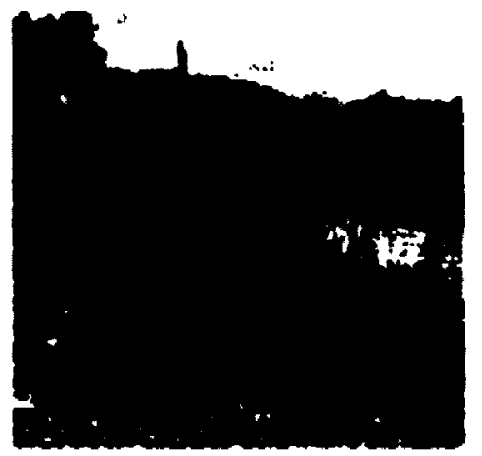

(c)

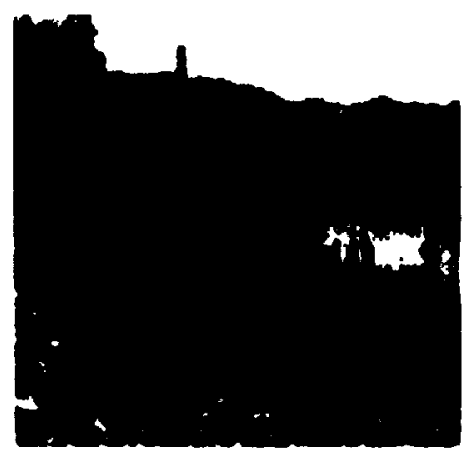

(e)

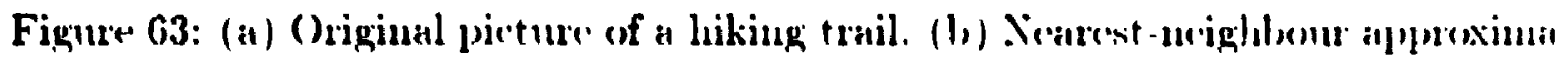

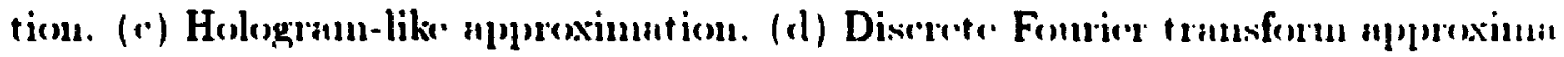
tion. (a) Discrete cosiue transform inpreseximntions. 


\begin{tabular}{|c|c|c|c|c|c|}
\hline $\begin{array}{l}\text { Approximation } \\
\text { Munnod }\end{array}$ & $\begin{array}{c}\text { Comprossion } \\
\text { Ratio }\end{array}$ & $\begin{array}{c}\text { Timo } \\
\text { Required }\end{array}$ & $\begin{array}{l}M E \\
\left(E_{-\infty}\right)\end{array}$ & $\begin{array}{c}M S E \\
\left(E_{2}, N\right)\end{array}$ & $\begin{array}{l}\text { SNR } \\
\text { (d) }\end{array}$ \\
\hline Hologram titike & $16: 1$ & 119 sec. & 244 & 806.4289 & -12.7094 \\
\hline Noureat nolotbour & $16: 1$ & 200 & 100 & 303.7206 & 12871 \\
\hline DFT & $8: 1$ & 720 sec. & 255 & 36126.7125 & -29.222 \\
\hline DCt & 16:1 & 600 & 232 & 1790008 & 6.1903 \\
\hline
\end{tabular}

(a)

\begin{tabular}{|c|c|c|c|c|c|}
\hline $\begin{array}{l}\text { Approximation } \\
\text { Mothod }\end{array}$ & $\begin{array}{c}\text { Compresetion } \\
\text { Ratio }\end{array}$ & $\underset{\text { Requived }}{\text { Timo }}$ & $\begin{array}{l}M E \\
\left(E_{-1}\right)\end{array}$ & $\begin{array}{l}\text { MSE } \\
\left(E_{2} N\right)\end{array}$ & $\begin{array}{l}\text { SNR } \\
\text { (CB) }\end{array}$ \\
\hline Hobgrem tike & $16: 1$ & $118 \mathrm{sec}$. & 252 & 1828.7845 & -11.9300 \\
\hline Neored neiditbour & $10: 1$ & 200 & 160 & 2007711 & -8.7002 \\
\hline DFT & $8: 1$ & 744 sec. & 255 & 23828.5419 & -23.0802 \\
\hline ocr & $10: 1$ & $7+4=0$ & to4 & sat.7504 & 6.0566 \\
\hline
\end{tabular}

(b)

Figure 64: (a)Results of approximation techniques applied to the squirrel inage (image \#3). (b) Results of approximation terhniques applied to the hiking trail image (image \#4). 


\section{Chapter 4}

\section{Moment-Preserving Method for 1-D Functions}

As mentioned earlier. most if not all of the aproximation tedmignes that hasce furen proposed in the literature, tried to approximate $f(x)$ ly some function $f(x)$ in such it way that the two functions are reasonably close to each of her in the domain of the variable $x$. This requirement will be extended so as to obtain an approximattend function which is reasonably close in both the domain of variable $r$ and its transform domain. where the transformation is the geometric moment function. Since the constraints to be satisfied are much more stringent, they will hopefully lend to a more interesting and powerful strategy.

The novel work done in chapters 4 to 6 are a result of a joint collaloorative work with Professor (Ommen. The work is currently available as a potential pulblication [.i() 94]. A preliminary version of this paper will appear in the Procreediug of IAS-4, the Fourth International Conference on Intelligent Autouomous Systruss, Kinslsruhe. Germany, March 1995.

\subsection{Introduction to Moments}

In classical merhanies, the concept of moments is ntsed extensively. For cxample, an olject of mass $m$ located at position $x$ on the $x$-axis is said to have monent $x$ ' about the point $x=0$, or more generally. moment $\left(s-s_{0}\right) m$ alsont the point $r_{11}$. If several ohjerts of masses $m_{1}, m_{2}, \ldots m_{N}$ are lorated at the points $x_{1}, r_{2} \ldots \ldots r_{N}$. respertively: then the total moment of the system of masses alont the point $r_{11}$ is 
the sum of the individual monernts.

$$
M=\left(r_{1}-r_{1}\right) m m_{1}+\left(r_{2}-x_{1}\right) m_{2}+\cdots+\left(r_{1}-r_{1}\right) m m_{x}=\sum_{i=0}^{x}\left(x_{1}-x_{0}\right) m_{1} .
$$

For a me-dimensional distribution of mass with continumoly variable line cleusity $1(x)$ lying along an interval $[0 . a]$ of the $x$-axis. an element of length $d x$ at porition $x$ contains mass $d m=p(x) d x$. has moment $d . M=x d m=x \rho(x) d x$ albont the origin. Therefore. the total monent aloont the origin is defined as

$$
M=\int_{0}^{n} x \rho(x) d x .
$$

In probalility theory of raudom variables. moments play an important role. For example. if in a game of rolling a single die. a player can win $X$ dollars where $X$ is the anmber showing on top of the rolled die, then in each game the possible winuings are $1,2,3.4$. 5 , or 6 dollars, earh with probalility $1 / 6$. In $N$ number of games. a player can expect to win approximately

$$
\frac{N}{6}+\frac{2 N}{6}+\frac{3 . N}{6}+\frac{4 N}{6}+\frac{5 N}{6}+\frac{6 . N}{6}=\frac{21 N}{6}=\frac{7 N}{2} \text { dollars. }
$$

Thus. his expected average winnings per game are $7 / 2$ dollars, or \$3.50. By using this information, the gaming house can expect a profit if it charges the player more than $\$ 3.50$ for the privelege of rolling the die. The value $7 / 2$ is called the expectation or mean of the discrete random variable $X$. In general. if a random variable can take on values $x_{1}$ with probability $p_{1}, x_{2}$ with probability $p_{2}, \ldots, x_{N}$ with probalsility $p$ where $\sum_{i}^{N} p_{t}=1$, then the mean $\mu$ or expectation $E[X]$ of that random variable is given by

$$
\mu=E[X]=\sum_{i=1}^{N} x_{1} p_{i} .
$$

For a continuous random variable $X$ with probability rensity function $\rho(x)$ " in the interval $[a, b]$, the analogous definition of the mean or the expectation of $\mathrm{X}$ is

$$
\mu=E[X]=\int_{a}^{b} x \rho(x) d x .
$$

\footnotetext{
"If $\mu(x)$ were a mass density such as the case in the classical mechanics example, then $\mu$ would he the moment of the mass about 0 , and since the total mass would be $\int_{a}^{b} \rho(x) d x=1$, $\mu$ would in fact be the centre of mass.
} 
Mere generally: the expectation of any function $g(x)$ of the random varialse $X$ is givell as

$$
E[g(X)]=\int_{a}^{h} g(x) \rho(x) d x
$$

and the particular asse of the mean of a random variable $, X, !(x)=x$. The variunce $\sigma^{2}$ of a raulom varialue $X$ with clensity $\mu(x)$ in the interval $[a . b]$ is the expertation of the square of the distance from $x$ to the mean $\mu$, and hence

$$
\begin{aligned}
\sigma^{2} & =E\left[(X-\mu)^{2}\right]=\int_{a}^{h}(x-\mu)^{2} \mu(x) d x \\
& =E\left[(X-\mu)^{2}\right]=\int_{a}^{h} x^{2} \rho(x) d x-2 \mu \int_{n}^{b} x \rho(x) d x+\mu^{2} \int_{n}^{h} \mu(x) d x .
\end{aligned}
$$

Since $\int_{1}^{h} \rho(x) d x=1$. the expresion above for $\sigma^{2}$ can be simplified as

$$
\begin{aligned}
\sigma^{2} & =E\left[X^{2}\right]-2 \mu^{2}+\mu^{2} \\
& =E\left[X^{2}\right]-\mu^{2} \\
& =E\left[X^{-2}\right]-E[X]^{2}
\end{aligned}
$$

Typically, the first three moments of a function are very useful in describing some of the characteristies of a random variable $X$ with density function $\rho(x)$. The zero ${ }^{\text {th }}$ moment is the area under the curve $\rho(x)$, which can be interpreted as the mass of an object or the total probability. The first moment describes the centre of mass of an object or equivalently the mean or average of the random variable $X$. The second moment in combination with the mean describes the moment of inertin for that object or the variance of the random variable $X$.

\subsection{Relationship between Moments and the Characteristic Equations}

The characteristic function of a random variable $X$ is the Fourier transform of its density function $f(x)$ (with a reversal in sign) [Pap 65], and is clefinerl as

$$
\phi(\omega)=E\left[\kappa^{j \omega x}\right]
$$




$$
=\int_{-x}^{x}, j w r f(x) d x \text {. }
$$

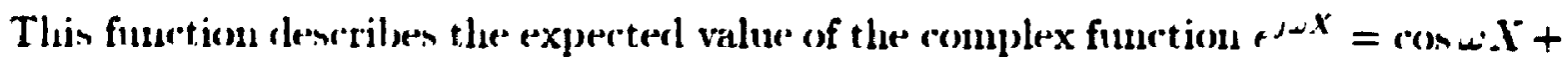
$j$ in $X$ of $X$ where $j=\sqrt{-1}$. If $X$ is of cliscrete type taking values $p$ then

$$
\partial(\omega)=\sum_{k}, \omega^{\prime} \alpha_{k} P\left\{\mathbf{X}=x_{k}\right\}
$$

where $P\left\{X=x_{k}\right\}$ is the probability that the raudom varialue $X$ is equal to some value $r_{k}$.

If ink represents the $k^{\text {th }}$ geometrical moment of a function $f(x)$

$$
m_{k}=E\left[X^{-k}\right]=\int_{-x}^{\infty} x^{k} f(x) d x
$$

where $f(x)$ is the density function of a random variable $x$, then the derivatives of the chararteristic funtion of a random variable $X$ are related to its moments by

$$
\frac{d^{k} \phi(0)}{d \omega^{k}}=j^{k} m_{k}
$$

This correlation can be shown by expanding the chararteristic function $Q(\omega)$ and continuonsly differentiating it with respect to 2 as follows:

$$
\begin{aligned}
o(\omega) & =E\left[e^{j \omega x}\right] \\
& =\int_{-\infty}^{\infty} e^{j \omega x} f(x) d x \\
& =\int_{-\infty}^{\infty}\left(1+\frac{j \omega x}{1 !}+\frac{(j \omega x)^{2}}{2 !}+\cdots+\frac{(j \omega x)^{n}}{n !}+\cdots\right) f(x) d x .
\end{aligned}
$$

Assimming that the termwise integration of the equation above is valid, the following is. thus, obtained,

$$
\begin{aligned}
\phi(\omega)= & \int_{-\infty}^{x} f(x) d x+\frac{j \omega}{1 !} \int_{x}^{\infty} x f(x) d x+\frac{(j \omega)^{2}}{2 !} \int_{x}^{\infty} x^{2} f(x) d x \\
& +\frac{(j \omega)^{3}}{3 !} \int_{x}^{\infty} x^{3} f(x) d x+\cdots+\frac{(j \omega)^{n}}{n !} \int_{\infty}^{\infty} x^{n} f(x) d x+\cdots \\
= & m_{0}+\frac{j \omega}{1 !} m_{1}+\frac{(j \omega)^{2}}{2 !} m_{2}+\cdots+\frac{(j \omega)^{n}}{n !} m_{n}+\cdots
\end{aligned}
$$

As indirated by Papoulis, the above operation holds if the moments $m_{n}$ are finite and the series from equation (14) converges absolutely near $\omega=0$. In this case $o(\omega)$ is given explicitly by (14); therefore. $f(x)$ is uniquely determined from its moments. 


\subsection{Moment-Preserving Approximation}

If $f(x)$ and $g(x)$ are two functions detined loetween the interval $[a, b]$, then from the theory of moments all the heth orcher moments $f x^{k} f(x) d x$ and $f x^{k} y(x) d x$ will be exactly equal for all values of $k$ iff $f(x) \triangleq !(x)$. Howereer. $f(x)$ will lee considerred to be at reasonably good approximation of $f(x)$ if the ir respertive moments matele to some tinite order. $k$. Another requirement in this approximation technique is that it must also be reasonably good in the transform clomain. Althongh this provides much more stringent recquirements to the strategy. these coustraints will hope fully: lead to a more interesting and powerful solution.

To initiate this strategy. it is assimed that the $f(x)$ is continoms 12 . integtalde. and that all of its moments exist. The above assumption is identical to assuming that the appropriate transform of the function exists. In a practionl situation. Lowerer. the explicit functional form of $f(x)$ will be unknown, and it is often spercitien by a set of $S$ of $N$ aliscrete sampling points as

$$
S=\left\{p_{i}=\left(x_{1}, y_{2}\right) \mid i=0,1, \ldots . N\right\} \text {. }
$$

An approximation $\hat{f}(x)$ will be derived from $S$ such that $\hat{f}(x)$ is speritied an set $S$ of $n$ unique points where $n<<$.

$$
\hat{S}=\left\{\hat{p}_{k}=\left(\hat{r}_{k}, \hat{j}_{k}\right) \mid k=0,1, \ldots, n\right\}
$$

$\hat{f}(x)$ is a piecewise polynomial joining the points in the set, $\hat{S}$, and in this particulan case the polynomial is restricted to be linear functions. The notation $\hat{r}_{k}$ and $y_{k}$ is used to emphasize the fart that the set $\dot{S}$ is not a sulsset of $S$. In other worch, the approximation points do uot necessarily lie on the original given curve. $f(x)$.

The main premise of this approximation technique is based on the icleat that two functions will be approximately the same if a finite number of their monuents

\footnotetext{
"For the sake of simplicity in the explanation, all of the derivations will be done on the assummption that $f(x)$ is continuous. In other words. the derivation of the approximation values is baserd on the assumption that a function $f(x)$ is given in its explicit form. The analogous rase where $f(x)$ is n discrete function will also be shown.
} 
are ceptul. Sinde the function of $f(x)$ is ansimed to be known. the monento of the

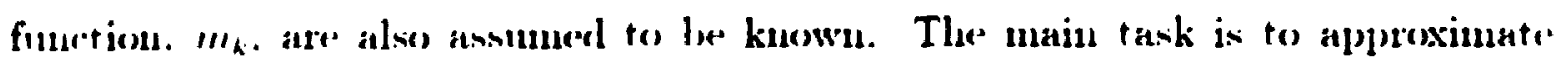
f(r) by perewise linear functions. As indieated in the previons sections. there are many different ways of approathing this problem. However. our constraint here will loe to determine au approximation function $f(x)$ such that a tinite mumber of it sheoretional anoments will be exactly identical to the moments of the original furtion $f(x)$.

Definition 1 Let $f(x)$ and $g(x)$ be two integrable functions between interval [o. b]. If $\int r^{\prime} f(x) d x=\int \cdot r^{2} !(x) d x$ for $a \leq x \leq b$ for all $0 \geq i \geq k$, then $f(x)$ and $g(x)$ are suid to be k:-order equivalent.

Cousider a known function $f$ and some function $g$ which is used to approximate $f$. If we make $f$ and $g$ to be $k$-order equivalent. it implies that the moments, n] to order $k$. of $f$ and $y$ are exartly irlentical which. in turn. implies that in the time/spacial domain and in the transform domain they are approximations.

Let $f(x)$ be the single variable function to be approximated. Then the $k^{\text {th }}$ monent of the function $f(x)$ is defined as

$$
m_{k}=\int x^{k} f(x) d x
$$

where $k=0.1,2 \ldots$. are non-negative integers. It ran be seen that by substituting in for $k=0$ into the equation above. $m_{0}$, the zeroth moment. is the area of under the curve $f(x)$. In the analogous rase of a cliscrete function $f$ defined ly the set of points $\left\{\left(x_{0}, f_{0}\right),\left(x_{1}, f_{1}\right) \ldots,\left(x_{N}, f_{N}\right)\right\}$. the $k^{\text {th }}$ moment is

$$
m_{k}=\sum_{i=0}^{N-1} x_{i}^{k} f_{i} \Delta x_{i+1}
$$

where $J r_{1+1}=r_{1+1}-r_{1}$.

Derivatious for the moment-preserving approximation method will be done for three cases. The first resse approximates a given function $f$ by a single line segment: 
the serend ase approximates it ly two line segments: the thircl case is the general solution where the number of line segments is 11 . In oreler to show some insight into the moment-preserving technique. we will use a speritir axample to ansist in the.

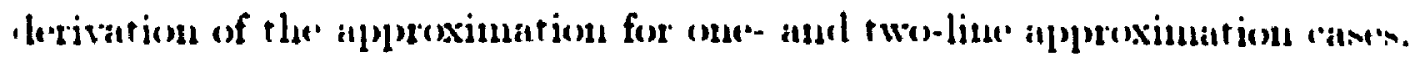

\subsubsection{Single Straight Line (2-point) Approximation}

Let $f(x)$ be a one-dimensional funetion to be approximated ly two prints $\left(. r_{10}, f_{1, n}\right)$ and $\left(x_{1}, \dot{f}_{14}\right)$ where $x_{t 0}$ and $x_{t_{1}}$ are the knot values defined in the domain of $f(x)$

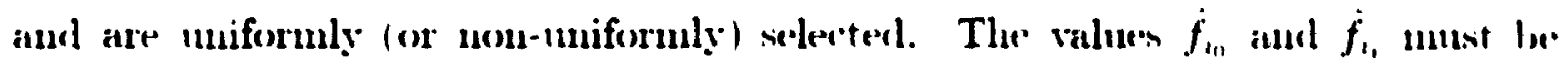
ralculated such that a tinite number of moments of the line segment passing throngh the approximated points $\left(x_{10}, \hat{f}_{t_{0}}\right)$ and $\left(x_{t_{1}}, \hat{f}_{11}\right)$ are exactly iclentical to that of the given function $f$. Since there are two unknowns, a system of at least two analytir ecpuations involving the moments and the two unkuowns $\hat{f}_{10}$ and $\hat{f}_{11}$ is reculired.

Let $\widehat{m}_{11}$ and $\bar{m}_{1}$ be the zeroth and first moments of the function $f(x)$. resilectively. where $f(x)$ is an approximation of the function $f(x)$. and let $m_{10}$ and $m$, he. the zero" and first moments of the function $f(x)$. Then the tirst two monents of the approximated function $\hat{f}(x)$ are

$$
\begin{aligned}
& \widehat{m}_{0}=\int_{x_{10}}^{r_{1_{1}}} \hat{f}(x) d x \\
& \widehat{m}_{1}=\int_{r_{10}}^{r_{11}} x \hat{f}(x) d x
\end{aligned}
$$

The equation of the straight line segment passing throngh the points $\left(, x_{10}, f_{10}\right)$, and $\left(r_{11}, \hat{f}_{1_{1}}\right)$ is givon by:

$$
\begin{aligned}
\frac{\hat{f}(x)-\hat{f}_{11}}{x-x_{11}} & =\frac{\hat{f}_{21}-\hat{f}_{20}}{x_{11}-x_{10}} \\
\hat{f}(x) & =\frac{\hat{f}_{11}-\hat{f}_{20}}{x_{11}-x_{10}}\left(x-x_{11}\right)+\dot{f}_{11} .
\end{aligned}
$$

Substituting $\hat{f}(x)$ into the moment erguations (15) and (16) alove and proceedling 
with the integration. the following expations ate derived.

$$
\begin{aligned}
& \tilde{i}_{111}=\int_{x_{10}}^{x_{11}}\left[\frac{\hat{f}_{1_{1}}-\dot{f}_{10}}{x_{21}-x_{10}} \cdot\left(x-x_{11}\right)+\dot{f}_{21}\right] d x \\
& =\frac{\hat{f}_{i_{1}}-\dot{f}_{t_{1}}}{2\left(r_{11}-x_{10}\right)} \cdot\left(x_{11}^{2}-x_{10}^{2}\right)-r_{11} \cdot \frac{\hat{f}_{11}-\dot{f}_{10}}{x_{11}-x_{10}} \cdot\left(. r_{11}-r_{10}\right) \\
& +\dot{f}_{11} \cdot\left(x_{11}-r_{10}\right) \\
& =\dot{f}_{10} \cdot\left[-\frac{r_{11}^{2}-r_{t 0}^{2}}{2\left(x_{11}-r_{10}\right)}+\frac{r_{11}\left(x_{11}-x_{10}\right)}{x_{11}-x_{10}}\right] \\
& +\hat{f}_{11} \cdot\left[\frac{x_{11}^{2}-x_{10}^{2}}{2\left(x_{11}-x_{10}\right)}-\frac{x_{11}\left(x_{11}-x_{10}\right)}{x_{11}-x_{10}}+\left(x_{11}-x_{10}\right)\right] \\
& =\hat{f}_{10} \cdot\left[\frac{x_{11}-x_{i 0}}{2}\right]+\hat{f}_{i_{1}} \cdot\left[\frac{x_{i_{1}}-x_{i_{0}}}{2}\right]
\end{aligned}
$$

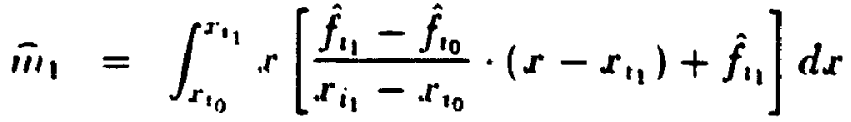

$$
\begin{aligned}
& =\frac{\hat{f}_{11}-\hat{f}_{10}}{3\left(x_{11}-x_{10}\right)} \cdot\left(\cdot r_{11}^{3}-x_{10}^{3}\right) \\
& -x_{11} \cdot \frac{\hat{f}_{11}-\hat{f}_{10}}{2\left(x_{11}-x_{10}\right)} \cdot\left(x_{11}^{2}-x_{10}^{2}\right) \\
& +\frac{\dot{f}_{11}}{2} \cdot\left(x_{11}^{2}-r_{10}^{2}\right) \\
& =\hat{f}_{10} \cdot\left[-\frac{x_{11}^{3}-x_{i 0}^{3}}{3\left(x_{t_{1}}-x_{i 0}\right)}+\frac{x_{11}\left(x_{11}^{2}-x_{10}^{2}\right)}{2\left(x_{11}-x_{10}\right)}\right] \\
& +\hat{f}_{11} \cdot\left[\frac{x_{11}^{3}-x_{10}^{3}}{3\left(x_{11}-x_{10}\right)}-\frac{x_{11}\left(x_{11}^{2}-x_{10}^{2}\right)}{2\left(x_{11}-x_{10}\right)}+\frac{x_{11}^{2}-x_{10}^{2}}{2}\right] \\
& =\hat{f}_{i_{0}} \cdot\left[\frac{x_{11}^{3}-3 x_{11} x_{i 0}^{2}+2 x_{i 0}^{3}}{6\left(x_{11}-x_{i_{0}}\right)}\right] \\
& +\hat{f}_{i_{1}} \cdot\left[\frac{-x_{i_{1}}^{3}+3 x_{11} x_{10}^{2}-2 x_{10}^{3}}{6\left(x_{11}-x_{i n}\right)}+\frac{x_{11}^{2}-x_{10}^{2}}{2}\right] \text {. }
\end{aligned}
$$

At this juncture we re-jterate our goal: the main purpose of this momentpreserving approximation technique is to find a good approximation which will itso preserve the moments of the original function. In the particular rase of a single straight line segment approximation. we therefore require that the first two moments of the of the original function be preserved. and we therefore equate, $\widehat{m}_{0}=m_{0}$ and $\bar{m}_{1}=m_{1}$. By simplifying the equations (17) and (18) from above. the following 
system of equations of two unknowns $\hat{f}_{t_{0}}$ ind $\hat{f}_{t_{1}}$ are formed:

$$
\begin{aligned}
& {\left[\frac{x_{11}-x_{i 0}}{2}\right] \cdot \dot{f}_{t_{0}}+\left[\frac{x_{11}-x_{10}}{2}\right] \cdot \dot{f}_{11}=m_{11}}
\end{aligned}
$$

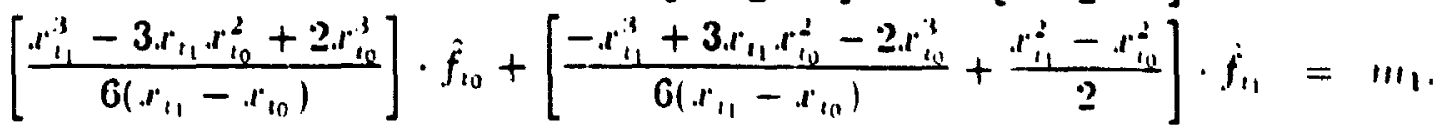

They can be expressed in a matrix notation as

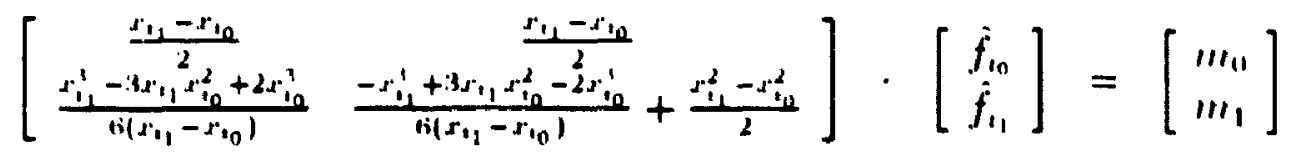

Therefore. the values for $\dot{f}_{i 0}$ and $\hat{f}_{i_{1}}$ and be foumd by

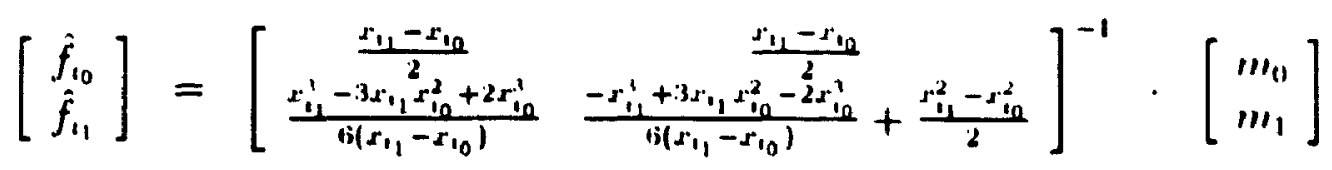

The example below will further illustrate this technique. Suppose that the function $f(x)$ defined in the interval $[0,2]$ is given as $f(x)=-(. x-2)^{2}+4$, and the two kuot values are $x_{i_{0}}=0$ and $x_{11}=2$ as shown in Figure 65. Visnal inspertion of the function indirates that it is symmetrical abont the line $x=2$. and since one of knot values, $r_{i_{1}}$, lies directly on this line of symmetry while the other knot value is 2 units from this line. it can be experted that the line of approximation has a positive slope and that it will pass through the two eud points of the curve. If the knot value $x_{i 1}$ is moved away from the line $x=2$ such that it is closer to the kuot. value $x_{80}$, the slope of the line of approximation should increase positively, beroming more vertical. On the other hand, if the kuot value $x_{10}$ is moved elosere to the line $x=2$, the opposite should ocrur, that is, the slope of the line of approximation will become more horizontal. If the kuot $x_{10}$ is mover closer to the line $r=2$ and the other knot value $x_{1}$ is moved away from the line $x=2$ by the same nmount Deltu. then the values $\hat{f}_{t_{0}}$ and $\hat{f}_{i_{1}}$ will become larger berause the zeroth moment or aren under the function $f$ and $\hat{f}$ are set to be equal so as to presserve the moments.

These visual inspertions are easily veritied by the artual calculations of the moments and parameters required by the matrix as shown in equation (19). The 


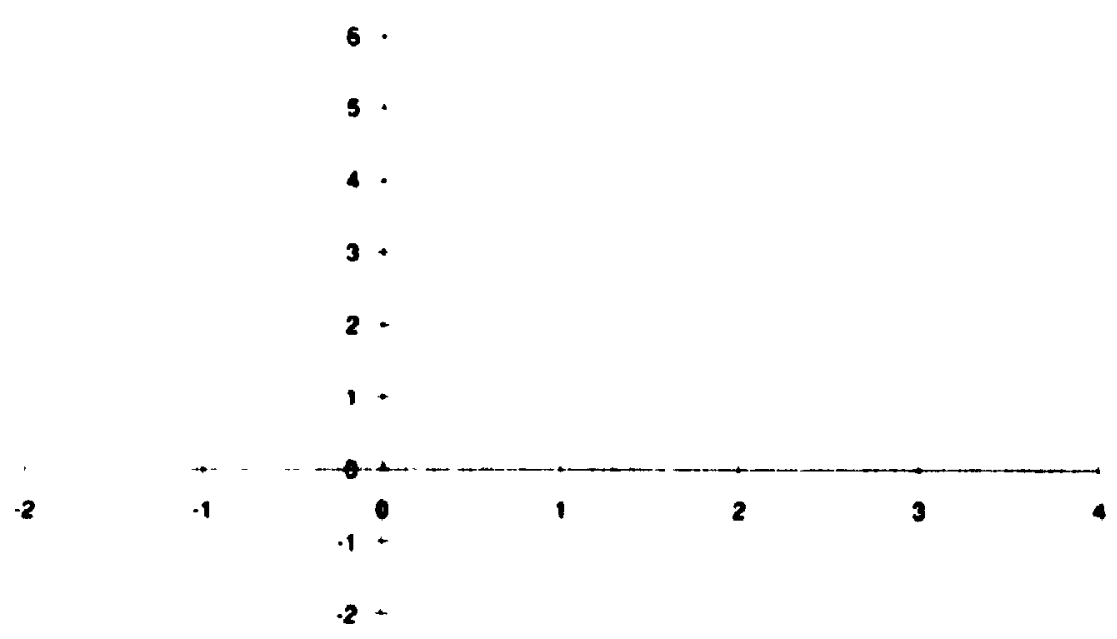

Figure 65: Function $f(x)=-(x-2)^{2}+4$ defined in the interval $[0,2]$

zerocth and tirst moments of $f(x)$ are calculated to be $\frac{16}{3}$ and $\frac{20}{3}$. respectively. The mutrix of equation (19) and its inverse are determined to be

$$
\left[\begin{array}{ll}
1 & 1 \\
\frac{2}{3} & \frac{4}{3}
\end{array}\right]
$$

ind

$$
\left[\begin{array}{cc}
2 & -\frac{3}{2} \\
-1 & \frac{3}{2}
\end{array}\right]
$$

By sulbitituting these values into equation $(20)$, the results $\hat{f}_{i_{0}}$ and $\hat{f}_{i_{1}}$ are found to be equal to $\frac{2}{3}$ and $\frac{14}{3}$. respectively. These values indicate that the line segment which passes through $\left(0, \frac{2}{3}\right)$ and $\left(4, \frac{14}{3}\right)$ is approximately the same as the function $f(x)$ in terms of the first two moments $m_{0}$ and $m_{1}$ as shown in Figure 66(a). The results of the artual calculations correspond with the visually observed properties indicated above, and these results are shown in Figure 66(b)-(d). It should be noted thut as the values of $x_{10}$ and $x_{i}$ come closer together and the moments remain the shme. then the magnitude of the slope of the approximating line segment becomes larger and larger (more vertical) causing the approximation $f(x)$ to diverge from the function $f(x)$. 


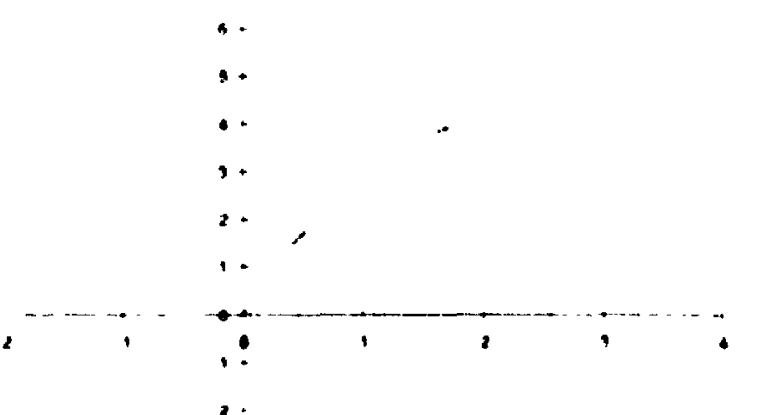

(a)

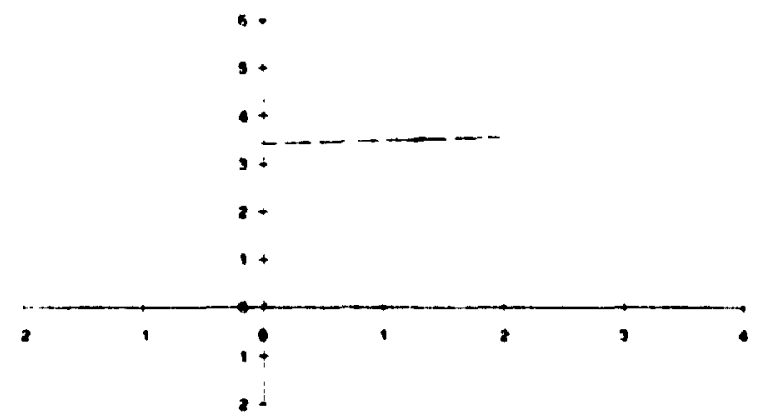

(c)

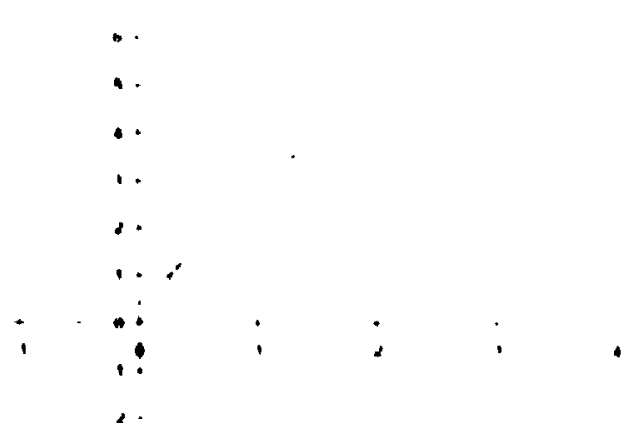

(b)

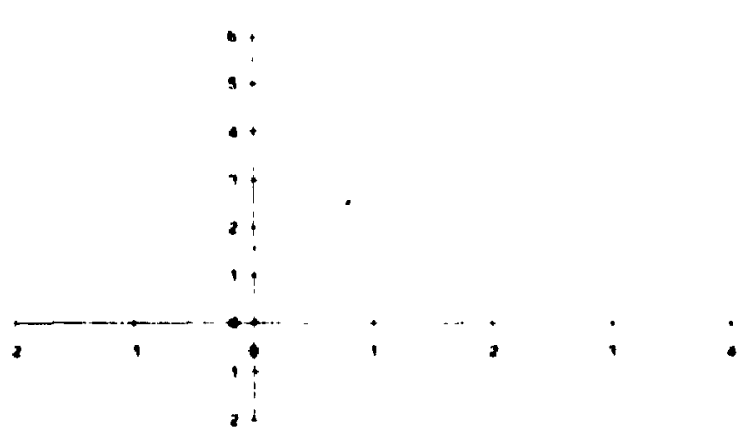

(d)

Figure 66: Restult of single line approximation passing through the different kuos values. (a) Kinot values $x_{10}=0$ and $x_{i_{1}}=2$. (b) Knot valuess $x_{i_{0}}=0$ and $x_{11}=3 / 2$. (c) Kinot values $x_{10}=1$ and $x_{i_{1}}=2$. (d) Knot values $x_{1_{0}}=1 / 2$ and $x_{11}=3 / 2$

\subsubsection{Two-Piecewise-Linear (3-point) Approximation}

The same approach can be applied when the number of approximated points is increased from two to three. The only difference between this rase and the single line approximation is the location of the middle point which is required to join the two line segments together. In order to approximate $f(x)$ with two line seguneuts passing through the points $\left(x_{i_{0}}, \hat{f}_{i_{0}}\right),\left(x_{i_{1}}, \hat{f}_{i_{1}}\right)$, and $\left(x_{i_{1}}, \hat{f}_{i_{2}}\right)$ where $\hat{f}_{i_{1}}$ 's are the approximaterl values, there must be a third linearly independent equation in the new system of equations involving the three unknowns. By using the first three moments of the approximated and artual funrtions, a linear system of thres equations involving the three unknowus $\hat{f}_{i_{0}}, \hat{f}_{i_{1}}$, and $\hat{f}_{i_{2}}$ can be set up. This motivates the following rule necressary for this moment-preserving terhnique: 
Rule 1 Lod $f(s)$ be the orignal function and $f(x)$ be it. approximation. If $f(x)$ approsemates $f(x)$ by $" 1$ pieceunse linear segments. it is necessury that the first " or more momentuts of $f(x)$ be: prese.rwed. This is equimalent too sayping that at least ther first. "mome:n.t.s of $f(x)$ and $\hat{f}(x)$ must be equal.

To l,e more speecific for oner particular scenario, the tirst three moments of $\hat{f}(x)$ are detined as follows.

$$
\begin{aligned}
& \tilde{m i n}_{11}=\int_{x_{10}}^{r_{11}} \hat{f}(x) d x+\int_{r_{11}}^{r_{12}} \hat{f}(x) d x \\
& =\int_{x_{10}}^{x_{11}}\left[\frac{\hat{f}_{11}-\hat{f}_{i_{0}}}{x_{11}-x_{i_{0}}} \cdot\left(x-x_{11}\right)+\hat{f}_{11}\right] d x \\
& +\int_{x_{11}}^{x_{12}}\left[\frac{\hat{f}_{i 2}-\hat{f}_{i_{1}}}{x_{12}-x_{11}} \cdot\left(x-x_{i_{2}}\right)+\hat{f}_{i_{2}}\right] d x \\
& =\frac{\hat{f}_{11}-\hat{f}_{i 0}}{2\left(x_{11}-x_{10}\right)} \cdot\left(x_{11}^{2}-x_{10}^{2}\right) \\
& -x_{11} \cdot \frac{\hat{f}_{11}-\hat{f}_{10}}{x_{11}-x_{10}} \cdot\left(x_{21}-x_{10}\right) \\
& +\hat{f}_{11} \cdot\left(x_{i 1}-x_{10}\right) \\
& +\frac{\hat{f}_{i_{2}}-\hat{f}_{i_{1}}}{2\left(x_{i_{2}}-x_{i_{1}}\right)} \cdot\left(x_{i_{2}}^{2}-x_{i_{1}}^{2}\right) \\
& -x_{i_{2}} \cdot \frac{\hat{f}_{i_{2}}-\hat{f}_{i_{1}}}{x_{i_{2}}-x_{i_{1}}} \cdot\left(x_{i_{2}}-x_{i_{1}}\right) \\
& +\hat{f}_{i_{2}} \cdot\left(x_{t_{2}}-x_{1_{1}}\right) \text {. }
\end{aligned}
$$

Similarly,

$$
\begin{aligned}
& \widehat{m}_{1}=\int_{x_{1_{0}}}^{x_{1_{1}}} x \hat{f}(x) d x+\int_{x_{11}}^{x_{1_{2}}} x \hat{f}(x) d x \\
& =\int_{x_{i_{0}}}^{x_{11}} x\left[\frac{\hat{f}_{i_{1}}-\hat{f}_{i_{0}}}{x_{i_{1}}-x_{i_{0}}} \cdot\left(x-x_{i_{1}}\right)+\hat{f}_{i_{1}}\right] d x \\
& +\int_{x_{11}}^{x_{i_{2}}} x\left[\frac{\hat{f}_{i_{2}}-\hat{f}_{i_{1}}}{x_{i_{2}}-x_{i_{1}}} \cdot\left(x-x_{i_{2}}\right)+\hat{f}\left(x_{i_{2}}\right)\right] d x \\
& =\frac{\left.\hat{f}_{i_{1}}\right)-\hat{f}_{i_{0}}}{3\left(x_{i_{1}}-x_{10}\right)} \cdot\left(x_{11}^{3}-x_{i_{0}}^{3}\right)
\end{aligned}
$$




$$
\begin{aligned}
& -r_{t_{1}} \cdot \frac{\dot{f}_{t_{1}}-\dot{f}_{t_{0}}}{2\left(x_{t_{1}}-x_{t_{1}}\right)} \cdot\left(x_{t_{1}}^{2}-x_{t_{0}}^{2}\right) \\
& +\frac{f_{i_{1}}}{2} \cdot\left(. x_{i_{1}}^{2}-x_{i_{0}}^{2}\right) \\
& +\frac{\hat{f}_{t_{2}}-f_{t_{1}}}{3\left(x_{t_{2}}-x_{t_{1}}\right)} \cdot\left(x_{t_{2}}^{\prime}-x_{t_{1}}^{\prime}\right) \\
& -x_{t_{2}} \cdot \frac{\hat{f}_{i_{2}}-\hat{f}_{i_{1}}}{2\left(x_{i_{2}}-x_{i_{1}}\right)} \cdot\left(x_{i_{2}}^{2}-x_{1_{1}}^{2}\right) \\
& +\frac{\hat{f_{12}}}{\underline{2}} \cdot\left(x_{t_{2}}^{2}-x_{11}^{2}\right) \text {. }
\end{aligned}
$$

Finally:

$$
\begin{aligned}
& \bar{m}_{2}=\int_{x_{10}}^{x_{11}} x^{2} \hat{f}(x) d x+\int_{x_{11}}^{x_{12}} x^{2} \hat{f}(x) d x \\
& =\int_{x_{10}}^{x_{11}} x^{2}\left[\frac{\hat{f}_{11}-\hat{f}_{10}}{x_{11}-x_{10}} \cdot\left(x-x_{21}\right)+\hat{f}_{11}\right] d x \\
& +\int_{x_{11}}^{x_{12}} x^{2}\left[\frac{\hat{f}_{12}-\hat{f}_{i_{1}}}{x_{1_{2}}-x_{1_{1}}} \cdot\left(x-x_{1_{2}}\right)+\hat{f}_{i_{2}}\right] d x \\
& =\frac{\hat{f}_{i_{1}}-\hat{f}_{i_{0}}}{4\left(x_{i_{1}}-x_{i_{0}}\right)} \cdot\left(x_{11}^{4}-x_{i_{0}}^{4}\right) \\
& -x_{11} \cdot \frac{\hat{f}_{11}-\hat{f}_{i 0}}{3\left(x_{21}-x_{i 0}\right)} \cdot\left(x_{11}^{3}-x_{10}^{3}\right) \\
& +\frac{\left.\hat{f}_{11}\right)}{3} \cdot\left(r_{11}^{3}-x_{t 0}^{3}\right) \\
& +\frac{\hat{f}_{i_{2}}-\hat{f}_{11}}{4\left(x_{12}-x_{11}\right)} \cdot\left(x_{i_{2}}^{4}-x_{11}^{4}\right) \\
& -x_{12} \cdot \frac{\hat{f}_{12}-\hat{f}_{i_{1}}}{3\left(x_{1_{2}}-x_{11}\right)} \cdot\left(x_{1_{2}}^{3}-x_{11}^{3}\right) \\
& +\frac{\hat{f}_{12}}{3} \cdot\left(. x_{12}^{3}-x_{11}^{3}\right) \text {. }
\end{aligned}
$$

The three moments of the approximation function $f(x)$ must be aflual to the three corresponding moments of the given function $f(s)$. By erputiug these re. spertive quantities, a system of equations is formed and ran be expressed using the 
matrix notation as

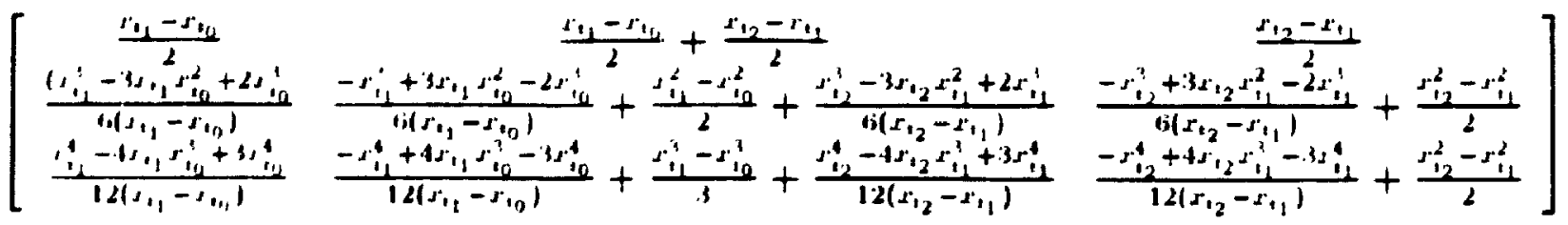

$$
\begin{aligned}
& {\left[\begin{array}{l}
\hat{f}_{t_{0}} \\
\hat{f}_{i_{1}} \\
\hat{f}_{i_{2}}
\end{array}\right]=\left[\begin{array}{l}
m_{0} \\
m_{1} \\
m_{2}
\end{array}\right]}
\end{aligned}
$$

The thres unknown values $\hat{f}_{10} \cdot \hat{f}_{i_{1}}$, and $\hat{f}_{i_{2}}$ can easily be found by multiplying the inverse of the metrix by the known moments. Figure 67 shows the tesinlts of approximating the fumetion $f(x)=-(x-2)^{2}+4$ with two. three. four and five piecewise linear segments where the $x$ values of the knot points are unifurmly distributed aloug the $r$-axis.

\subsubsection{Approximation using $n$ Piecewise Linear Segments}

The general rase in which the number of piecewise linear segments contained in the approximation function is $n$ ran be derived in the same manner as the cases for a single line and two-line approximations. Let the $k^{\text {th }}$ moment of an $n$-pieceswise linear approximation function $\hat{f}(x)$ be defined as the sum of the moments of the individual segments

$$
\widehat{m}_{k}=S_{k, 1}+S_{k, 2}+\cdots+S_{k, n}
$$

Then the $k^{\text {th }}$ moment of the indivirlual segments can be obtained as follows.

$$
\begin{aligned}
& S_{k, 1}=\int_{x_{10}}^{x_{11}} x^{k}\left[\frac{\hat{f}_{i_{1}}-\hat{f}_{i_{0}}}{x_{11}-x_{10}} \cdot\left(x-x_{11}\right)+\hat{f}_{i_{1}}\right] d x \\
& =\int_{x_{i_{0}}}^{x_{i_{1}}}\left[\frac{\hat{f}_{i_{1}}-\hat{f}_{i_{0}}}{x_{i_{1}}-x_{i_{0}}} \cdot x^{k+1}-\frac{x_{i_{1}}\left(\hat{f}_{i_{1}}-\hat{f}_{i_{0}}\right)}{x_{i_{1}}-x_{i_{0}}} \cdot x^{k}+\hat{f}_{i_{1}} \cdot x^{k}\right] d x \\
& =\left[\frac{\hat{f}_{11}-\hat{f}_{i_{0}}}{(k+2)\left(x_{i 1}-x_{i 0}\right)} \cdot x^{k+2}-\frac{r_{i_{1}}\left(\hat{f}_{i_{1}}-\hat{f}_{i_{0}}\right)}{(k+1)\left(x_{i_{1}}-x_{i_{0}}\right)} \cdot x^{k+1}+\hat{f}_{i_{1}} \cdot \frac{x^{k+1}}{k+1}\right]_{i_{10}}^{x_{11}} \\
& =\frac{\hat{f}_{11}-\hat{f}_{10}}{(k+2)\left(r_{11}-x_{10}\right)} \cdot\left(x_{11}^{k+2}-r_{10}^{k+2}\right)
\end{aligned}
$$




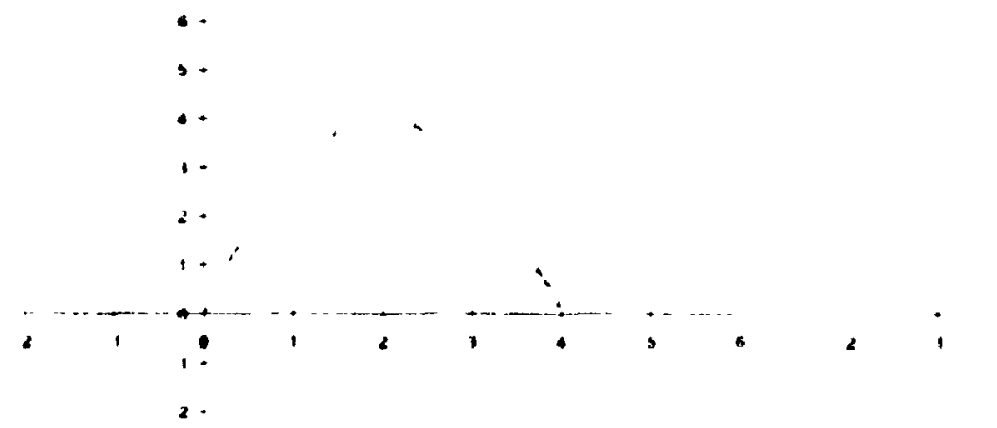

(a)

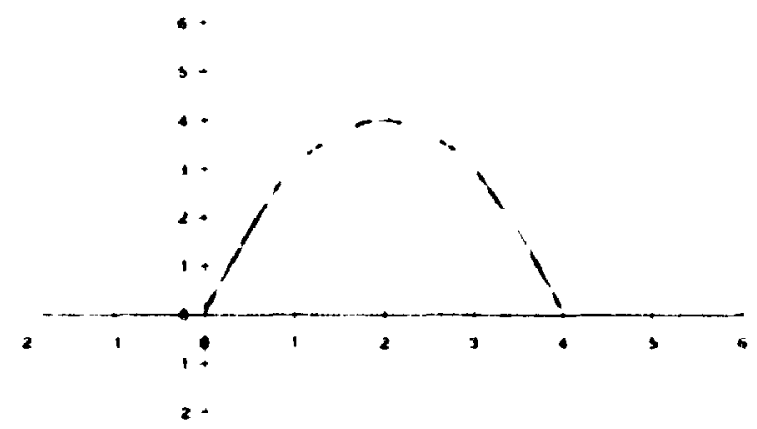

(c)

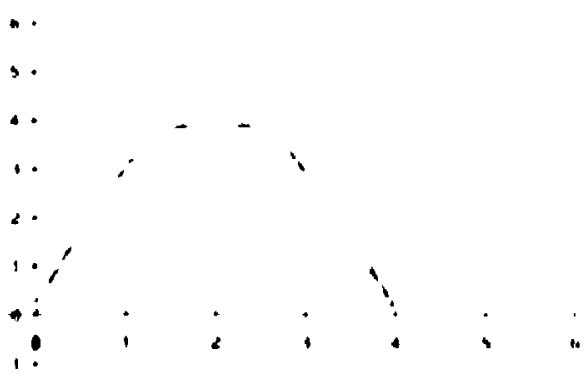

(b)

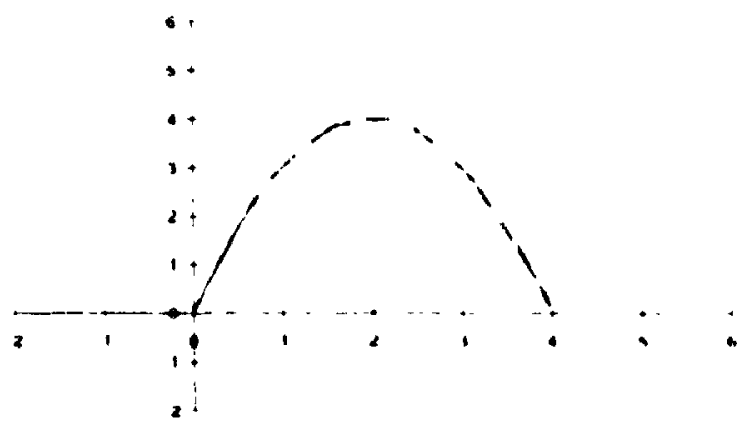

(d)

Figure 67: Results of different number of approximating lines different kuot values. (a) Three knot values $x_{i_{0}}=0, x_{i_{1}}=2$, and $x_{i_{2}}=4$. (b) Four kuot values $r_{t_{n}}=0$. $r_{1_{1}}=4 / 3 . x_{t_{2}}=8 / 3$, and $x_{t_{3}}=4$. (c) Five knot values $x_{t_{0}}=0$ and $r_{t_{1}}=1, r_{t_{2}}=2$. $r_{11}=3$. and $x_{14}=4$. (d) Six knot values $x_{i_{0}}=0 . x_{11}=4 / 5, x_{12}=8 / 5, x_{11}=12 / 5$. $r_{14}=16 / 5$. and $x_{1 ;}=4$.

$$
\begin{aligned}
& -\frac{x_{11}\left[\hat{f}_{i_{1}}-\hat{f}_{i_{0}}\right]}{(k+1)\left(x_{i_{1}}-x_{i_{0}}\right)} \cdot\left(x_{11}^{k+1}-x_{i_{0}}^{k+1}\right)+\hat{f}_{i_{1}} \cdot \frac{x_{11}^{k+1}-x_{t_{0}}^{k+1}}{k+1} \\
& =\hat{f}_{i_{0}} \cdot\left[-\frac{x_{11}^{k+2}-x_{i_{0}}^{k+2}}{(k+2)\left(x_{11}-x_{10}\right)}+\frac{x_{i_{1}}\left(x_{11}^{k+1}-x_{t_{0}}^{k+1}\right)}{(k+1)\left(x_{11}-x_{i_{0}}\right)}\right] \\
& +\hat{f}_{i_{1}} \cdot\left[\frac{x_{i_{1}}^{k+2}-x_{i_{0}}^{k+2}}{(k+2)\left(x_{i_{1}}-x_{10}\right)}-\frac{x_{i_{1}}\left(x_{11}^{k+1}-x_{i_{0}}^{k+1}\right)}{(k+1)\left(x_{i_{1}}-x_{10}\right)}+\frac{x_{11}^{k+1}-x_{i_{0}}^{k+1}}{k+1}\right] \\
& =\hat{f}_{i_{0}} \cdot\left[\frac{x_{11}^{k+2}-(k+2) x_{1} \cdot x_{10}^{k+1}+(k+1) x_{10}^{k+2}}{(k+1)(k+2)\left(x_{i_{1}}-x_{i_{0}}\right)}\right] \\
& +\hat{f}_{11} \cdot\left[\frac{-x_{i 1}^{k+2}+(k+2) x_{11} x_{10}^{k+1}-(k+1) x_{10}^{k+2}}{(k+1)(k+2)\left(x_{11}-x_{10}\right)}+\frac{x_{11}^{k+1}-x_{10}^{k+1}}{k+1}\right] \\
& S_{k .2}=\int_{x_{11}}^{x_{i_{2}}} x^{k}\left[\frac{\hat{f}_{i_{2}}-\hat{f}_{i_{1}}}{x_{i_{2}}-x_{i_{1}}} \cdot\left(x-x_{t_{2}}\right)+\hat{f}_{i_{2}}\right] d x
\end{aligned}
$$




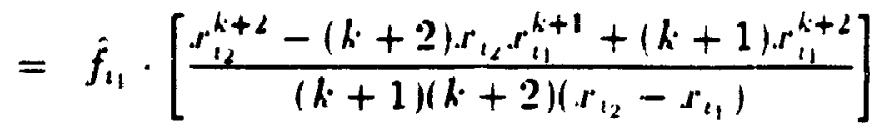

$$
\begin{aligned}
& +\hat{f}_{i_{2}} \cdot\left[\frac{-x_{t_{2}}^{k+k}+(k+2) \cdot r_{t_{2}} \cdot r_{11}^{k+1}-(k+1) \cdot x_{11}^{k+2}}{(k+1)(k+2)\left(r_{i_{2}}-x_{t_{1}}\right)}+\frac{x_{t_{2}}^{k+1}-x_{t_{1}}^{k+1}}{k+1}\right]
\end{aligned}
$$

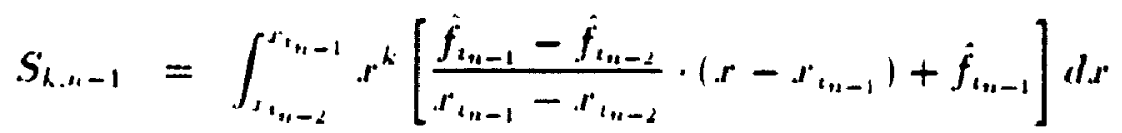

$$
\begin{aligned}
& =\hat{f}_{t n-2} \cdot\left[\frac{x_{t n-1}^{k+2}-(k+2) \cdot x_{t n-1} \cdot x_{t n-2}^{k+1}+(k+1) x_{t n-2}^{k+2}}{(k+1)(k+2)\left(x_{i n-1}-x_{i n-2}\right)}\right] \\
& +\hat{f}_{i_{n-1}} \cdot\left[\frac{-x_{i_{n-1}}^{k+2}+(k+2) x_{i_{n-1}} x_{i_{n-2}}^{k+1}-(k+1) x_{i_{n-2}}^{k+2}}{(k+1)(k+2)\left(x_{i_{n-1}}-x_{i_{n-2}}\right)}+\frac{x_{i_{n-1}}^{k+1}-x_{i_{n-2}}^{k+1}}{k+1}\right]
\end{aligned}
$$

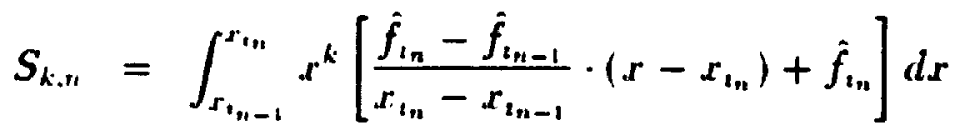

$$
\begin{aligned}
& =\hat{f}_{i n-1} \cdot\left[\frac{r_{i n}^{k+2}-(k+2) x_{i n} x_{i n-1}^{k+1}+(k+1) x_{i n-1}^{k+2}}{(k+1)(k+2)\left(x_{i n}-x_{i n-1}\right)}\right] \\
& +\dot{f}_{i_{n}} \cdot\left[\frac{-x_{t_{n}}^{k+2}+(k+2) \cdot x_{t_{n}} x_{t_{n-1}}^{k+1}-(k+1) x_{t_{n-1}}^{k+2}}{(k+1)(k+2)\left(x_{i_{n}}-x_{i_{n-1}}\right)}+\frac{x_{t_{n}}^{k+1}-x_{i_{n-1}}^{k+1}}{k+1}\right]
\end{aligned}
$$

Therefore. $\tilde{m}_{k}$ ran be rewritten as

$$
\begin{aligned}
& \overline{m i n}_{k}=\hat{f}_{10} \cdot\left[\frac{x_{11}^{k+2}-(k+2) \cdot x_{11} \cdot x_{10}^{k+1}+(k+1) x_{20}^{k+2}}{(k+1)(k+2)\left(x_{11}-x_{10}\right)}\right] \\
& +\hat{f}_{11} \cdot\left[\frac{-x_{11}^{k+2}+(k+2) x_{11} x_{20}^{k+1}-(k+1) x_{10}^{k+2}}{(k+1)(k+2)\left(x_{11}-x_{10}\right)}+\frac{x_{11}^{k+1}-x_{20}^{k+1}}{k+1}\right. \\
& \left.+\frac{x_{32}^{k+2}-(k+2) x_{i_{2}} x_{11}^{k+1}+(k+1) x_{11}^{k+2}}{(k+1)(k+2)\left(x_{12}-x_{11}\right)}\right] \\
& +\hat{f}_{i_{2}} \cdot\left[\frac{-x_{12}^{k+2}+(k+2) x_{i_{2}} x_{i_{1}}^{k+1}-(k+1) x_{i_{1}}^{k+2}}{(k+1)(k+2)\left(x_{i_{2}}-x_{i_{1}}\right)}+\frac{x_{t_{2}}^{k+1}-x_{i_{1}}^{k+1}}{k+1}\right. \\
& \left.+\frac{x_{23}^{k+2}-(k+2) x_{t_{3}} x_{t_{2}}^{k+1}+(k+1) x_{i_{2}}^{k+2}}{(k+1)(k+2)\left(x_{12}-w_{1_{2}}\right)}\right] \\
& + \\
& +\hat{f}_{i_{n-1}} \cdot\left[\frac{-x_{i_{n-1}}^{k+2}+(k+2) x_{i_{n-1}} x_{i_{n-2}}^{k+1}-(k+1) x_{i_{n-2}}^{k+2}}{(k+1)(k+2)\left(x_{i_{n-1}}-x_{i_{n-2}}\right)}+\frac{x_{i_{n-1}}^{k+1}-x_{i_{n-2}}^{k+1}}{k+1}\right. \\
& \left.+\frac{r_{i n}^{k+2}-(k+2) x_{i n} x_{i n-1}^{k+1}+(k+1) x_{i n-1}^{k+2}}{(k+1)(k+2)\left(x_{i n}-x_{i n-1}\right)}\right]
\end{aligned}
$$




$$
+\hat{f}_{n n} \cdot\left[\frac{-x_{n n}^{k+2}+(k+2) \cdot x_{t n} \cdot x_{t n-1}^{k+1}-(k+1) \cdot x_{t n-1}^{k+2}}{(k+1)(k+2)\left(\cdot x_{t n}-x_{t n-1}\right)}+\frac{x_{n+1}^{k+1}-x_{t n-1}^{k+1}}{k+1}\right]
$$

Let

$$
\begin{aligned}
& C_{k, t}=\frac{r_{1+1}^{k+2}-(k+2) x_{,+1} x_{j}^{k+1}+(k+1) x_{1}^{k+2}}{(k+1)(k+2)\left(x_{1+1}-x_{1}\right)} \\
& D_{k, .,}=\frac{r_{1+1}^{k+1}-x_{1}^{k+1}}{k+1}
\end{aligned}
$$

where $0 \leq j \leq(n-1)$ and $0 \leq k \leq n$, then

$$
\begin{aligned}
\widehat{m}_{k}= & \hat{f}_{i_{0}} \cdot C_{k, 0} \\
& +\hat{f}_{i_{1}} \cdot\left(-C_{k, 11}+D_{k, 0}+C_{k, 1}\right) \\
& +\hat{f}_{i_{2}} \cdot\left(-C_{k, 1}+D_{k, 1}+C_{k, 2}\right) \\
& + \\
& \vdots \\
& +\hat{f}_{i_{n-1}} \cdot\left(-C_{k, n-2}+D_{k, n-2}+C_{k, n-1}\right) \\
& +\hat{f}_{i_{n}} \cdot\left(-C_{k, n-1}+D_{k, n-1}\right)
\end{aligned}
$$

If $\mathbf{E}_{\mathrm{j}}$ is a column vector of $n$ elements clefined by

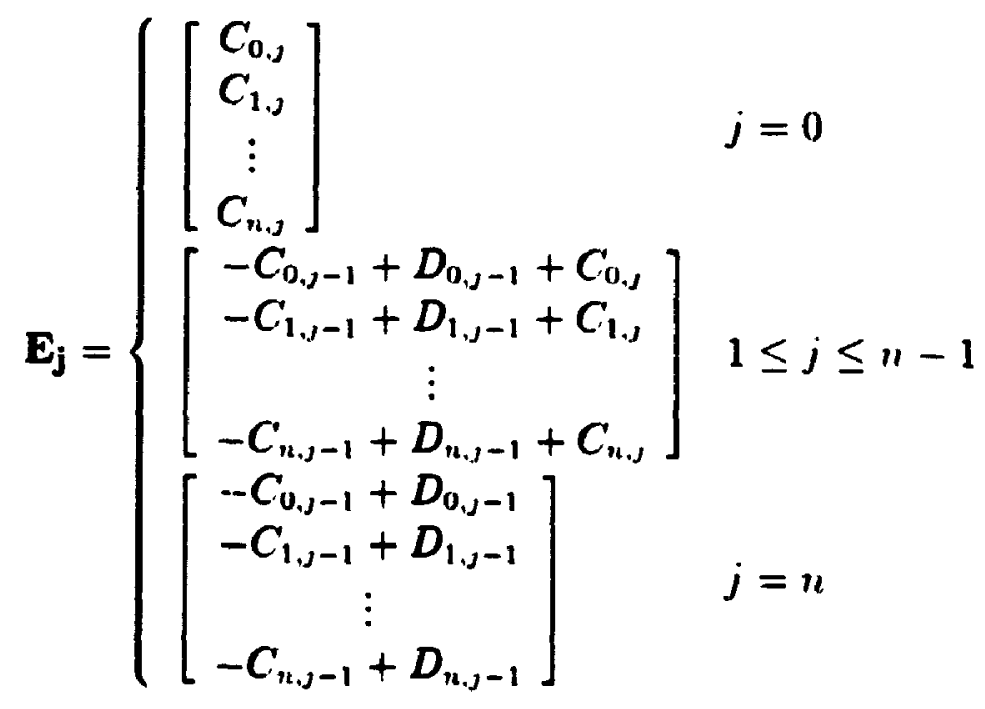


then the system involving the $"$ equations and $n$ unknowns $f_{i_{0}} . f_{i_{1}} \ldots f_{\text {In }}$ cau loe silmmarized in a matrix notation as

$$
\left[\begin{array}{llllll}
\mathbf{E}_{0} & \mathbf{E}_{1} & \mathbf{E}_{2} & \cdots & \mathbf{E}_{11-1} & \mathbf{E}_{\mathbf{u}}
\end{array}\right] \cdot\left[\begin{array}{c}
\hat{f}_{1 n} \\
\hat{f}_{11} \\
\hat{f}_{12} \\
\vdots \\
\hat{f}_{i_{n-1}} \\
\hat{f}_{i n}
\end{array}\right]=\left[\begin{array}{c}
m_{11} \\
m_{1} \\
m_{2} \\
\vdots \\
m_{n-1} \\
m_{n}
\end{array}\right]
$$

\subsubsection{Continuous versus Discrete Functions $f(x)$}

All of the derivations described previonsly are based on the assumption that the given function $f(x)$ is continuous. However, in many practical applications, the function is never given in its closed form. In these situations. if $f(x)$ is described by a sequence of discrete points, then the same formula from above can be applied to the original function $f(x)$. Let $f(x)$ be given as a sequence of $N+1$ points:

$$
\left\{\left(x_{i}, f_{i}\right) \mid i=0,1,2, \ldots, v\right\}
$$

Then the $k^{\text {th }}$ moment of the original function $f(x)$ is given by:

$$
\begin{aligned}
m_{k}= & f_{0} \cdot C_{k, 0} \\
& +f_{1} \cdot\left(-C_{k, 0}+D_{k, 0}+C_{k, 1}\right) \\
& +f_{2} \cdot\left(-C_{k, 1}+D_{k, 1}+C_{k, 2}\right) \\
& + \\
& \vdots \\
& +f_{N-1} \cdot\left(-C_{k, N-2}+D_{k, N-2}+C_{k, N-1}\right) \\
& +f_{N} \cdot\left(-C_{k, N-1}+D_{k, N-1}\right)
\end{aligned}
$$

where

$$
C_{k, j}=\frac{x_{j+1}^{k+2}-(k+2) x_{j+1} x_{j}^{k+1}+(k+1) x_{j}^{k+2}}{(k+1)(k+2)\left(x_{j+1}-x_{j}\right)}
$$




$$
D_{k .,}=\frac{r_{j+1}^{k+1}-x_{j}^{k+1}}{k+1}
$$

for $0 \leq j \leq(x-1)$ and $0 \leq k \leq x$. Using this, the exart $k^{\text {th }}$ moment of $f(x)$ amd $\hat{f}(x)$ can be equated to yield the piecewise linear approximation.

\subsection{Experimental Results on One-dimensional Functions}

In this chapter. a new moment-preserving piecewise linear approximation technichne has been presented. This approximation method is analysed in detail for speritic cases of single-line-segment and two-piecewise-line-segment approximations. A general solution for $\boldsymbol{N}$-piecewise-line- segments is also derived from the hasic principle of moments.

In order to arcurately rompare this technique with the other technicques reviewed in Chapter 2. the same list of one-dimensional functions will be used:

1. $f_{1}(x)=5 \sin 4 x+4 \cos 3 x$, defined in interval $[0,10]$.

2. $f_{2}(x)=\frac{20}{\sqrt{2 \pi}} e^{-2 x^{2}}$ defined in interval $[-6,6]$.

3. $f_{3}(x)=$ Sawtooth waves defined in interval $[-12,12]$.

4. $f_{4}(x)=\frac{i \sin x}{x}$ defined in interval $[-10.2,12.1]$.

5. $f_{5}(x)=\frac{7 \sin x}{x}+$ Sawtooth waves defined in interval $[-10.2,12.1]$.

6. $f_{6}(x)=5 \sin 4 x+4 \cos 3 x+2 \cos 200 x$ defined in interval $[0,10]$.

Results of this approximation terhnique as it is applied to the list of ompdimensional functions are shown and tabulated below. A comparison can be moule between these moment-preserving approximations and the previous methorls listerl in Sertion 3.3. Using the SNR as the major criterion, results from the momentpreserving technique as applied to function $f_{1}$ are much better than the nerarestneighbour, split and merge, and minimax methorls. It is not as good as the linear 
nud recursive split methork if the same number of line segments are nsed. Howerer.

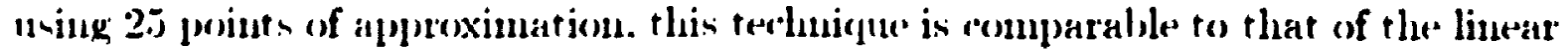
ind recursive split methods. This terdmigne ontperforms all other time/spacial domain terlaniches for the approximation of the normal bell curve (function $f_{2}$ ): with cxartly tive points of approximation this terhinique arhietes the S.NR of orer $14 d B$. whereas the linear and recoursive split methods has an SNR of under 12dB. This rerlinique has a lot of difficulty appreximating the sawtoxth waves; the SNR value of at 21-point moment-presierving approximation is less than the S.NR value of an 18-point approximation of the split and merge method. This seems to indiate that the moment-preserving methor? cannot be applied to functions which have sharp arlges (dratistic changes). It is interesting to note that the approximation of the uoisy function (function $f_{6}$ ) is identical to that of the approximation of the nomuoisy function (function $f_{1}$ ). Our experimental experience tends to show that the moment-preserving approximation is capalble of filtering undesirable high frequency nuise in any signal. 


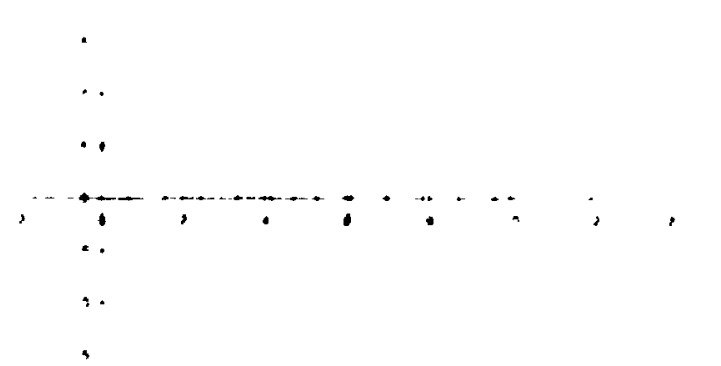

(a)

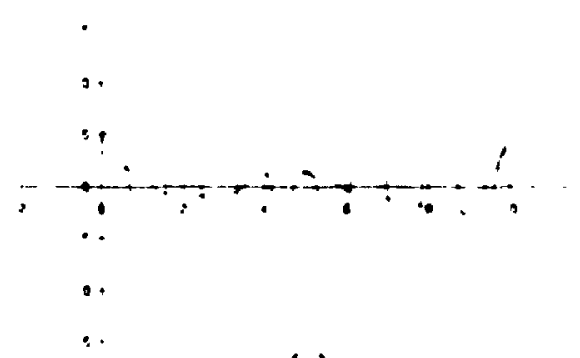

(c)

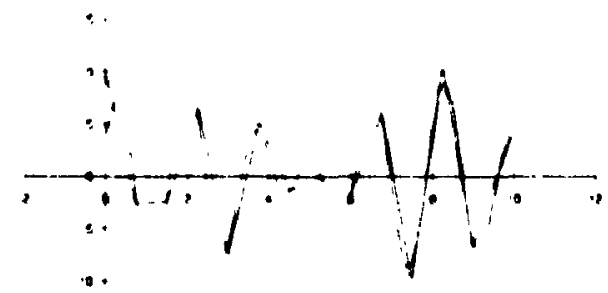

(e)

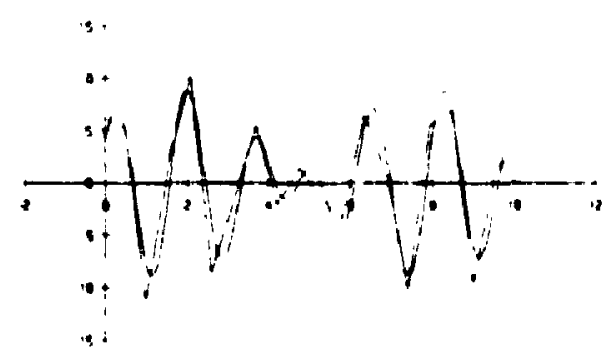

(g)

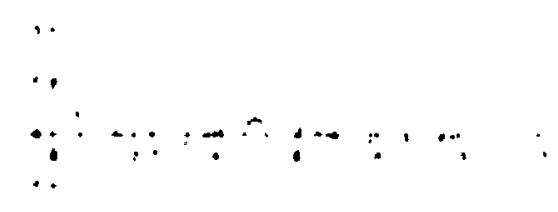

(b)

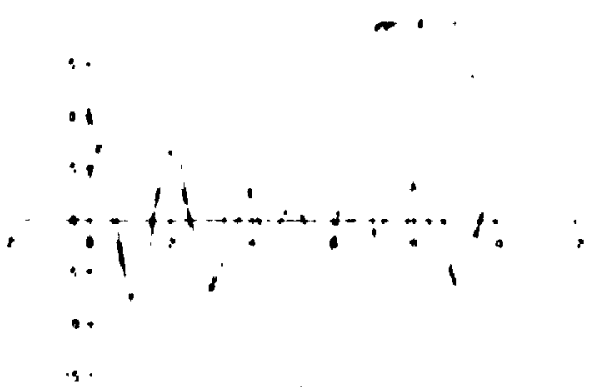

(d)

(f)

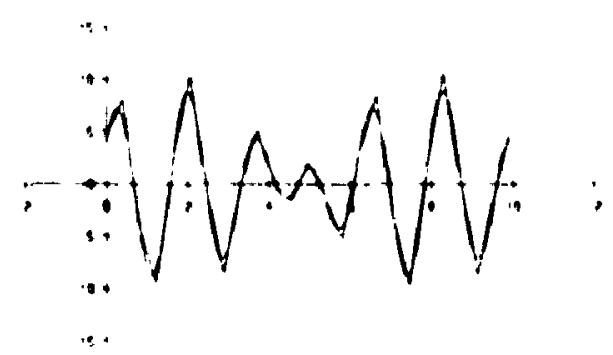

(h)

Figure 68: (a) to (h) Original function $f_{1}$ and several moment-presterving mpproximations with the number of approximating points loeing $5,8,11,14,17,20$, and 25. resperetively. 


\begin{tabular}{|c|c|c|c|c|c|}
\hline $\begin{array}{l}\text { Approximetion } \\
\text { Mothod }\end{array}$ & $\begin{array}{l}\text { of Approx. } \\
\text { Pounts }\end{array}$ & $\underset{\text { Roquined }}{\text { Time }}$ & $\underset{\left(E_{m}\right)}{M E}$ & $\begin{array}{c}\text { MSE } \\
\left(E_{2} N\right)\end{array}$ & $\begin{array}{l}\text { SNR } \\
\text { (DB) }\end{array}$ \\
\hline $\begin{array}{l}\text { Unear Split } \\
\text { (Ramer) }\end{array}$ & 14 & 216 & 2.359 & 1.1337 & .11 .7755 \\
\hline Splinnerpes & $3 c$ & 1004 & 40758 & 3.0508 & -17.1851 \\
\hline $\begin{array}{l}\text { Avg. neughbours } \\
\text { (Tanimoto) }\end{array}$ & 18 & 52 & 8.9249 & 19.2216 & -24.0685 \\
\hline $\begin{array}{l}\text { Mologrant tho } \\
\text { (Prudintiemes) }\end{array}$ & 18 & 40 & 3.0049 & 2.4637 & -15.2042 \\
\hline$\underset{\text { (Kurozumin) }}{\text { Minimax }}$ & 14 & 1664 & 8.3923 & 6.7534 & -19.5258 \\
\hline $\begin{array}{l}\text { Pacuming exim } \\
\text { (Lowim) }\end{array}$ & 14 & 200 & 2.350 & 1.1337 & -11.7750 \\
\hline DFT & N/A & 236 & 9.5971 & 9.8354 & -21.1585 \\
\hline DCT & $m A$ & 100 & 21801 & 0.0098 & -0.5873 \\
\hline $\begin{array}{l}\text { Moment- } \\
\text { Presenving }\end{array}$ & 5 & 242 & 9.6563 & 24.2376 & .25 .0755 \\
\hline " & 8 & 180 & 10.004 & 2a.4cat & 25.1183 \\
\hline$"$ & 11 & 206 & 9.5889 & 15.043 & 23.0039 \\
\hline • & 14 & 219 & 63154 & 5.8214 & +188908 \\
\hline$"$ & 17 & 233 & 5.019 & 4.1455 & .17 .4064 \\
\hline • & 2 & 29 & $4 \pi 002$ & 3.189t & .16.19at \\
\hline " & 25 & 300 & 1.7276 & 0.3549 & -6.7314 \\
\hline
\end{tabular}

Figure 69: Comparison table of various approximation terhniques on function $f_{1}$. 


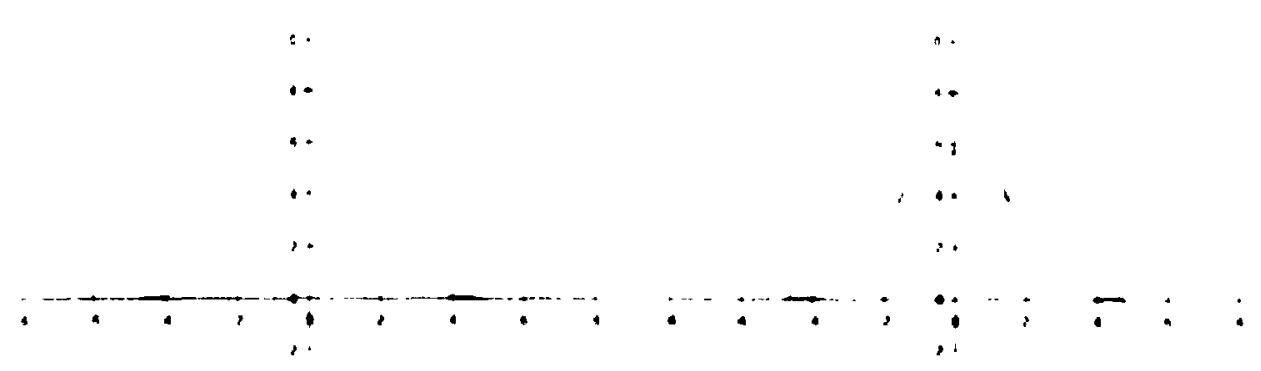

(a)

(b)

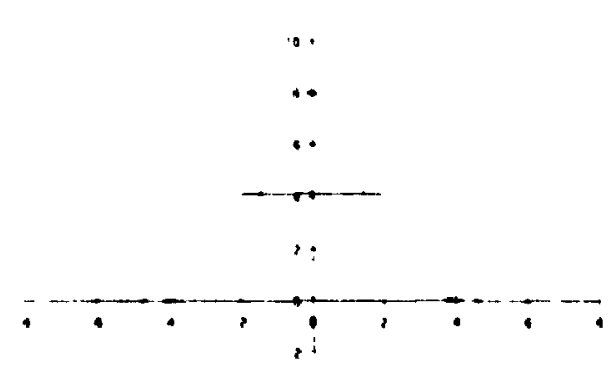

(c)

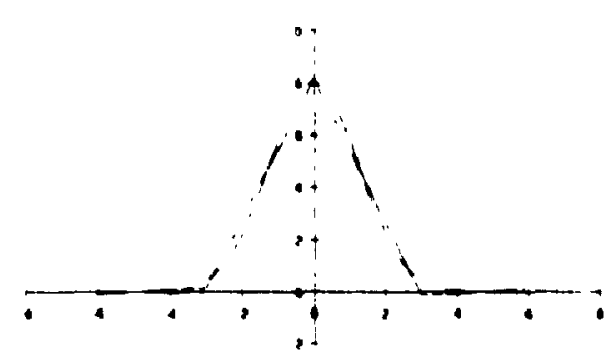

(e)

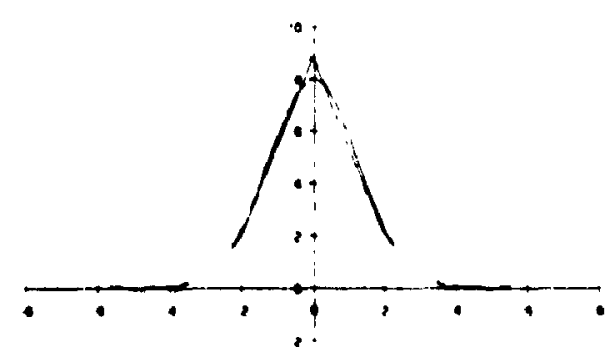

Figure 70: (a) to (h) Original function $f_{2}$ and several mounent-prestrving (h)prox- $^{\text {(g) }}$

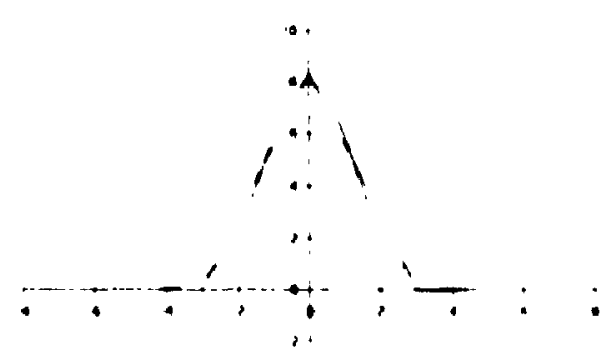

(d)

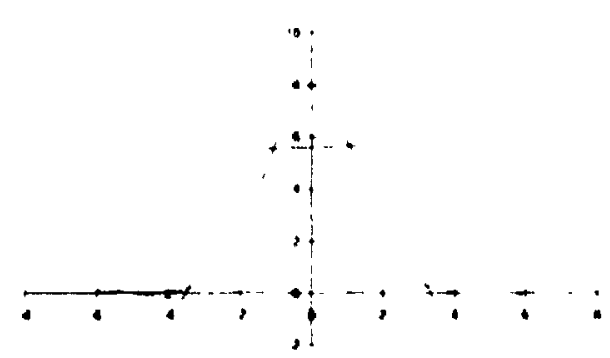

(f)

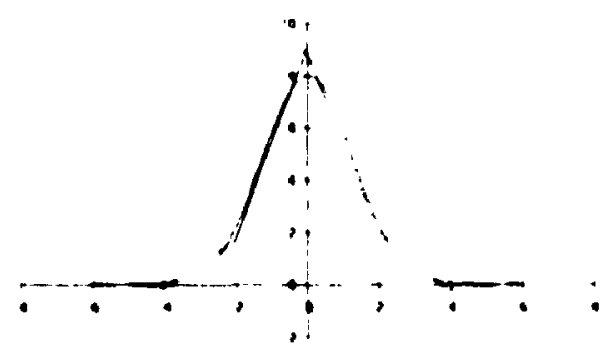

Figure 70: (a) to (h) Original function $f_{2}$ and several moment-pereserving npproximations with the number of approximating points leiug 3, 4. 5. 5. 6. 7 , iurl 8 , respertively. 


\begin{tabular}{|c|c|c|c|c|c|}
\hline $\begin{array}{l}\text { Appraximation } \\
\text { Mothod }\end{array}$ & $\begin{array}{l}\text { of Approx. } \\
\text { Ponts }\end{array}$ & Required & $\begin{array}{c}M E \\
\left(E_{-}\right)\end{array}$ & $\begin{array}{c}M S E \\
\left(E_{2} N\right)\end{array}$ & $\begin{array}{l}\text { SNR } \\
\text { (dB) }\end{array}$ \\
\hline $\begin{array}{l}\text { Linoar Splin } \\
\text { (Ramer) }\end{array}$ & 5 & 129 & 0.73505 & 0.1346 & 11.9091 \\
\hline Eximpringe & 12 & 62 & 0.0003 & 0.133 & 11.0560 \\
\hline $\begin{array}{l}\text { Avg. neighbours } \\
\text { (Tanimoto) }\end{array}$ & 34 & 62 & 0.8028 & 0.1633 & 11.0704 \\
\hline 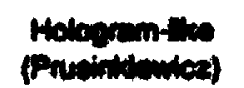 & 10 & $\mathbf{s}$ & 0.2442 & 0.0058 & 20.7908 \\
\hline$\underset{\text { (Kurazumi) }}{\text { Minimax }}$ & 7 & 5901 & 1.4142 & 0.2721 & 8.8518 \\
\hline 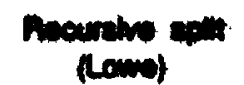 & 8 & 12 & 0.745 & 0.1346 & 11.0001 \\
\hline DFT & NA & 243 & 1.6673 & 0.2059 & 10.0619 \\
\hline Det & $M$ & 19 & $0.12 \pi s$ & 0.002 & so:24t1 \\
\hline $\begin{array}{l}\text { Momant- } \\
\text { Presenving }\end{array}$ & 3 & 157 & 2.3925 & 1.695 & 0.9038 \\
\hline$*$ & 4 & 207 & sexs & $3 \sin x$ & 21140 \\
\hline " & $\mathbf{5}$ & 247 & 0.5522 & 0.0697 & 14.7607 \\
\hline - & 5 & 184 & 0.6124 & 0.000 & Mo171 \\
\hline$*$ & 6 & 171 & 1.8403 & 0.9427 & 3.4518 \\
\hline * & 7 & 20 & $0.700 \mathrm{~s}$ & 0.000 & 14040 \\
\hline$"$ & a & 181 & 0.9755 & 0.0751 & 14.4392 \\
\hline
\end{tabular}

Figure i1: Comparison table of various approximation terhniques on function $f_{2}$. 


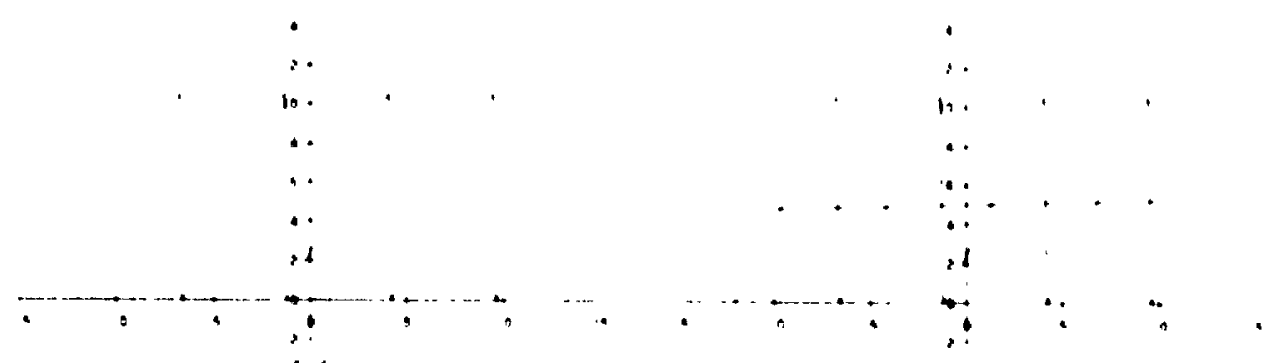

(a)

(b)

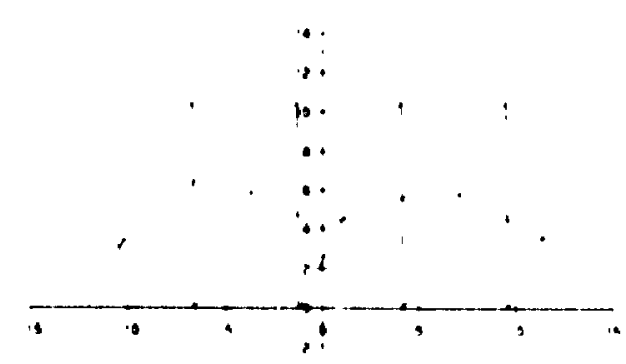

(c)

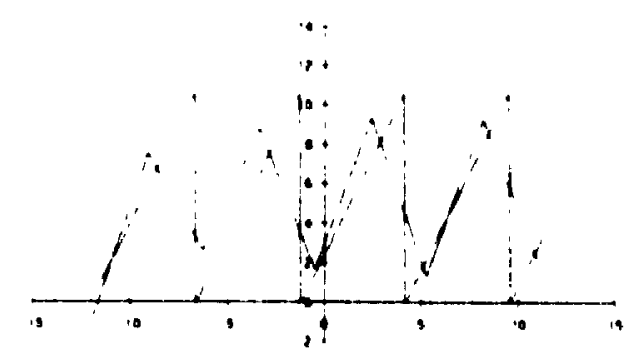

(e)

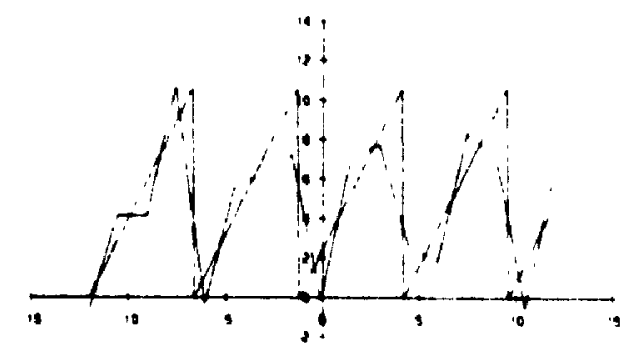

(g)

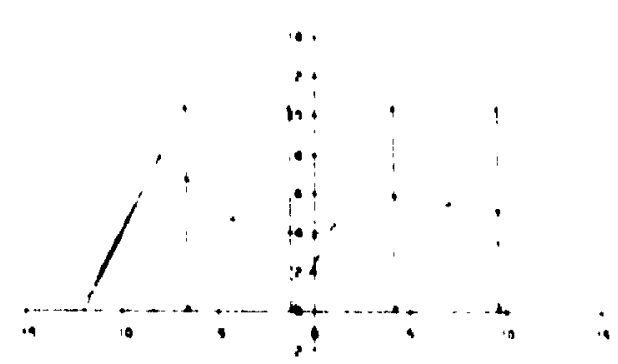

(d)

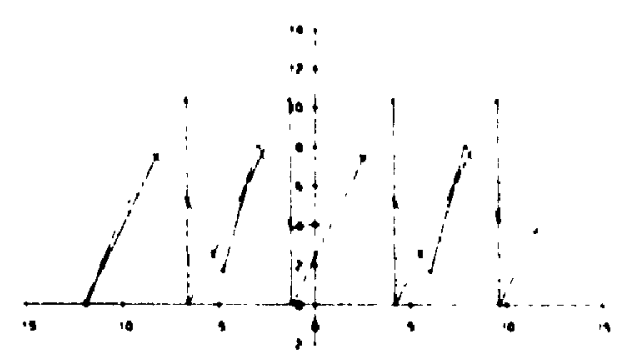

(f)

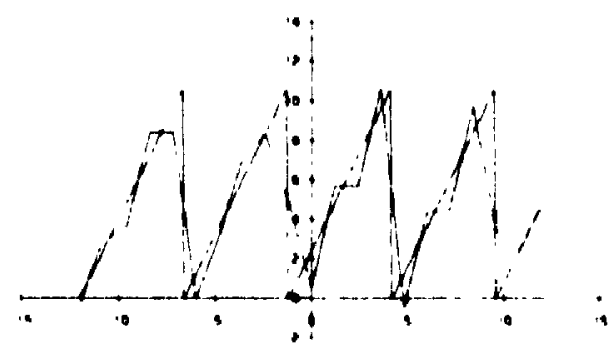

(h)

Fignre 72 : (a) to (h) Original function $f_{33}$ and several moment-preserving approximations with the number of approximating points being $2.5,6,10.14,17$, and 21 , respertively. 


\begin{tabular}{|c|c|c|c|c|c|}
\hline $\begin{array}{l}\text { Approximation } \\
\text { Mothod }\end{array}$ & $\begin{array}{l}\text { of Apporox. } \\
\text { Points }\end{array}$ & Roquined & $\begin{array}{l}M E \\
\left(E_{-}\right)\end{array}$ & $\begin{array}{c}M S E \\
\left(E_{2} / N\right)\end{array}$ & $\begin{array}{l}\text { SNR } \\
\text { (dB) }\end{array}$ \\
\hline $\begin{array}{l}\text { Limaar Solit } \\
\text { (Remer) }\end{array}$ & 10 & 200 & $7.11 E-15$ & $3.86 E-30$ & 301.1069 \\
\hline $\begin{array}{l}\text { Splumberes } \\
\text { (Pevilits) }\end{array}$ & 16 & 1122 & • & 2.1178 & 3.7139 \\
\hline $\begin{array}{l}\text { Avg. noighbours } \\
\text { (Tanimoto) }\end{array}$ & 34 & 64 & 7.71 & 4.2873 & 0.6505 \\
\hline 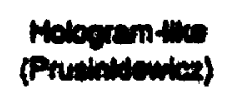 & 10 & 4 & 0.182 & 6.0971 & 0.8709 \\
\hline$\underset{\text { (Kurozumi) }}{\operatorname{Munimax}}$ & 10 & 192 & $7.11 E-15$ & $3.86 E-30$ & 301.1069 \\
\hline $\begin{array}{l}\text { Pecunative split } \\
\text { (Lom) }\end{array}$ & 5 & 122 & 0.759 & 0.1346 & 11.9001 \\
\hline DFT & NA & 240 & 3.918 & 1.5705 & 5.0118 \\
\hline DCt & $\mathbf{N A}$ & 198 & 3.7447 & 0.794 & 8.0268 \\
\hline $\begin{array}{l}\text { Moment- } \\
\text { Preserving }\end{array}$ & 2 & 123 & 5.7201 & 9.7143 & -2.9018 \\
\hline " & 5 & 17 & 6.672 & 9.5026 & 220061 \\
\hline$"$ & 6 & 173 & 6.6516 & 8.6691 & -2.4074 \\
\hline - & 10 & $m$ & 7.1118 & 5.0342 & -0.7813 \\
\hline$n$ & 14 & 211 & 6.4233 & 5.4649 & -0.4036 \\
\hline " & 17 & 20 & $6 \times$ & 3.7098 & 1.1764 \\
\hline$"$ & 21 & 252 & 6.4968 & 3.0019 & 2.1983 \\
\hline
\end{tabular}

Figure 73: Comparison tahle of various approximation techniqnes on function $f_{33}$. 


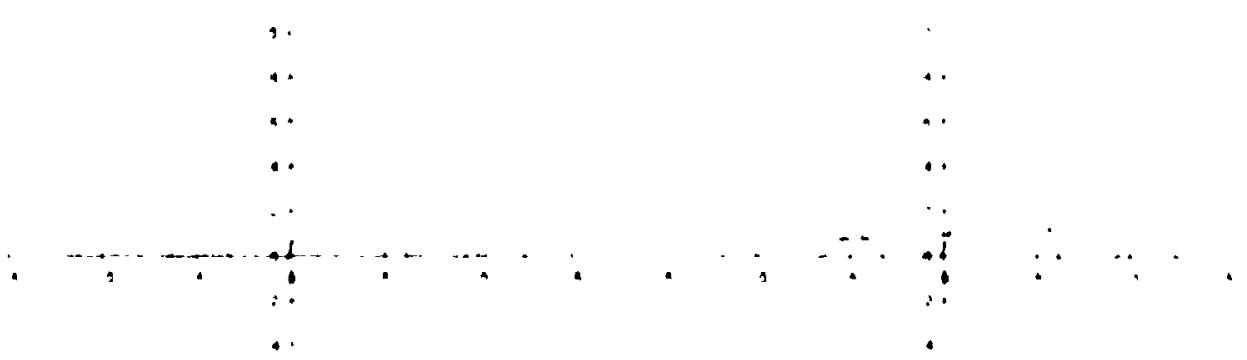

(a)

(b)

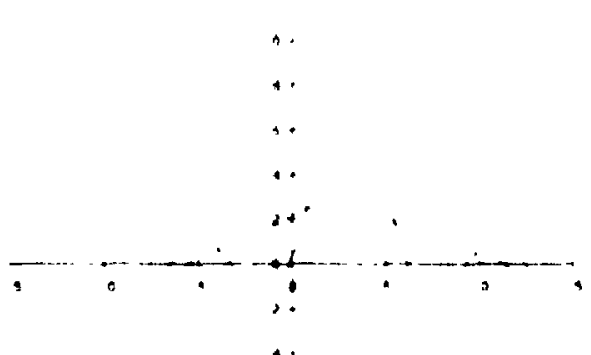

(c)

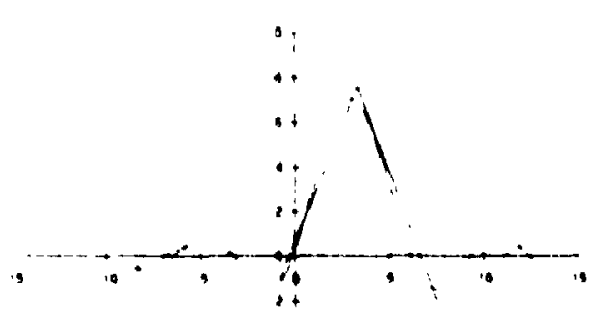

(e)

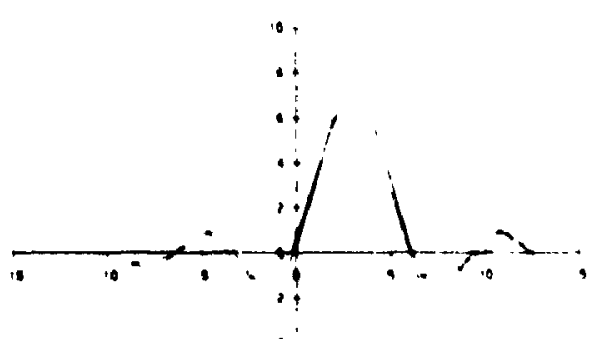

(g) (d)

(f)

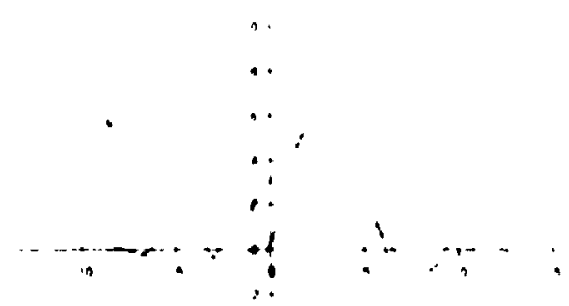

$\therefore$

-

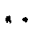

$\therefore+$

,

$\because \quad \cdots, \cdots$

10.

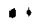

.

$\because$,

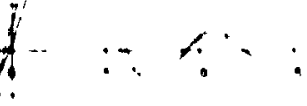

(h)

Figure it: (a) to (h) Original function $f_{4}$ and several moment-preserving appreximations with the number of approximating points being $2.3,5.6 .8 .11$, and 17 . respectively. 


\begin{tabular}{|c|c|c|c|c|c|}
\hline $\begin{array}{l}\text { Approximation } \\
\text { Mothod }\end{array}$ & $\begin{array}{l}\text { of Approx. } \\
\text { Points }\end{array}$ & $\begin{array}{l}\text { Time } \\
\text { Required }\end{array}$ & $\begin{array}{c}M E \\
\left(E_{-}\right)\end{array}$ & $\begin{array}{c}M S E \\
\left(E_{2} N\right)\end{array}$ & $\begin{array}{l}\text { SNR } \\
\text { (OB) }\end{array}$ \\
\hline $\begin{array}{l}\text { Linoar Split } \\
\text { (Ramer) }\end{array}$ & 8 & 155 & 0.998 & 0.1579 & 7.974 \\
\hline $\begin{array}{l}\text { Spivanerge } \\
\text { (Povidity) }\end{array}$ & 24 & 887 & 1.0608 & 0.1377 & 8.5694 \\
\hline $\begin{array}{l}\text { Avg. noighbours } \\
\text { (Taninzoto) }\end{array}$ & 34 & 62 & 1.1705 & 0.3105 & 5.0371 \\
\hline $\begin{array}{l}\text { Hologrentitio } \\
\text { (Pruintionicx) }\end{array}$ & 18 & 48 & 0.3983 & 0.021 & 16,7336 \\
\hline $\begin{array}{l}\text { Minimax } \\
\text { (Kurozumi) }\end{array}$ & 12 & 2121 & 1.3175 & 0.0993 & 9.9887 \\
\hline $\begin{array}{l}\text { Accumive split } \\
\text { (Lowio) }\end{array}$ & 8 & 148 & asso & 0.1578 & 7.974 \\
\hline DFT & NA & 235 & 2.4872 & 0.3941 & 4.0023 \\
\hline DCt & w & 197 & 0.2168 & 0.0037 & 242460 \\
\hline $\begin{array}{l}\text { Moment- } \\
\text { Preserving }\end{array}$ & 2 & 124 & 5.9463 & 5.7091 & -7.5446 \\
\hline " & 3 & 160 &.- .1754 & 3.7600 & .5 .7310 \\
\hline • & 5 & 173 & 3.3175 & 2.322 & -3.6376 \\
\hline - & 6 & 168 & 12000 & 0.3086 & 4.1260 \\
\hline " & 8 & 196 & 2.133 & 0.8652 & 0.6498 \\
\hline " & 11 & 175 & 1.68 & 0.278 & 58674 \\
\hline " & 17 & 237 & 1.2462 & 0.2302 & 6.4007 \\
\hline
\end{tabular}

Figure $i \bar{J}$ : Comparison table of various approximation terhniques on function $f_{4}$. 


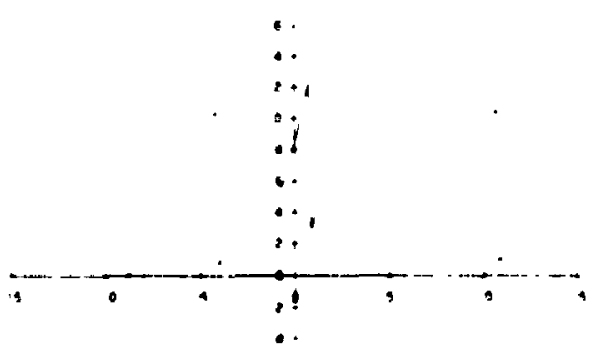

(a)

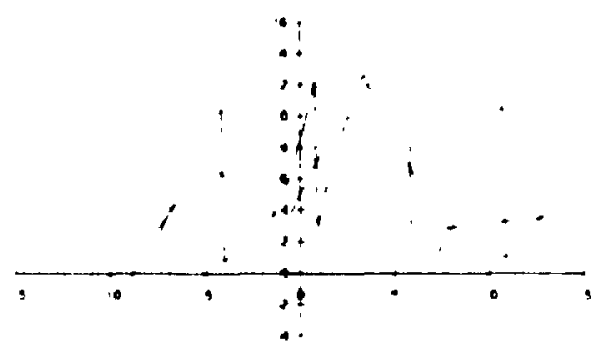

(c)

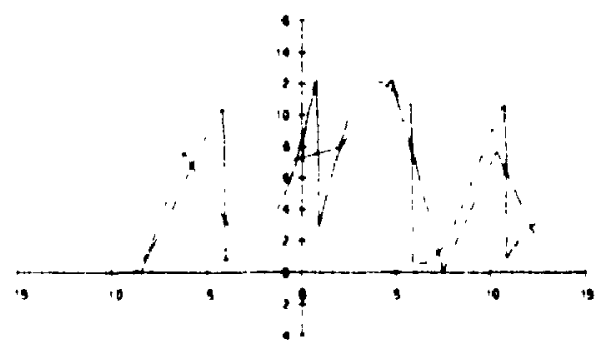

(e)

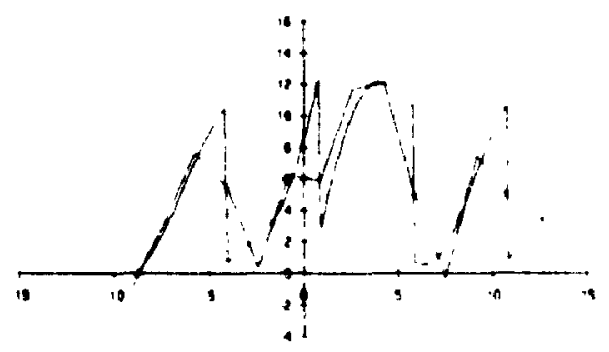

(g)

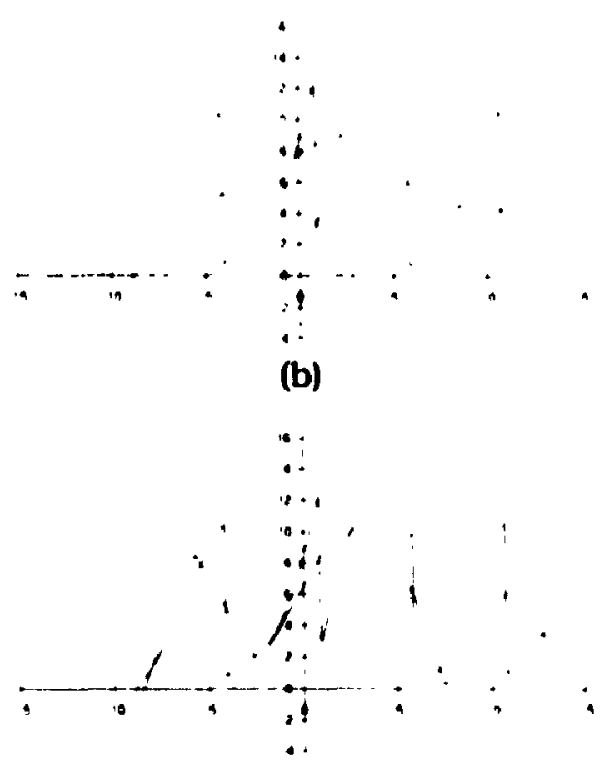

(d)

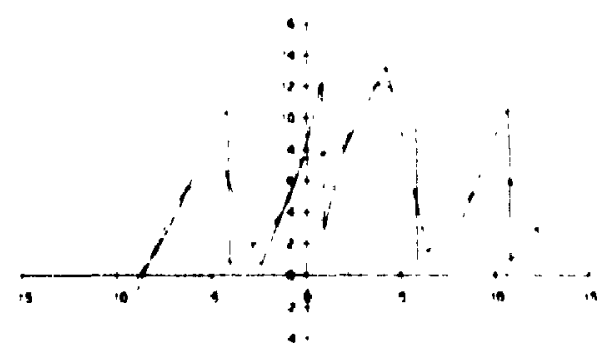

(f)

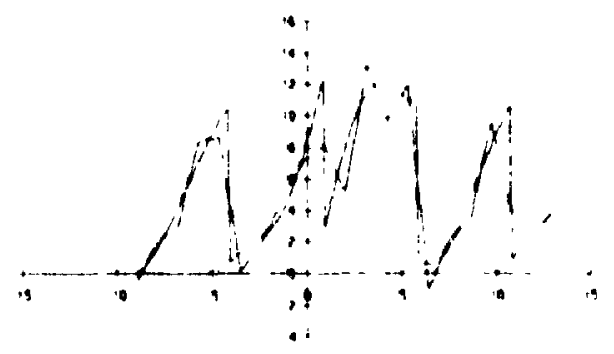

(h)

Figure i6: (a) to (h) Original function $f_{5}$ and several moment-preserving approximations with the number of approximating points being 5, 6. 8. 9. 11, 14, aul 21 . respectively. 


\begin{tabular}{|c|c|c|c|c|c|}
\hline $\begin{array}{l}\text { Approximation } \\
\text { Mothod }\end{array}$ & $\begin{array}{l}\text { - of Apprax. } \\
\text { Points }\end{array}$ & $\begin{array}{c}\text { Time } \\
\text { Required }\end{array}$ & $\begin{array}{l}M E \\
\left(E_{-}\right)\end{array}$ & $\begin{array}{l}M S E \\
\left(E_{2} / N\right)\end{array}$ & $\begin{array}{l}\text { SNA } \\
\text { (OB) }\end{array}$ \\
\hline $\begin{array}{l}\text { Linear Split } \\
\text { (Ramer) }\end{array}$ & 15 & 210 & 1.5017 & 0.2252 & 13.9691 \\
\hline $\begin{array}{l}\text { Sptulapes } \\
\text { (Pantidis) }\end{array}$ & 20 & 1011 & 8.3011 & 1.9746 & 45400 \\
\hline $\begin{array}{l}\text { Avg. neighbours } \\
\text { (Tanimoto) }\end{array}$ & 34 & 62 & 8.3229 & 4.1081 & 1.3591 \\
\hline 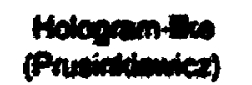 & 18 & 47 & 9.760 & 5302 & 0.207 \\
\hline $\begin{array}{l}\text { Minimax } \\
\text { (Kurozumi) }\end{array}$ & 16 & 1458 & 30.1181 & 26.2339 & -6.6931 \\
\hline $\begin{array}{c}\text { Pacurive spin } \\
\text { fancl }\end{array}$ & 15 & 201 & 1.5017 & 0.2052 & 13.5091 \\
\hline DFT & N/A & 238 & 4.4599 & 1.7246 & 5.1287 \\
\hline DCt & $N$ & 108 & 36019 & 0.6716 & 9206 \\
\hline $\begin{array}{l}\text { Moment- } \\
\text { Preserving }\end{array}$ & 5 & 176 & 6.3611 & 11.1963 & -3.0274 \\
\hline * & 6 & 180 & 7.3 & 8.1039 & -1.05it \\
\hline$"$ & 8 & 191 & 5.4633 & 6.1083 & -0.3959 \\
\hline$"$ & $\bullet$ & 201 & 60105 & s.7nas & a.tsen \\
\hline$"$ & 11 & 216 & 5.6859 & 4.3837 & 1.0448 \\
\hline * & 24 & 227 & asres & 4830 & astes \\
\hline$*$ & 21 & 273 & 6.0681 & 2.7291 & 3.1032 \\
\hline
\end{tabular}

Figure it: Comparison table of various approximation techniques on function $f_{5}$. 


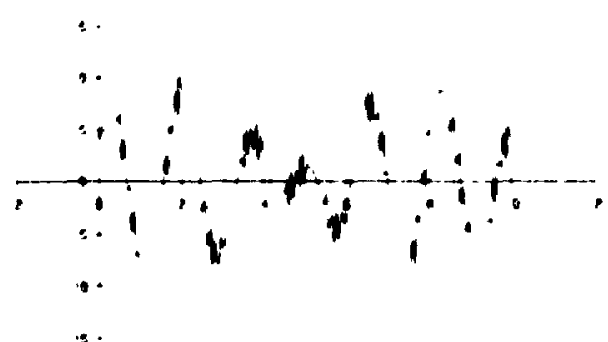

(a)

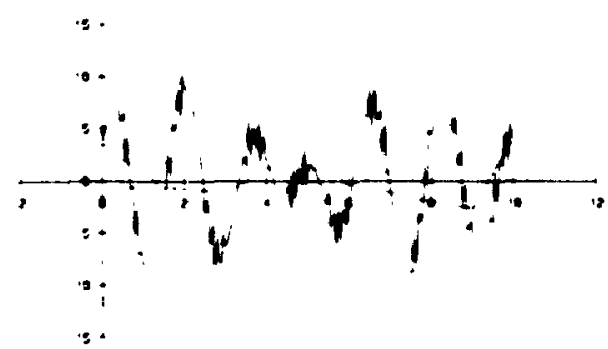

(c)

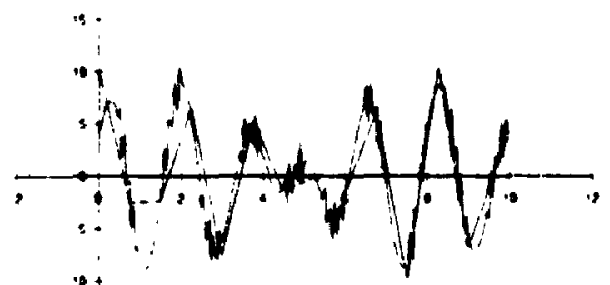

(e)

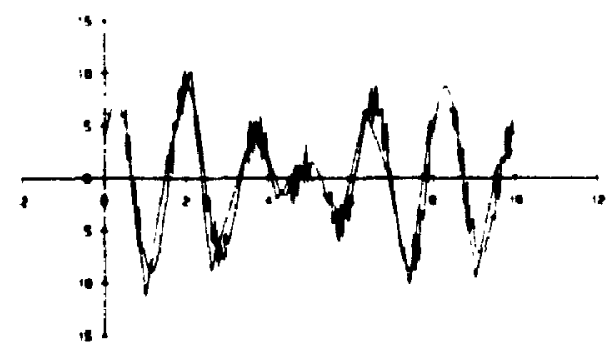

(d)

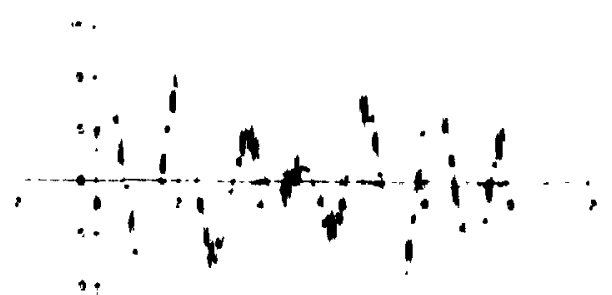

(b)

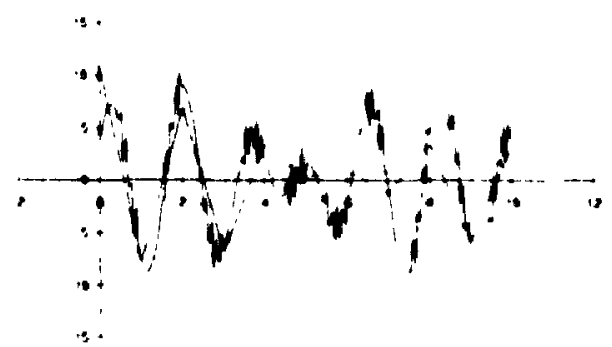

(d)

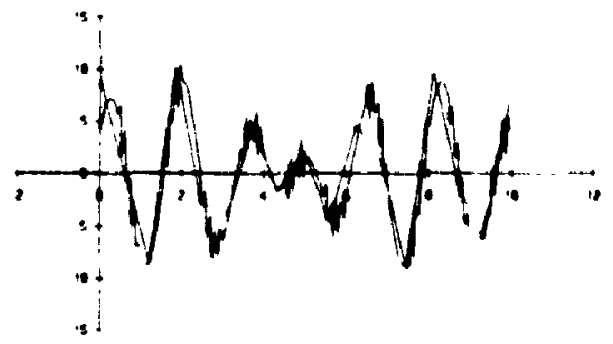

(n)

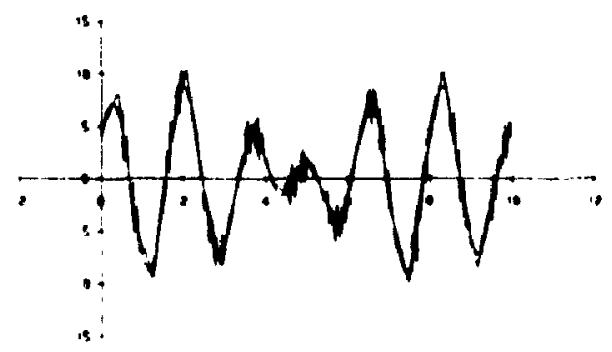

(h)

Figure 78: (a) to (h) Original function $f_{6}$ and several moment-preserving approximations with the number of approximating points being $5,8,11,14,17,20$, and 25. respertively. 


\begin{tabular}{|c|c|c|c|c|c|}
\hline $\begin{array}{l}\text { Approxumation } \\
\text { Methot }\end{array}$ & $\begin{array}{l}\text { - of Approx. } \\
\text { Pounts }\end{array}$ & $\begin{array}{l}\text { Time } \\
\text { Requined }\end{array}$ & $\begin{array}{l}M E \\
\left(E_{-}\right)\end{array}$ & $\begin{array}{l}M S E \\
\left(E_{2} N\right)\end{array}$ & $\begin{array}{l}\text { SNR } \\
\text { (OB) }\end{array}$ \\
\hline $\begin{array}{l}\text { Linear Solit } \\
\text { (Ramer) }\end{array}$ & 14 & 252 & 4.6696 & 2.7531 & -15.525 \\
\hline 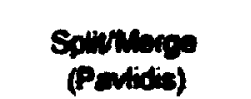 & 28 & 873 & 6.3503 & 6.218 & -19.0602 \\
\hline $\begin{array}{l}\text { Avg. neighbours } \\
\text { (Tanimoto) }\end{array}$ & 34 & 62 & 6.9121 & 9.306 & -20.8143 \\
\hline 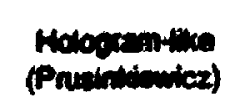 & 18 & 46 & 48008 & $3 \sec 2$ & -47.1270 \\
\hline $\begin{array}{c}\text { Munumax } \\
\text { (Kurozumi) }\end{array}$ & 16 & 1491 & 42.5632 & 115.6800 & -31.7593 \\
\hline $\begin{array}{c}\text { Placusine equth } \\
\text { (Lom) }\end{array}$ & 14 & 22 & Lecos & 2.7231 & -15825 \\
\hline DFT & NA & 237 & 9.5968 & 10.5518 & -21.36 \\
\hline DCt & $\omega$ & 10 & 20001 & 1.0720 & -11 ansos \\
\hline $\begin{array}{l}\text { Momem. } \\
\text { Presenving }\end{array}$ & 5 & 251 & 11.2025 & 25.2792 & -25.1543 \\
\hline " & $a$ & tex & 11.1594 & 25000 & $\$ 5.1972$ \\
\hline " & 11 & 208 & 10.0301 & 16.0793 & -23.1894 \\
\hline - & 14 & 210 & $7,4 \cos$ & cotse & $40 \operatorname{sen} 4$ \\
\hline " & 17 & 233 & 6.2464 & 5.0877 & -18.1919 \\
\hline - & 20 & 2 & 20044 & 40778 & $-172 \times 97$ \\
\hline - & 25 & 330 & 2.8278 & 1.3448 & -12.4134 \\
\hline
\end{tabular}

Fig.. + 79: Comparison table of various approximation techniques on function $f_{6}$. 


\section{Chapter 5}

\section{Moment-Preserving Methods for 2-D Func- tions}

In this chapter. the moment-preserving approximation method will be used to alyproximate two-dimensional functions. The two categories of two-dimensional functions to be covered by this approximation method are planar curves and digitized images. Results of the moment-preserving technique as they are applied to planar curves and digitized images are summarized at the end of this rhapter.

\subsection{Approximating Two-dimensional Planar Curves Using Moments}

The moment-preservilos approximation technique can be extended and appliect to planar curve approximations. However, in order to approximate two-dimensional planar curves using the moment-preserving method describerl above. the planar curve must be normalized to be a one-dimensional function. There are several ways to normalize a planar curve to a one-rlimensional function. For example, the methorl described by Zahn and Roskies [ZR 72] uses the angular direction of the curve as it funrtion of its arc length.

The normalizing function used by us in this thesis is clifferent from that of Zalus and Roskies. For any arbitrary planar curve described by a discrete sett of $\boldsymbol{N}+1$ points, $S=\left\{p_{i}=\left(x_{i}, y_{i}\right) \mid 0 \leq i \leq N\right\}$, the $s$ - and $y$-coordinates of the centre of 
the rarve. denoted by p. $=\left(. r . . y_{r}\right)$. are detined as

$$
\begin{aligned}
& x=\frac{1}{x} \sum_{i=11}^{N} x_{i} \\
& y=\frac{1}{x} \sum_{i=1}^{N} y_{i}
\end{aligned}
$$

The normalizing function. $p(\theta)$. of a planar curve is defined as the Eucliclean disrance of a point on the curve from its centre as a function of the monalized angle loetween 0 and $2 \pi$. Formally: it ran be summarized as

$$
\boldsymbol{r}\left(\theta_{1}\right)=\left|<p_{1} \cdot p_{i}\right\rangle \mid
$$

where

$$
\theta_{1}=\frac{2 \pi i}{N} \quad 0 \leq i \leq . v .
$$

There are two main reasons why this partirular normalizing fumetion is used instearl of the one used by Zahn and Roskies. First of all. since the moments of the curve are of primary interest. the centre of mass (closely related to the zero ${ }^{\text {th }}$ moment) is the most logical position to be used as a reference point describing all of the other points on the curve. A circle. for example, when clescribed by this normalizing function becomes a straight horizontal line. Serondly, by using the Euclidean distance, the normalized function is always positive. Finally, the normuluzing function is invariant with respect to certain affine transformations.

\subsection{Approximating Digitized Images Using Moments}

A digitized image $f(x, y)$ is often considered as a two-dimensional matrix of size $N \times N$, whose elements are the quantized brightness values at that point. Thus, $f(x, y)$ is defined as

$$
f\left(x_{1}, y_{k}\right)=\hat{I}\left(x_{0}+i \Delta x . y_{0}+k \Delta y\right) \quad \text { for } i, k=0.1,2, \ldots, N-1
$$

where $\dot{I}$ is the quantized brightness of the analogue image $I$. and $\Delta x$ and $\Delta y$ are the stumpling intervals along the $r$ - and $y$-axis. respertively. 


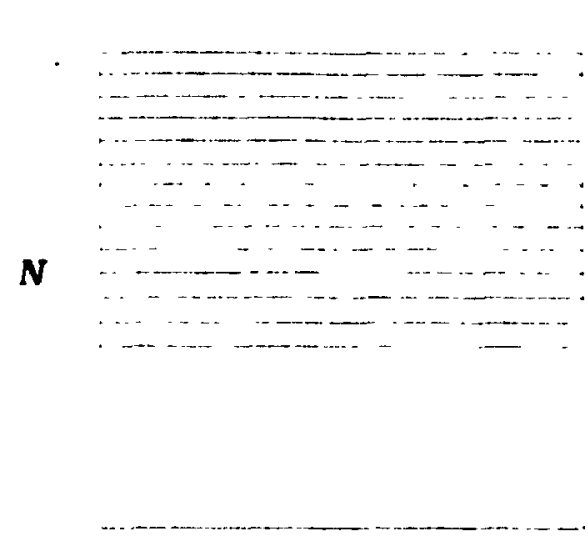

(a)

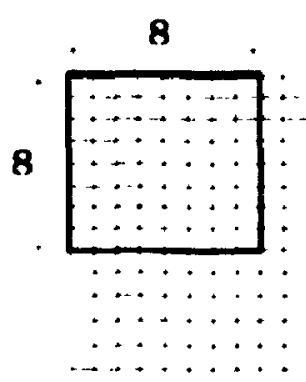

(b)

$\begin{array}{lrrrrrrr}1-2 & 3 & -4 & 5 & -6 & 7 & 8 \\ 9 & 10 & 11 & 12 & 13 & 14 & 15 & 16 \\ 17 & 18 & 19 & 20 & 21 & 22 & 23 & 24 \\ 25 & 26 & 27 & 28 & 29 & 30 & 31 & 32 \\ 33 & 34 & 35 & 36 & & & & \end{array}$

(c)

Figure 80: Subdividing an image into smaller components. (a) Dividing an inugu into rows. (b) Dividing an image into blocks. (c) Reorganizing pixel values into linear form.

Esing this refinition, it is possible to consider an image as $\mathcal{V}$ sepurate and independent one-rlimensional functions. For example, if all the rows of the image ar's defined as

$$
\begin{array}{r}
r_{0}\left(y_{k}\right)=\dot{I}\left(x_{0}, y_{0}+k \cdot \Delta ! 1\right) \\
r_{1}\left(y_{k}\right)=\dot{I}\left(x_{0}+\Delta \cdot r \cdot y_{0}+k \cdot \Delta y\right) \\
\vdots v-1\left(y_{k}\right)=\hat{I}\left(x_{0}+(N-1) \Delta r \cdot y_{0}+k \Delta y\right)
\end{array}
$$

for $k=0.1 .2 \ldots \ldots N-1$, then the moment-preserving methocl ran be applierl to the $V$ independent rows. By separating the rows or colnums in this manuer. lowevere 


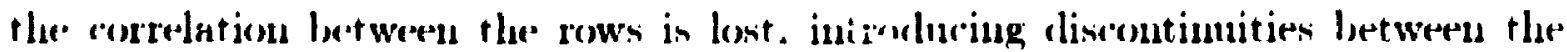
rows in the imnge.

Au ofton used strategy of subdividing an inage is to break it up into $8 \times 8$ or $(16 \times 16)$ blorks an shown in Fignere 80(b). By sublilividing the image into such

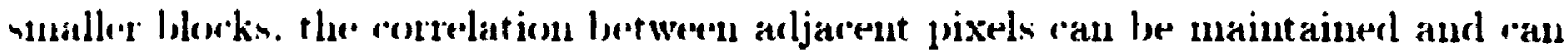
lec aned to assint in the approximation of other pixels. For example. in a row of a digitized image. each pixel (except for the two pixels at the end of the row) contains "Xactly two adjacent neighlsours. whereas, in a $8 \times 8$ block the each corner pixel coutcius 3 ueighlonurs, each edge pixel contains 5 neighbours, and earh interior pixel contains 8 urighbours.

In order to apply the moment-preserving technique to the block of pixels. it in uecessary to reorder these values so as to form a single-varialsle function. An inportant part of the reorganization is to preserve the closeness of the pixels from a square block into a linear form. If the rows in a block were concatenated together to form a line. then in most cases, there would be no correlation between the pixel at the end of one row and a pixel at the beginning of the next row even though they are plared adjarent to each other in a linear form. Results from the momnent-preserving terhuique as it applied to one-dimensional functions indicate that noisy signals or "spikes" are removed by this technique. Therefore. it does not make any sense to place dissimilar pixels side-by-side and then attempt to preserve the moments of those pixel values. A well-known conversion technique called the zigzag scan is used in the moment-preserving approximation of images as shown in Figure $80(r)$. Once an approximation of the zigzag pixel values is found. the zigzag operation is reversed to restore the square block structure of the approximation image. 


\subsection{Experimental Results on Planar Curves and Digitized Images}

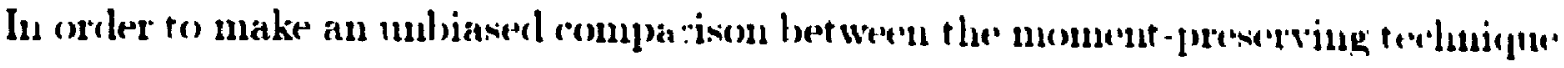

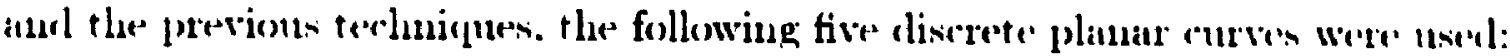

1. (Open ellipse:

$$
\left\{\left(x_{1}, y_{1}\right) \mid x_{1}=J \cos (0.05 i)+3 . y_{t}=i \sin (0.05 i)+4 . i=0.1 \ldots .200\right\}
$$

2. Rotated normal bell curve:

$$
\left\{\left(r_{2} \cdot y_{1}\right) \mid r_{2}=x_{1}^{\prime} \cdot \cos \frac{\pi}{3}-y_{1}^{\prime} \cdot \sin \frac{\pi}{3} \cdot y_{2}=x_{1}^{\prime} \cdot \sin \frac{\pi}{3}+y_{1}^{\prime} \cdot \cos \frac{\pi}{3}\right\}
$$

where

$$
x_{\imath}^{\prime}=0.05 i-6, y_{\imath}^{\prime}=\frac{20}{\sqrt{2 \pi}} \epsilon^{-x^{2} / \pi} . i=0.1, \ldots 200
$$

3. Complex closied curve:

$\left\{\left(r_{1}, y_{2}\right) \mid r_{1}=3 \cos (0.025 i)-4 \sin (0.025 i)+4 . y_{1}=5 \cos (0.025 i)+\sin 2 x+6\right\}$

for $i=0.1, \ldots, 251$.

4. Simulated noisy complex closed rurve:

$\left\{\left(x_{i}, y_{1}\right) \mid x_{2}=3 \cos (0.025 i)-4 \sin (0.025 i)+4 . y_{2}=5 \cos (0.025 i)+\sin 2 . r+6\right\}$

for $i=0.1, \ldots 251$. The simulated uoise is the value sin $200 x$, addecl to $y_{t}$ when $10 \leq i$ morlulo $40 \leq 18$.

5. Self-intersecting curv :

$$
\left\{\left(x_{i}, y_{i}\right) \mid x_{i}=3 \cos (0.02 i)-4 \sin (0.02 i)+4, y_{1}=5 \cos (0.02 i+\sin 2 x)\right\}
$$

for $i=0.1 \ldots 300$. 
These planar curves are identical to the ones uned in the review of previons planas "urve methods from chapter 3. Csing the S.TR and the unmber of approximatimg points as the criterin. the moment-preserving method can approximate the open plauat elliprical curce with the fewest unuber of points and the least amonut of ercor: it ontperforms all of the time/spacial clomain terdmigues lexecept for the recorsive split technique) and transform domain tedniçues. The moment-preserving method doess not perform as well as the hologram-like technique in approximatiug the rotated hell curve, however. its results are comparable with the other technicues. The latter technique performs poorly on the approximation of a complex curve and the noisy complex (nurve compared to all the previous techniques. however, the momentpreserving approximations of these two planar curves are virtually identical. From oute experiments we conclude that if the noise is relatively small compared to the artual signal, it will not arlversely affect its moment-preserving approximation. and the latter will serve as a good low-pass filter. The moment preserving methorl outperforms all of the previous terhniques in approximating self-intersecting curves.

The moment-preserving terhnique was also applied to the following four different digitized images presiented in Chapter 3:

1. A human face

2. A drer in a grey background

3. A squirrel in a dark background

4. A mountain hiking trail containing light backgronund

The results are fairly reasonable and typical of image approximation schemes. Since the moment-preserving method does not handle signals which contain drastio changes, it has a tendency to blur sharp edges contained in the images. In all four cases, the moment-presserving approximating images seem to appear more blurry than the hologram-like and discrete cosine transform approximations. 
(a)

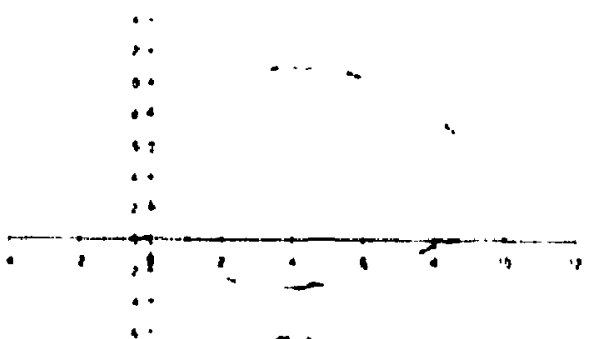

(b)

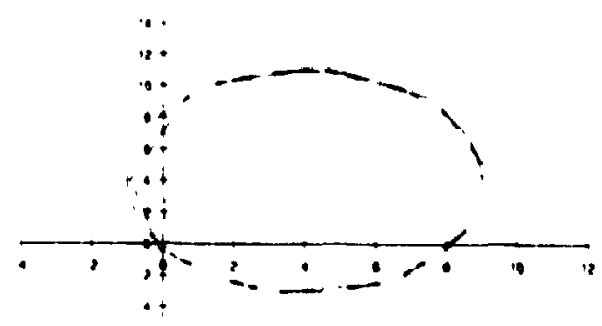

(d)

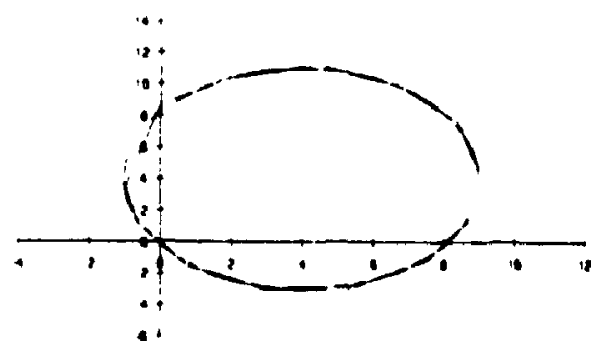

(f)

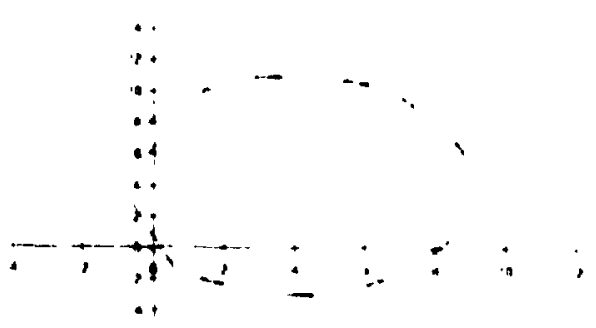

(c)

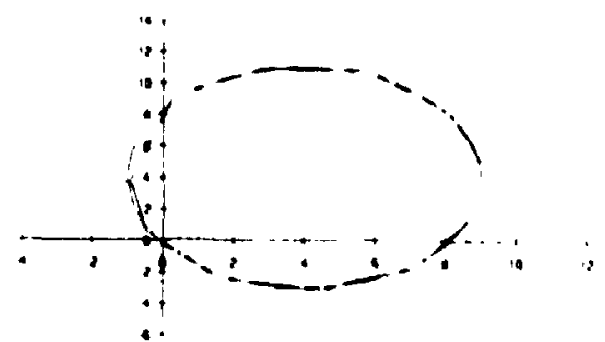

(e)

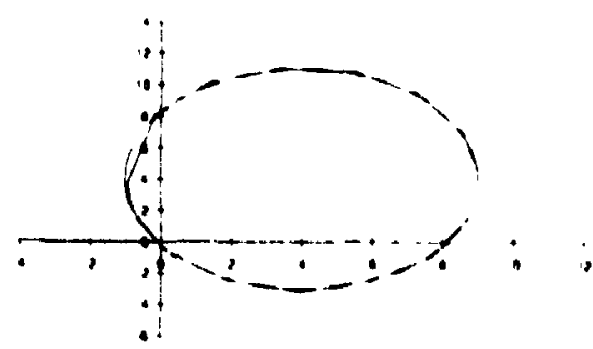

(d)

Figure 81: (a) to (g) Open elliptical curve and several moment-preserving approximations with the number of approximating points being $5,7,9,11.13$. and 15. respertively. 


\begin{tabular}{|c|c|c|c|c|c|}
\hline $\begin{array}{l}\text { Approximation } \\
\text { Mothod }\end{array}$ & $\begin{array}{l}\text { - of Approx. } \\
\text { Pounts }\end{array}$ & $\begin{array}{c}\text { Time } \\
\text { Required }\end{array}$ & $\begin{array}{l}M E \\
\text { (E.) }\end{array}$ & $\begin{array}{c}M S E \\
\left(E_{2}, N\right)\end{array}$ & $\begin{array}{l}\text { SNR } \\
\text { (D8) }\end{array}$ \\
\hline $\begin{array}{l}\text { Linear Split } \\
\text { (Ramor) }\end{array}$ & 11 & 784 & 0.4035 & 0.0197 & 23.1234 \\
\hline Splinumpes & 30 & 1004 & 4.9760 & 3.9308 & -17.1861 \\
\hline $\begin{array}{l}\text { Avg. noighbours } \\
\text { (Tanimoto) }\end{array}$ & 34 & 102 & 0.3231 & 0.0415 & 19.8924 \\
\hline $\begin{array}{l}\text { Hotogranitien } \\
\text { (Prualindendez) }\end{array}$ & 18 & 72 & 0.0063 & 1.47E-0s & 344006 \\
\hline$\underset{\text { (Kurozum) }}{\operatorname{Minimax}}$ & 16 & 2079 & 0.6281 & 0.1146 & 15.4858 \\
\hline $\begin{array}{c}\text { Proumine eplin } \\
\text { (Low) }\end{array}$ & 13 & 160 & 0.1881 & 5.35E-0s & 28.8136 \\
\hline DFT & N/A & 210 & 2.1044 & 0.5862 & 8.397 \\
\hline oct & MA & 17 & 0.0402 & 0.0108 & 25.9476 \\
\hline $\begin{array}{l}\text { Moment- } \\
\text { Preserving }\end{array}$ & 5 & 86 & 1.5727 & 0.3004 & 11.3023 \\
\hline " & 7 & 106 & 0.6149 & 0.0003 & 17.0000 \\
\hline - & 9 & 144 & 0.4322 & 0.0273 & 21.7232 \\
\hline * & 11 & 177 & 0.306 & 0.074 & 24.4032 \\
\hline - & 13 & 216 & 0.2675 & 0.0084 & 26.8536 \\
\hline • & 16 & 24 & 0218 & 0.0041 & axpon \\
\hline$x \times x$ & $x x x$ & $x \times x$ & $x x x$ & $x \times x$ & $x x x$ \\
\hline
\end{tabular}

Figure 82: Comparison table of varions approximation techniques. 
J MOME.IT-PRESERITIG METHODS FOR 2-D FI:YCTIONS

164
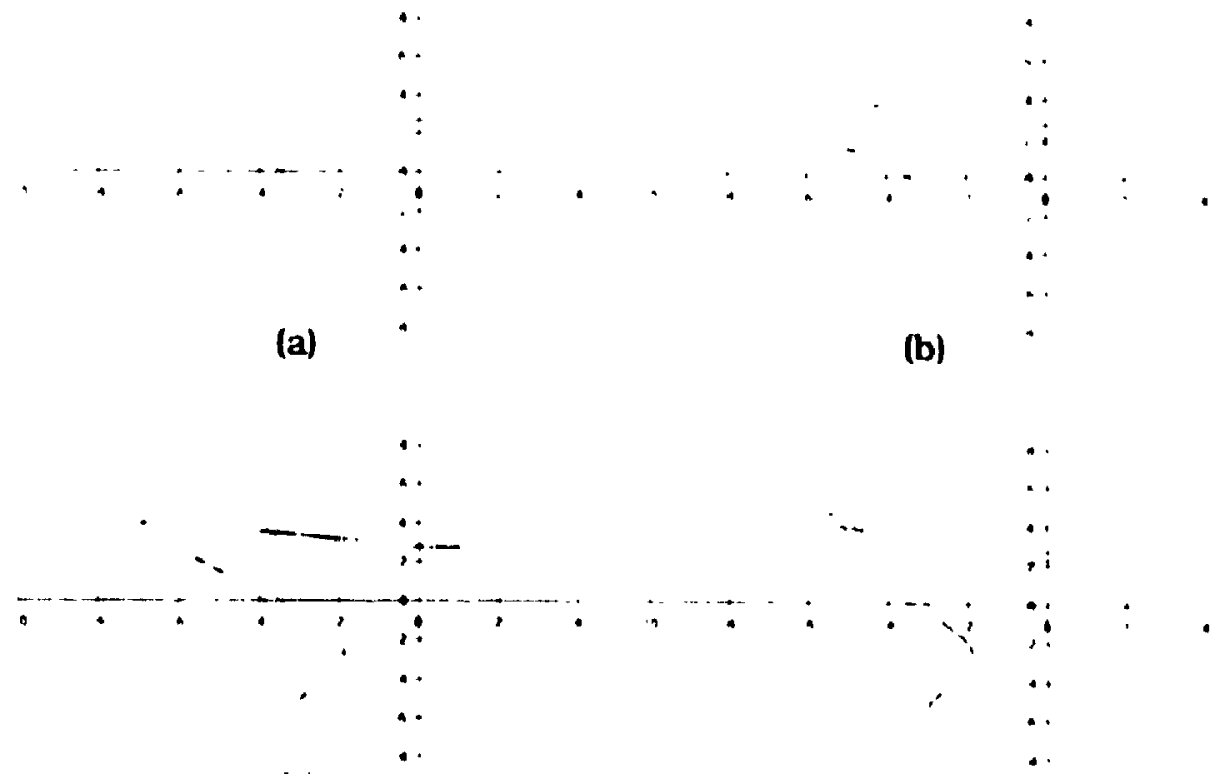

(c)

(d)

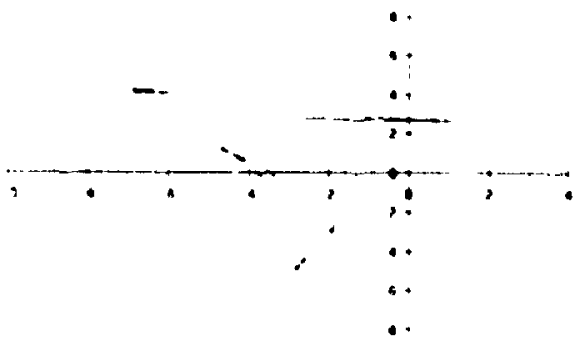

(e)

(f)

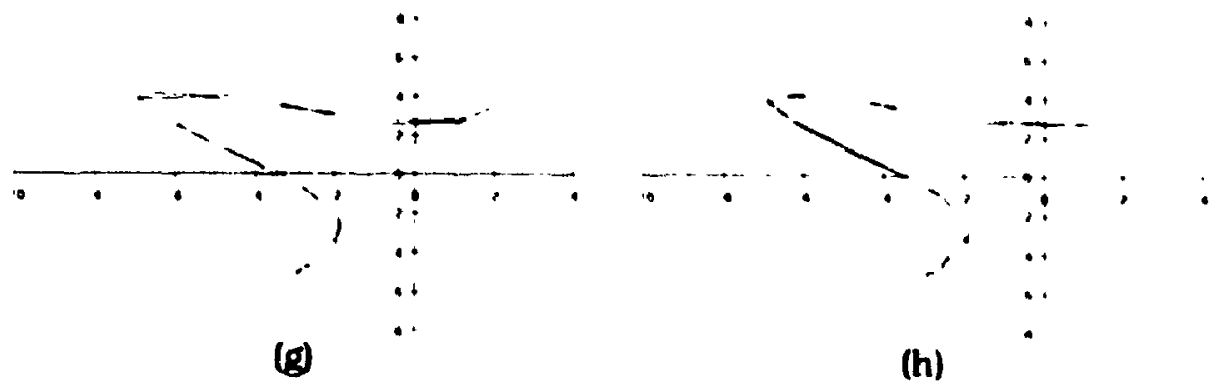

Figure 83: (a) to (h) Rotated bell curve and several moment-prescerving approximations with the number of approximating points being 3. 5. 5, 8, 9. 11, iurl 14. respertively. 


\begin{tabular}{|c|c|c|c|c|c|}
\hline $\begin{array}{l}\text { Approximation } \\
\text { Mothod }\end{array}$ & $\begin{array}{l}\text { of Approx. } \\
\text { Ponts }\end{array}$ & $\begin{array}{c}\text { Time } \\
\text { Requinet }\end{array}$ & $\underset{\left(E_{-}\right)}{M E}$ & $\begin{array}{c}\text { MSE } \\
\left(E_{2} N\right)\end{array}$ & $\begin{array}{l}\text { SNR } \\
\text { (OB) }\end{array}$ \\
\hline $\begin{array}{l}\text { Linear Split } \\
\text { (Ramer) }\end{array}$ & 6 & 194 & 0.4044 & 0.0209 & 12.4223 \\
\hline Somninge & 7 & 790 & 0.2637 & 0.011 & 152147 \\
\hline $\begin{array}{l}\text { Avg. newghbours } \\
\text { (Tanmoto) }\end{array}$ & 34 & 133 & 0.3488 & 0.0234 & 119199 \\
\hline $\begin{array}{l}\text { Holooramtites } \\
\text { (Prueintiomicz) }\end{array}$ & 18 & 87 & 0.0005 & 42GE-O4 & 29.3477 \\
\hline$\underset{\text { 'Murozumi) }}{\text { Minimax }}$ & 7 & 9227 & 1.03 & 0.1454 & 3.9925 \\
\hline $\begin{array}{c}\text { Plecuraive equil } \\
\text { (Lomol }\end{array}$ & 6 & 185 & 0.4044 & 00200 & 12.4020 \\
\hline OFT & NA & 297 & 2.1847 & 0.1348 & 4.3221 \\
\hline Dor & $m$ & 208 & 1.4054 & 0.0152 & 138014 \\
\hline $\begin{array}{l}\text { Mh nent- } \\
\text { Preserving }\end{array}$ & 3 & 108 & 5.3642 & 7.1352 & .12 .9149 \\
\hline$"$ & 5 & 116 & 0.5643 & 0.0354 & 10851 \\
\hline “ & 5 & 110 & 1.7804 & 0.6584 & -2.5658 \\
\hline$\cdot$ & 8 & 121 & 0.000 & acosist & 7.6178 \\
\hline$"$ & 9 & 153 & 0.7592 & 0.0403 & 9.5673 \\
\hline - & $m$ & 161 & 0.4139 & 0.0201 & $12 x+18$ \\
\hline$"$ & 14 & 167 & 0.5642 & 0.035 & 10.1746 \\
\hline
\end{tabular}

Figure S4: Comparisou table of various approximation technicques. 


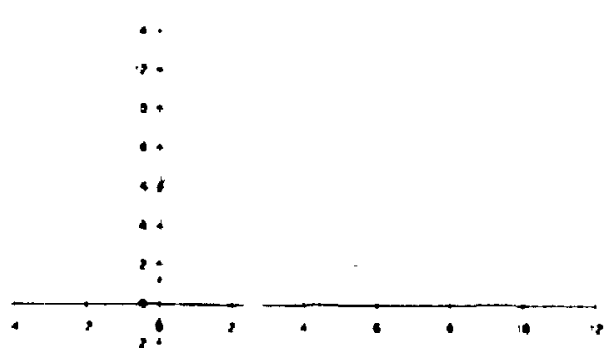

(a)

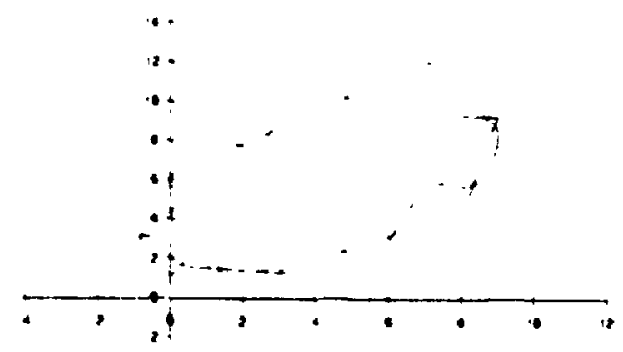

(c)

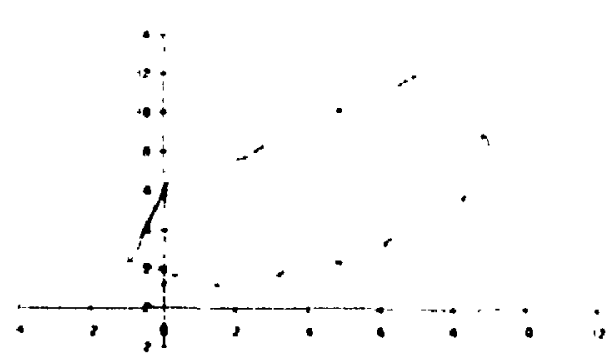

(b)

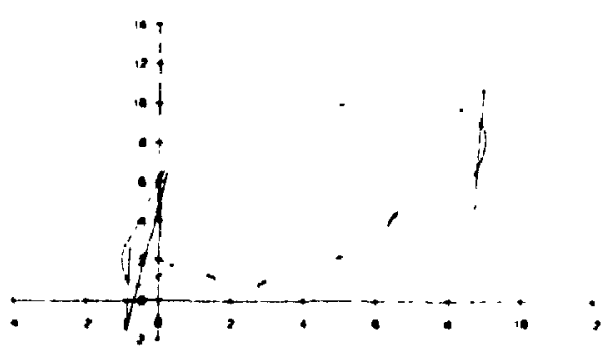

(d)

Figure 85: (a) to (d) Complex closed murve and several moment-preserving alproximations with the number of approximating points being 9, 12, and 14, respesctively. 


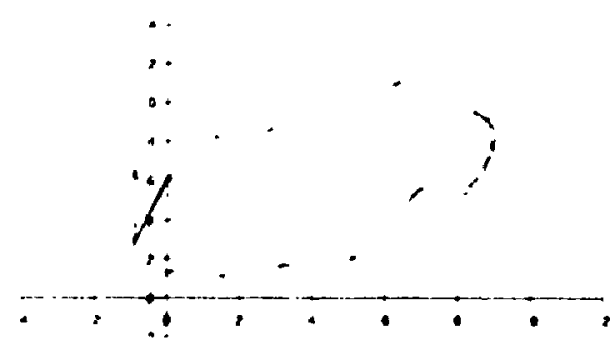

(e)

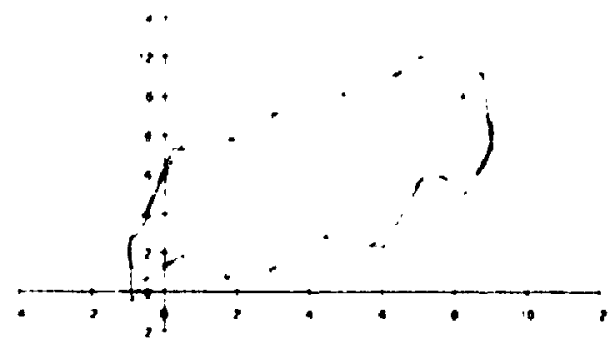

(ख)

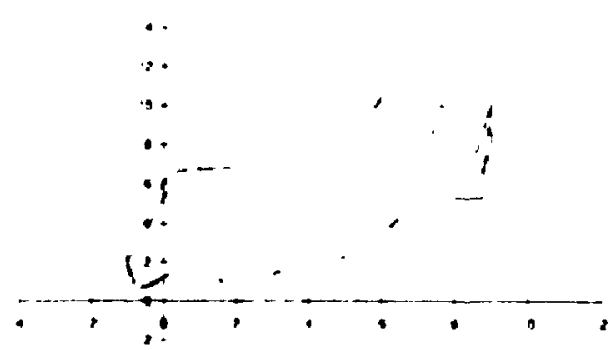

(t)

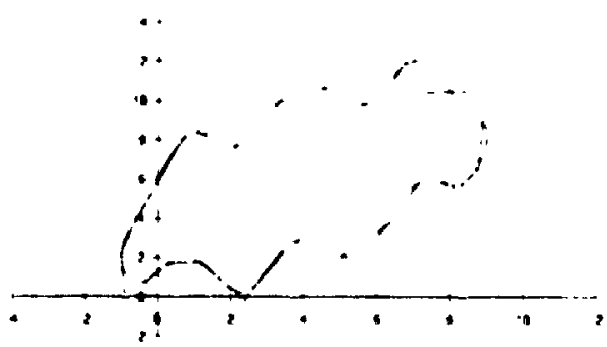

(h)

Figure 86: (e) to (h) Moment-preserving approximations of complex closed curve with the number of approximating points being 16, 19. 22. and 23, respectively: 


\begin{tabular}{|c|c|c|c|c|c|}
\hline $\begin{array}{l}\text { Approximation } \\
\text { Mothod }\end{array}$ & $\begin{array}{l}\text { * of Approx. } \\
\text { Pornts }\end{array}$ & $\begin{array}{c}\text { Time } \\
\text { Requined }\end{array}$ & $\begin{array}{c}M E \\
\left(E_{\infty}\right)\end{array}$ & $\begin{array}{c}M S E \\
\left(E_{2}, N\right)\end{array}$ & $\begin{array}{l}\text { SNR } \\
\text { (DA) }\end{array}$ \\
\hline $\begin{array}{l}\text { Linear Solit } \\
\text { (Ramer) }\end{array}$ & 16 & 229 & 0.3013 & 0.0167 & 25.4022 \\
\hline $\begin{array}{l}\text { Solinnerge } \\
\text { (Pantitis) }\end{array}$ & 16 & 1017 & 0.5682 & 0.0355 & 22.1208 \\
\hline $\begin{array}{l}\text { Avg. noighbours } \\
\text { (Tanimoto) }\end{array}$ & 34 & 107 & 0.6062 & 0.0567 & 20.0959 \\
\hline $\begin{array}{l}\text { Hologram-fice } \\
\text { (Pruainkiemica) }\end{array}$ & 18 & 76 & 1.0002 & 0.0747 & 18.0042 \\
\hline $\begin{array}{c}\text { Minimax } \\
\text { (Kurozumi) }\end{array}$ & 18 & 1511 & 1.1935 & 0.1519 & 15.8125 \\
\hline $\begin{array}{c}\text { Plocursive spif } \\
\text { (Lownot }\end{array}$ & 16 & 205 & 0.3013 & 0.0167 & 25.4022 \\
\hline DFT & N/A & 231 & 7.2335 & 2.091 & 4.4256 \\
\hline DCT & $\mathbf{N A}$ & 187 & 5.2306 & 0.3676 & 11.9749 \\
\hline $\begin{array}{l}\text { Moment- } \\
\text { Presenving }\end{array}$ & 9 & 281 & 1.2716 & 0.3705 & 11.9409 \\
\hline - & 12 & 306 & 2.90027 & 0.71 .30 & 9.009 \\
\hline " & 14 & 305 & 2.9857 & 0.7234 & 9.0354 \\
\hline " & 16 & 357 & 1.208 & 0.27 & 132043 \\
\hline$"$ & 19 & 340 & 1.7961 & 0.4305 & 11.2894 \\
\hline • & 22 & 397 & 2.6872 & 0.374 & 11.0008 \\
\hline$"$ & 23 & 456 & 1.9107 & 0.2859 & 13.0674 \\
\hline
\end{tabular}

Figure 87: Comparison talse of varions approximation terenuiques. 


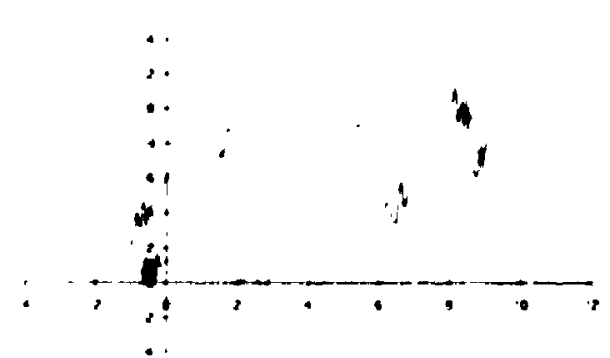

(a)

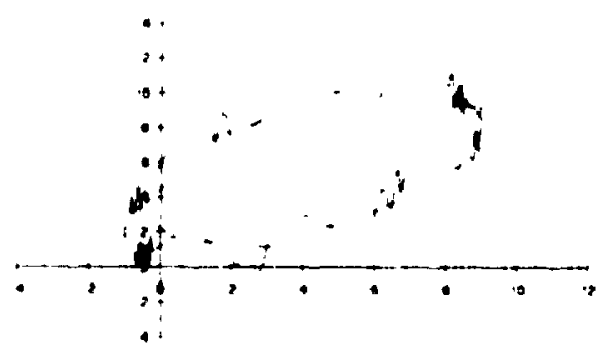

(c)

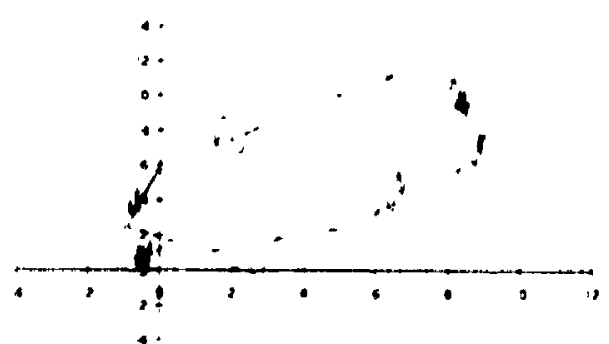

(b)

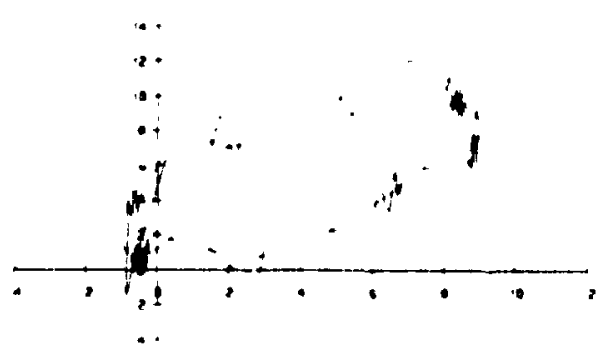

(d)

Figure 88: (a) Noisy complex closed curve and several moment-preserving approximations with the number of approximating points being 9,12 , and 14, respertively. 


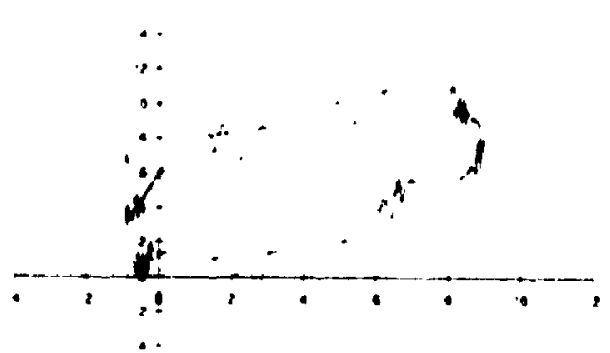

(e)

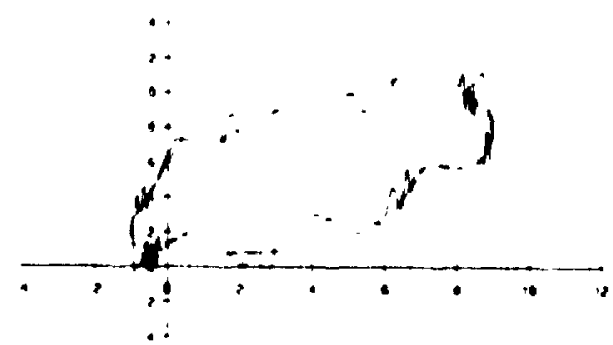

(g)

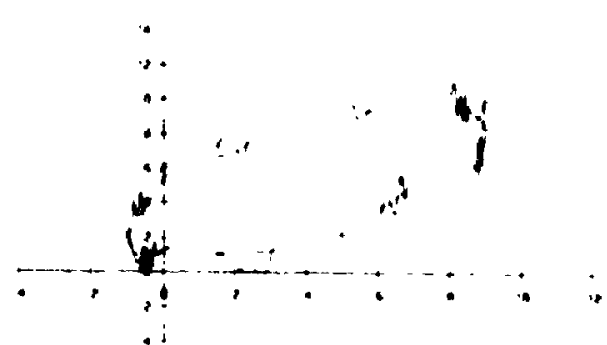

(f)

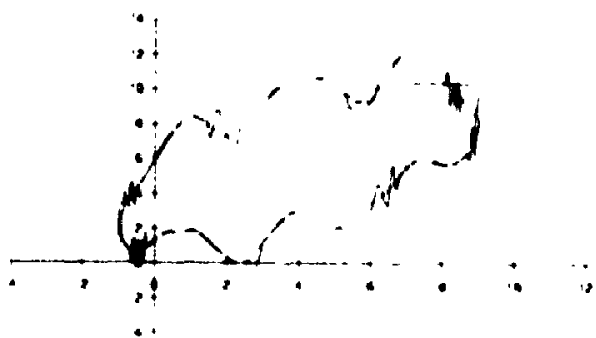

(h)

Figure 89: (e) to (h) Moment-preserving approximations of uosisy romuplex relosicel rurve with the number of approximating points being 16. 19, 22. and 23, respertively. 


\begin{tabular}{|c|c|c|c|c|c|}
\hline $\begin{array}{l}\text { Approximation } \\
\text { Mathod }\end{array}$ & $\begin{array}{l}\text { - of Approx. } \\
\text { Points }\end{array}$ & $\begin{array}{c}\text { Time } \\
\text { Alequired }\end{array}$ & $\begin{array}{c}M E \\
\left(E_{-}\right)\end{array}$ & $\begin{array}{c}M S E \\
\left(E_{2} N\right)\end{array}$ & $\begin{array}{l}\text { SNR } \\
\text { (dB) }\end{array}$ \\
\hline $\begin{array}{l}\text { Lineas Split } \\
\text { (Ramer) }\end{array}$ & 32 & 558 & 0.3718 & 0.0151 & 25.8644 \\
\hline Splinumpe & 24 & 22052 & 1.0721 & 0.0578 & 20.0403 \\
\hline $\begin{array}{l}\text { Avg. noighbours } \\
\text { (Tanimoto) }\end{array}$ & 34 & 160 & 1.1191 & 0.1124 & 17.1616 \\
\hline $\begin{array}{l}\text { Holograntileo } \\
\text { (Prutimionica) }\end{array}$ & 18 & 160 & 1.2505 & 0.1183 & 165001 \\
\hline $\begin{array}{l}\text { Mirimax } \\
\text { (Kurozumi) }\end{array}$ & 24 & 3479 & 0.9114 & 0.0676 & 19.3705 \\
\hline $\begin{array}{l}\text { Amamaine sout } \\
\text { flowal }\end{array}$ & 32 & 405 & 0.3718 & 0.0151 & 25.8044 \\
\hline DFT & N/A & 471 & 7.1492 & 0.7526 & 8.9026 \\
\hline DCt & WA & 30 & 4 Exp & 0.1720 & 152007 \\
\hline $\begin{array}{l}\text { Moment- } \\
\text { Presenving }\end{array}$ & 9 & 186 & 1.8844 & 0.4657 & $: 0.9317$ \\
\hline • & 12 & 201 & 2806s & 02079 & 85000 \\
\hline$"$ & 14 & 204 & 2.9241 & 0.7748 & 8.7202 \\
\hline • & 18 & 2 & 10000 & 0.3087 & 120024 \\
\hline " & 19 & 230 & 2.1161 & 0.4736 & 10.8582 \\
\hline " & 22 & $2 \pi$ & 25510 & $0.200 x$ & 11.0115 \\
\hline " & 23 & 320 & 1.649 & 0.1833 & 14.981 \\
\hline
\end{tabular}

Figure 90: Comparison table of various approximation techniques. 


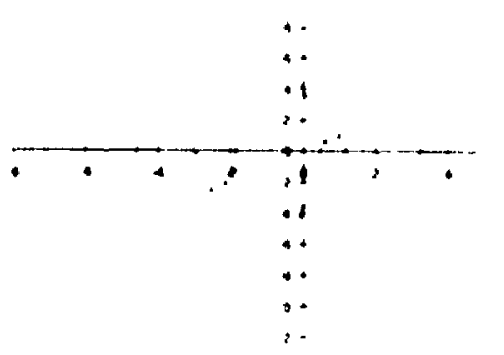

(a)

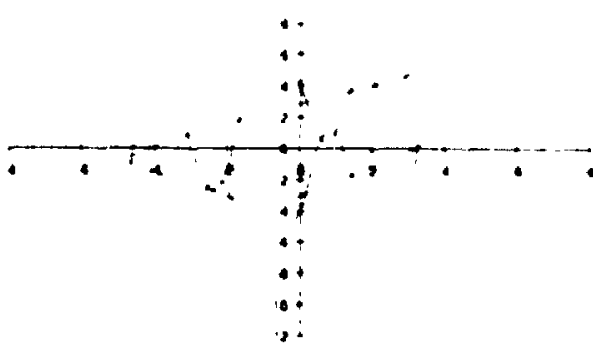

(c)

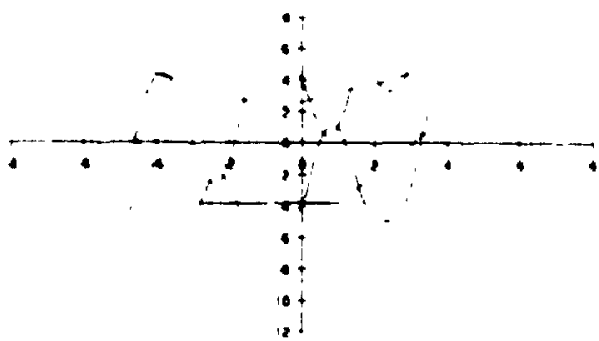

(e)

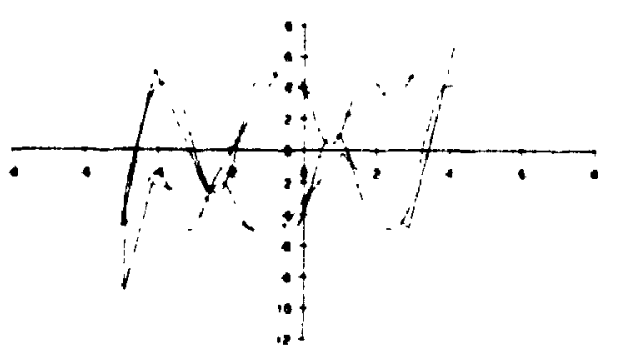

(g)

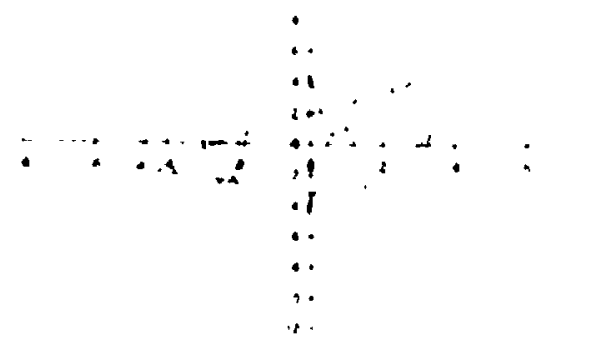

(b)

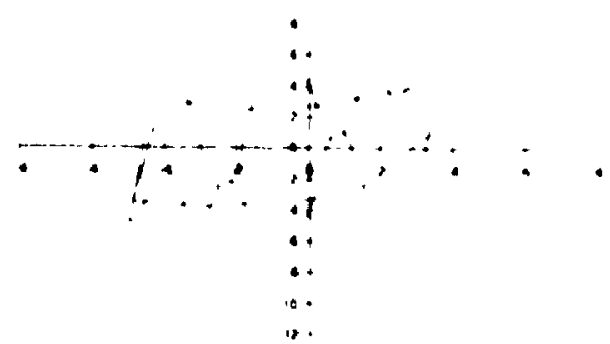

(d)

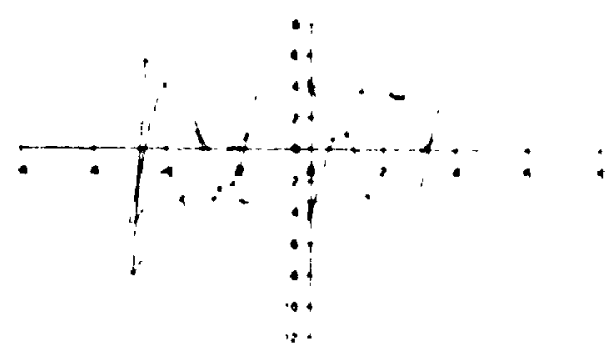

(f)

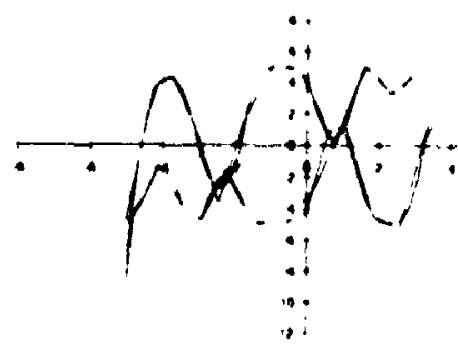

(h)

Figure 91: (a) to (h) Self-intersecting rurve and several moment-preserving alpproximations with the number of approximating points being 4, 5, 7, 7. 9. 13. nud 20. respertively. 


\begin{tabular}{|c|c|c|c|c|c|}
\hline $\begin{array}{l}\text { Aporoximation } \\
\text { Mothod }\end{array}$ & $\begin{array}{l}\text { of Approx. } \\
\text { Pounts }\end{array}$ & $\underset{\text { Required }}{\text { Time }}$ & $\begin{array}{l}M E \\
\left(E_{-}\right)\end{array}$ & $\begin{array}{c}M S E \\
\left(E_{2} / N\right)\end{array}$ & $\begin{array}{l}\text { SNR } \\
\text { (dB) }\end{array}$ \\
\hline $\begin{array}{l}\text { Linear Solit } \\
\text { (Ramor) }\end{array}$ & 23 & 342 & 0.3838 & 0.0182 & 5.1000 \\
\hline Equnderses & 22 & 1497 & $1.3 \times 1$ & 0.150 & 4.1346 \\
\hline $\begin{array}{l}\text { Avg. neighbours } \\
\text { (Tanimoto) }\end{array}$ & 34 & 128 & 1.892 & 0.2253 & -5.8149 \\
\hline 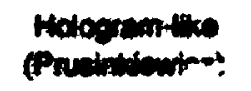 & 18 & 87 & 3200 & 0.6024 & .104994 \\
\hline$\underset{\text { (Kurozumu) }}{\text { Minimax }}$ & 24 & 1942 & 2.7917 & 0.6481 & -10.4039 \\
\hline 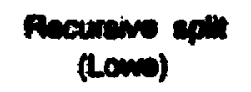 & 23 & 206 & 0.3058 & 0.0182 & 5.1008 \\
\hline DFT & NA & 296 & 3.4027 & 1.3516 & $\cdot 13.5966$ \\
\hline DCT & $\omega$ & 20 & 1.3002 & 0.1778 & -47000 \\
\hline $\begin{array}{l}\text { Moment- } \\
\text { Preenving }\end{array}$ & 4 & 200 & 4.4197 & 3.4505 & -7.0962 \\
\hline " & 5 & 160 & 3.418 & 3.5516 & .72216 \\
\hline " & 7 & 203 & 5.2028 & 2.6076 & -6.2007 \\
\hline$*$ & 7 & 20 & 4904 & 2948 & +2416 \\
\hline “ & 9 & 251 & 4.1781 & 1.4715 & -3.3948 \\
\hline$\bullet$ & 13 & 20 & 1.0602 & 0.2760 & 32001 \\
\hline$"$ & 29 & 423 & 0.6756 & 0.0361 & 12.7084 \\
\hline
\end{tabular}

Figure 92: Comparison table of various approximation terhniques. 


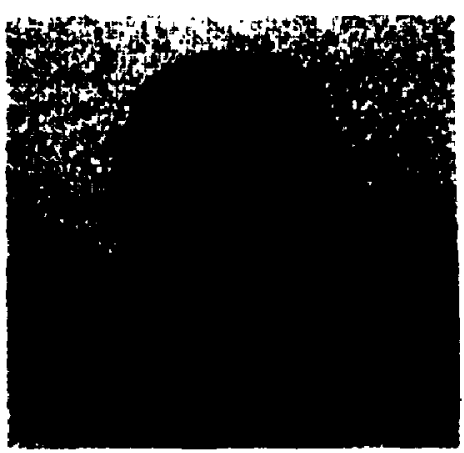

(a)

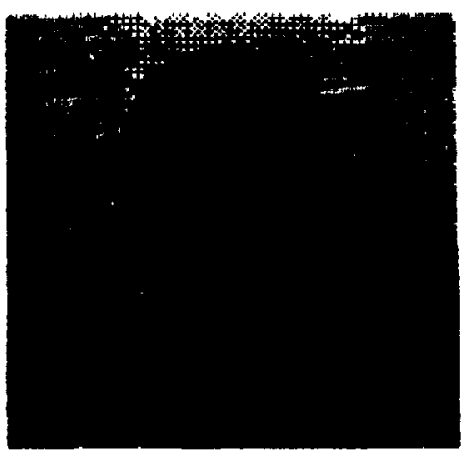

(c)

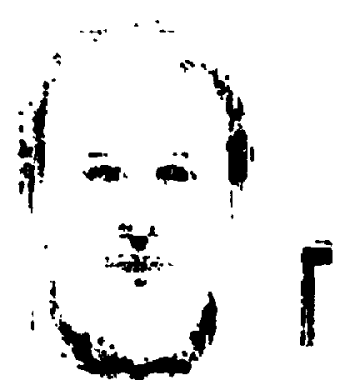

(e)

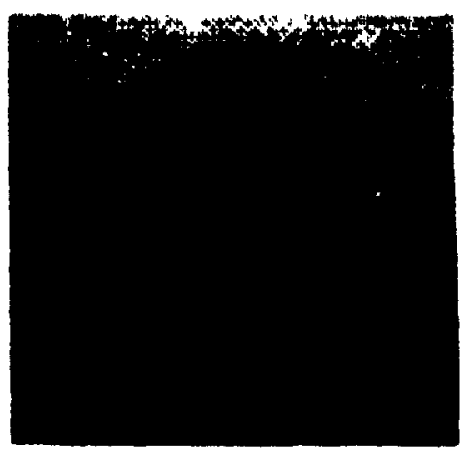

(b)

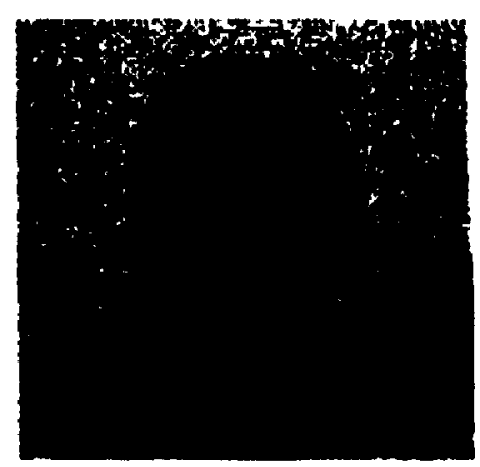

(d)

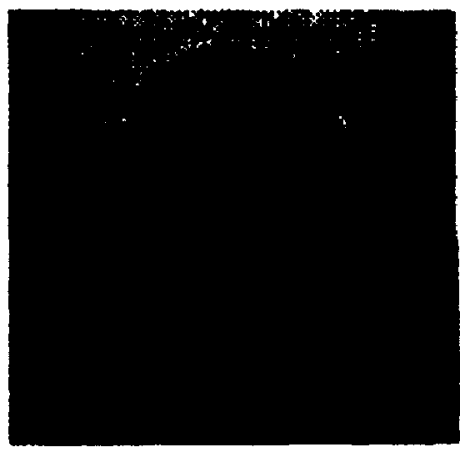

(f)

Figure 93: (a) ()riginul image of human fuce. (b) Me sent-preserving approximation

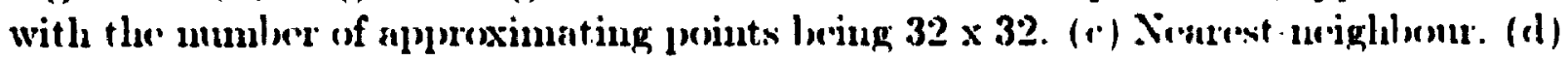
Ho'oggram-like. (e) Discrete Fonuier transform. (f) Discrete cosiue transform. 


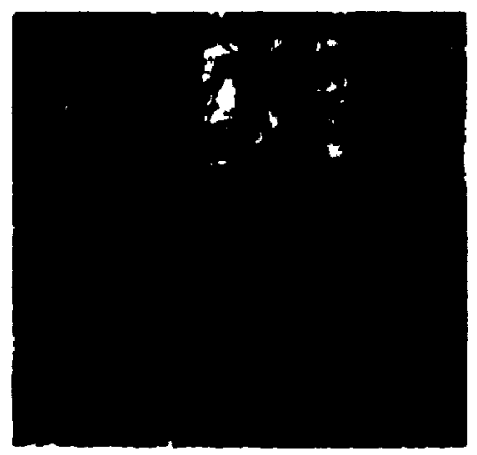

(a)

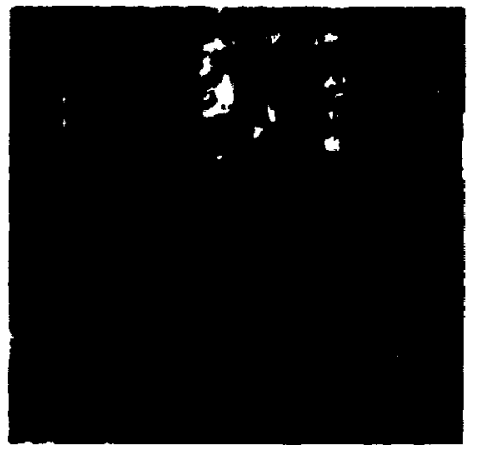

(c)

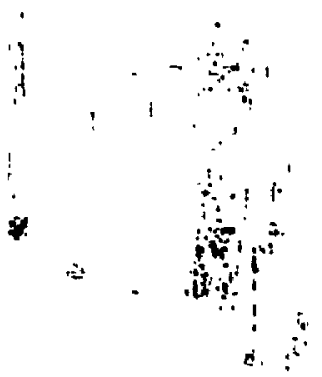

(e)

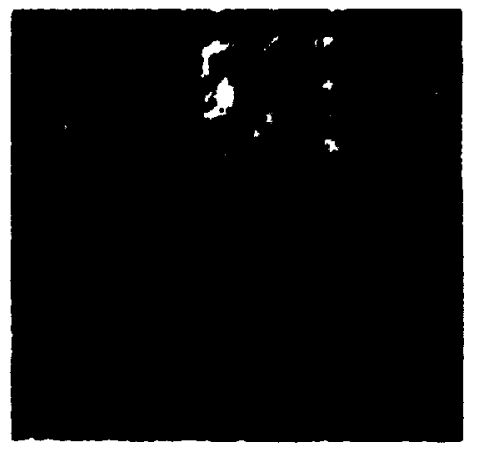

(b)

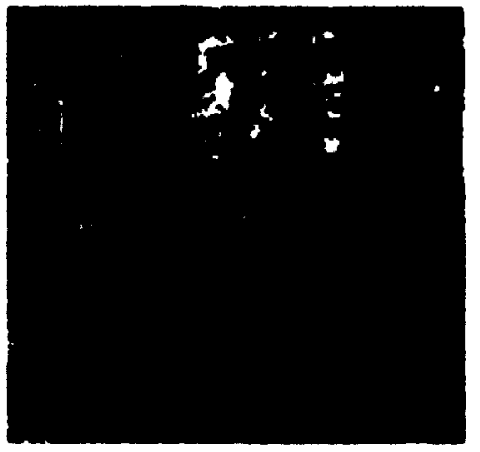

(d)

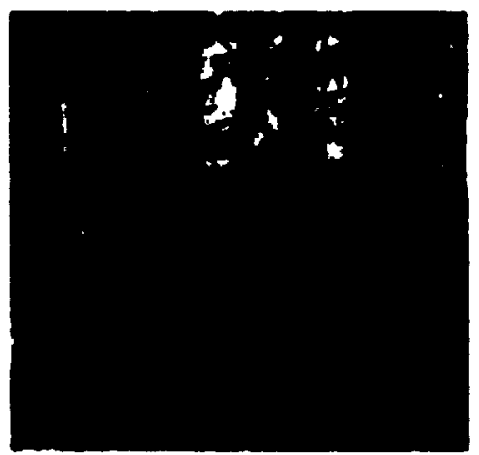

(f)

Fignor 94: (a) Originnl imnge of a deer. (b) M.oment-presterving approximation with the mumber of apposimating points heing $32 \times 32$. (c) Xearest-neighlowur. (d) Hologgram-like. (e) Discrete Fourier transform. (f) Discrete cosine transform. 


\begin{tabular}{|c|c|c|c|c|c|}
\hline $\begin{array}{c}\text { Approximation } \\
\text { Monod }\end{array}$ & $\begin{array}{c}\text { Compression } \\
\text { Patio }\end{array}$ & $\begin{array}{c}\text { nime } \\
\text { Required }\end{array}$ & $\begin{array}{c}M E \\
\left(E_{-}\right)\end{array}$ & $\begin{array}{c}\text { MSE } \\
\left(E_{z} N\right)\end{array}$ & $\begin{array}{l}\text { SNA } \\
\text { (dB) }\end{array}$ \\
\hline Hologram-tike & $16: 1$ & $118 \mathrm{sec}$. & 198 & 545.0332 & 6.5354 \\
\hline Namen-naigitour & $16: 1$ & 242 enc. & 128 & 262.3665 & .3 .30003 \\
\hline DFT & $8: 1$ & 710 sec. & 255 & 21665.0011 & -22.5288 \\
\hline OCT & $40: 1$ & 600 sec. & 69 & 20.1518 & 26804 \\
\hline Moment-preserving & 16:1 & $943 \mathrm{sec}$. & 154 & 289.9788 & -3.7949 \\
\hline
\end{tabular}

(a)

\begin{tabular}{|c|c|c|c|c|c|}
\hline $\begin{array}{c}\text { Approximation } \\
\text { Method }\end{array}$ & $\begin{array}{c}\text { Compresion } \\
\text { Ratio }\end{array}$ & $\begin{array}{c}\text { Timo } \\
\text { Axquined }\end{array}$ & $\begin{array}{c}M E \\
\left(E_{-\infty}\right)\end{array}$ & $\begin{array}{c}\text { MSE } \\
\left(E_{2} N\right)\end{array}$ & $\begin{array}{l}\text { SNA } \\
(0 \theta)\end{array}$ \\
\hline Hologramtike & $16: 1$ & 118 sec. & 252 & 1839.1405 & -13.8981 \\
\hline 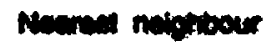 & $16: 1$ & 244 sec. & 211 & 816.3004 & -10.3705 \\
\hline OFT & $8: 1$ & 726 sec. & 255 & 34371.1837 & -26.6139 \\
\hline DET & $19: 1$ & 700 sace. & 137 & 408.5241 & $\$ .1146$ \\
\hline Morment-presenving & $16: 1$ & 881 sec. & 203 & 898,3696 & -10.7865 \\
\hline
\end{tabular}

(b)

Figure 95: (a) Comparison table of varionss approximation techniques on inage \#1. (b) Comparison table of varions approximation to indques on image \#2. 


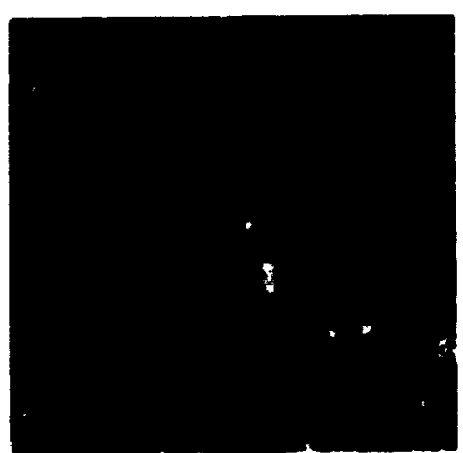

(a)

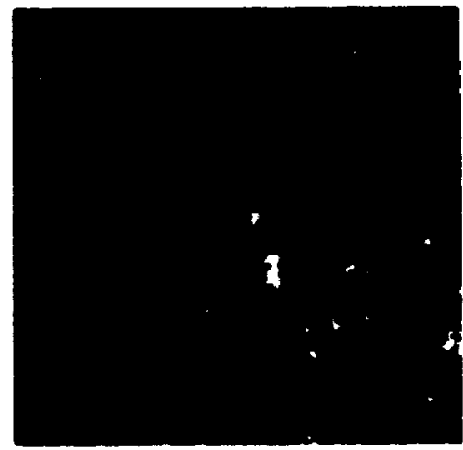

(c)

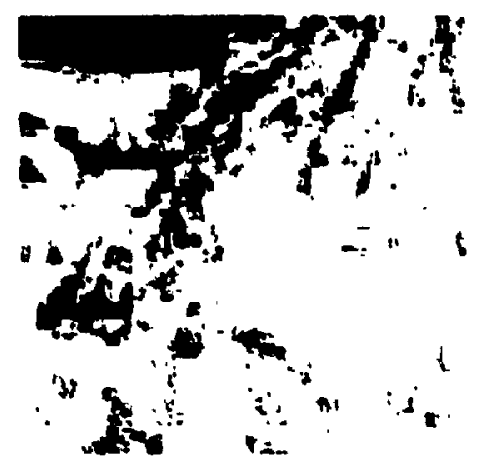

(e)

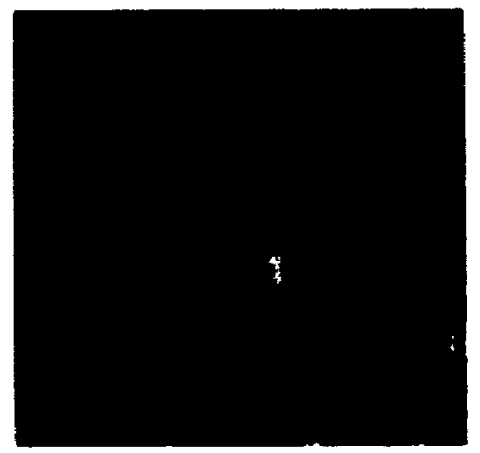

(b)

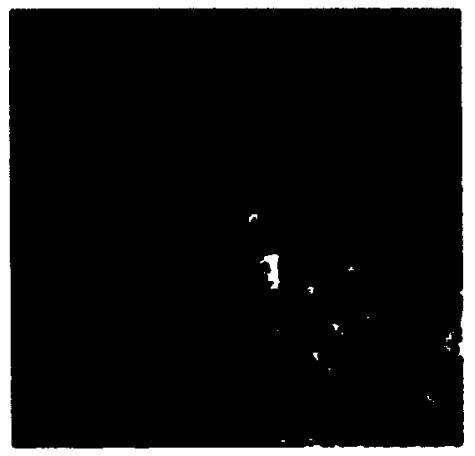

(d)

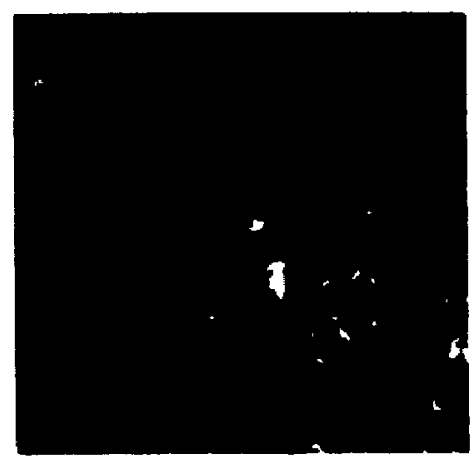

(f)

Figure 06: (a) ()riginal iuage of a sepurrel. (b) Moment-preserving appreximation with the mumber of approximating points being $32 \times 32$. (c) Xearest-neighbour. (d) Hologram-like. (e) Diserete Fonrier trunsform. (f) Diserete rosime trunsform. 


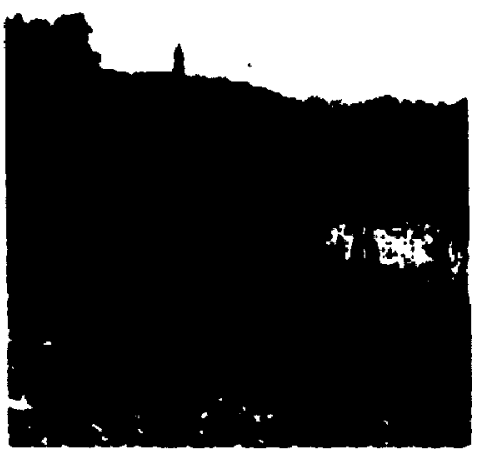

(a)

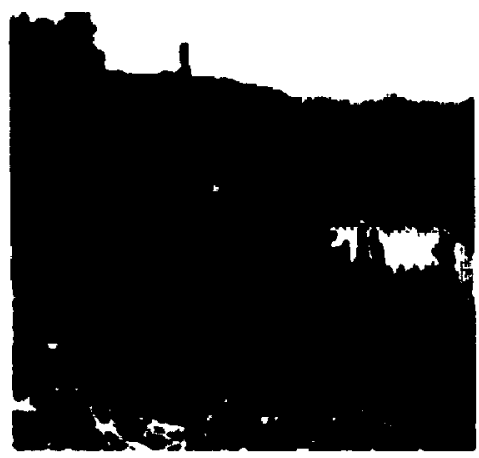

(c)

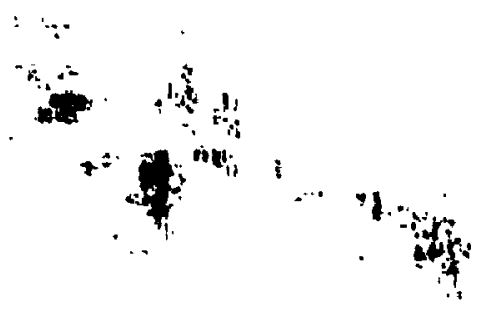

(e)

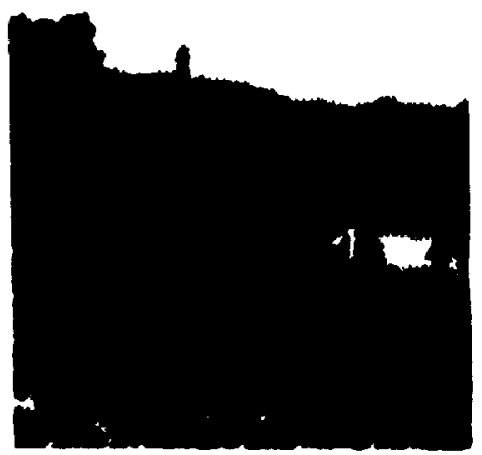

(b)

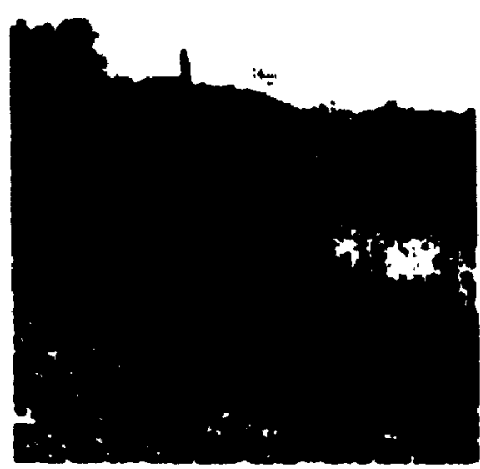

(d)

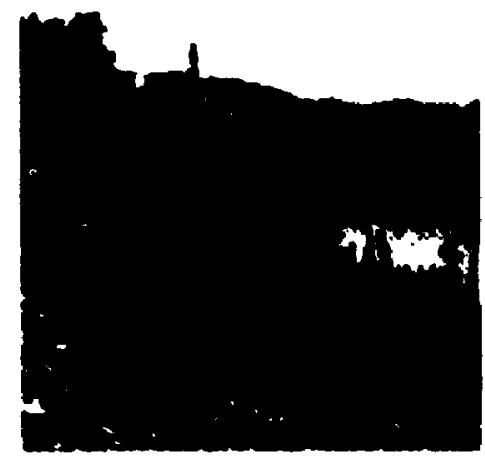

(ก)

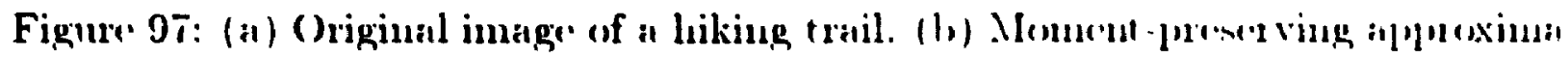

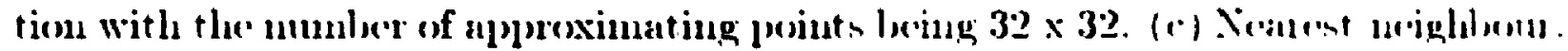

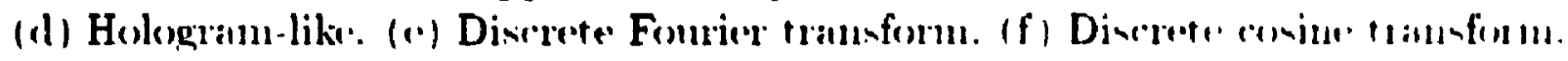



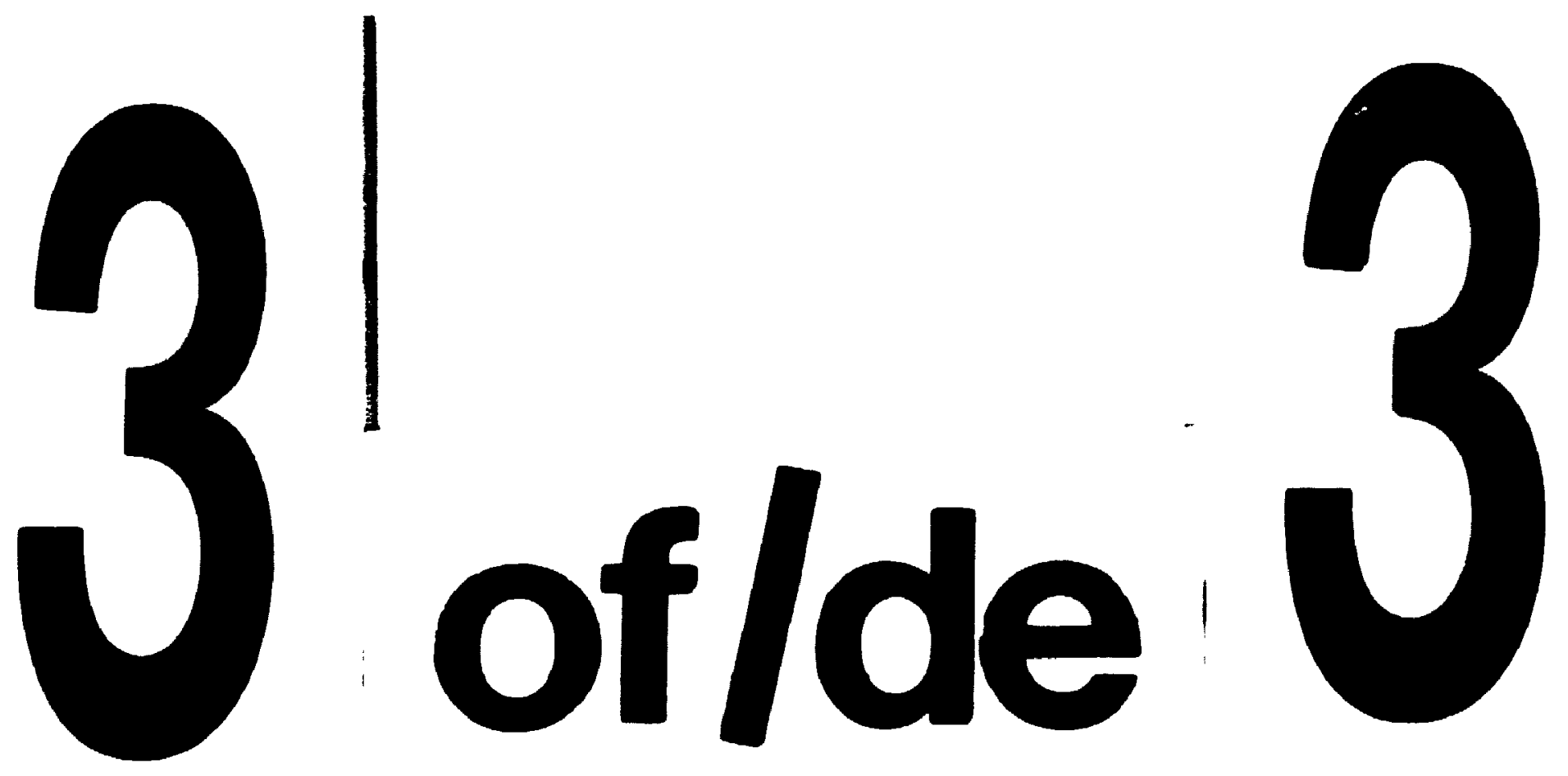

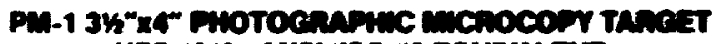

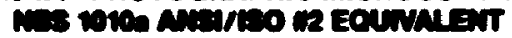

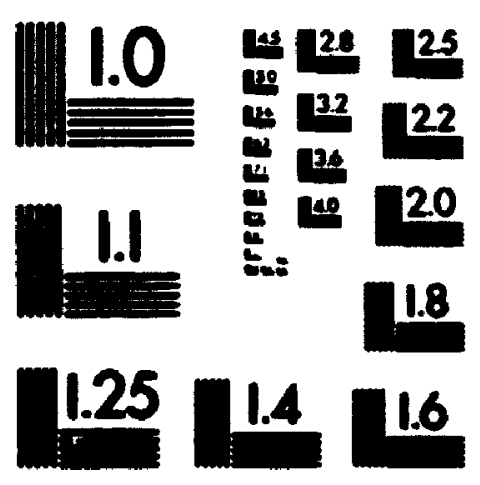

Precunoum nesoumon tanerTs 


\begin{tabular}{|c|c|c|c|c|c|}
\hline $\begin{array}{l}\text { Appraximeiton } \\
\text { Mrinad }\end{array}$ & Componen & Trmo & $\underset{\left(E_{-}\right)}{M E}$ & $\begin{array}{c}\text { MsE } \\
\left(E_{Z}: N\right)\end{array}$ & $\begin{array}{l}\text { SNA } \\
\text { (da) }\end{array}$ \\
\hline Mologranthe & 16:1 & 119 sece. & 24 & 005.4209 & -12.7034 \\
\hline 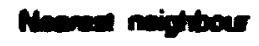 & $16: 1$ & 2013 & $m$ & sastras & 92.871 \\
\hline DFT & $8: 1$ & 720 sec. & 255 & 36126.7125 & -29.222 \\
\hline DCT & $16: t$ & 60 sace. & 182 & 170000 & 0.103 \\
\hline Monent-presenving & $16: 1$ & 606 sec. & 197 & 463.7054 & -10.3062 \\
\hline
\end{tabular}

(a)

\begin{tabular}{|c|c|c|c|c|c|}
\hline $\begin{array}{c}\text { Approximution } \\
\text { cenmod }\end{array}$ & $\begin{array}{c}\text { Compunseion } \\
\text { Anco }\end{array}$ & Rrimo & $\begin{array}{l}M E \\
\left(E_{-}\right) \\
\end{array}$ & $\begin{array}{r}\text { MSE } \\
\left(E_{z} N\right)\end{array}$ & $\begin{array}{l}\text { sing } \\
(a)\end{array}$ \\
\hline Hogorantiles & 16:1 & 118 sec. & 252 & 1820.7945 & -11.9000 \\
\hline Nomer nimplear & $16: 1$ & $2 x$ & 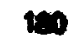 & 27711 & a.700e \\
\hline DFT & $8: 1$ & $744 \mathrm{sec}$ & 255 & 20.045419 & 23.0 .002 \\
\hline Det & r:t & $n 4=$ & $15 t$ & Salrow & 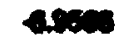 \\
\hline Monentpreserving & $16: 1$ & $\operatorname{seg}$ exc. & 197 & $\sin 8 \operatorname{sen}$ & -92297 \\
\hline
\end{tabular}

(b)

Figure 98: (a) Comparixon talshe of varions approximation terluiqumes an image \#3. (1,) Comparixom table of varions मpproximation ter-huiques on image \#4. 


\section{Chapter 6}

\section{Conclusion and Open Problems}

In this chatpter. we present a summary of the moment-preserving approximation une thorl. and compare it with previoms terluniques. We also present a short diwenssion of the implementation of these approximation techniques. We comrlude this rhapter and the thesis with a list of open problems which could be investigated by future rowarch.

\subsection{Review of Moment-preserving Technique}

The germetric moments and the Fourier transform of a function are closely relaterl in the sense that a tinite number of these moments ran be used to reronstruct au ipproximation of the Fontier conetticients. Beraluse of the close relationship between these. the germuetric moments can be considered to contain information typically fonul in the transforsn domain. In this thesis. we have introduced a new linear pierewise approximation terhnique which explores this interdependence.

The original function $f(x)$ and an approximation function $f(x)$ are $k^{\text {eh }}$ order

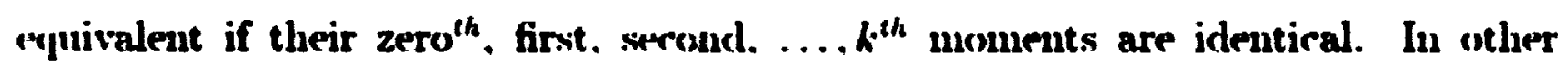
words, by preserving the first $k+1$ moments of the original function $f(x)$. the fuurtion $f(x)$ is approximately equal to $f(x)$. By approximating $f(x)$ by a $k^{\text {th }}$ corrler

"vuivalent $f(x)$. transform domain values are presierved while simultaneously providling an approximation in the time/sparial domain. Thus, we ran avoid the nsial -Trensformation $\rightarrow$ Approximation $\rightarrow$ Inverse Transformation " process. Another inreresting feature aloout the moment-presserving terhnique is that the knot values 


\begin{tabular}{|c|c|c|c|}
\hline $\begin{array}{c}\text { Apluroximation } \\
\text { Method }\end{array}$ & $\begin{array}{c}\text { Type of urig. } \\
\text { function }\end{array}$ & $\begin{array}{c}\text { Typo of } \\
\text { Limot Valuex }\end{array}$ & $\begin{array}{c}\text { Pro-speritiod } \\
\text { Revpuired }\end{array}$ \\
\hline $\begin{array}{c}\text { Linear split } \\
\text { (Ramer) }\end{array}$ & $\begin{array}{c}\text { entimusus/ } \\
\text { discretes }\end{array}$ & tucin-111if(otul & 9 \\
\hline $\begin{array}{l}\text { Split-and-Alerge } \\
\text { (Pav-lidlis) }\end{array}$ & $\begin{array}{c}\text { routimusus/ } \\
\text { dinereste }\end{array}$ & ton-nuiform & Yex \\
\hline $\begin{array}{l}\text { Tearest-meighlocurr } \\
\text { (Tanimuto) }\end{array}$ & discreoter & uniform & IIII \\
\hline $\begin{array}{l}\text { Hologram-like } \\
\text { (Prusiukiewirz) }\end{array}$ & dix-retere & uniform & IMI \\
\hline $\begin{array}{l}\text { Minimax } \\
\text { (Kurozumi) }\end{array}$ & distrete & non-nuiform & $y$ \\
\hline $\begin{array}{c}\text { Rerursive split } \\
\text { (Durla deHart. Lowe) }\end{array}$ & $\begin{array}{l}\text { eomtimums/ } \\
\text { discretes }\end{array}$ & uon-ıniform & yes \\
\hline DFT & discreter & $x / A$ & yex \\
\hline DCT & discretere & $\pi / A$ & yex \\
\hline Moment-preserving & $\begin{array}{l}\text { eoutinuous/ } \\
\text { discrete }\end{array}$ & $\begin{array}{c}\text { uniform/ } \\
\text { non-uniform }\end{array}$ & IIO \\
\hline
\end{tabular}

Talble 2: Comparison of different approximation terhmiqum.

ran lse uniformly or nou-nuiformly selerted.

\subsection{Comparison with Other Techniques}

The moment-preserving method is loet ter thau all existing sparial domain terluingus

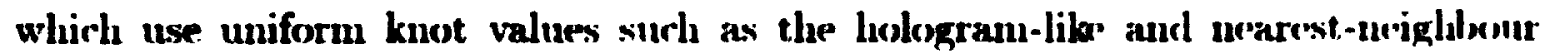
alproximation terleniques. Although it. rerpures more compututional time than these other terhnigues. the anomut of error lotwewn the upproximation und the artual fuuction is siguificantly smaller. This property is elourly remumetraterl in the approximation examples of oup-rlinumsional functions hul planar courves.

()f the four approximation terluigunes whirh use non-nuiform knots (liuesr split. split-and-merge. minimax, and rerursive split), only the linear split and rerursive 


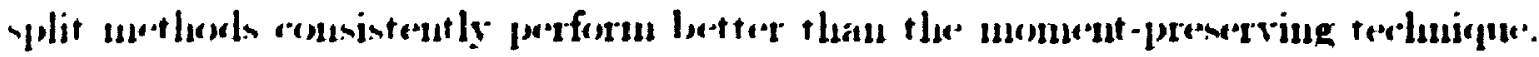
Thin conchesion is consistent with an obsertation made log Rire [Ri 69] that the

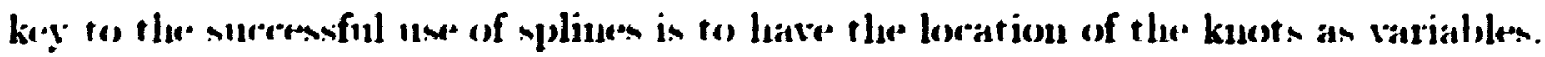

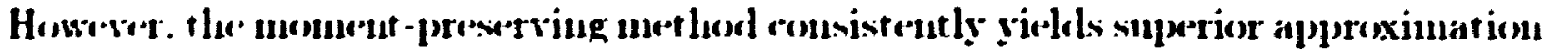
result c conpareed to the minimax and the split-aud-merge merthods. A compatative

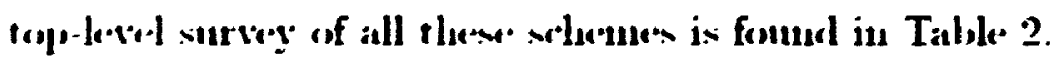

(Bnly t wo transform domain approximation techniquess are used in the conngariwol. namely the Fonrier transform and discrete conine transform. The Fonriet conefhorents contain tos) many spurious frectuencies. and as such when a small unumlner of trumeated conefficients are used to approximate the original fumetion. they introduce at lot of noise into the approximation. The moment-preserving method ontperforms the. Fonrier transform on approximating one-dimensional and two-dimensional functions. The discrete cosine transform is very efficient in the euergy-parking sense. and therrfore. conly a small number of discrete cosine ropefficients are recpuirerl to provide a gorol approximation. Results from the planar rurve and digitized image alproximations show that the moment-presserving method performs as well as or leetere than the discrete cosine transform. However. for one-rlimensional functions. the discrete cosine transform is murh more effertive than the moment-presserving ter-lnicpur.

\subsection{Discussion on Implementation}

All the previous approximation terhniques and the new moment-presserving methorl were fully implemented in Smalltalk. They have bern applied to oup-rlimensional functions. two-dimensional planar curves, and rigitized images. In the implementration of the moment-preserving terlnique. there is no maximum error limit requirement. e. that is typirally used hy other time/spacial domain approximation trelumigures surh as the linear split. rerursive split, split-and-merge, and minimax merhorls. As oppowerl to them. for each moment-preserving approximation. the 


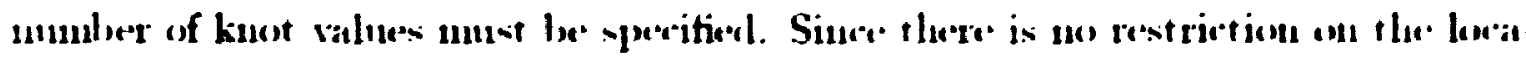

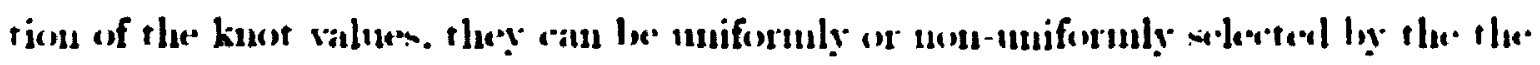

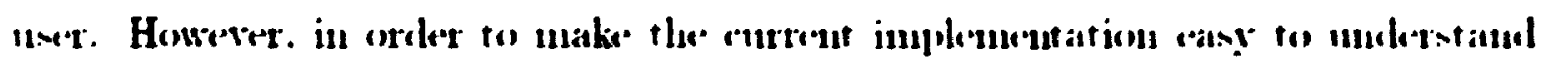

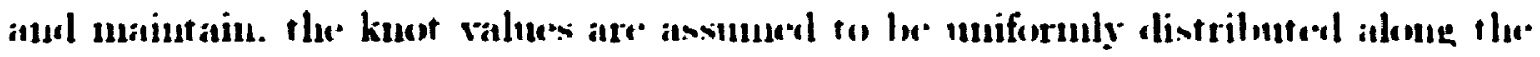
$r$-inis.

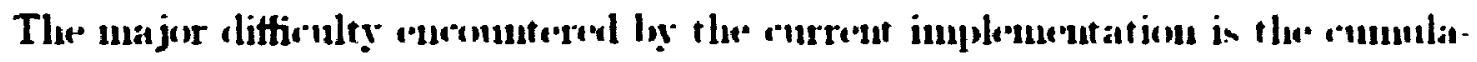
tive errors from floating-point mathemational operations. For example. the function $f(s)=\frac{\text { sins }}{s}$ eaunot be plotted correctly log the computer due to the fact that when $r=0$. a division-by-zero error will ocenr. To overeome this problem. a very suatl

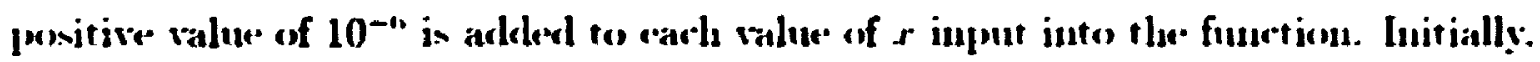

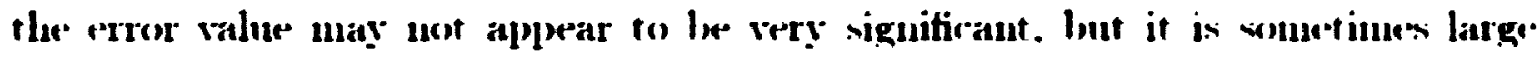
enomgh to skew some of these approximation restults.

\subsection{Open Problems}

The current moment-preserving terhuique is based on the assumption that the "alpproximation points are connerterl by line segments. One common complaint alomit pierewise linear approximations is that interpolated values from linear functions are uor as arsthetically pleasing as interpolated values from polyuomials of higherer degreess surh as quadratir or cubir functions. It wonld be interesting to ser if the current derivations can be extenderl from being valid for pierewise linesar approximations to higher order polynomials. Also. it would be interestimg to study wherther the use of polynomials such as quadratir and cubir functions would provide a Inet. ter approximation than linear functions in terms of the amonnt of error introrluciel leetween an approximation and the original function. Althessgh the complexity of

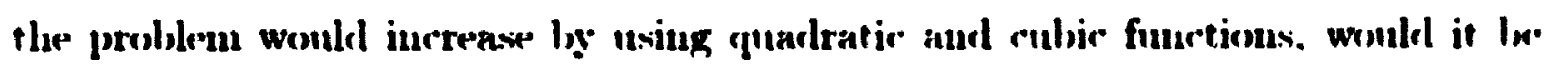
arreptable to domble the time complexity in orrer to rerlure the crror loy one-half?

As indirate by Rire [Ri 69]. and Pavlidis [Pa 70]. the selertion of the pensition of the knots are very important in making a goxel approximation. Siure our curreut. 


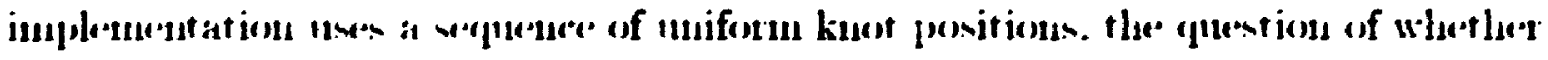

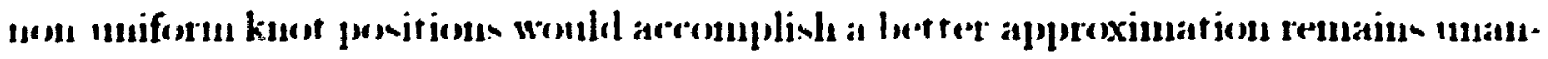

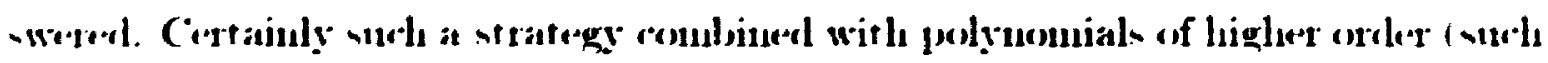

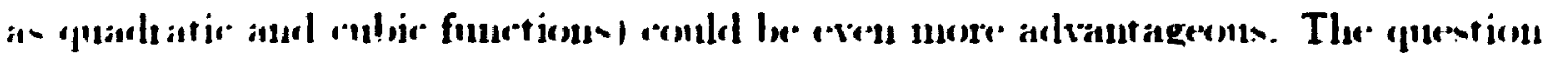
of lowatime the kusts in order to minimize the etror berweren the approximation

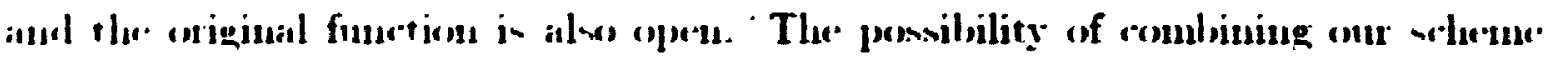

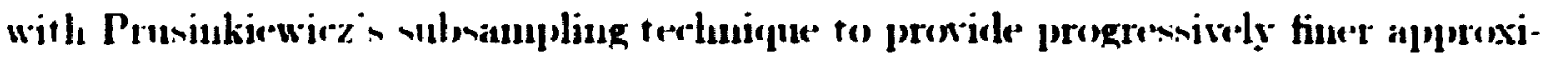

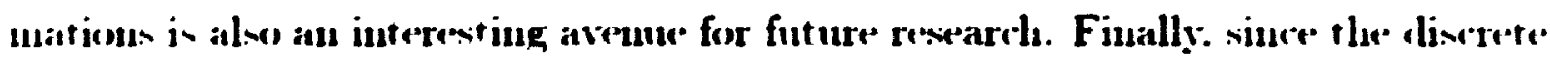
coniue transform is related to the diserete Fonrier transform. and the Fonrier transform ix. in thrn. related to the moments. it would it be interesting to determine "Wherlaet one condel use moments to assist in the determination of the approximated discrete anitue transform. or rice versa.

\subsection{The Final Word}

There are currently many approximation terhniques. and they can only be applied in either the time/sparial or the transform domain. but not both. Our new pierswis. linear moment-presserving methorl bridges the gap between time/sparial and trausform ikmain approximations. Experimental evidenre obtainerl from the results of using this ter-huique indicate that it is a viable option. and that it condel well lie is powerful approximation strategy for the future. 


\section{References}

[.11 s!!

I.IK -i.

[.1K 91]

[BB :2]

$[\mathrm{H} \times \mathbf{6}, 1]$

[HK :A]

[BH N6]

$[\mathrm{Br}$ 6N]

[ro b0]

[Bo (i.3)]

[B.M 91]

[1)aL 79]

[DaP 6:3]

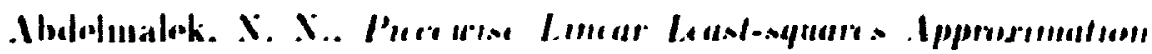

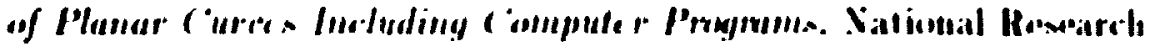

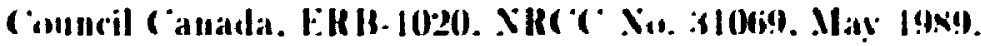

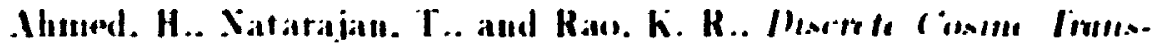

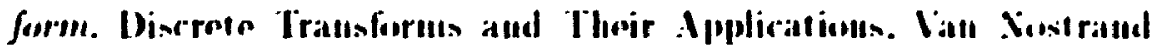

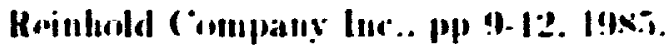

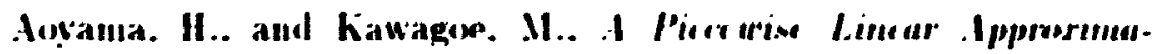

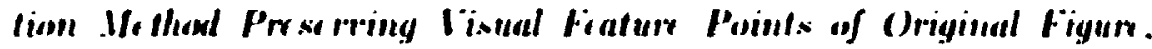

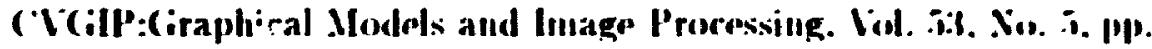
13.T-146. Sept. 1991.

Ballard. D. H.. and Brow'tn. (C. M.. ( omputer Vision. I'rentico-llall. Iır.. I:9N2.

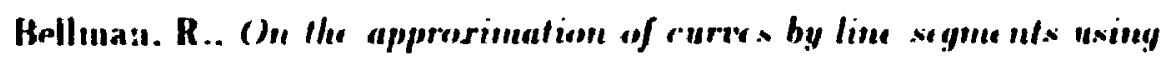

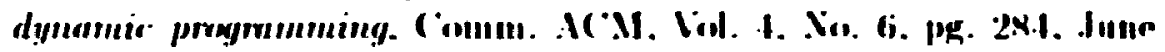
1961 .

Barnhill. R. E.. and Riessenfeld. R. F.. Compunter Aided (imonturetrir Desigu. Arademir Press. Sow York. 1974.

Belliman, R. E., and Roth. S. R.. Me thods in Approsimation - Tirle. nique s for Mathe matiral Modelling. D). Reidel Publishing ('umpantly $19 \times 6$ i.

Brill. E. L.. (Marmeter Rerugnition ria Fourier Descriptors. in WEsc ON Terhnical Papers. Session 2i. Qualitative Pattern Recogg. nition Through Image Shaping. Los Angeles. ('alifornia, 1963x.

('osgriff. R. L.. Ide ntifiration of Shapr. Ohio State Veniversity Hosearch Foundation. ('olumbus, Ohio. Report 820-11, ASTIA AI) 25.1 792. Derember 1960.

Borel. R. J.. A Mathe matiral Pattern Rerregneitione Torhenique Based

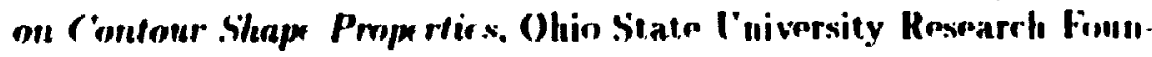
dation, (columbus. Ohio. Report Ix01-11. ASTIA AI) Iffi I13. Wr. rember 196.i.

Buck. B.. and Maranlay. V. A.. Marimum En'mpy in Arfiron. Clarrdon Press. 1991.

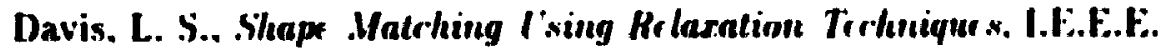
Transartions on Pattern Analysis and Marhine Intelligener. Viol. PAIII-I. pp. 60-72. 1979.

Davis. P. J.. Interpolation and Approximation. Hlaisdell. PR.lill. 1963. 
[IIIW 90]

[alols $-x]$

[III) $7: 3]$

[1)HA

[J)11 K(i]

$[\mathrm{F} k \times 1]$

$[\mathrm{EH} \times 2$ ]

[FWL X9]

[FH Xij]

[Fr 61]

[Fr io]

[(i) 61]

[(i) 62]
Inokin. I). 1.. Lay. S. I. F. Thurston. W. P.. and Wilks. A. R..

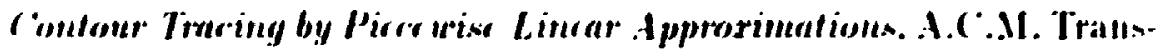
actions onl Giraphics. Viol. 9. No. 4. pp. 369-421. Oct. 1990.

do Boor. ( '.. A P'ractical Cinde to Splines. Springer-lerlag. New York. link.

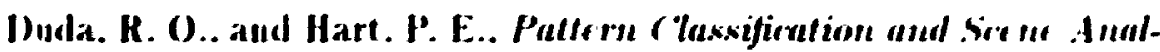
ynis. Wiley d Sonn. Juc.. lup. 32x-3339. 1973.

Dudani. S. A.. Brepding. K. J.. and Mrehes. K. B.. Airrruft Ih ulifiration by .Home nt Inrariants. I.E.E.E. Transartions on (imuputers. Vol. (-26. pp. 39.46. 1975 .

Dunham. J. (i.. Optimum Eniform Picce wise Lincar Approrimation of Planar Curres. I.E.E.E. Transactions on Pattern Analyisis and Marhine Intelligence. Vol. PAMI-X. pp. 67-75. 19x6.

Ekstrom. M. P.. Digital Image Procsssing Trrhniques. Academic Press, 19K4.

Elliot. D. F.. and Rao. K. R.. Fast Transforms - Algorithms. Analy. sfs. Applications. Academic Press. 1982.

Fahn, (. S.. Wang, J. F.. and Lee, J. Y.. An Adaptive Rfduction Procrdure for the Piccevise Linear A pproximation. I.E.E.E. Transartions on Pattern Analysis and Machine Intelligence. Vol. PA.M1-11. No.?. pp. 967-973. 1989.

Fischler, M. A., and Bolles. R. ('.. Perreptual Organization and ('urv' Parfitioning. I.E.E.E. Transartions on Pattern Analysis and Marhine Intelligence. Vol. PAMI-צ, pp. 100-105, $19 \times 6$.

Freeman. H.. On the Encoding of Arbitrary Cicome tric Configumtions, I.R.E. Transartions on Electronic Computers. Vol. E( '-10. pp. 260.26K. 1961.

Freeman. H., Boundary Encoding and Porcessing, Pirture Processing and Psychopictorics, Lipkin and Rosenfeld, Eds., Academic Press. pp. 241-306. 1970.

(iluss, B., Further remarks on line segment rurve-fitting using dynamic programming. ('omm. A( M, Vol. 4, No. \&, pp 4+1-443. A 11gust 1961.

(iluss, B.. A line scgment rume-fitting algorithm related to optimal crooding of information, Information and Control. Vol. 5. pp261-26i. 1962. 
[ ir -2$]$

$[\operatorname{cir}(j x)$

[lli xi]

[III $6 ; 2$ ]

[IX 9I]

[.1a 91]

[.Ja $x . i]$

[.lar il]

$[.1 \times \times 1]$

[ha 89 ]

[hexi]

[KI *2]

[La xT]

[Le 90]

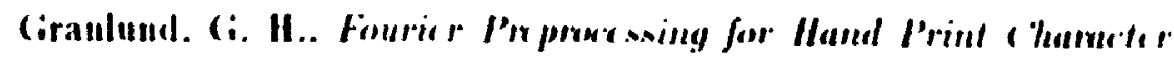

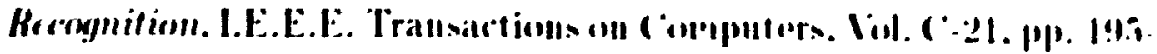
201.1972.

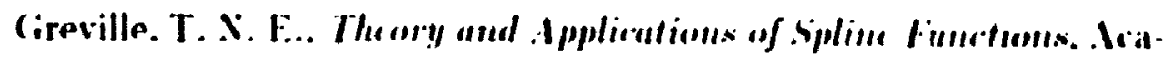
drotuic l'ress. 196!!.

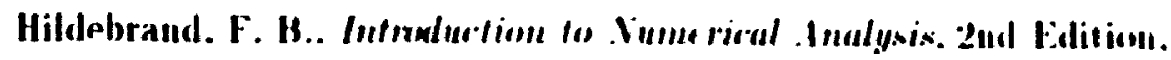
Dover Publicatiuns. I9ki.

Hu. M.. Visual Pattern Recognition by Moment Invariants. I.F.F.t. Transactions on Information Theury. Vol. 2. pp. 17!-1x. 196i2.

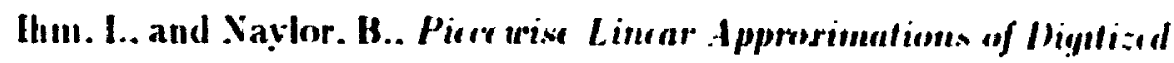
Spuer ('urres with tpplicutions. Sicientifir Visualization of Illysical Phenomena (Proceedings of ('omputer ( iraphies Intornatiunal IM!1). Ed. I'atrikalakis. N. M.. Springer-Verlag. pp. iti-ili!. 19!1.

Jahne. B.. Iigital Image l'ruxy ssing - ( ionr pts. Algoritlems, and siacutifiv Ipplicntions. Springor-Verlag. 1991.

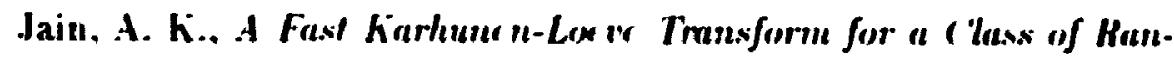
dom Proxesses. Discrete Transforms and Their Applications. Van

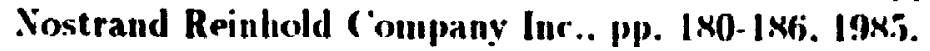

Jarvis. ('. L.. A Mifhod for Fitting Polygones to Figur Benundary

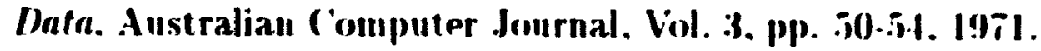

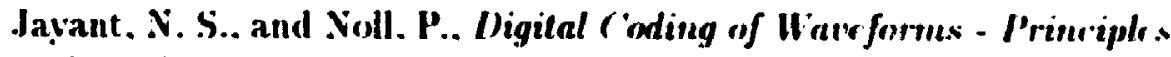

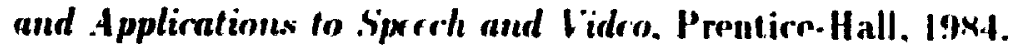

Karl, J. H.. An Introdurtion to Ihigital Signal Provessing, Acadomic Press. 19x9.

Kemperman. J. H. B.. (ifometry of the Mome ut Pmblem. Moment. in Mathematirs. Proceedings of Symposia in Applied Mathematirs, Volume 37, Ameriran Mathematical Soriety Short ('unrse Lerture Notes, 19k7.

Kurozumi. Y., and Davis. W. A.. Polygonal Approrimatione by the Minimar Method. ('omputer (iraphics and lmage Proressing, Viol. 19. pp. $24 \times-264$. $19 \times 2$.

Landau, H. J.. ('lassiral Barkgonund of the Moment Problem. Mr. ments in Mathematirs. Proreedings of Symposia in Applierl Mat/l. ematics, Volume 37, American Mathematical Society Sluort ('ourso Lerture Notes, 19xi.

Lewis. R.. Pmrtirnl Digital Imagr Prorsssing. Ellis Horwoxal I.t1.. 1990. 
$[1,1 \times 7]$

Mn: TI

(10)!.11]

[0r xil]

[1'ap (ji) ]

[1': 72 ]

[1": $7: 8]$

$[1 \cdot H \div 1]$

[1:a

[In $-x]$

["a :2]

[NF

[Ph 6x]

[11) !.1]

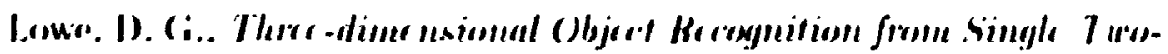

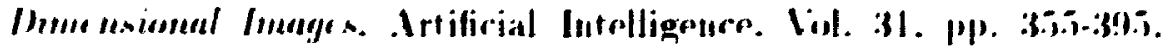
$1 ! \times 5$.

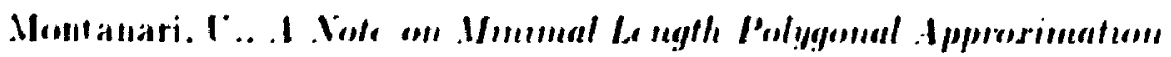

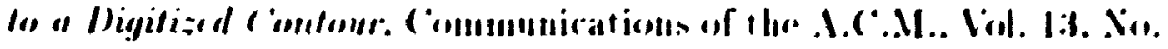
1. 111.1!- Ti. dalluary 1970.

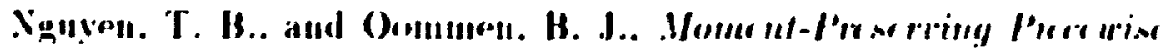

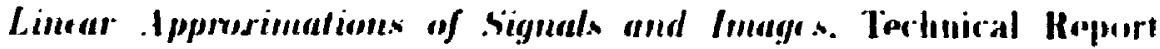
TR\#2ix. ('arleton I'niversily. Ottawa. Ontario. 1994.

Orfanidis. S. J.. Optimum Signual Prorossing: All Intmoluction. Macmillan P'ublishing ('ompany. 19x.i.

Papoulis. A.. Probahility. Random Variables. and Stochastic Processa.s. MrC iraw-Hill Book. Inc.. 196.j.

Pavlidis. T.. Piscr mist Approsimation of Funrtions of Turo lariables through Krgions arith lariable Boundarirs. Proceedings of the A.C.A. Anumal ('onfereuce. pp. 6i2-66;2. Aug. 1972.

Parlidis. T.. Uareform Sigmentation Thmugh Functional Approrimation. I.E.E.E. Transartions on ('omputers. Vol. ('-22. No. T. pl. (ix!)-697. July 1973).

Pavlidis. T.. and Horowitz. S. L. Sfgmentation of Plane Curves. I.E.E.E. Transartions on ('omputers. Vol. ('-23. .Yo. x. pl). xbio-xio. August 1974.

Pavlidis. T.. Strucfuml Pattcrn Rerognition. Springer-Verlag. 197T.

Pavlidis. T.. A Re ric u of Algorithms for Shape Analysis. (omputer (iraphics and Image Processing, Vol. T. pp. 243-2.5x. 197x.

Pavlidis. T.. Algorithms for (iraphics and Image Processing. (omIputer Science Press. pp. 275-297, $19 \times 2$.

Perscon. E.. and Fu. K. S., Shape Discrimination (sing Fouricr Dr scriptors. I.E.E.E. Transactions on Systems. Man and (ybernetics. Vol. SMC'-7. pp. 170.179, $197 \%$.

Phillips. (i. M.. Algorithm for pieccurise stmight line approximations. ('omputer Journal. Vol. 11. pp 211-212. 196K.

Pikns. A.. and Dinstein. I., I sing .Simple Deromposition for Simoothing and Fratury Point Detertion of Noixy Digital ('urves. I.E.E.E. Transartions on Pattern Analysis and Machine Intelligence. Vol. 16. Nio. $\times$. pp. xox-813. 1994. 
[P'rit]

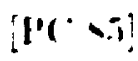

flrist

[Ki (i:9)

[R.I !) ] ]

[RY !0]

[RaIII ì]

[Ha K.i]

[HII ; :-1]

$[\mathrm{Hh}$ iti]

[HII *9]

[RII :91]

[R 11 :2]

[Sk io]

[S(F $\times$ X]

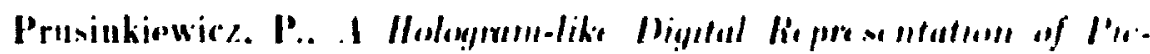

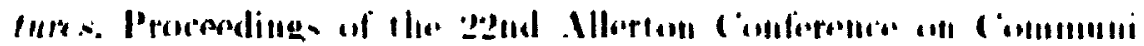

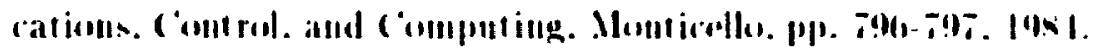

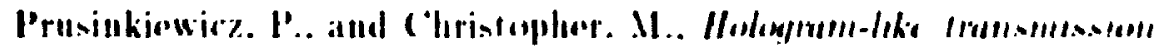

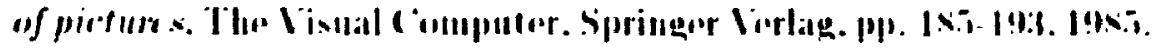

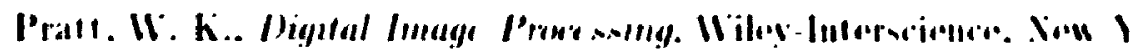
ork. $197 \mathrm{~T}$.

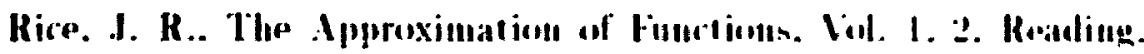
Mass.. Addisou-Wiesler. 196.t. 196!!.

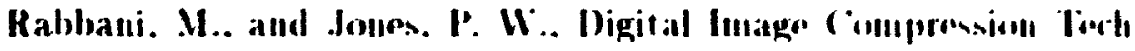
nignes. SPIE - The International sorienty for Optioal linginuering. Washlington. 1991.

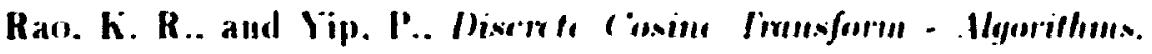

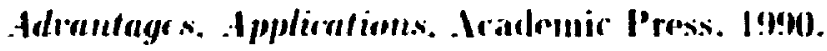

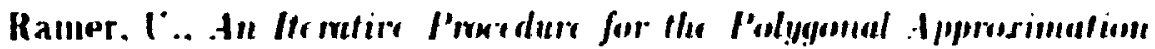
of Plane C'urves. ('ompluter Ciraphies and linage l'rocomsing. Viol. I. pp. 244-256. 1972.

Rao. K. R.. Discrete Trantsformes and the ir Applicatioms, Lill Nons trand Reinhold ('o.. 19x.j.

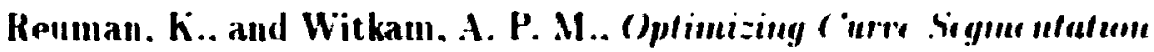

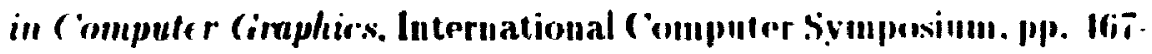
17.2. 1972.

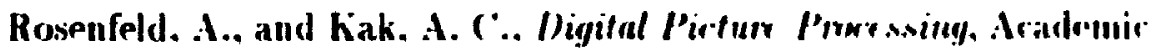
Press, i9i6.

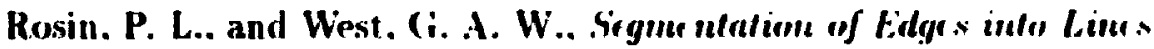
and Arrs, lmage and Vision ('omputing. Viol. T. No. 2. p.. 1(1)!-111. $19 \times 9$.

Rosin. P. L., and West. (i, A. W., Terhenigues for Segrme neling Irmege

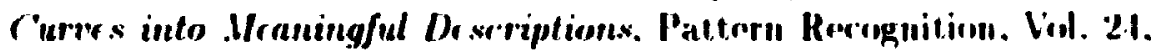
No. T. pp. 6.43-6;.52. 19991.

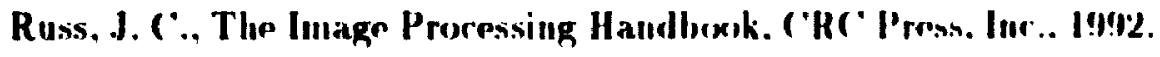

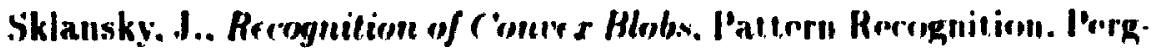
atmon Press, Vol.2. pp. 3-10, 1970.

Sklansky. J.. and (ionzalez, V.. Fast Polygoneal dpprrsimatioun of Dig. itised ('ureres, Pattern Recognition. Vol. 12. pp. 327-331. I!n(1). 
$\{4,71\}$

[Sill (M)]

[it (ii)

$\left[\begin{array}{ll}1 & -9\end{array}\right]$

[l' $\mathrm{N}(\mathrm{N})$

[ii, -1$]$

[Vh $\times 2$ ]

[Wa Xx]

[Wi (i2]

[Wi -s]

[Wi1 *4]

[YH Xi]

[Za 66]

[ZR i2]
Späth. H.. Spliue .Mgorithum, for ('urves and Surfaces. Translatod from (ierman by lloskins. W. I).. alld Sager. H. II.. I'tilitas Mathes. matica l'ublishing Incorporated. Winnipeg. 1974.

Stoarus. S. H.. and Hush. O. R.. Digilal Signal Analysis. P'renticeHall. 1!!!o.

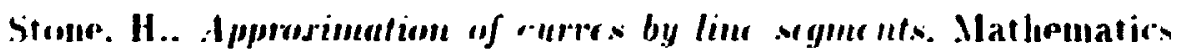

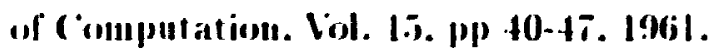

Tanimoto. S. L.. Imagr Transmeission with Giross Information First. ('omputer (iraphirs and lumage Proressing. Vol. 9. pp. i2-ifi. 1979.

Teh. ('. H.. and ('hin. R. T.. On Digital Approrimation of Mome nt Intriants. ('omputer Vision. (iraphirs. and lmage Proressing. Vol. 33. pp. $31 \times-326.19 k 6$.

Tomek. I.. Piccruse Linfar Approrimations. I.E.E.E. Transactions on ('omputers. Vol. ('-23.pp. 44i-44K, 1974.

Van Valkenburg. M. E.. and Kinariwala. B. K.. Linear ('ircuits. Prentice-Hall, Inc., 19k2.

Wang. L.. Progı isive Imagr Trmemission - Ph.d Thrsis Dissertation, I'niversity of Ottawa. Ottawa. Ontario. 19KX.

Wilkes. S. S.. Mathematical Statistics. John Wiley X: Sons, Inc.. 1962.

Willians. ( . M.. An Efficient Algorithm for the Pierc uisc Linfar .tpproximation of Planar ('urres. ('omputer (iraphirs and lmage Processing, Vol. $\times$. pp. 286-29:3, 1978.

WiI. L. D., A Piere urise Linear Approximation Based on a Statistiral Morel. I.E.E.E. Transactions on Pattern Analysis and Marhilie Intelligence, Vol. PAMI-6, pp. 41-44, 1984.

Yannakoudakis, E. J., and Hutton. P. J., Speech Synthesis and Recrgnition Systems, Ellis Horwood Ltd., 1987.

Zahn, ('. T., Tuo-Dimensional Pattern Description and Rerognition via C'urinturr Points, Stanford Linear Accelerator ('enter, Stanford University, Stanford, ('alifornia, SLAC' Report No. io. 1966.

Zahn, ('. T.. Roskies, R. Z., A Fourier Description for Plane Close ruries, I.E.E.F. Transactions on Computers. Vol. ('-21, pp. 269-2×1. 1972. 


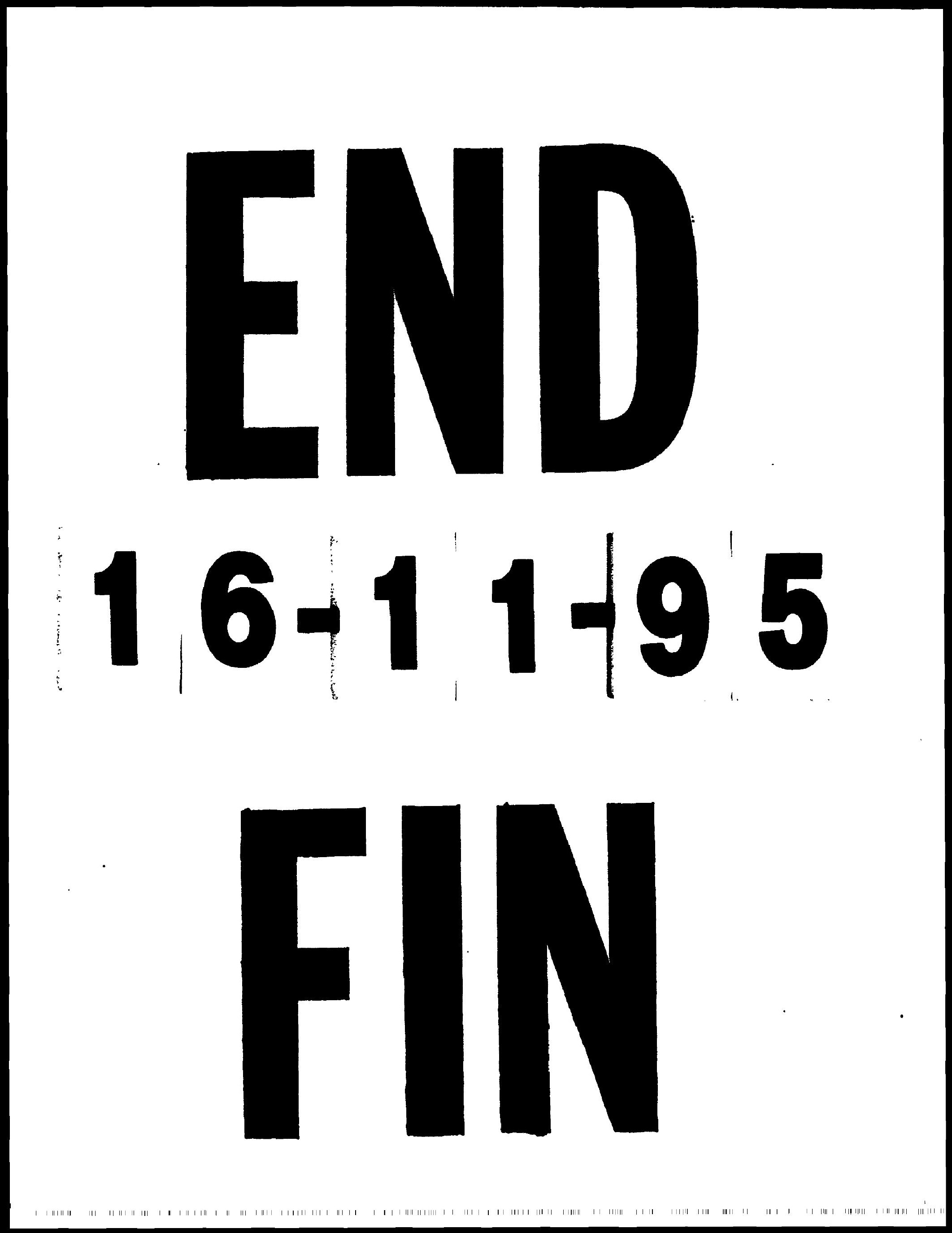

